\title{
Um modelo matemático para tanques com agitação
}

\author{
Olga Harumi Saito
}

DISSERTAÇÃO APRESENTADA

$\mathrm{AO}$

INSTITUTO DE MATEMÁTICA E ESTATÍSTICA

DA

UNIVERSIDADE DE SÃO PAULO

PARA

OBTENÇÃO DO GRAU DE MESTRE

EM

MATEMÁTICA APLICADA

Área de concentração: Análise Numérica

Orientador: Prof. Dr. Luis Carlos de Castro Santos

São Paulo, 4 de janeiro de 2002 


\section{Um Modelo Matemático para Tanques com Agitação}

Este exemplar corresponde à redação final da dissertação devidamente corrigida e defendida por Olga Harumi Saito e aprovada pela comissão julgadora.

São Paulo, 4 de janeiro de 2002.

Banca examinadora:

- Prof. Dr. Luis Carlos de Castro Santos (Presidente) - IME - USP

- Prof. Dr. Alexandre Megiorin Roma - IME - USP

- Prof. Dr. Efraim Cekinski - IPT 

A meus pais e irmãos, pelo apoio e confiança durante todos estes anos. 
$\therefore \therefore$ 


\section{Agradecimentos}

Por este trabalho ter levado mais tempo do que previ para ser concluído um grande número de pessoas foram envolvidas durante o processo e de alguma forma especial fizeram e fazem parte da minha história.

Agradeço ao Cefet-Pr - Centro Federal de Educação Tecnológica do Paraná pela oportunidade, contribuindo para o meu crescimento profissional, em particular aos colegas do DAMAT - Departamento Acadêmico de Matemática e ao Chefe do DAMAT, prof. João Adão Inácio, pela confiança em mim depositada.

Ao meu orientador, Prof. Dr. Luis Carlos de Castro Santos, por suas diretrizes, paciência, incentivo e presteza em me ajudar.

À Universidade de São Paulo que permitiu, através do IME - Instituto de Matemática e Estatística, o meu crescimento científico.

À Divisão de Química do IPT - Instituto de Pesquisas Tecnológicas do Estado de São Paulo S.A., que contribuiu para a realização desta dissertação. Ao Eng. Dr. Efraim Cekinski pela disponibilidade e importantes sugestões e dicas para este trabalho.

Ao LCCA - Laboratório de Computação Científica Avançada do Centro de Computação Eletrônica da Universidade de São Paulo, que permitiu a realização das simulações de forma dinâmica. Ao analista Francisco Ribacionka pela atenção e presteza.

Agradeço o incentivo recebido dos colegas aqui do IME, desde a fase inicial e ao longo deste trabalho, pelas dicas e a saudável convivência; pelo apoio moral e pela amizade que muito me ajudaram a perseverar nesta trajetória. Em especial, ao meu amigo Rudimar pelos momentos de convívio, pela paciência e pela sua força passada nos momentos difíceis.

Aos professores do IME-USP e funcionários das secretarias, biblioteca, setor de pós-graduação que de forma direta e/ou indireta contribuíram para a realização deste trabalho.

Agradeço também ao prof. Dr. Alexandre Megiorin Roma, IME-USP Instituto de Matemática e Estatística da Universidade de São Paulo, e ao Eng. Dr. Efraim Cekinski, Divisão de Química do IPT - Instituto de Pesquisas Tecnológicas do Estado de São Paulo S.A., pela gentileza em aceitarem o convite de participarem da Banca de Defesa e pelas 
sugestões que contribuíram para melhorar este texto. 


\section{Resumo}

Este trabalho objetiva modelar o problema hidrodinâmico envolvido na agitação mecânica e cristalização de uma fase sólida a partir de uma mistura de reagentes, largamente empregado na indústria química e relatado pela Divisão de Química do IPT Instituto de Pesquisas Tecnológicas do Estado de São Paulo S.A.. A modelagem matemática foi feita através das equações de Navier-Stokes em coordenadas cilíndricas para a representação do escoamento em um tanque com geometria simples. Obteve-se a solução numérica resolvendo tais equações segundo a malha MAC (marker and cell) pelo Método das Diferenças Finitas. Além disso, um estudo de estabilidade e convergência foi conduzido para o método de Runge-Kutta k-estágios. O transporte de partículas foi modelado por um sistema de EDO's (equações diferenciais ordinárias) e foi feita uma análise da concentração das partículas nas células das malhas de acordo com o seu diâmetro, densidade e velocidade do fluido e da partícula, entre outras variáveis.

A agitação mecânica pode ser empregada em processos semelhantes, presentes na indústria alimentícia, farmacêutica, nuclear, petroleira e de produção de papel. 


\section{Abstract}

The goal of the present work is to model the hidrodynamic problem involving mechanical agitation and cristalization of a solid phase from a mixture of reactants widely used in the chemical industry, as reported by IPT (Instituto de Pesquisas Tecnológicas do Estado de São Paulo S.A.) Division of Chemistry. The mathematical modeling was made via the Navier-Stokes equations in cylindrical coordinates for the representation of the flow in a tank with simple geometry. The numerical solution was obtained by solving the Navier-Stokes equations according to the MAC (marker and cell) mesh for the Finite Differences Method. Moreover, a study of stability and convergence was conducted for Runge-Kutta k-Step Method. The particle transport was modeled by an ODE's (Ordinary Differential Equations) System. An analysis was made for concentration of particles in the cells of the mesh in accordance with particle's diameters, fluid and particle's density and velocity, among others variable. Mechanical agitation can be employed in other similar processes present in food, pharmaceutical, nuclear and oil industries. 


\section{Índice}

Lista de Figuras $\quad$ xvii

Lista de Tabelas $\quad$ xxiii

Introdução 1

1 Agitação 5

1.1 A Agitação Mecânica . . . . . . . . . . . . . . . . . . . . . . . 5

1.2 A Geometria do Sistema de Agitação . . . . . . . . . . . . . . . . 6

1.2.1 Base do Tanque . . . . . . . . . . . . . 8

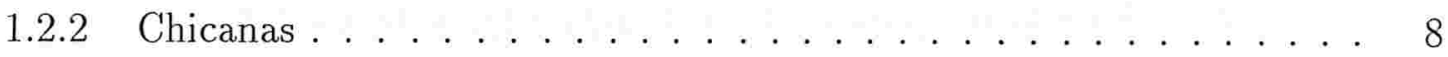

1.2 .3 Impelidores . . . . . . . . . . . . . . . . . . 9

1.3 Algumas Variáveis Envolvidas no Processo de Agitação . . . . . . . . . . . 14

1.4 Aplicações Clássicas . . . . . . . . . . . . . . . . . . . 16

1.5 A Fluidodinâmica e a CFD - Computational Fluid Dynamics . . . . . . . . 17

2 Solução das Equações de Navier- Stokes na Cavidade pelo Método das Diferenças Finitas

2.1 Equações de Navier-Stokes . . . . . . . . . . . . . . . . . . . . . . . 21

2.2 Formulação em Variáveis Primitivas . . . . . . . . . . . . . . . . 23

2.3 Método da Compressibilidade Artificial . . . . . . . . . . . . . . . . . 24 
2.4 Método de Runge-Kutta (R-K) k-estágios . . . . . . . . . . . . . 30

2.5 Estabilidade e Convergência para o Método MAC . . . . . . . . . . . . 32

2.6 Equações de Navier-Stokes na Modelagem de um Tanque Agitado . . . . . 37

2.6.1 Discretização das Equações em Coordenadas Cilíndricas . . . . . . . 40

3 Modelagem Matemática do Transporte de Partículas $\quad 45$

3.1 Fenômenos de Transporte . . . . . . . . . . . . . . . . 45

3.2 O Modelo Matemático do Movimento de uma Partícula no Fluido . . . . 48

3.3 Discretização Temporal do Modelo . . . . . . . . . . . . . . . . . 52

3.3 .1 Método de Euler . . . . . . . . . . . . . . . . 52

3.3.2 Método de Euler Modificado . . . . . . . . . . . . . 53

3.3.3 Método de Runge-Kutta de Quarta Ordem . . . . . . . . . . . . 53

3.4 Modelagem Matemática para Colisões entre as Partículas e a Parede . . . . 54

3.5 Testes do Comportamento das Partículas sem Influência do Campo de Velocidades . . . . . . . . . . . . . . . . . . 59

4 Simulações para Suspensão de Partículas $\quad 65$

4.1 Definição do estado de suspensão . . . . . . . . . . . . . . . 65

4.2 Simulações . . . . . . . . . . . . . . . . . . . . . 67

4.2.1 Simulações para $\mathrm{C} / \mathrm{T}=1 / 2, \mathrm{D} / \mathrm{T}=1 / 2$ e $\mathrm{D} / \mathrm{T}=3 / 4 \ldots \ldots . . \ldots 69$

4.2.2 Simulações para $\mathrm{C} / \mathrm{T}=1 / 4, \mathrm{D} / \mathrm{T}=1 / 2$ e $\mathrm{D} / \mathrm{T}=3 / 4 \ldots \ldots$. . . . 88

4.2.3 Simulações para $\mathrm{C} / \mathrm{T}=1 / 4, \mathrm{~S} / \mathrm{T}=1 / 4, \mathrm{D} / \mathrm{T}=1 / 2$ e $\mathrm{D} / \mathrm{T}=3 / 4 \ldots 97$

4.2.4 Simulações para partículas não-esféricas . . . . . . . . . . 106

5 Conclusão

A Equações de Navier Stokes em Coordenadas Cilíndricas $\quad 125$

A.1 Coordenadas Polares Cilíndricas . . . . . . . . . . . . . . . . . 129

B Método das Diferenças Finitas $\quad 135$

B.1 Teorema de Taylor . . . . . . . . . . . . . . . . . . 136

B.2 Fórmulas de Diferenças Finitas . . . . . . . . . . . . . . 136 


\section{Lista de Figuras}

1 Tanque de agitação mecânica e sua representação geométrica para mode-

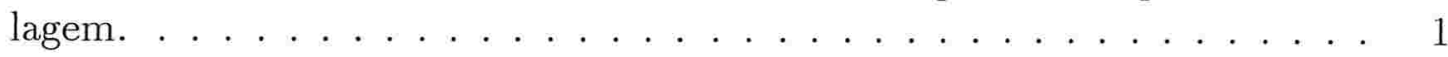

1.1 Biobulk: exemplo de um tanque continuamente agitado. . . . . . . . . . . . 6

1.2 Ilustração da esquematização de um tanque agitado convencional. . . . . . 7

1.3 Tanque com base esférica abaulada. . . . . . . . . . . . . . . 8

1.4 Tanque com chicanas. . . . . . . . . . . . . . . . . . . . . 9 9

1.5 Impelidor fluxo axial: as principais correntes ocorrem ao longo do eixo do impelidor e paralelo ao mesmo. . . . . . . . . . . . . . . . . . 10

1.6 Impelidor fluxo radial: as principais correntes ocorrem na direção radial ou tangencial. . . . . . . . . . . . . . . . 11

1.7 Impelidores típicos utilizados em regime laminar. . . . . . . . . . . . . . 12

1.8 Impelidores típicos utilizados em regime turbulento. . . . . . . . . . . . . 12

1.9 Simulações em tanques utilizado um e três impelidores montados no eixo, respectivamente. . . . . . . . . . . . . . . . . 13

2.1 Célula da malha deslocada. A pressão é armazenada nos nós e as componentes da velocidade, u e v, são deslocadas para os pontos médios da malha. . . . . . . . . . . . . . . . . . . . 26

2.2 Técnica da reflexão aplicada à condição de contorno. . . . . . . . . . . . 29

2.3 Desenho da geometria e condições de contorno da cavidade. . . . . . . . . . 30 
2.4 Solução numérica das equações de Navies-Stokes na cavidade para $\mathrm{n}=32$ e $\operatorname{Re}=1,2$, com as condições inciais da Figura 2.1: (a) representa o campo de velocidade por vetores e (b) representa o campo de velocidades pela magnitude da velocidade .

2.5 Gráfico $\beta \times$ it, it: eixo vertical e $\beta$ : eixo horizontal, caso a: $\operatorname{Re}=1,2 \mathrm{e}$ $\mathrm{n}=32$ e caso b: $\operatorname{Re}=1,2$ e $\mathrm{n}=64 \ldots \ldots \ldots \ldots$

2.6 Gráfico $\beta \times$ it, it: eixo vertical e $\beta$ : eixo horizontal, caso c: $\operatorname{Re}=100 \mathrm{e}$ $\mathrm{n}=32$ e caso $\mathrm{d}: \mathrm{Re}=100$ e $\mathrm{n}=64 \ldots \ldots \ldots \ldots$

2.7 Gráfico $\beta \times$ it, it: eixo vertical e $\beta$ : eixo horizontal, caso e: $\operatorname{Re}=400 \mathrm{e}$ $\mathrm{n}=32$ e caso $\mathrm{f}: \operatorname{Re}=400$ e $\mathrm{n}=64 \ldots \ldots \ldots$

2.8 Região de estabilidade: $\alpha \times \beta, \alpha$ : eixo horizontal e $\beta$ : eixo vertical, para testes realizados com níveis de discretização $n=16,32$ e 64 . . . . . . . .

2.9 Região de estabilidade: $R e * \Delta x^{2} \times \Delta t, R e * \Delta x^{2}$ : eixo horizontal e $\Delta t$ : eixo vertical. . . . . . . . . . . . . . . . . . . . .

2.10 (a) Representação de um tanque simples com o eixo e o impelidor. (b) Representação da região $r \times z$ utilizada na modelagem empregando as equações de Navier-Stokes.

2.11 Condições empregadas na modelagem do tanque com geometria simples.

2.12 Representação do comportamento do fluido na região $[0,1] \times[0,1]$ do cilindro, através do campo de velocidade por vetores, com um disco-atuador definido pela função: $f(r)=-0,5 * r$, para uma malha $32 \times 32, R e_{\text {fluido }}=$

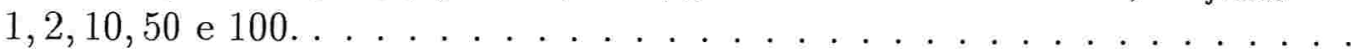

2.13 Representação do comportamento do fluido na região $[0,1] \times[0,1]$ do cilindro, através do campo de velocidades por vetores, com um disco-atuador definido pela função: $f(r)=0,5 * r$, para uma malha $32 \times 32, R e_{\text {fluido }}=$ $1,2,10,50$ e $100 \ldots \ldots \ldots \ldots \ldots$

2.14 Representação do comportamento do fluido na região $[0,1] \times[0,1]$ do cilindro, através do campo de velocidades por vetores, com dois discos-atuadores definidos pelas funções: $f_{1}(r)=-0,5 * r$ e $f_{2}(r)=-2 / 9 * r$ para uma malha $32 \times 32, \operatorname{Re}_{\text {fluido }}=1,2,10,50$ e $100 \ldots \ldots \ldots \ldots$. . . . . . . . 44

3.1 Transferência de calor molecular. . . . . . . . . . . . . . . . 46

3.2 Transferência de massa molecular. . . . . . . . . . . . . . . . . . 47

3.3 Transferência de momento. . . . . . . . . . . . . . . . . . 48

3.4 Contorno físico considerado no rebatimento. . . . . . . . . . . 55 
3.5 Rebatimento usado na parede $0 \leq y_{p} \leq 1$ e $x_{p}>1 \ldots \ldots \ldots$

3.6 Rebatimento empregado na parede $0 \leq x_{p} \leq 1$ e $y_{p}<0 . \ldots \ldots$

3.7 Rebatimento usado na parede $0 \leq x_{p} \leq 1$ e $y_{p}>1 \ldots \ldots \ldots$. . . . . 56

3.8 Rebatimento usado na parede $0 \leq y_{p} \leq 1$ e $x_{p}<0 \ldots \ldots$. . . . . 57

3.9 Pontos empregados em uma interpolação bilinear. . . . . . . . . . . . . . 58

3.10 Comportamento das partículas que partem da diagonal, utilizando o método de Euler e os dados da Tabela $3.1\left(\rho_{p} / \rho_{f}=1 / 2\right) . \ldots . . . . . .660$

3.11 Comportamento das partículas que partem da diagonal, utilizando o método de Euler e os dados da Tabela $3.1\left(\rho_{p} / \rho_{f}=2 / 1\right)$. . . . . . . . . .

3.12 Comportamento das partículas que partem da diagonal, utilizando o método de Euler e constante de elasticidade $\epsilon=0,6$.

3.13 Comportamento das partículas que partem da diagonal, utilizando o método de Euler e constante de elasticidade $\epsilon=0,3 \ldots$

4.1 Representação do campo de velocidade no tanque, região $[0,1] \times[0,1]$, malha $64 \times 64$, utilizando um disco-atuador definido por $f(r)=-0,5 * r, C / T=$

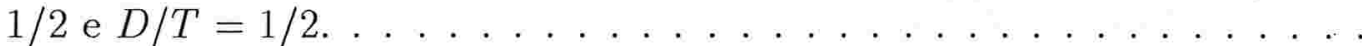

4.2 Posições das partículas $\left(d_{p}=100 \mu \mathrm{m}\right)$, ao longo da trajetória (10s), plotadas a 0 s, $2 \mathrm{~s}, 3 \mathrm{~s}, 5 \mathrm{~s}, 7,5 \mathrm{~s}$ e $10 \mathrm{~s}: C / T=1 / 2, D / T=1 / 2$ e $f(r)=-0,5 * r . \quad . \quad 70$

4.3 distância percorrida $\times$ número de partículas: representação do espaço percorrido pelas 4096 partículas $\left(d_{p}=100 \mu \mathrm{m}\right)$ ao longo da trajetória (tempo de simulação: $10 \mathrm{~s}), C / T=1 / 2, D / T=1 / 2$ e disco-atuador representado por $f(r)=-0,5 * r$.

4.4 Posições das partículas $\left(d_{p}=10 \mu \mathrm{m}\right)$ ao longo da trajetória (10s), plotadas a 0 s, $2 \mathrm{~s}, 3 \mathrm{~s}, 5 \mathrm{~s}, 7,5 \mathrm{~s}$ e $10 \mathrm{~s}: C / T=1 / 2, D / T=1 / 2$ e $f(r)=-0,5 * r . \quad . \quad 73$

4.5 Posições das partículas $\left(d_{p}=50 \mu \mathrm{m}\right)$ ao longo da trajetória (10s), plotadas a 0 s, $2 \mathrm{~s}, 3 \mathrm{~s}, 5 \mathrm{~s}, 7,5 \mathrm{~s}$ e $10 \mathrm{~s}: C / T=1 / 2, D / T=1 / 2$ e $f(r)=-0,5 * r \ldots \ldots .74$

4.6 distância percorrida $\times$ número de partículas: representação do espaço percorrido pelas 4096 partículas $\left(d_{p}=10 \mu \mathrm{m}\right)$ ao longo da trajetória (tempo de simulação: $10 \mathrm{~s}), C / T=1 / 2, D / T=1 / 2$ e disco-atuador representado por $f(r)=-0,5 * r \ldots \ldots \ldots \ldots$

4.7 distância percorrida $\times$ número de partículas: representação do espaço percorrido pelas 4096 partículas $\left(d_{p}=50 \mu \mathrm{m}\right)$ ao longo da trajetória (tempo de simulação: $10 \mathrm{~s}), C / T=1 / 2, D / T=1 / 2$ e disco-atuador representado por $f(r)=-0,5 * r$. 
4.8 Representação do campo de velocidades no tanque, região $[0,1] \times[0,1]$, malha $64 \times 64$, utilizando um disco-atuador definido por $f(r)=-0,5 * r$,

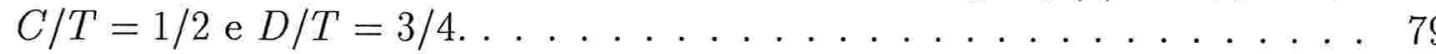

4.9 Posições das partículas $\left(d_{p}=100 \mu \mathrm{m}\right)$ ao longo da trajetória (10s), plotadas a 0 s, $2 \mathrm{~s}, 3 \mathrm{~s}, 5 \mathrm{~s}, 7,5 \mathrm{~s}$ e $10 \mathrm{~s}: C / T=1 / 2, D / T=3 / 4$ e $f(r)=-0,5 * r . . .80$

4.10 distância percorrida $\times$ número de partículas: representação do espaço percorrido pelas 4096 partículas $\left(d_{p}=100 \mu \mathrm{m}\right)$ ao longo da trajetória (tempo de simulação: $10 \mathrm{~s}), C / T=1 / 2, D / T=1 / 2$ e disco-atuador representado por $f(r)=-0,5 * r \ldots \ldots \ldots \ldots \ldots$

4.11 Representação do campo de velocidades no tanque, região $[0,1] \times[0,1]$, malha $64 \times 64$, utilizando um disco-atuador definido por $f(r)=-2 / 9 * r$, $C / T=1 / 2$ e $D / T=3 / 4 \ldots \ldots \ldots \ldots \ldots \ldots$

4.12 Posições das partículas ao longo da trajetória (10s), plotadas a $0 \mathrm{~s}, 2 \mathrm{~s}, 3 \mathrm{~s}$, 5s, 7,5 s e 10 s: $C / T=1 / 2, D / T=3 / 4$ e $f(r)=-2 / 9 * r \ldots \ldots$.

4.13 distância percorrida $\times$ número de partículas: representação do espaço percorrido pelas 4096 partículas $\left(d_{p}=100 \mu \mathrm{m}\right)$ ao longo da trajetória (tempo de simulação: $10 \mathrm{~s}), C / T=1 / 2, D / T=3 / 4$ e disco-atuador representado por $f(r)=-2 / 9 * r \ldots \ldots \ldots \ldots \ldots$

4.14 Representação do campo de velocidade no tanque, região $[0,1] \times[0,1]$, malha $64 \times 64$, utilizando um disco-atuador definido por $f(r)=-0,5 * r, \mathrm{C} / \mathrm{T}=1 / 4$

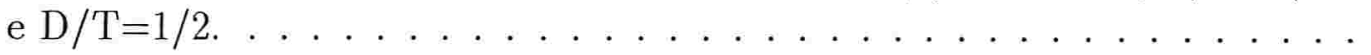

4.15 Posições das partículas ao longo da trajetória (10s), plotadas a $0 \mathrm{~s}, 2 \mathrm{~s}, 3 \mathrm{~s}$, 5s, 7,5 s e $10 \mathrm{~s}: C / T=1 / 4, D / T=1 / 2$ e $f(r)=-0,5 * r \ldots \ldots$

4.16 distância percorrida $\times$ número de partículas: representação do espaço percorrido pelas 4096 partículas $\left(d_{p}=100 \mu \mathrm{m}\right)$ ao longo da trajetória (tempo de simulação: $10 \mathrm{~s}), C / T=1 / 4, D / T=1 / 2$ e disco-atuador representado por $f(r)=-0,5 * r$

4.17 Representação do campo de velocidade no tanque, região $[0,1] \times[0,1]$, malha $64 \times 64$, utilizando um disco-atuador definido por $f(r)=-2 / 9 * r, C / T=$ $1 / 4$ e $D / T=3 / 4 \ldots \ldots \ldots \ldots \ldots \ldots$

4.18 Posições das partículas ao longo da trajetória (10s), plotadas a 0s, 2s, 3s, 5s, 7,5 s e $10 \mathrm{~s}: C / T=1 / 4, D / T=3 / 4$ e $f(r)=-2 / 9 * r . \ldots$.

4.19 distância percorrida $\times$ número de partículas: representação do espaço percorrido pelas 4096 partículas $\left(d_{p}=100 \mu \mathrm{m}\right)$ ao longo da trajetória (tempo de simulação: $10 \mathrm{~s}), C / T=1 / 4, D / T=3 / 4$ e disco-atuador representado por $f(r)=-2 / 9 * r$. 
4.20 Representação do campo de velocidade no tanque, região $[0,1] \times[0,1]$, malha $64 \times 64$, utilizando dois discos-atuadores definidos por $f(r)=-0,5 *$ $r, C / T=1 / 4, S / T=1 / 4$ e $D / T=1 / 2 \ldots \ldots \ldots \ldots$

4.21 Posições das partículas ao longo da trajetória (10s), plotadas a $0 \mathrm{~s}, 2 \mathrm{~s}, 3 \mathrm{~s}$, 5s, 7,5s e 10s: $C / T=1 / 2, S / T=1 / 4, D / T=1 / 2$ e $f(r)=-0,5 * r . \quad . .98$

4.22 distância percorrida $\times$ número de partículas: representação do espaço percorrido pelas 4096 partículas $\left(d_{p}=100 \mu \mathrm{m}\right)$ ao longo da trajetória (tempo de simulação: $10 \mathrm{~s}$ ), $C / T=1 / 2, S / T=1 / 4, D / T=1 / 2$ e disco-atuador representado por $f(r)=-0,5 * r \ldots \ldots \ldots \ldots$

4.23 Representação do campo de velocidade no tanque, região $[0,1] \times[0,1]$, matha $64 \times 64$, utilizando dois discos-atuadores definidos por $f(r)=-0,5 *$ $r, C / T=1 / 4, S / T=1 / 4$ e $D / T=3 / 4 \ldots \ldots \ldots \ldots$

4.24 Posições das partículas ao longo da trajetória (10s), plotadas a $0 \mathrm{~s}, 2 \mathrm{~s}, 3 \mathrm{~s}$, 5s, 7,5 s e 10s: $C / T=1 / 4, S / T=1 / 4, D / T=1 / 2$ e $f(r)=-0,5 * r . \quad . .102$

4.25 distância percorrida $\times$ número de partículas: representação do espaço percorrido pelas 4096 partículas $\left(d_{p}=100 \mu \mathrm{m}\right)$ ao longo da trajetória (tempo de simulação: $10 \mathrm{~s}), C / T=1 / 4, S / T=1 / 4, D / T=3 / 4$ e disco-atuador representado por $f(r)=-2 / 9 * r \ldots \ldots \ldots 103$

4.26 Posição das partículas não-esféricas ao longo da trajetória, com variação aleatória em $1 \%$ das componentes $u$ e $v$ da velocidade da partícula: $C / T=$ $1 / 2, D / T=2$ e $f(r)=-0,5 * r \ldots \ldots \ldots \ldots$

4.27 Posição das partículas não-esférica ao longo da trajetória, com variação aleatória em $2 \%$ das componentes $u$ e $v$ da velocidade da partícula: $C / T=$ $1 / 2, D / T=1 / 2$ e $f(r)=-0,5 * r . \ldots \ldots \ldots \ldots$

4.28 Posição das partículas não-esférica ao longo da trajetória, com variação aleatória em $5 \%$ das componentes $u$ e $v$ da velocidade da partícula: $C / T=$ $1 / 2, D / T=2$ e $f(r)=-0,5 * r \ldots \ldots \ldots \ldots \ldots$

4.29 Posição das partículas não-esférica ao longo da trajetória, com variação aleatória em $10 \%$ das componentes $u$ e $v$ da velocidade da partícula: $C / T=$ $1 / 2, D / T=2$ e $f(r)=-0,5 * r \ldots \ldots \ldots \ldots$

4.30 distância percorrida $\times$ número de partículas, representando o espaço percorrido pelas 4096 partículas não-esféricas ao longo da trajetória com uma variação aleatória de $1 \%$ das componentes da velocidade da partícula. . . . 115

4.31 distância percorrida $\times$ número de partículas, representando o espaço percorrido pelas 4096 partículas não-esféricas ao longo da trajetória com uma variação aleatória de $2 \%$ das componentes da velocidade da partícula. . . . 116 
4.32 distância percorrida $\times$ número de partículas, representando o espaço percorrido pelas 4096 partículas não-esféricas ao longo da trajetória com uma variação aleatória de $5 \%$ das componentes da velocidade da partícula. . . . 117

4.33 distância percorrida $\times$ número de partículas, representando o espaço percorrido pelas 4096 partículas não-esféricas ao longo da trajetória com uma variação aleatória de 10\% das componentes da velocidade da partícula. . . 118

4.34 Posição das partículas não-esféricas, com variação aleatória em 1\%, 2\%, $5 \%$ e $10 \%$ das componentes $u$ e $v$ da velocidade da partícula: $C / T=1 / 2$,

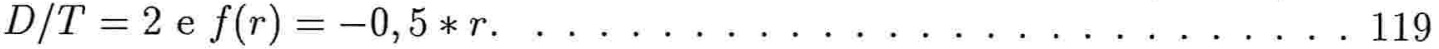

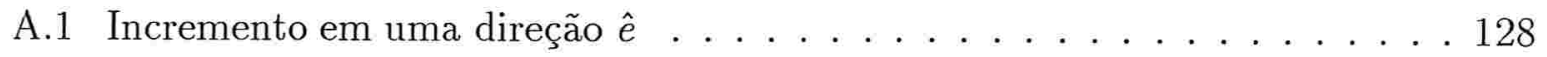

A.2 Coordenadas cilíndricas. . . . . . . . . . . . . . . 130

B.1 (a) Região contínua; (b) região discretizada. . . . . . . . . . . . . . 135 


\section{Lista de Tabelas}

1.1 Relação padrão utilizada para um escoamento turbulento. . . . . . . . . . 7

1.2 Variáveis de projeto na agitação. . . . . . . . . . . . . . . . . 14

1.3 Adicionais empregados em agitação de líquidos. . . . . . . . . . . . 15

1.4 Processo de agitação, mistura e dispersão. . . . . . . . . . . . . . . . 16

3.1 Comportamento das partículas na cavidade sem influência do fluido: pt é o índice da partícula, $x_{p}$ e $y_{p}$ são as coordenadas de cada partícula pt, r é o raio, $u_{p}$ e $v_{p}$ são as componentes horizontal e vertical da velocidade, $\rho_{p} \mathrm{e}$ $\rho_{f}$ as densidades da partícula e do fluido. . . . . . . . . . . . . . 59

4.1 Número de partículas $\left(d_{p}=100 \mu \mathrm{m}\right)$ por célula no instante final (10s), $C / T=1 / 2, D / T=1 / 2$ e disco-atuador: $f(r)=-0,5 * r . \ldots \ldots 71$

4.2 Número de partículas $\left(d_{p}=10 \mu \mathrm{m}\right)$ por célula no instante final (10s), $C / T=$ $1 / 2, D / T=1 / 2$ e $f(r)=-0,5 * r \ldots \ldots \ldots \ldots \ldots \ldots$

4.3 Número de partículas $\left(d_{p}=50 \mu \mathrm{m}\right)$ por célula no instante final $(10 \mathrm{~s}), C / T=$ $1 / 2, D / T=1 / 2$ e $f(r)=-0,5 * r . \ldots \ldots \ldots \ldots \ldots \ldots$

4.4 Número de partículas $\left(d_{p}=100 \mu m\right)$ por célula no instante final (10s), $C / T=1 / 2, D / T=3 / 4$ e $f(r)=-0,5 * r \ldots \ldots \ldots 2$

4.5 Número de partículas $\left(d_{p}=100 \mu \mathrm{m}\right)$ por célula no instante final (10s), $C / T=1 / 2, D / T=3 / 4$ e $f(r)=-2 / 9 * r \ldots \ldots . \ldots 66$

4.6 Quadro-resumo das simulações realizadas nesta seção, 4.2.1. . . . . . . . 87

4.7 Número de partículas $\left(d_{p}=100 \mu \mathrm{m}\right)$ por célula no instante final (10s), $C / T=1 / 4, D / T=1 / 2$ e disco-atuador $f(r)=-0,5 * r \ldots \ldots . \ldots 1$ 
4.8 Número de partículas $\left(d_{p}=100 \mu m\right)$ por célula no instante final (10s), $C / T=1 / 4, D / T=3 / 4$ e disco-atuador: $f(r)=-2 / 9 * r . \ldots . \ldots 9$

4.9 Quadro-resumo das simulações realizadas nesta seção, 4.2.2 . . . . . . . 96

4.10 Número de partículas $\left(d_{p}=100 \mu \mathrm{m}\right)$ por célula no instante final $(10 \mathrm{~s})$, $C / T=1 / 4, S / T=1 / 4, D / T=3 / 4$ e disco-atuador: $f(r)=-2 / 9 * r . \ldots 100$

4.11 Número de partículas $\left(d_{p}=100 \mu \mathrm{m}\right)$ por célula no instante final (10s), $C / T=1 / 4, S / T=1 / 4, D / T=3 / 4$ e disco-atuador: $f(r)=-2 / 9 * r . \quad .104$

4.12 Quadro-resumo das simulações realizadas nesta seção, 4.2.3, para dois discosatuadores, $\mathrm{S} / \mathrm{T}=1 / 4 \ldots \ldots \ldots \ldots$. . . . . . . . . . . . . . . . . . . . . . .

4.13 Número de partículas não-esférica por célula no instante final (10s) com variação aleatória em $1 \%$ das componentes $u$ e $v$ da velocidade da partícula: $C / T=1 / 2, D / T=1 / 2$ e $f(r)=-0,5 * r \ldots \ldots \ldots$. . . . . . . . . . 108

4.14 Número de partículas não-esférica por célula no instante final (10s) com variação em $2 \%$ das componentes $u$ e $v$ da velocidade da partícula: $C / T=$ $1 / 2, D / T=1 / 2$ e $f(r)=-0,5 * r . \ldots \ldots \ldots 110 \ldots \ldots \ldots \ldots$

4.15 Número de partículas não-esférica por célula no instante final (10s) com variação em $5 \%$ das componentes $u$ e $v$ da velocidade da partícula, $C / T=$ $1 / 2, D / T=1 / 2$ e $f(r)=-0,5 * r . \ldots \ldots \ldots 112$

4.16 Número de partículas não-esférica por célula no instante final (10s) com variação aleatória de $10 \%$ das componentes $u$ e $v$ da velocidade da partícula, $C / T=1 / 2, D / T=1 / 2$ e $f(r)=-0,5 * r \ldots \ldots 114$

4.17 Quadro-resumo das simulações realizadas nesta seção, 4.2.4 . . . . . . . 120

5.1 Quadro-resumo das simulações realizadas na análise da trajetória e sedimentação das partículas. . . . . . . . . . . . . . . . . . . 123

5.2 Quadro-resumo das simulações realizadas na análise da trajetória e sedimentação das partículas não-esféricas. . . . . . . . . . . . . . . . . . . . . 124 


\section{Introdução}

A partir do problema relatado pela Divisão de Química do IPT - Instituto de Pesquisas Tecnológicas do Estado de São Paulo S.A. citando a importância da agitação mecânica utilizando tanques cilíndricos (Figura 1 [18]) e a cristalização de partículas na indústria química, percebeu-se a possibilidade de realização de um trabalho conjunto entre analistas numéricos e o grupo de Engenharia Química do IPT. Considerando o problema citado surgiu a idéia de uma formulação simplificada dos métodos tradicionais para um melhor entendimento dos processos envolvidos em uma agitação mecânica com o intuito de, a longo prazo, reduzir a dependência de ferramentas proprietárias como, por exemplo, o FLUENT.

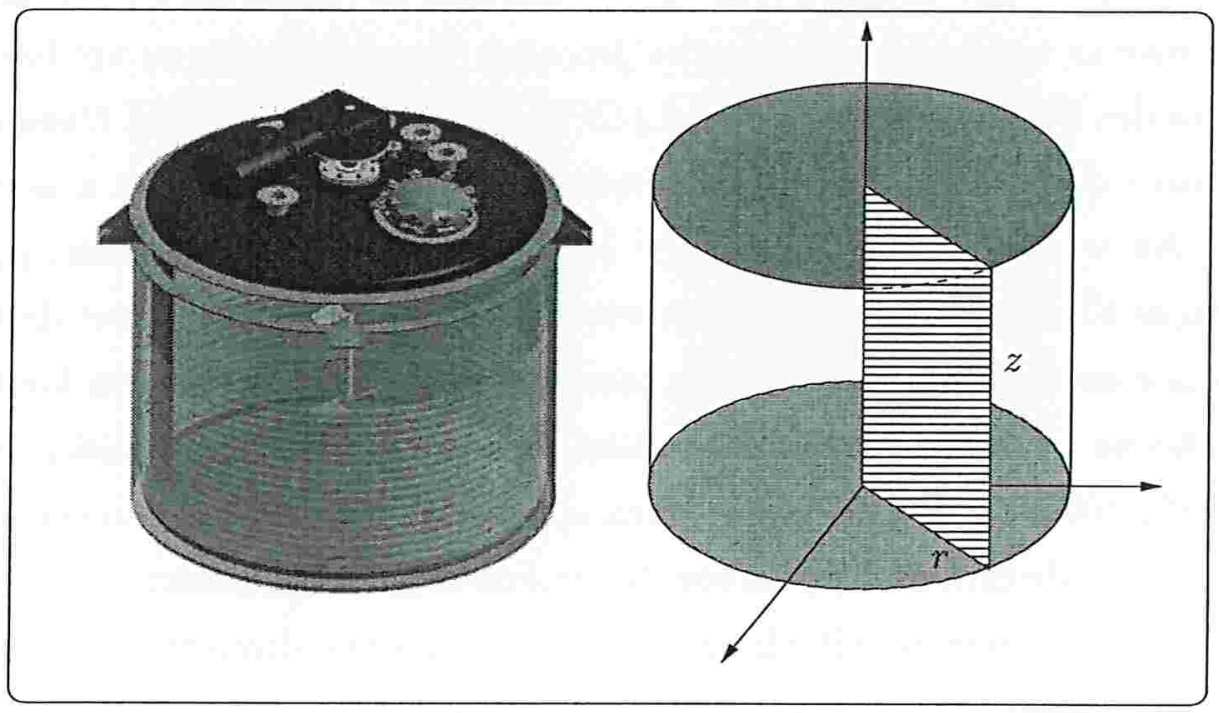

Figura 1: Tanque de agitação mecânica e sua representação geométrica para modelagem. 
No projeto final da disciplina MAP-5726 - Introdução à Mecânica dos Fluidos Computacional [24] foi implementado um código para solucionar as equações de Navier-Stokes na cavidade com as condições de contorno citadas em Peyret [22], p.200. Posteriormente, foi realizado um estudo da estabilidade e convergência do método de Runge-Kutta k-estágios apresentado no XXII CNMAC - Congresso de Matemática Aplicada e Computacional [28]. Tendo este estudo como ponto de partida, decidiu-se incluir ao código acadêmico a capacidade de simulação dinâmica de partículas em suspensão.

Para tanto, neste trabalho objetiva-se:

- descrever qualitativamente o processo hidrodinâmico;

- modelar o problema hidrodinâmico através das equações de Navier-Stokes em coordenadas cilíndricas para uma representação simples do tanque agitado;

- modelar a trajetória das partículas e analisar a influência do campo de velocidades nesta trajetória;

- analisar a influência dos discos-atuadores, de acordo com a sua localização, função representativa e seu comprimento, na suspensão das partículas.

Em sua essência, esse é um trabalho de Modelagem Matemática reunindo o interesse prático, o fenômeno físico e a formulação matemática.

Assim, num primeiro instante, é descrita a agitação mecânica em um tanque cilíndrico, sua geometria e as variáveis envolvidas no processo. Em seguida faz-se um breve histórico da Mecânica dos Fluidos Computacional (CFD - Computational Fluid Dynamics) e uma descrição física das Equações de Navier-Stokes, ponto de partida para a modelagem do problema. Na seqüência, as equações de Navier-Stokes são discretizadas pelo Método das Diferenças Finitas e o problema discreto é resolvido numericamente. Um estudo de convergência e estabilidade é conduzido para o método de Runge-Kutta k-estágios para o escoamento na cavidade, trabalhando com alguns valores de Reynolds, por exemplo $\operatorname{Re}=1,2,100,400$, no regime laminar. Uma relação entre os fatores de relaxação é obtida através da análise de estabilidade de von Neumann. Ainda, é apresentada a discretização das equações em coordenadas cilíndricas com implantação do disco-atuador na cavidade e os testes que foram realizados para analisar o comportamento do fluido a partir da função dada para definir o disco-atuador além do sentido do fluido. 
A trajetória da partícula é modelada por um sistema de Equações Diferenciais Ordinárias (EDO's), e também, solucionadas numericamente pelo Método das Diferenças Finitas. Um estudo é feito para discretizações pelo método de Euler, Euler Modificado e Runge-Kutta de $4^{\mathrm{a}}$ ordem e influência da constante de elasticidade " $\epsilon$ " na trajetória da partícula.

Para finalizar, é feita uma análise do comportamento das partículas, através de sua trajetória e sua concentração através de algumas variáveis envolvidas no processo, a partir de uma partícula em cada célula. Utilizando-se dois discos-atuadores, optou-se por aquele que resultasse em uma melhor mistura para fazer uma seqüência de testes mais detalhados.

Como o comprimento do impelidor é uma das variáveis envolvidas no processo de mistura e agitação, mais testes foram feitos variando-se o comprimento do mesmo para uma análise da suspensão e concentração das partículas.

Um pequeno estudo sobre a hipótese de partículas não-esféricas também foi realizado.

Sugestões de trabalhos futuros e desafios estão dispostos na conclusão. 


\section{Agitação}

Este capítulo traz a definição geral de agitação, processo que fornece movimento ao líquido auxiliando a mistura e a dispersão, a geometria do tanque onde ocorre a mistura, complexo de dois ou mais ingredientes que mesmo em contato não perdem a sua identidade individual, e os principais tipos de impelidores, além das variáveis envolvidas neste processo. Também são descritas as principais aplicações.

\subsection{A Agitação Mecânica}

A agitação mecânica é encontrada na maioria dos sistemas de produção e em vários processos químicos. É de vital importância nas indústrias químicas, farmacêuticas, alimentícias, nuclear, petroleira, de produção de papel e no tratamento do lixo industrial e municipal.

A agitação é usada para diferentes finalidades como:

- mistura de líquidos;

- dissolução de partículas sólidas;

- dispersão de líquidos imiscíveis entre si e gases em líquidos;

- aquecimento ou resfriamento da massa agitada a partir de uma superfície (camisas ou serpentinas).

A Figura 1.1 [3] ilustra uma aplicação do uso da agitação em um tanque continuamente agitado, Biobulk, que se trata de um processo anaeróbico convencional aplicável a detritos 
contendo grandes concentrações de gorduras, óleos e graxas. O Biobulk foi especialmente projetado para assegurar que os detritos líquidos entrem em contato constante com a biomassa, sendo válido quando o fluxo é baixo, assim a retenção hidráulica é mais longa permitindo maior degradação dos sólidos. Este procedimento é excelente no tratamento de processos que descarregam efluentes com alto nível em gorduras biodegradáveis e óleos.

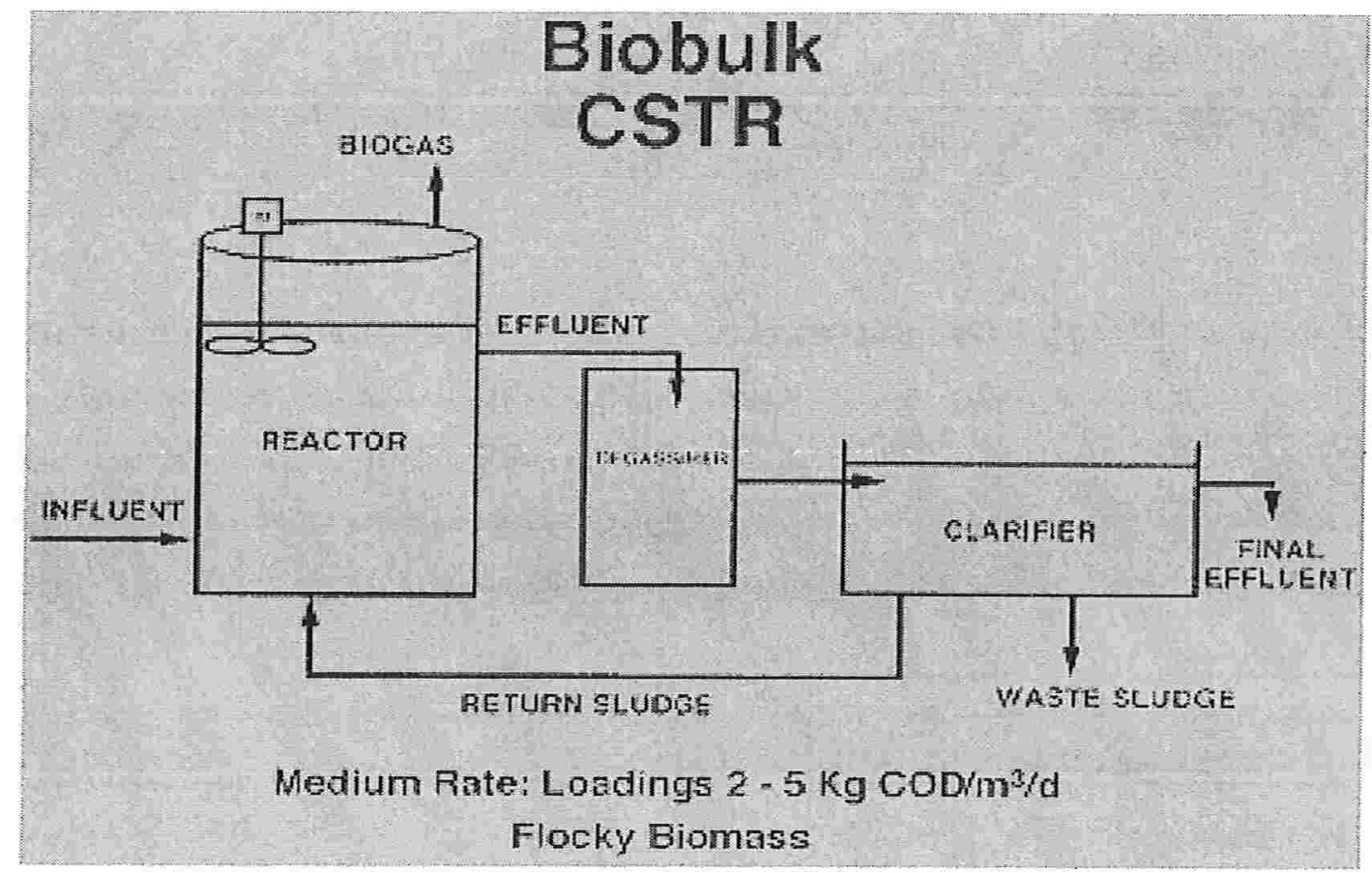

Figura 1.1: Biobulk: exemplo de um tanque continuamente agitado.

Há diferentes formas de promover a mistura em um tanque e isto inclui algumas considerações básicas como o efeito do tanque no processo de misturas, a geometria do tanque, dimensão e estrutura, além do tipo de misturador (impelidor) utilizado na aplicação.

\subsection{A Geometria do Sistema de Agitação}

A agitação mecânica geralmente utiliza um tanque cilíndrico equipado com um conjunto composto de um motor, eixo, um ou mais impelidores e freqüentemente serpentinas ou camisas para troca de calor, além de chicanas igualmente espaçadas fixadas na parede do tanque. A Figura 1.2 [18] apresenta a esquematização de um tanque agitado convencional. 


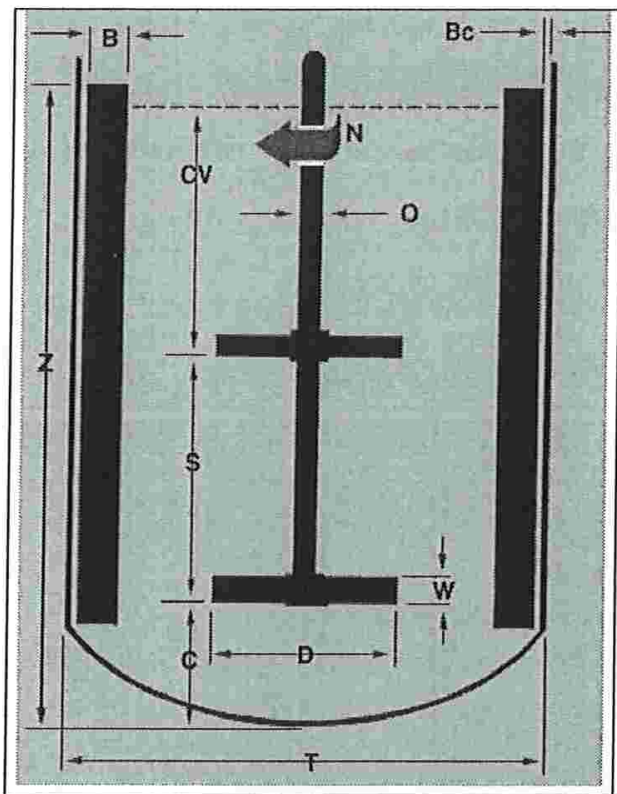

Z: altura do líquido

T: diâmetro interno do tanque

B: largura da chicana

Bc: distância da chicana à parede do tanque

C: distância do impelidor ao fundo do tanque

S: distância entre impelidores

CV: distância entre impelidor e superfície

D: diâmetro do impelidor

W: largura do impelidor

O: diâmetro do eixo

$\mathrm{N}$ : rotação do agitador (rpm)

Figura 1.2: Ilustração da esquematização de um tanque agitado convencional.

As configurações geométricas, ou arranjos do conjunto tanque-agitador são estudados com diferentes abordagens para cada região do sistema como os impelidores, o eixo, as chicanas, etc. As relações entre as partes do tanque dependem do objetivo a ser alcançado e das características do fluidos envolvidos. Na Tabela 1.1 [14] tem-se a relação padrão que é normalmente utilizada para escoamento turbulento. Para escoamento laminar outros tipos de impelidores são utilizados.

\begin{tabular}{|l|l|}
\hline RELAÇÃ O & OBSERVAÇÃO \\
\hline$D / T=1 / 4$ a $1 / 2$ & $1 / 3$ é o mais comum \\
\hline$Z / T=1$ & \\
\hline$C / T=1 / 6$ a $1 / 2$ & Também é usado $0,30 \mathrm{D}<\mathrm{C}<1,25 \mathrm{D}$ \\
\hline$B / T=1 / 12$ a $1 / 10$ & Também é usado $0,055 \mathrm{~T}<\mathrm{B}<0,083 \mathrm{~T}$ \\
\hline$W / D=1 / 4$ a $1 / 6$ & \\
\hline$S / D=1$ a 2 & \\
\hline$B c=T / 72$ & \\
\hline
\end{tabular}

Tabela 1.1: Relação padrão utilizada para um escoamento turbulento. 


\subsubsection{Base do Tanque}

O fundo do tanque pode ter diversas formas como abaulados, cônicos, planos, entre outros. Normalmente considera-se uma base plana ou no formato de um cone raso (menos de $15^{\circ}$ ). Entretanto isso não é sempre válido para aplicações com suspensões sólidas muito sensíveis. A Figura 1.3 [2] mostra um tanque de base esférica abaulada.
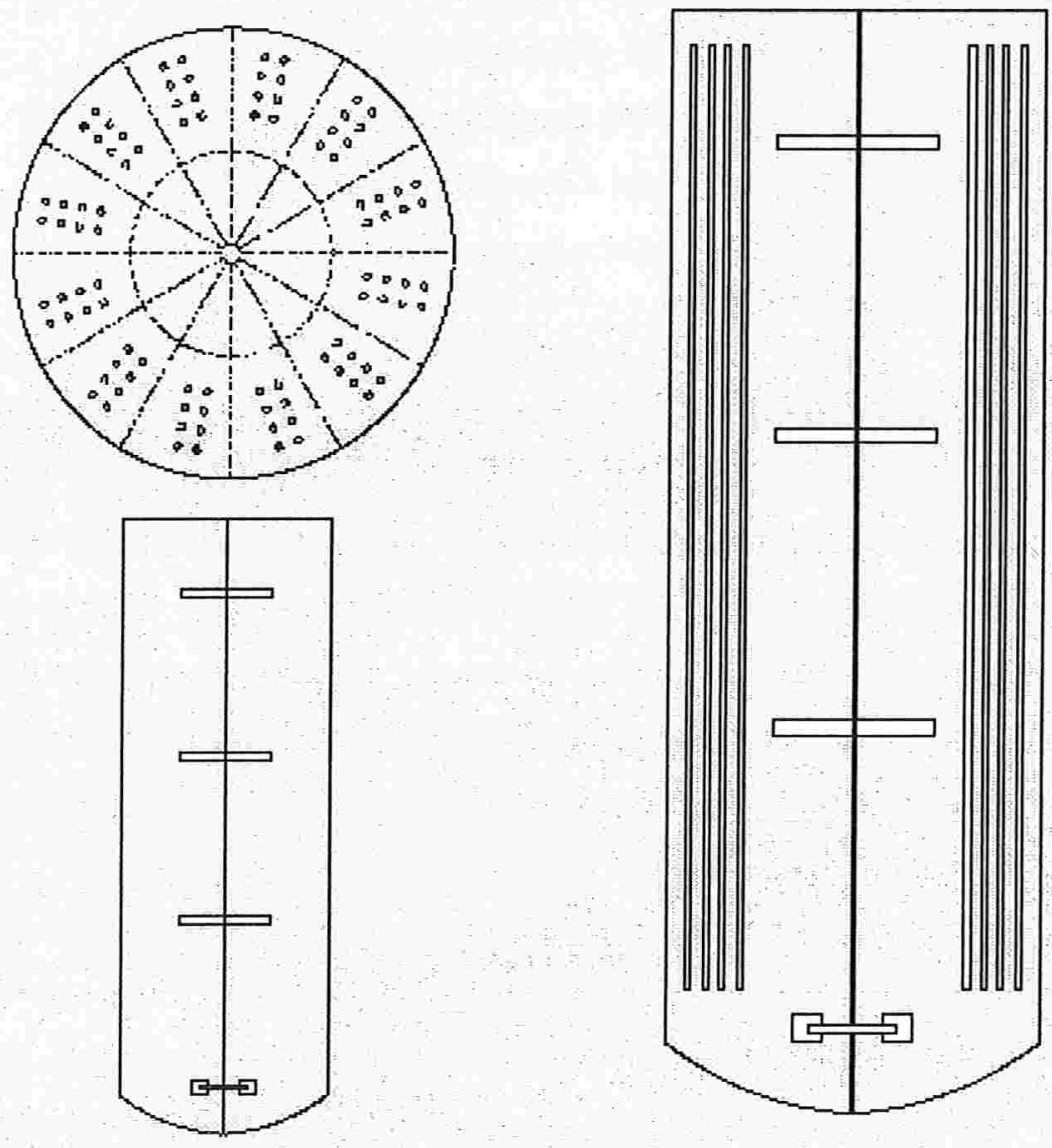

Figura 1.3: Tanque com base esférica abaulada.

\subsubsection{Chicanas}

Com bases esféricas ou cones profundos, algumas chicanas devem ser colocadas para prevenir vórtices nestas áreas, Figura 1.4 [2]. 


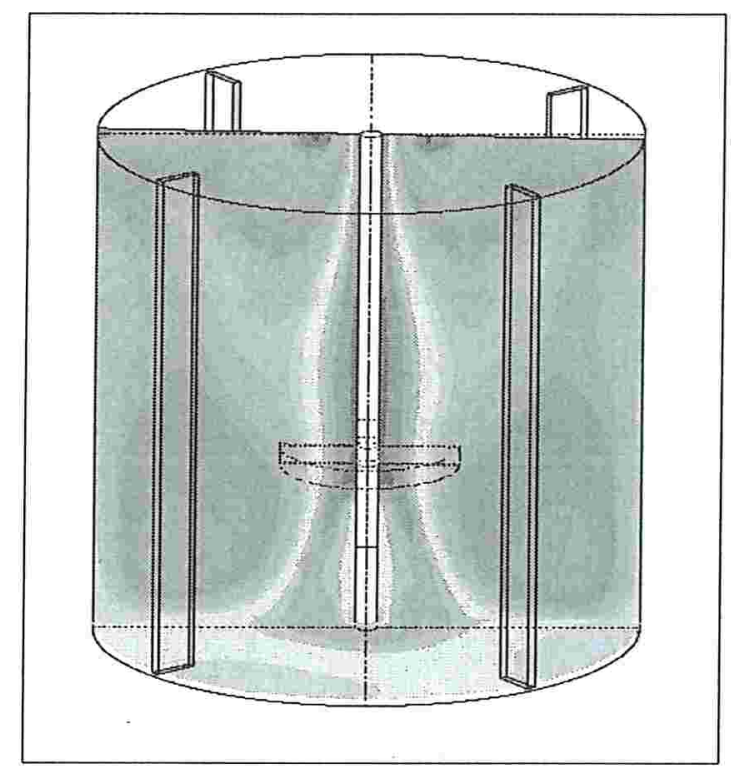

Figura 1.4: Tanque com chicanas.

As chicanas são chapas introduzidas no tanque a fim de redirecionar o escoamento ou ainda provocar um distúrbio, maximizando a transferência de potência para o fluido e minimizando a rotação sólida do fluido no tanque evitando a entrada de ar no sistema de mistura causada pelo vórice na superfície. Normalmente a largura das chicanas é expressa em função do diâmetro do tanque, o mais comum é $1 / 12$ a 1/10 deste diâmetro.

\subsubsection{Impelidores}

O impelidor de misturas ou simplesmente impelidor é usado em determinados processos de mistura. Existe um grande número de tipos de impelidores e sempre que uma nova aplicação exige, novos modelos são construídos.

As forças aplicadas pelo impelidor em movimento em um fluido são responsáveis pelo padrão do escoamento promovendo trocas que permitem reduzir ou mesmo eliminar as diferenças de propriedades entre regiões diferentes. Assim, a escolha do impelidor a ser adotado depende dos requisitos do processo a ser realizado.

Os impelidores são classificados em três grupos, relacionando-se ao tipo de fluxos 
que são capazes de gerar: os impelidores de fluxo axial, os de fluxo radial e os de fluxo tangencial.

Os impelidores de fluxo axial, Figura 1.5 [18], são aqueles que as linhas de fluxo tendem a serem paralelas ao eixo do agitador e impulsionam a massa líquida para o fundo do tanque. São impelidores de menor consumo de potência e grande abrangência na maioria dos processos agitados, podendo ser aplicados de forma unitária em tanques com níveis de líquido $\mathrm{Z}$ até $1,5 \mathrm{~T}$ e são usados para promover um perfil descendente da velocidade que é importante para:

- mistura de líquidos miscíveis;

- suspensão contínua;

- transferência de calor.
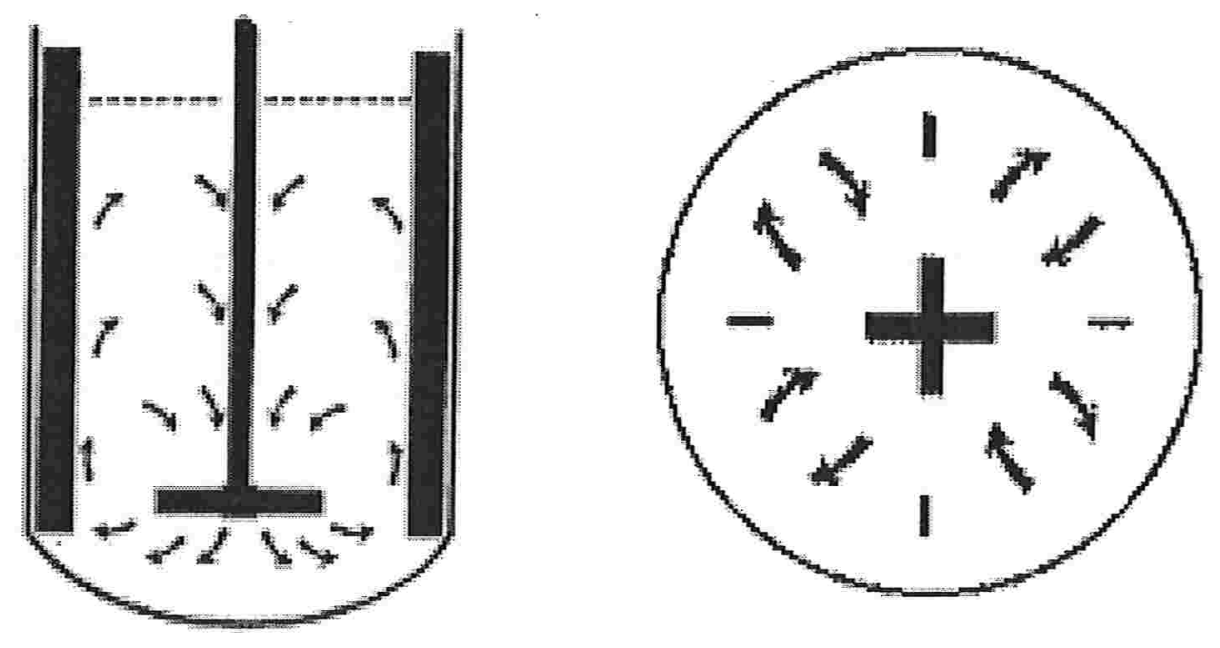

Figura 1.5: Impelidor fluxo axial: as principais correntes ocorrem ao longo do eixo do impelidor e paralelo ao mesmo.

Um impelidor radial é aquele cuja maioria das linhas de fluxo tendem a ser de forma perpendicular ao eixo-agitador, ou seja, tendem a impulsionar a massa líquida contra as paredes do tanque. São impelidores de alto consumo de potência, com maior capacidade dispersiva, normalmente empregados em processo que requeiram ações dispersivas. É usado para promover um perfil de velocidade para:

- misturar líquidos imiscíveis; 
- dispersão de gás;

- promover a transferência de calor.

Na Figura 1.6 [18] é apresentado o impelidor tipo turbina fluxo radial e é uma opção para instalação em tanques com baixo nível de líquido (baixa relação Z/T). O líquido é desenhado na área do impelidor do alto e do fundo em um sentido axial e descarregando então radial à parede do tanque. Na parede o líquido é dirigido para baixo, do fundo do tanque até a superfície.
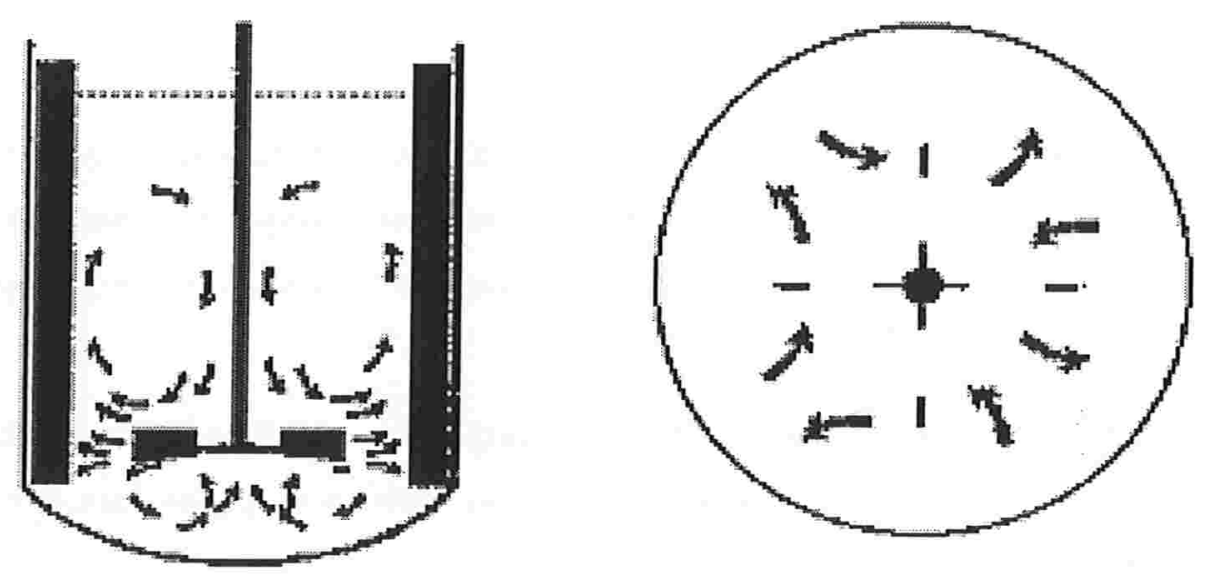

Figura 1.6: Impelidor fluxo radial: as principais correntes ocorrem na direção radial ou tangencial.

Os impelidores de fluxo tangencial operam em regime laminar, destinados a misturar produtos de alta viscosidade que não produzem movimento nem axial nem radial, mas sim impulsionam a massa em movimento circular ao redor da parede do tanque da mistura. São impelidores de alto consumo de energia e por operarem com baixas rotações exigem acionamento de alto torque, e por conseguinte alto custo de investimento.

Uma reclassificação dos impelidores é feita de acordo com o regime da mistura: laminar ou turbulento. Para um regime laminar o diâmetro do impelidor se aproxima do diâmetro do tanque, uma vez que a característica deste tipo de escoamento é que o transporte da quantidade de movimento é baixo. Na Figura 1.7 [5] temos os dois impelidores típicos usados neste tipo de escoamento, o impelidor tipo âncora e o impelidor tipo hélice. 


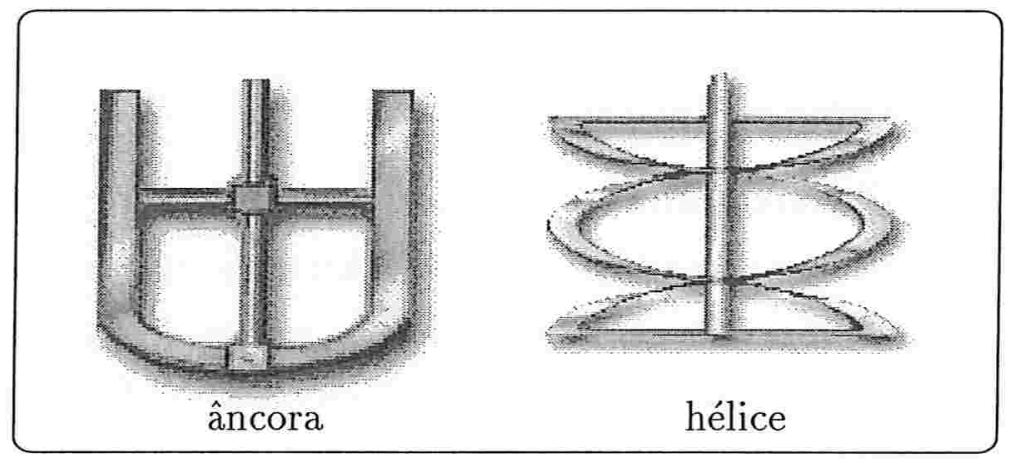

Figura 1.7: Impelidores típicos utilizados em regime laminar.

Em um escoamento turbulento a transferência de quantidade de movimento é eficiente. Neste caso, impelidores largos próximo ao diâmetro do tanque não são necessários, variando de um quarto à metade do diâmetro do tanque, classificados em impelidores fluxo axial.

A Figura 1.8 [23] apresenta alguns tipos de impelidores utilizados em regime turbulento que tem o formato de hélice, pá inclinada, pá ou turbina e respondem por mais de $90 \%$ das aplicações industriais.

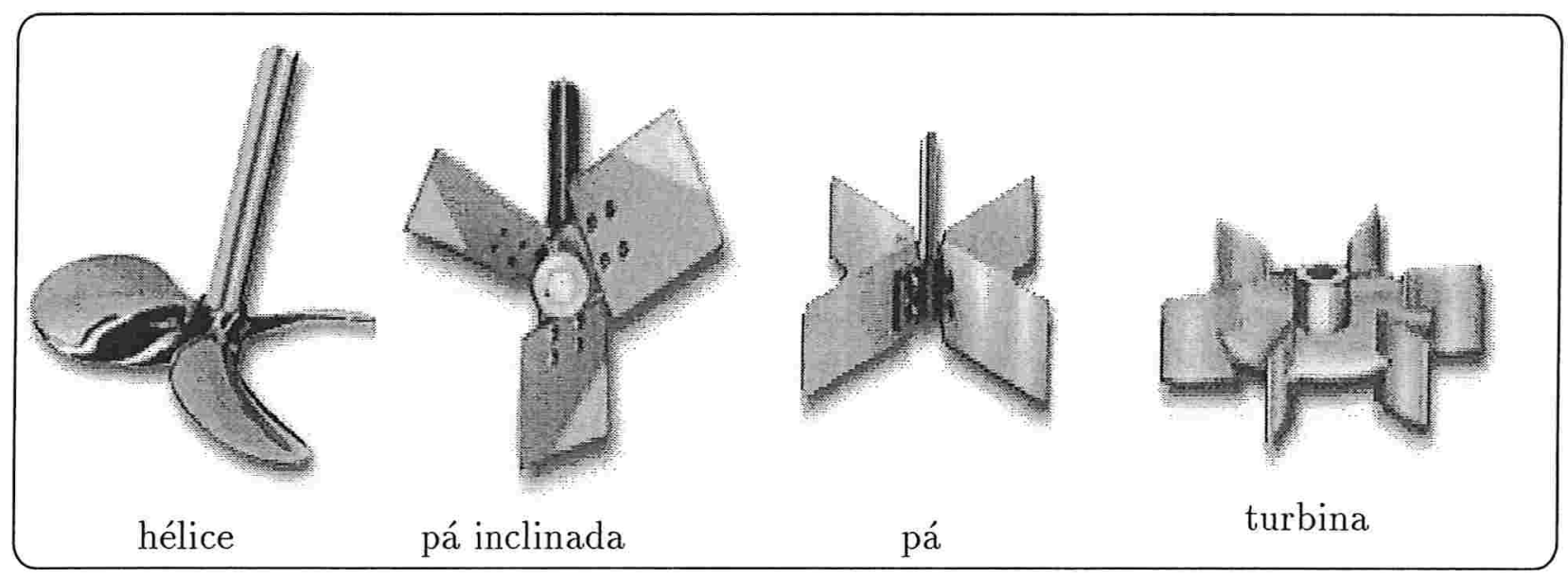

Figura 1.8: Impelidores típicos utilizados em regime turbulento.

Os impelidores tipo hélice são do tipo fluxo axial, utilizados para líquidos de baixa viscosidade que requer alta rotação e raramente apresentam diâmetro acima de $45 \mathrm{~cm}$, independente do diâmetro do tanque. O número de impelidores é outra variável importante 
no projeto e, geralmente, em tanques mais profundos dois ou mais impelidores podem ser montados no eixo, em função da relação $Z / T$ do equipamento e da capacidade de deslocamento volumétrico do impelidor, Figura 1.9 [2].

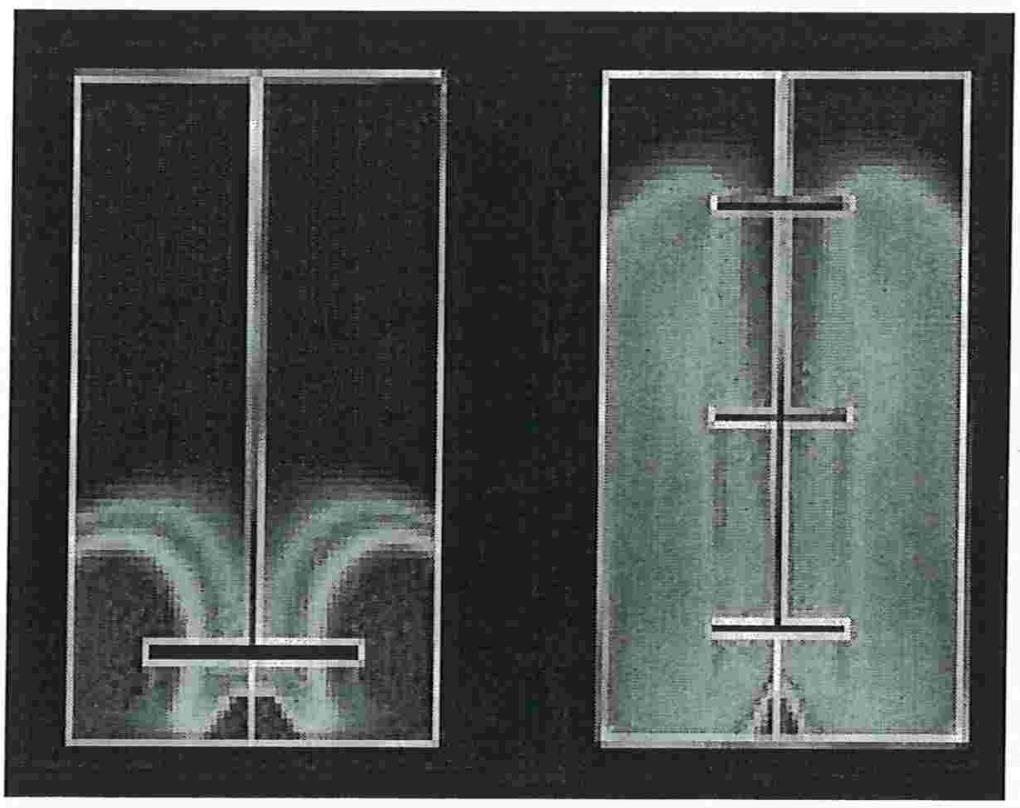

Figura 1.9: Simulações em tanques utilizado um e três impelidores montados no eixo, respectivamente.

Os impelidores tipo pá geram principalmente correntes radiais e tangenciais e o seu comprimento total varia de $30 \%$ a $50 \%$ do diâmetro interno do tanque. Os agitadores do tipo pá inclinada apresentam só movimento vertical e o comprimento total do impelidor varia de $50 \%$ a $80 \%$ do diâmetro interno do tanque e são utilizados para misturas de líquidos e suspensão de sólidos. Para trabalhos em uma ampla faixa de viscosidade os impelidores mais indicados são os do tipo turbina e as principais correntes geradas são tangenciais e radiais, empregadas em processos de transferência de massa entre uma fase gasosa e uma fase líquida [14]. 


\subsection{Algumas Variáveis Envolvidas no Processo de Agi- tação}

As propriedades dos fluidos como viscosidade $(\mu)$, densidade $(\rho)$, tensão superficial $(\tau)$, condutividade térmica $(\mathrm{k})$, calor específico $\left(\mathrm{c}_{p}\right)$ e a velocidade de rotação do impelidor $(\mathrm{N})$ devem ser levadas em consideração para o cálculo da potência $(\mathrm{P})$ e do torque $\left(\mathrm{T}_{q}\right)$. Na Tabela 1.2 [14] tem-se as principais variáveis de projeto para um escoamento turbulento e um escoamento laminar.

\begin{tabular}{|l|l|l|l|}
\hline SÍMBOLO & ITEM & $\begin{array}{l}\text { ESCOAMENTO } \\
\text { TURBULENTO }\end{array}$ & $\begin{array}{l}\text { ESCOAMENTO } \\
\text { LAMINAR }\end{array}$ \\
\hline $\mathrm{P}$ & potência & $k_{1} \rho N^{3} D^{5}$ & $k_{2} \mu N^{2} D^{3}$ \\
\hline $\mathrm{V}$ & volume do tanque & $k_{3} T^{3}$ & $k_{3} T^{3}$ \\
\hline $\mathrm{P} / \mathrm{V}$ & $\begin{array}{l}\text { potência por unidade } \\
\text { de volume }\end{array}$ & $k_{4} N^{3} D^{5} / T^{3}$ & $k_{5} \mu N^{3} D^{5} / T^{3}$ \\
\hline $\mathrm{T}_{q}$ & torque & $k_{6} \rho N^{2} D^{5}$ & $k_{7} \mu N D^{3}$ \\
\hline $\mathrm{T}_{q} / \mathrm{V}$ & $\begin{array}{l}\text { torque por unidade de } \\
\text { volume }\end{array}$ & $k_{8} \rho N^{2} D^{5} / T^{3}$ & $k_{9} \mu N D^{3} / T^{3}$ \\
\hline $\mathrm{U}_{t}$ & $\begin{array}{l}\text { velocidade da ponta do } \\
\text { impelidor }\end{array}$ & $\pi N D$ & \\
\hline
\end{tabular}

k é uma constante de proporcionalidade

Tabela 1.2: Variáveis de projeto na agitação.

A potência é o principal elemento do custo operacional em uma agitação e o torque do custo de investimento, pois dele dependem o dimensionamento da engrenagem de transmissão, o tamanho do eixo e o peso do impelidor.

A complexidade no estudo teórico de sistemas líquidos submetidos a agitação é considerável já que freqüentemente o balanço de massa, energia e quantidade de movimento têm de ser resolvidos simultaneamente. Uma forma de contornar as dificuldades citadas é através do uso de correlações adimensionais empíricas, algumas apresentadas na Tabela $1.3[14]$. 


\begin{tabular}{|c|c|c|c|}
\hline NOME & SÍMBOLO & EQUAÇÃO & COMENTÁRIOS \\
\hline $\begin{array}{l}\text { Número de } \\
\text { Reynolds }\end{array}$ & Re & $R e=D^{2} N \rho / \mu$ & $\begin{array}{l}\text { Seu significado está relacionado } \\
\text { com a razão entre transporte } \\
\text { de quantidade de movimento por } \\
\text { meio de convecção molecular e di- } \\
\text { fusão. }\end{array}$ \\
\hline $\begin{array}{l}\text { Número de } \\
\text { Potência }\end{array}$ & Po & $P o=P /\left(\mu N^{3} D^{5}\right)$ & $\begin{array}{l}\text { Para sistemas com chicanas, } \\
\text { gráficos com } \mathrm{P}=\text { Re mostram que } \\
\text { o número de potência é igual a } \\
\text { uma constante para Re acima de } \\
10^{4} \text {. }\end{array}$ \\
\hline $\begin{array}{l}\text { Número de } \\
\text { Mistura }\end{array}$ & B & $B=N \theta$ & $\begin{array}{l}\text { O número de mistura é o produ- } \\
\text { to da velocidade de rotação }(\mathrm{N}) \text { e } \\
\text { o tempo de mistura }(\theta) \text { requerido } \\
\text { para misturar líquidos miscíveis } \\
\text { de fases uniformes ao longo do vo- } \\
\text { lume do tanque. }\end{array}$ \\
\hline $\begin{array}{l}\text { Número de } \\
\text { Froude }\end{array}$ & $\mathrm{Fr}$ & $F r=N^{2} D / g$ & $\begin{array}{l}\text { A princípio o número de Froude } \\
\text { (Fr) é a relação entre convecção } \\
\text { e fatores gravitacionais no trans- } \\
\text { porte de quantidade de movimen- } \\
\text { to, sendo utilizado para conside- } \\
\text { rar efeitos na superfície (como for- } \\
\text { mação de vórtices) no número de } \\
\text { potência. }\end{array}$ \\
\hline $\begin{array}{l}\text { Número de } \\
\text { Bombeamen- } \\
\text { to }\end{array}$ & Bo & $B o=Q /\left(N D^{3}\right)$ & $\begin{array}{l}\text { O número de bombeamento (Bo) } \\
\text { relaciona a vazão volumétrica } \\
\text { através da área do impelidor com } \\
\text { a velocidade e diâmetro do impe- } \\
\text { lidor. O número de bombeamen- } \\
\text { to correlaciona diferentes capaci- } \\
\text { dades de bombeamento e diferen- } \\
\text { tes geometrias do sistema. }\end{array}$ \\
\hline
\end{tabular}

Tabela 1.3: Adicionais empregados em agitação de líquidos. 
Os diversos parâmetros envolvidos na mistura e na agitação podem ser estudados utilizando uma unidade-piloto. Para isso é necessário estabelecer critérios de "scale-up" para prever os resultados do processo nos equipamentos maiores, verificando qual é o parâmetro de maior interesse uma vez que não é possível manter todas as relações de fluxo e cisalhamento da escala menor para a maior.

A análise dimensional aplicada a um tanque agitado pode ser encontrada em Deckey e Fenic (1976).

\subsection{Aplicações Clássicas}

Os processos relacionados à agitação são classificados em 5 grupos, conforme mostra a Tabela 1.4 [19].

\begin{tabular}{|l|l|l|}
\hline CLASSE DE APLICAÇÃO & PROCESSO FÍSICO & PROCESSO QUÍMICO \\
\hline líquido-sólido & suspensão & dissolução \\
\hline líquido-gás & dispersão & absorção \\
\hline líquidos imiscíveis & emulsão & extração \\
\hline líquidos miscíveis & mistura & reação \\
\hline movimento do fluido & bombeamento & transferência de calor \\
\hline
\end{tabular}

Tabela 1.4: Processo de agitação, mistura e dispersão.

Nas aplicações que envolvem o processo de agitação apresentam diferenças entre o processo físico e o processo químico, detalhado a seguir:

- na aplicação sólido-líquido a concentração de sólidos, por exemplo: areia, na suspensão pode ser medida por parâmetros físicos e por um processo de transferência de massa tem-se a dissolução do material que passa de uma fase sólida para uma fase líquida;

- na aplicação líquido-gás a dispersão é caracterizada pela distribuição física do gás no líquido e a absorção é um processo de transferência de massa;

- nos líquidos imiscíveis o objetivo é a descrição do tipo de emulsão (processo físico) que são requeridos em produtos como xampús, polidores e outros produtos químicos; 
- nos líquidos miscíveis o objetivo é efetuar uma mistura homogênea entre dois líquidos (processo físico) ou ainda a reação química entre duas matérias-primas que se encontram na fase líquida;

- a agitação produz o movimento do fluido. Para a parte física cabe a capacidade de bombeamento do impelidor, análise do escoamento do fluido, fundo do tanque, chicanas, etc. Na parte química está a transferência de calor, pois geralmente há necessidade de troca de calor quando ocorrem reações químicas.

\subsection{A Fluidodinâmica e a CFD - Computational Fluid Dynamics}

A mecânica dos fluidos, que estuda o movimento dos fluidos, preocupou-se em estudar o comportamento de elementos de forma experimental muito antes da forma matemática, o que explica o surgimento da hidráulica, que trata do movimento de líquidos em tubos, canais e outros dispositivos, antes da hidrodinâmica, que estabelece relações entre o movimento dos fluidos e as forças que causam esse movimento. Leonhard Euler foi o primeiro a deduzir as equações de movimento de fluidos, as chamadas equações de Euler.

No século XIX, a partir dos trabalhos pioneiros dos franceses Claude Navier (1822), Simeon Poisson (1829) e do inglês George Stokes (1845), as descrições dos fluidos ganharam força na forma das Equações de Navier-Stokes que são o modelo matemático mais utilizado para descrição do comportamento dos fluidos.

Por se tratarem de equações diferenciais parciais (EDP's) não-lineares, há dificuldades para se determinar soluções fechadas, sendo que as soluções analíticas só foram descobertas para alguns poucos casos com enormes simplificações. Uma forma de determinar as soluções com o advento dos computadores foi a partir de 1950 utilizando-se de técnicas computacionais e do campo de velocidade que compõem o escoamento, a CFD (Computational Fluid Dynamics), tecnologia computacional que permite estudar a dinâmica dos fluidos. Antes disso, os trabalhos eram realizados por processos primitivos com o envolvimento de "calculadoras humanas" ou de máquinas de calcular rudimentares.

A solução numérica para um escoamento viscoso foi primeiramente proposta por Thom 
(1933). Diversos métodos numéricos para a solução de escoamentos viscosos e incompressíveis surgiu na década de 60 e um dos primeiros foi o método de Fromm (1964). No ano seguinte surgiu o método MAC (marker and cell), descrito por Harlow \& Welch [9], se tornou rapidamente popular e serve para simular tanto escoamentos internos como escoamentos externos com superfícies livres. Este método popularizou o uso da malha deslocada (staggered grid) bastante empregada na discretização das equações de escoamentos incompressíveis.

O Método da Compressibilidade Artificial foi apresentado por Chorin (1967) [9]. Neste método as equações do escoamento incompressível são modificadas para que se apresentem a mesma forma das equações para escoamentos compressíveis e assim adotar técnicas de solução para esta classe de escoamento.

Um dos primeiros estudos de turbulência foi feito por Amsden \& Harlow (1968) incorporando um modelo de turbulência diretamente às equações do método MAC. Depois dos bons resultados obtidos, outros métodos foram implementados como o SMAC (Simplified MAC) por Amsden \& Harlow (1970). E ainda, Viecelli (1969) desenvolveu um tratamento de fronteira e o Método Sola (1972) foi implementado por Hirt \& Cook.

Com o uso da CFD constrói-se um modelo computacional para a simulação de fenômenos que envolvem fluidos em movimento que representam um sistema ou um objeto que se quer estudar, então aplica-se as condições físicas a este modelo. Trata-se de uma técnica de análise sofisticada que não só analisa o comportamento do fluido mas também a transferência de calor, massa (como em uma transpiração ou dissolução), mudança de fase e reação química como combustão.

As razões para se usar a CFD são basicamente três:

- Facilidade: a análise da CFD permite a representação e a visualização de campos de variáveis como: velocidade (v), pressão (p) e temperatura (T). Ainda, mostra partes de um sistema ou fenômeno que não seriam possíveis por qualquer outro meio, mesmo o experimental.

- Previsão: a CFD é uma ferramenta que pode prever comportamentos sob determinadas circunstâncias, fornecidos os parâmetros a solução é obtida e os resultados analisados iniciando um novo ciclo (fornece-se as variáveis e o sistema dá os resultados). Em pouco tempo, através da repetição deste processo, chega-se a um resultado ótimo, antes 
que o protótipo físico seja testado. A CFD ajuda a projetar melhor e mais rapidamente.

- Eficiência: economiza-se tempo e dinheiro, conseqüentemente os produtos podem ser comercializados mais rapidamente. São feitas melhorias nos equipamentos, reduzindo o tempo de manutenção.

Pode-se observar que a CFD tem como objetivo básico reduzir o número de experimentos, avaliando numericamente os diversos parâmetros envolvidos em um problema, alterando-os de acordo com as exigências do projeto em questão.

Mas estes estudos devem ser feitos com um certo cuidado pois existem algumas limitações como:

- solução discreta;

- os dados de entrada são por vezes aproximados;

- as condições de contorno ou iniciais podem representar a situação de forma simplificada;

- o escoamento pode envolver fenômenos que não são perfeitamente descritos por teorias científicas, tais como a turbulência.

De acordo com Sharrat (1990), o uso de CFD nas Engenharias teve início nos anos 70 e tem marcado presença em áreas como engenharia aeronáutica, percolação em barragens e águas subterrâneas, dispersão de poluentes em rios e oceanos, engenharia ambiental, engenharia costeira, medicina, siderurgia, entre outras.

A utilização de programas de fluidodinâmica computacional está sendo cada vez mais freqüente na Engenharia Química e dentre as várias aplicações está o seu emprego em diversos tipos de reatores, em especial em tanques agitados, tornando-se uma ferramenta importante no seu estudo, possibilitando a sua modelagem matemática, visualização gráfica de todo o domínio estudado e das variáveis que interferem no seu desempenho como velocidade, pressão e concentração de sólidos.

As operações envolvidas no processo de misturas são controladas pela velocidade do fluido, intensidade de turbulência, a taxa de dissipação de energia e sua distribuição no tanque. A cada etapa do processo torna-se necessário ter-se informações confiáveis a respeito dos resultados obtidos e de como a geometria do tanque influencia na obtenção de determinados produtos e ao final do processo ter-se um resultado mais otimizado, com 
menor custo e sem a perda de matéria-prima.

Assim sendo, a fluidodinâmica computacional (CFD-Computational Fluid Dynamics) é uma ferramenta que permite avaliar a eficiência da geometria do tanque e do arranjo tanque-agitador.

A possibilidade, às vezes em nível microscópio, de modelagem matemática permite uma compreensão mais profunda do processo. Além disso, sua representação espacial permite uma visualização gráfica das variáveis em todo o domínio estudado e do desempenho do processo em relação aos diversos parâmetros. 


\section{Solução das Equações de Navier- Stokes na Cavidade pelo Método das Diferenças Finitas}

Este capítulo apresenta uma das técnicas de solução das Equações de Navier-Stokes em duas dimensões e determina, através de experimentos numéricos, a região de estabilidade do método de Runge-Kutta k-estágios utilizado para integrar tais equações. O domínio de interesse é o clássico para o escoamento na cavidade.

O problema hidrodinâmico, citado no Capítulo 1, é modelado pelas equações de NavierStokes em coordenadas cilíndricas e em regime laminar representando um tanque com geometria simples em duas dimensões.

\subsection{Equações de Navier-Stokes}

As equações de Navier-Stokes são um sistema acoplado de equações diferenciais parciais não-lineares que modelam o escoamento de fluidos compressíveis e incompressíveis, turbulentos e laminares. Sua formulação se baseia na mecânica clássica, na termodinâmica e em suas Leis de Conservação, ou seja, as equações representam a expressão dos princípios físicos - massa, momento e energia:

- Conservação de Massa: é de extrema importância na Física e diz que toda massa que entra em um sistema deve sair e/ou se acumular neste sistema. 
Solução das Equações de Navier- Stokes na Cavidade pelo Método das

Pode-se dizer que o balanço de massa é dado por:

\begin{tabular}{|cc|}
\hline $\begin{array}{c}\text { Variação temporal } \\
\text { da quantidade de massa } \\
\text { do elemento }\end{array}$ & $\begin{array}{c}\text { descarga resultante } \\
\text { através das fronteiras } \\
\text { do elemento }\end{array}$ \\
\hline
\end{tabular}

E a equação de conservação de massa é dada por:

$$
\frac{\partial \rho}{\partial t}+\nabla(\rho \vec{V})=0
$$

onde

$\frac{\partial \rho}{\partial t}$ : variação temporal da densidade do fluido

$\nabla$ : operador divergente

$\vec{V}$ : velocidade do fluido na forma vetorial

- Conservação de Quantidade de Momento (Conservação do Momento - $2^{a}$ Lei de Newton): a taxa de variação temporal de momento do fluido é igual à resultante das forças que atuam sobre o fluido.

A equação da conservação da quantidade de movimento é dada por:

$$
\rho \frac{D \vec{V}}{D t}=\rho \vec{F}-\operatorname{grad} p
$$

onde

$\rho$ : dendade do fluido

$\vec{V}$ : vetor que representa a velocidade do fluido

$\frac{D \vec{V}}{D t}$ : representa a aceleração do elemento de fluido

$\vec{F}$ : vetor que representa a força exercida no elemento de fluido por unidade de massa

$p$ : pressão

$\operatorname{grad} p$ : representa a resultante das forças de superfície agindo por unidade de volume unitário de fluido

- Conservação de Energia (Primeira Lei da Termodinâmica): a taxa de variação temporal da energia é igual à soma do fluxo líquido, ou resultante, de calor para o fluido com o trabalho realizado sobre o mesmo. 
A equação que representa a conservação de energia é dada por:

$$
\rho \frac{\mathrm{D} e}{\mathrm{D} t}=-p \nabla \vec{V}
$$

onde

$\rho$ : densidade do fluido

$e$ : energia interna

$\frac{\mathrm{D} e}{\mathrm{D} t}$ : variação de energia interna em um fluido invíscido

$p$ : pressão

$-p \nabla \vec{V}$ : potência de compressão ou expansão do fluido

Esta equação é a Primeira Lei da Termodinâmica considerando um processo adiabático, ou seja sem adição ou retirada de calor.

Das formulações existentes para as equações de Navier-Stokes, foi adotada a Formulação em Variáveis Primitivas.

\subsection{Formulação em Variáveis Primitivas}

Desprezando-se forças externas e considerando o escoamento adiabático, ou seja, não há transferência de calor entre o fluido e o contorno, para um escoamento laminar, incompressível, viscoso e em regime permanente, as equações de Navier-Stokes se reduzem a

$$
\left\{\begin{array}{l}
\frac{\partial \vec{V}}{\partial t}+F(\vec{V})+\nabla p=\frac{1}{R e} \nabla^{2} \vec{V} \\
\nabla \vec{V}=0
\end{array}\right.
$$

onde

$\vec{V}$ : velocidade do fluido na forma vetorial

$\nabla$ : operador divergente

$\nabla^{2}$ : operador laplaciano

$p$ : pressão;

$R e=\frac{\rho L V}{\mu}$ : número de Reynolds, parâmetro adimensional que expressa a razão entre as forças inerciais ( $\rho$ : densidade, L e V são o comprimento e velocidade característica do escoamento) e as forças viscosas $(\mu)$ em um escoamento

$F(\vec{V})=\vec{V}(\nabla \vec{V})$ 
Solução das Equações de Navier- Stokes na Cavidade pelo Método das 24 Diferenças Finitas

Em coordenadas cartesianas as componentes de $F(\vec{V})=a_{i}+b_{j}, \operatorname{com} \vec{V}=(u, v)$, u: componente horizontal da velocidade e v: componente vertical da velocidade, é descrita por:

$$
\begin{aligned}
& a(u, v)=u \frac{\partial u}{\partial x}+v \frac{\partial u}{\partial y} \\
& b(u, v)=u \frac{\partial v}{\partial x}+v \frac{\partial v}{\partial y}
\end{aligned}
$$

Assim, escrevendo as equações de Navier-Stokes na forma simplificada, forma nãoconservativa, tem-se:

- conservação de momento em x:

$$
u \frac{\partial u}{\partial x}+v \frac{\partial u}{\partial y}+\frac{\partial p}{\partial x}=\frac{1}{R e}\left(\frac{\partial^{2} u}{\partial x^{2}}+\frac{\partial^{2} u}{\partial y^{2}}\right)
$$

- conservação de momento em y:

$$
u \frac{\partial v}{\partial x}+v \frac{\partial v}{\partial y}+\frac{\partial p}{\partial y}=\frac{1}{R e}\left(\frac{\partial^{2} v}{\partial x^{2}}+\frac{\partial^{2} v}{\partial y^{2}}\right)
$$

- equação da continuidade:

$$
\frac{\partial u}{\partial x}+\frac{\partial v}{\partial y}=0
$$

Tais equações são usadas na solução do escoamento na cavidade.

Para a discretização das equações de Navier-Stokes foi utilizada a malha MAC (marker and cell).

\subsection{Método da Compressibilidade Artificial}

O método da compressibilidade artificial admite várias formas de discretização, entre as formas explícitas destaca-se o método MAC (marker and cell) [9], que se baseia na 
formulação compressível e é usado para produzir uma equação para a pressão a partir da velocidade do som, $c$, que em um fluido é dada por:

$$
c^{2}=\frac{p}{\rho}
$$

onde:

$c$ : velocidade do som

$p$ : pressão

$\rho$ : densidade

Derivando (2.5) em relação ao tempo e assumindo que $c$ permanece constante, $c=c_{0}$, obtém-se:

$$
\frac{\partial p}{\partial t}-c_{0}^{2} \frac{\partial \rho}{\partial t}=0
$$

Da equação da continuidade, no caso de escoamento incompressível, tem-se:

$$
\frac{\partial \rho}{\partial t}+\rho\left(\frac{\partial u}{\partial x}+\frac{\partial v}{\partial y}\right)=0
$$

ou ainda,

$$
\frac{\partial \rho}{\partial t}=-\rho\left(\frac{\partial u}{\partial x}+\frac{\partial v}{\partial y}\right)
$$

Considerando-as adimensionalizadas $(\rho=1)$ e substituindo (2.8) em (2.6), tem-se:

$$
\frac{\partial p}{\partial t}+c_{0}^{2} \rho\left(\frac{\partial u}{\partial x}+\frac{\partial v}{\partial y}\right)=0
$$

Esta equação é tratada como pseudo-transiente, que emprega métodos que marcham no "tempo" até que o problema atinja o estado estacionário. Neste caso, o "tempo" não corresponde ao tempo físico, mas a um tempo numérico, colocado apenas para permitir que se encontre uma solução estacionária, e em conjunto com as equações de quantidade de movimento pode ser usada para convergir a solução em regime permanente.

Assim, o sistema a ser resolvido tem a seguinte forma:

$$
\left\{\begin{array}{l}
\frac{\partial u}{\partial t}+u \frac{\partial u}{\partial x}+v \frac{\partial u}{\partial y}+\frac{\partial p}{\partial x}=\frac{1}{R e}\left(\frac{\partial^{2} u}{\partial x^{2}}+\frac{\partial^{2} u}{\partial y^{2}}\right) \\
\frac{\partial v}{\partial t}+u \frac{\partial v}{\partial x}+v \frac{\partial v}{\partial y}+\frac{\partial p}{\partial y}=\frac{1}{R e}\left(\frac{\partial^{2} v}{\partial x^{2}}+\frac{\partial^{2} v}{\partial y^{2}}\right) \\
\frac{\partial p}{\partial t}+c_{0}^{2} \rho\left(\frac{\partial u}{\partial x}+\frac{\partial v}{\partial y}\right)=0
\end{array}\right.
$$




\section{Solução das Equações de Navier- Stokes na Cavidade pelo Método das 26 Diferenças Finitas}

O método MAC (marker and cell) é um dos esquemas explícitos mais populares para a solução numérica do sistema (2.10) e se baseia em diferenças finitas (Ver Apêndice B). Este método foi descrito por Harlow \& Welch (1965) [9], originalmente desenvolvido para tratar de escoamentos com superfícies livres, em que partículas marcadoras (markers) definem a localização da superfície livre do fluido. Para escoamentos sem superfícies livres as partículas marcadoras não são necessárias, uma vez que o fluido preenche todo o domínio computacional.

Existem várias formas de se distribuir as incógnitas $\mathrm{u}, \mathrm{v}$ e p, componentes da velocidade e pressão, quando não se exige que elas estejam armazenadas na mesma posição. Assim, para discretização espacial do domínio considera-se uma malha uniforme introduzida por Harlow e Welch (1965) e representada na Figura 2.1, que se tornou um padrão para o cálculo de escoamentos incompressíveis.

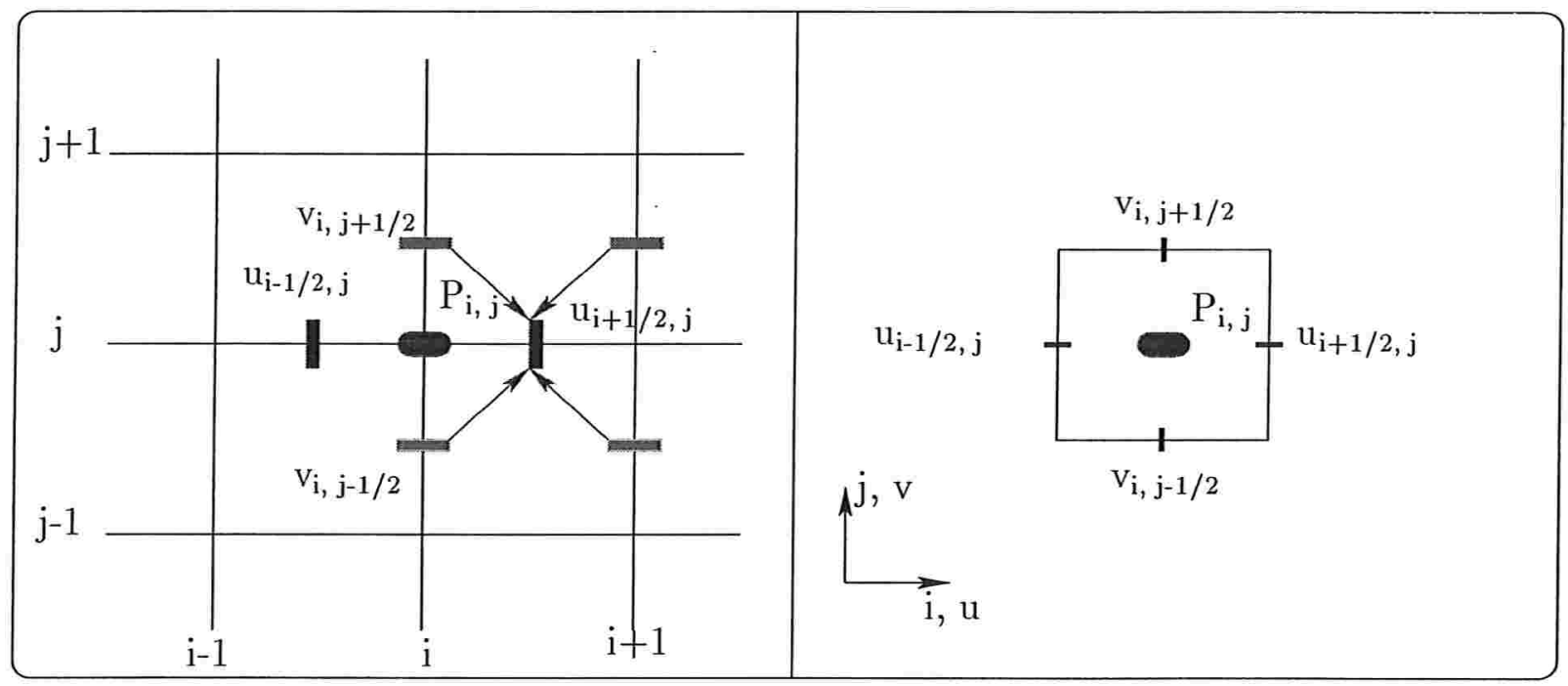

Figura 2.1: Célula da malha deslocada. A pressão é armazenada nos nós e as componentes da velocidade, u e v, são deslocadas para os pontos médios da malha.

As equações de Navier-Stokes são resolvidas numericamente empregando um método de diferenças finitas explícito.

$\mathrm{Na}$ discretização das equações de Navier-Stokes em uma malha deslocada (staggered grid), a equação de momento na direção $x$ é discretizada sobre a posição $(i+1 / 2, j)$ e na direção y sobre a posição $(i, j+1 / 2)$. Finalmente, a equação da continuidade é discretizada 
sobre os nós da malha no ponto $(i, j)$.

$\mathrm{Na}$ forma discretizada as equações são dadas por:

$$
\begin{aligned}
& \frac{u_{i+1 / 2, j}^{n+1}-u_{i+1 / 2, j}^{n}}{\Delta t}+a_{i+1 / 2, j}^{n}+\Delta_{x}^{1} p_{i+1 / 2, j}^{n}=\frac{1}{R e} \nabla_{h}^{2} u_{i+1 / 2, j}^{n} \\
& \frac{v_{i, j+1 / 2}^{n+1}-v_{i, j+1 / 2}^{n}}{\Delta t}+a_{i, j+1 / 2}^{n}+\Delta_{y}^{1} p_{i, j+1 / 2}^{n}=\frac{1}{R e} \nabla_{h}^{2} v_{i, j+1 / 2}^{n} \\
& \frac{p_{i, j}^{n+1}-p_{i, j}^{n}}{\Delta t}+c_{0}^{2}\left(\Delta_{x}^{1} u_{i+1 / 2, j}^{n+1}+\Delta_{y}^{1} v_{i, j+1 / 2}^{n+1}\right)=0
\end{aligned}
$$

Onde os operadores de diferença são definidos por:

$$
\begin{aligned}
& \Delta_{x}^{1} f_{l, m}=\frac{1}{\Delta x}\left(f_{l+1 / 2, m}-f_{l-1 / 2, m}\right) \\
& \nabla_{h}^{2} f_{l, m}=\Delta_{x x} f_{l, m}+\Delta_{y y} f_{l, m} \\
& \Delta_{x x} f_{l, m}=\frac{f_{l+1, m}-2 f_{l, m}+f_{l-1, m}}{(\Delta x)^{2}}
\end{aligned}
$$

e "l" e " $m$ " são inteiros ou "médios".

Expressões semelhantes podem ser descritas para $y$.

Os termos $a_{i+1 / 2, j}^{n}(u, v)$ e $b_{i, j+1 / 2}^{n}(u, v)$ são aproximações para $a(u, v)$ e $b(u, v)$, que são discretizados da seguinte forma:

$$
\begin{aligned}
& a_{i+1 / 2, j}^{n}=u_{i+1 / 2, j}^{n} \Delta_{x}^{0} u_{i+1 / 2, j}^{n}+\hat{v}_{i+1 / 2, j}^{n} \Delta_{j}^{n} u_{i+1 / 2, j}^{n} \\
& b_{i, j+1 / 2}^{n}=\hat{u}_{i, j+1 / 2}^{n} \Delta_{x}^{0} v_{i, j+1 / 2}^{n}+v_{i, j+1 / 2}^{n} \Delta_{y}^{0} v_{i, j+1 / 2}^{n}
\end{aligned}
$$

onde:

$$
\begin{aligned}
& \Delta_{x}^{0} f_{l, m}=\frac{1}{2 \Delta x}\left(f_{l+1, m}-f_{l-1, m}\right) \\
& \Delta_{y}^{0} f_{l, m}=\frac{1}{2 \Delta y}\left(f_{l, m+1}-f_{l, m-1}\right)
\end{aligned}
$$

Por se tratar de malhas desencontradas, para determinar a componente u na malha $v$ 
e a componente v na malha u, foi adotada a interpolação linear, indicada na Figura 2.1, ou seja, os valores das velocidades $\hat{u}_{i, j+1 / 2}$ e $\hat{v}_{i+1 / 2, j}$ são aproximados por:

$$
\begin{aligned}
& \hat{u}_{i, j+1 / 2}=\frac{1}{4}\left(u_{i+1 / 2, j}+u_{i+1 / 2, j+1}+u_{i-1 / 2, j+1}+u_{i-1 / 2, j}\right) \\
& \hat{v}_{i+1 / 2, j}=\frac{1}{4}\left(v_{i+1, j+1 / 2}+v_{i, j+1 / 2}+v_{i, j-1 / 2}+v_{i+1, j-1 / 2}\right)
\end{aligned}
$$

Assim, as equações discretizadas por diferenças finitas de segunda ordem no espaço (ver Apêndice B.2), segundo a malha MAC, com ajustes de índices, são dadas por:

- componente $u$ da velocidade $\mathrm{V}$

$$
\begin{aligned}
& \frac{u_{i, j}^{n+1}-u_{i, j}^{n}}{\Delta t}+u_{i, j}^{n} \frac{1}{2 \Delta x}\left(u_{i+1, j}^{n}-u_{i-1, j}^{n}\right)+\frac{1}{4}\left(v_{i+1, j}^{n}+v_{i, j}^{n}+\right. \\
& \left.+v_{i, j-1}^{n}+v_{i+1, j-1}^{n}\right)\left(\frac{u_{i, j+1}^{n}-u_{i, j-1}^{n}}{2 \Delta y}\right)+\frac{1}{\Delta x}\left(p_{i+1, j}^{n}-p_{i, j}^{n}\right)= \\
& =\frac{1}{R e}\left(\frac{u_{i+1, j}^{n}-2 u_{i, j}^{n}+u_{i-1, j}^{n}}{(\Delta x)^{2}}+\frac{u_{i, j+1}^{n}-2 u_{i, j}^{n}+u_{i, j-1}^{n}}{(\Delta y)^{2}}\right)
\end{aligned}
$$

- componente $v$ da velocidade $\mathrm{V}$

$$
\begin{aligned}
& \frac{v_{i, j}^{n+1}-v_{i, j}^{n}}{\Delta t}+v_{i, j}^{n} \frac{1}{2 \Delta y}\left(v_{i, j+1}^{n}-v_{i, j-1}^{n}\right)+\frac{1}{4}\left(u_{i, j+1}^{n}+u_{i, j}^{n}+\right. \\
& \left.+u_{i-1, j}^{n}+u_{i-1, j+1}^{n}\right)\left(\frac{v_{i, j+1}^{n}-v_{i, j-1}^{n}}{2 \Delta x}\right)+\frac{1}{\Delta x}\left(p_{i, j+1}^{n}-p_{i, j}^{n}\right)= \\
& =\frac{1}{R e}\left(\frac{v_{i, j+1}^{n}-2 v_{i, j}^{n}+v_{i, j-1}^{n}}{(\Delta y)^{2}}+\frac{v_{i+1, j}^{n}-2 v_{i, j}^{n}+v_{i-1, j}^{n}}{(\Delta y)^{2}}\right)
\end{aligned}
$$

- pressão $p$

$$
\frac{p_{i, j}^{n+1}-p_{i, j}^{n}}{\Delta t}+c_{0}^{2}\left(\frac{1}{\Delta x}\left(u_{i, j}^{n+1}-u_{i-1, j}^{n+1}\right)+\frac{1}{\Delta y}\left(v_{i, j}^{n+1}-v_{i, j-1}^{n+1}\right)\right)=0
$$

Neste tipo de malha deslocada não são necessárias condições de contorno para a pressão. Entretanto, para satisfazer a condição de contorno para a velocidade são necessários valores para a velocidade fora do domínio computacional ("pontos-fantasmas"). Para definir os "pontos-fantasmas", utiliza-se a Técnica da Reflexão, apresentada na Fi- 
gura 2.2:

$$
\begin{gathered}
v_{\Gamma}=\frac{v_{1}+v_{0}}{2} \Longrightarrow v_{0}=2 v_{\Gamma}-v_{1} \\
u_{\Gamma}=\frac{u_{1}+u_{0}}{2} \Longrightarrow u_{0}=2 u_{\Gamma}-u_{1}
\end{gathered}
$$

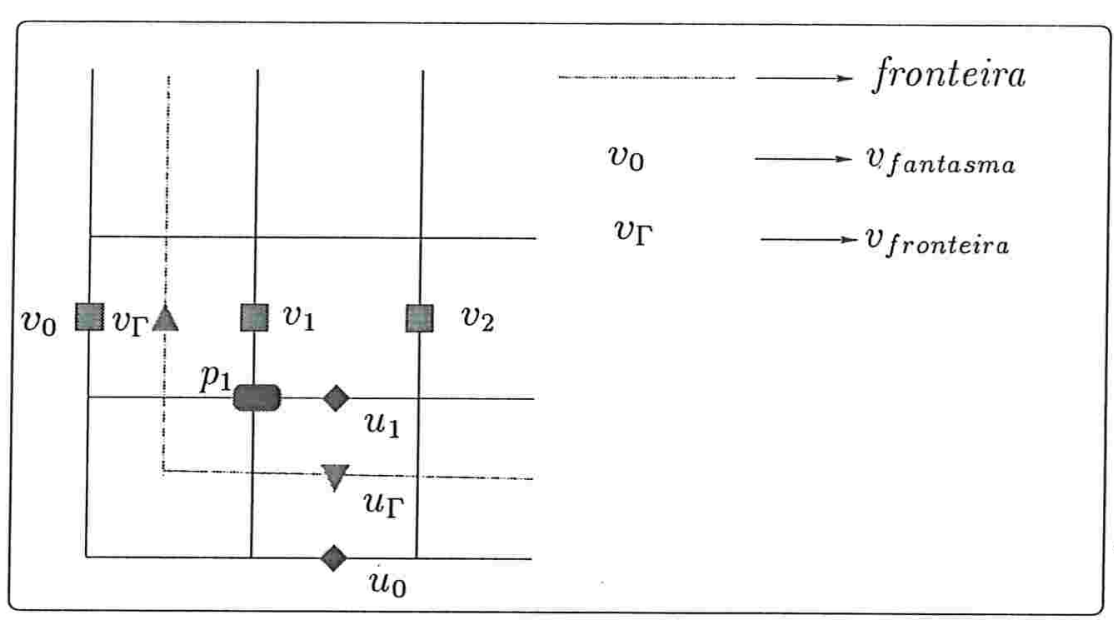

Figura 2.2: Técnica da reflexão aplicada à condição de contorno.

Esta técnica utiliza a formulação em diferenças finitas (Ver Apêndice B), aproximando a derivada de $v_{1}$ através de uma fórmula de diferenças não-centrada de primeira ordem:

$$
\begin{gathered}
\left(\frac{\partial v}{\partial x}\right)_{1}=\frac{1}{2 \Delta x}\left(v_{2}+v_{1}-2 v_{\Gamma}\right) \\
\left(\frac{\partial v}{\partial x}\right)_{1}=\frac{v_{2}-v_{0}}{2 \Delta x}
\end{gathered}
$$

Igualando as expressões de (2.14) e (2.15):

$$
\frac{1}{2 \Delta x}\left(v_{2}+v_{1}-2 v_{\Gamma}\right)=\frac{v_{2}-v_{0}}{2 \Delta x}
$$

Isolando $\mathrm{v}_{0}$, tem-se:

$$
v_{0}=2 v_{\Gamma}-v_{1}
$$

que é a forma empregada pela técnica da reflexão.

Analogamente, obtém-se

$$
u_{0}=2 u_{\Gamma}-u_{1}
$$


Solução das Equações de Navier- Stokes na Cavidade pelo Método das 30 Diferenças Finitas

Os valores de $\mathrm{u}$, componente horizontal da velocidade, são conhecidos nas paredes verticais e os valores de $\mathrm{v}$, componente vertical da velocidade, são conhecidos nas paredes horizontais.

O objetivo do método da compressibilidade artificial é obter uma solução em regime permanente caracterizado por um critério de convergência, por exemplo:

$$
\operatorname{máx}\left\{\frac{\left|u^{n+1}-u^{n}\right|}{\Delta t}, \frac{\left|v^{n+1}-v^{n}\right|}{\Delta t}, \frac{\left|p^{n+1}-p^{n}\right|}{c^{2} \Delta t}\right\}<\text { tol }
$$

onde tol é uma tolerância e o valor adotado é $t o l=10^{-8}$.

A escolha de um método explícito para a solução desse sistema não-linear, (2.10), apesar do menor custo computacional por iteração está limitada pela estabilidade do método que pode trazer severas restrições.

\subsection{Método de Runge-Kutta (R-K) k-estágios}

Em [24] foi implementado um código para solucionar (2.10) com as condições de contorno da Figura 2.3, Peyret [22], ou seja, para:

$$
\begin{aligned}
& x=0,0 \leq y \leq 1, x=1,0 \leq y \leq 1 \text { e } y=0,0 \leq x \leq 1: \vec{V}=(u, v)=(0,0) \\
& y=1,0 \leq x \leq 1: \vec{V}=(f(x), 0), \operatorname{com} f(x)=-16 x^{2}(1-x)^{2}
\end{aligned}
$$

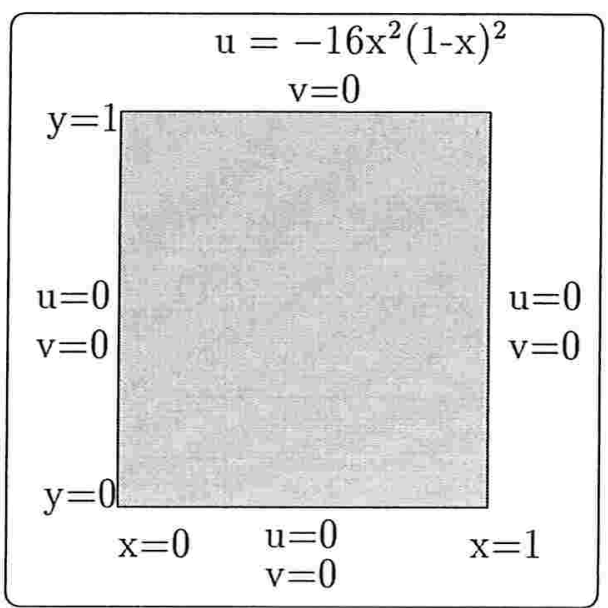

Figura 2.3: Desenho da geometria e condições de contorno da cavidade. 
Para integração temporal das equações, até o regime permanente, foi implementado o método de Runge-Kutta k-estágios, conforme o procedimento representado abaixo.

Considerando o sistema (2.10), na seguinte forma:

$$
\left\{\begin{array}{l}
\frac{\partial u}{\partial t}=f(u, v, p) \\
\frac{\partial v}{\partial t}=g(u, v, p) \\
\frac{\partial p}{\partial t}=h(u, v)
\end{array}\right.
$$

o algoritimo é dado por:

1ํ Passo: fornecer $\mathrm{k}$ (número de estágios de $\mathrm{R}-\mathrm{K}$ ), $\Delta t, u^{0}, v^{0}$ e $p^{0}$;

$2^{\circ}$ Passo: fazer uold $\leftarrow u^{0}$, vold $\leftarrow v^{0}$ e pold $\leftarrow p^{0}$;

$3^{\circ}$ Passo: $r k \leftarrow \frac{1}{k-i+1}$ e $\left\{\begin{array}{l}u=\text { uold }+r k * \Delta t * f\left(u^{0}, v^{0}, p^{0}\right) \\ v=\text { vold }+r k * \Delta t * g\left(u^{0}, v^{0}, p^{0}\right) \\ p=\text { pold }+r k * \Delta t * h(u, v)\end{array}\right.$;

4o Passo: atualizar os dados: $u^{0} \leftarrow u, v^{0} \leftarrow v, p^{0} \leftarrow p$ e $i \leftarrow i+1$;

$5^{\circ}$ Passo: repetir o $2^{o}, 3^{\circ}$ e $4^{\underline{o}}$ passo até $i=k$;

6o Passo: fazer $u^{1} \leftarrow u, v^{1} \leftarrow v, p^{1} \leftarrow p$;

7ํ Passo: repetir do $2^{\circ}$ ao $6^{\circ}$ passo até itmax ou até $t o l^{\prime}<$ tol, itmax é o número máximo de iterações, tol' é o erro e tol é a tolerância fornecida.

Como critério de parada utiliza-se um número máximo de iterações e verifica se a equação da continuidade está sendo satisfeita, ou seja, a simulação pára quando um número máximo de iterações é atingido ou quando a norma do divergente da velocidade é menor que uma tolerância dada (para este trabalho utilizou-se uma tolerância de $10^{-8}$ ).

Para um estudo do comportamento do escoamento na cavidade de acordo com a viscosidade do fluido e os níveis de discretização, realizou-se testes para alguns valores de Reynolds $(R e)$ e níveis de discretização $(n), n=\frac{1}{\Delta x}=\frac{1}{\Delta y}$. Na Figura 2.4 é apresentado um dos resultados obtidos, o campo de velocidades na solução numérica das equações de Navier-Stokes na cavidade para $n=32, R e=1,2$, na forma de vetores e magnitude da 
Solução das Equações de Navier- Stokes na Cavidade pelo Método das 32

velocidade.

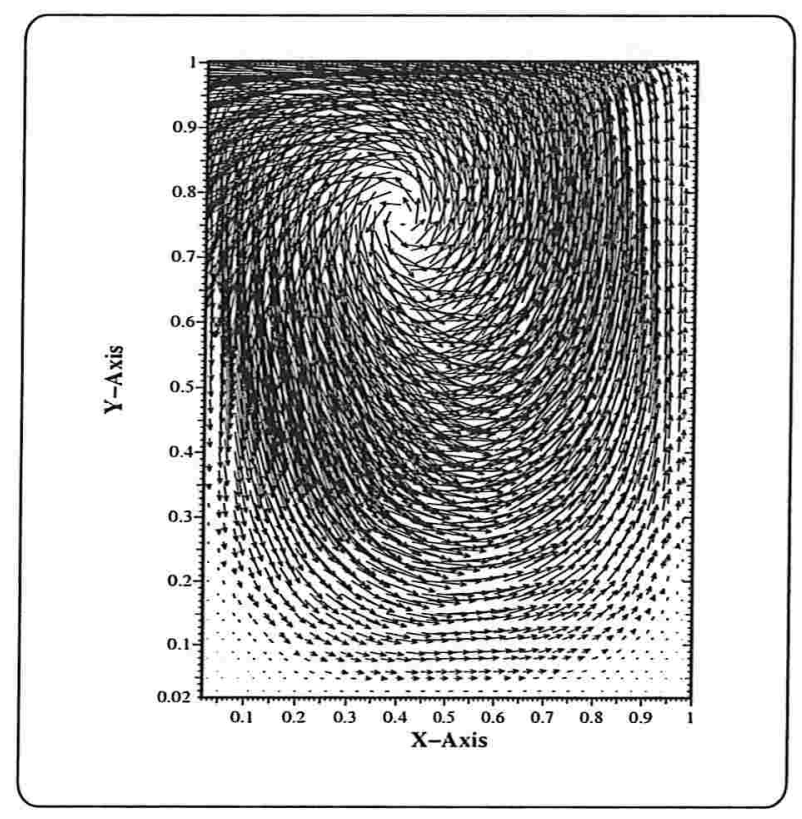

(a)

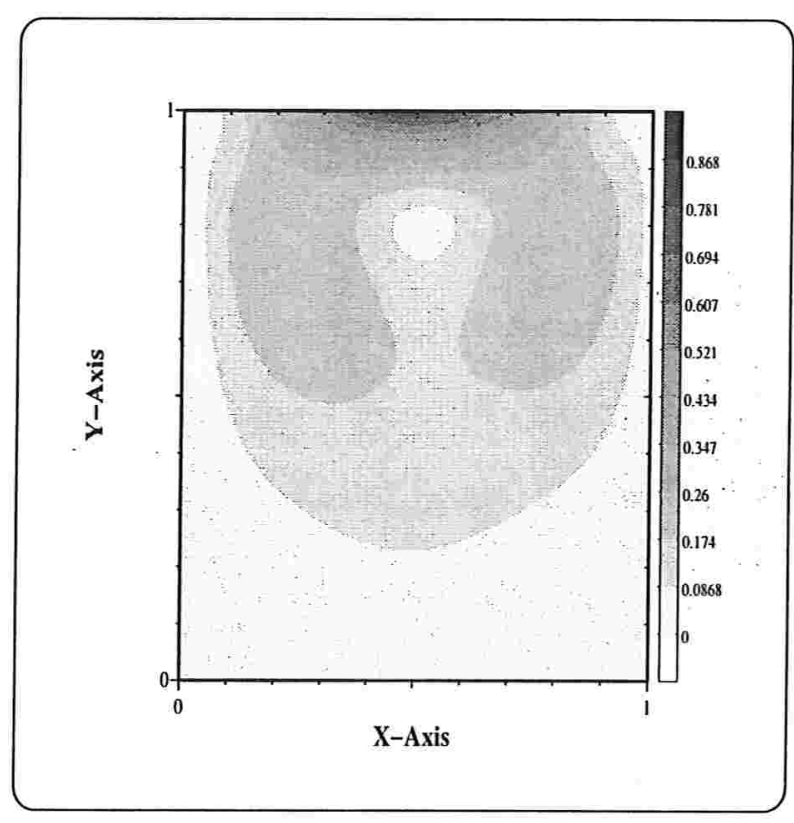

(b)

Figura 2.4: Solução numérica das equações de Navies-Stokes na cavidade para $\mathrm{n}=32 \mathrm{e}$ $\operatorname{Re}=1,2$, com as condições inciais da Figura 2.1: (a) representa o campo de velocidade por vetores e (b) representa o campo de velocidades pela magnitude da velocidade .

\subsection{Estabilidade e Convergência para o Método MAC}

A obtenção de um critério de estabilidade para o método MAC se baseia em dois argumentos:

- a solução de Stokes de um problema transiente tende para a solução de um problema de Stokes em regime permanente. Esta é uma prova de Fortin e outros (1971); 
- na consistência e estabilidade do esquema linearizado, que é uma extensão heurística do Teorema de Lax.

A análise da estabilidade utiliza a equação linearizada (2.1) desprezando o termo da pressão resultando na equação de advecção-difusão:

$$
f_{i, j}^{n+1}=\left\{I-\Delta t\left(u_{0} \Delta_{x}^{0}+v_{0} \Delta_{y}^{0}-\frac{1}{R e} \nabla^{2} h\right)\right\} f_{i, j}^{n},
$$

Através da análise de estabilidade de Fourier para uma malha uniforme $(\Delta x=\Delta y)$ obtém-se

$$
\begin{gathered}
\frac{4 \Delta t}{R e \Delta x^{2}} \leq 1 \\
\Delta t \leq\left(\frac{\operatorname{Re} \Delta^{2} x}{4}\right) \alpha, \quad \alpha<1
\end{gathered}
$$

que é o critério parabólico de estabilidade.

Uma segunda análise aproximada pode ser feita desprezando os termos convectivos e considerando o termo de pressão. Usando um método matricial de análise de estabilidade, observa-se que o raio espectral da matriz de amplificação não é maior que 1 se for satisfeita a relação

$$
\frac{4 \Delta t}{\Delta x^{2}}\left(\frac{1}{R e}+\frac{\Delta t c_{0}^{2}}{2}\right) \leq 1
$$

que inclui o critério anterior.

Reescrevendo a desigualdade (2.21), obtém-se o parâmetro artificial, $c_{0}^{2}$.

$$
\begin{gathered}
\frac{1}{R e}+\frac{\Delta t c_{0}^{2}}{2} \leq \frac{\Delta x^{2}}{4 \Delta t} \\
\frac{\Delta t c_{0}^{2}}{2} \leq \frac{\Delta x^{2}}{4 \Delta t}-\frac{1}{R e} \\
c_{0}^{2} \leq \frac{1}{2}\left(\frac{\Delta x}{\Delta t}\right)^{2}-\frac{2}{\Delta t R e}
\end{gathered}
$$

Entretanto, como o problema não é linear, os critérios são qualitativos. Assim, para verificar a adequação destes critérios foram realizados estudos numéricos, apresentados no XXII CNMAC - Congresso Nacional de Matemática Aplicada e Computacional [25] . 
Dos critérios de estabilidade (2.21) e (2.22), obtém-se:

$$
\begin{gathered}
\Delta t=\alpha \frac{\operatorname{Re} \Delta x^{2}}{4} \quad 0<\alpha \leq 1 \\
c_{0}^{2}=\beta(1-\alpha)\left(\frac{\Delta x}{\Delta t}\right)^{2} \quad 0<\beta \leq 1
\end{gathered}
$$

onde $\alpha$ e $\beta$ são introduzidos como fatores de relaxação dos critérios lineares.

Com a finalidade de analisar a região de estabilidade, algumas simulações foram feitas variando os fatores de relaxação $\alpha$ e $\beta$ dos critérios lineares (2.23) e (2.24), com níveis de discretização $n=16,32,64$ e 128, número de Reynolds $R e=1,2,100$ e 400 e aplicação do método de Runge-Kutta k-estágios, $\mathrm{k}=1,3$ e 5 .

Devido ao grande número de informações geradas por estas simulações foi selecionada uma amostra da solução do sistema (2.10) em uma cavidade.

Fixado um valor para $\alpha$, por exemplo $\alpha=0,5$, aumentam-se os valores de $\beta$, ou seja, para um $\Delta t$ fixo, aumentando-se o parâmetro $c_{0}^{2}$, o número de iterações necessárias para a convergência diminui.

As figuras, Figura 2.5, Figura 2.6 e Figura 2.7, mostram para $\mathrm{k}=5$ e para $\mathrm{Re}=1,2,100$ e 400 respectivamente, como decai o número de iterações, it: eixo vertical, conforme aumenta-se os valores de $\beta, \beta$ : eixo horizontal.

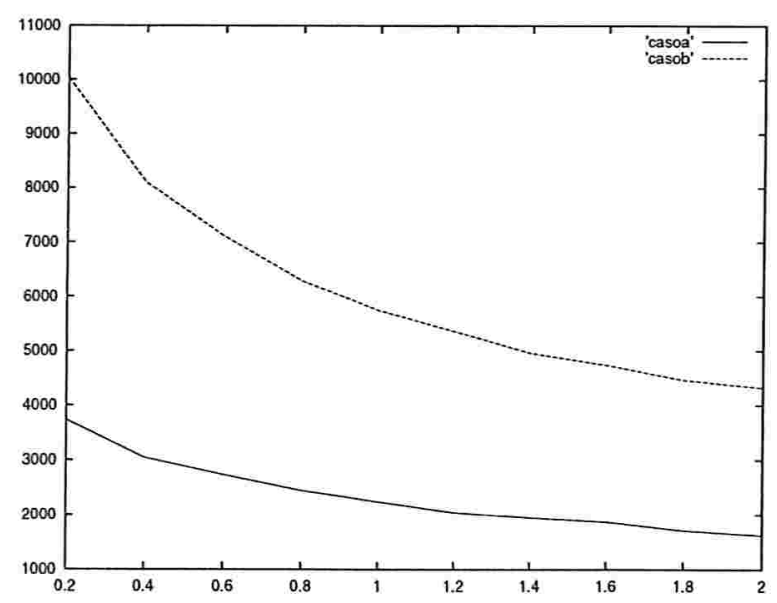

Figura 2.5: Gráfico $\beta \times$ it, it: eixo vertical e $\beta$ : eixo horizontal, caso a: $\operatorname{Re}=1,2$ e $\mathrm{n}=32$ e caso b: $\operatorname{Re}=1,2$ e $n=64$. 


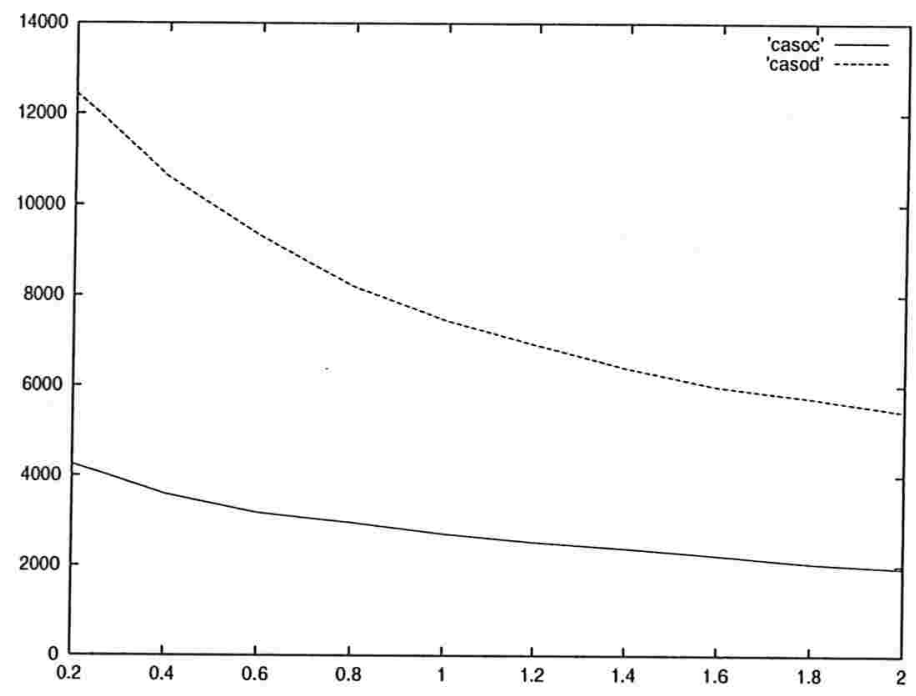

Figura 2.6: Gráfico $\beta \times i t$, it: eixo vertical e $\beta$ : eixo horizontal, caso c: $\operatorname{Re}=100$ e $\mathrm{n}=32$ e caso d: $R e=100$ e $n=64$.

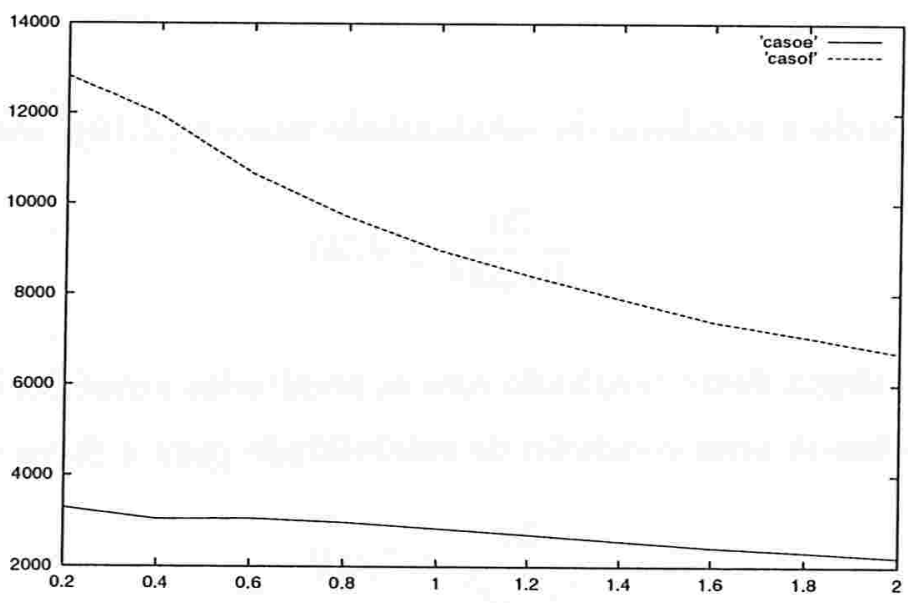

Figura 2.7: Gráfico $\beta \times$ it, it: eixo vertical e $\beta$ : eixo horizontal, caso e: $\operatorname{Re}=400$ e $\mathrm{n}=32$ e caso f: $R e=400$ e $n=64$. 


\section{Solução das Equações de Navier- Stokes na Cavidade pelo Método das 36 \\ Diferenças Finitas}

Através da análise dos resultados numéricos observou-se que os valores dos parâmetros $\alpha$ e $\beta$ devem respeitar as regiões em destaque na Figura 2.8, abaixo das curvas, e que independentemente dos níveis de discretização, as regiões $\alpha \times \beta$ são bem próximas. $\AA$ medida que se aumenta os valores de $\alpha$, os valores de $\beta$ podem ser maior que 1 , ou seja, mesmo com a restrição esperada, $0<\beta \leq 1$, para valores de $\beta>1$ o método permanece estável, mostrando a baixa sensibilidade deste parâmetro em termos de estabilidade.

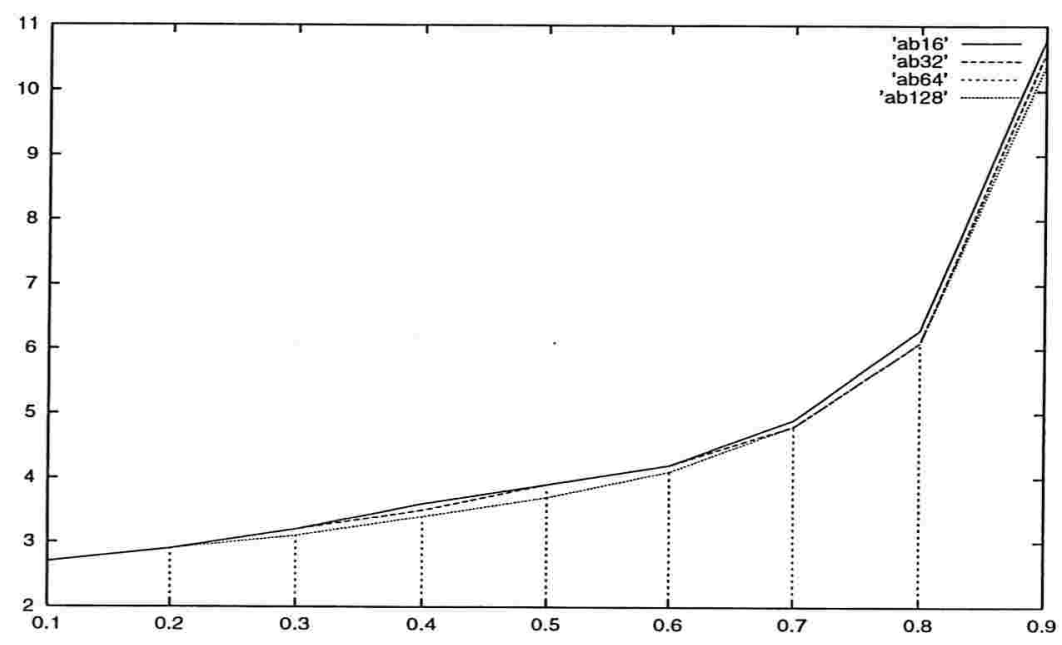

Figura 2.8: Região de estabilidade: $\alpha \times \beta, \alpha$ : eixo horizontal e $\beta$ : eixo vertical, para testes realizados com níveis de discretização $n=16,32$ e 64 .

Ainda, reescrevendo a condição de estabilidade teórica (2.19), tem-se:

$$
\frac{\Delta t}{R e \Delta x^{2}} \leq 0,25
$$

Fazendo uma analogia deste resultado com os resultados numéricos obtidos pelo estudo de estabilidade, obtém-se uma condição de estabilidade para a faixa de Reynolds testada

$$
\frac{\Delta t}{R e \Delta x^{2}} \leq 0,225
$$

As condições (2.25) e (2.26) ilustradas na Figura 2.9 mostram que a região de estabilidade obtida através de métodos numéricos está abaixo da região de estabilidade teórica, ou seja, comparando o resultado numérico (2.26) com o resultado teórico (2.25) conclui-se que este é satisfeito, Figura 2.9. 


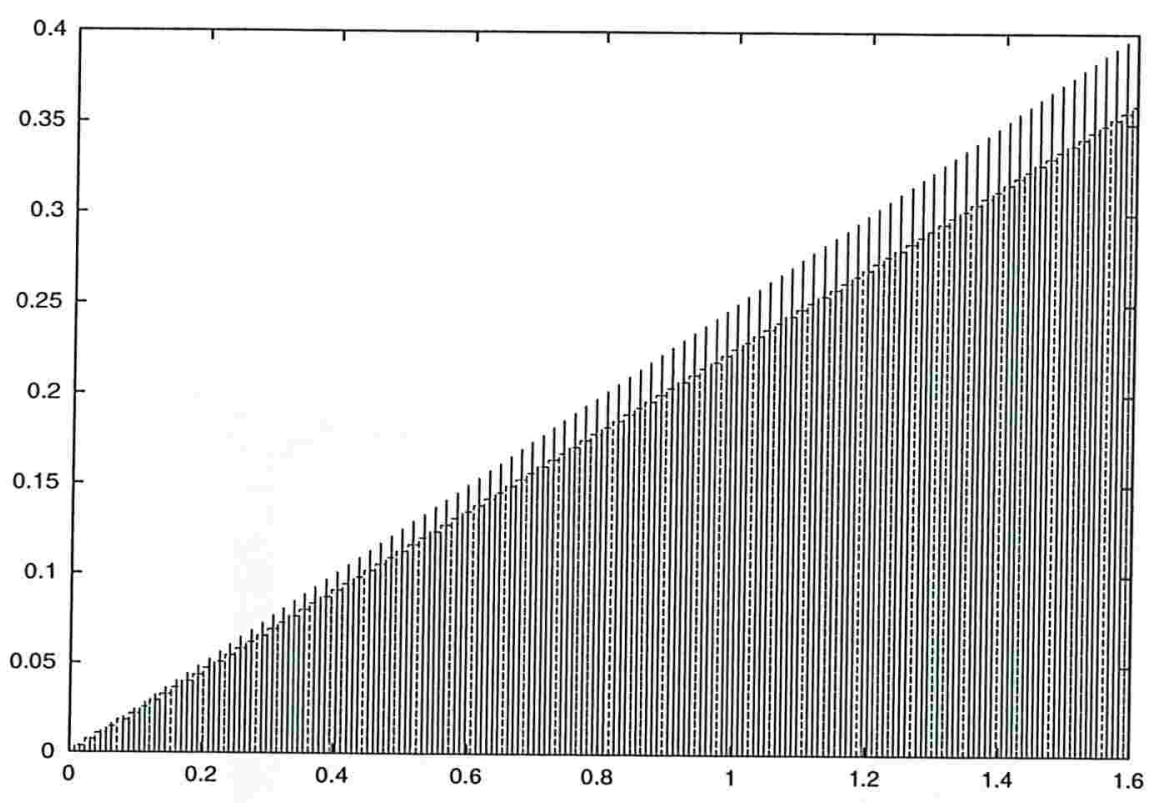

Figura 2.9: Região de estabilidade: $R e * \Delta x^{2} \times \Delta t, R e * \Delta x^{2}$ : eixo horizontal e $\Delta t$ : eixo vertical.

\subsection{Equações de Navier-Stokes na Modelagem de um Tanque Agitado}

Assim, a partir dos estudos anteriores, na modelagem de um tanque com geometria simples, representado na Figura 2.10, foram empregadas as equações de Navier-Stokes em coordenadas cilíndricas em duas dimensões, r e z, (2.27)(ver Apêndice A).

$$
\left\{\begin{array}{l}
\frac{D v_{r}}{D t}=-\frac{\partial p}{\partial r}+\frac{1}{R e}\left(\Delta v_{r}-\frac{v_{r}}{r^{2}}\right) \\
\frac{D v_{z}}{D t}=-\frac{\partial p}{\partial z}+\frac{1}{R e} \Delta v_{z}
\end{array}\right.
$$

onde:

$$
\begin{aligned}
& \Delta=\frac{1}{r} \frac{\partial}{\partial r}\left(r \frac{\partial}{\partial r}+\frac{\partial^{2}}{\partial z^{2}}\right) \\
& \frac{D}{D t}=\frac{\partial}{\partial t}+v_{r} \frac{\partial}{\partial r}+v_{z} \frac{\partial}{\partial z}
\end{aligned}
$$

Re: número de Reynolds 
$p:$ pressão

$v_{r}$ : componente da velocidade na direção $\mathrm{r}$

$v_{z}$ : componente da velocidade na direção $z$
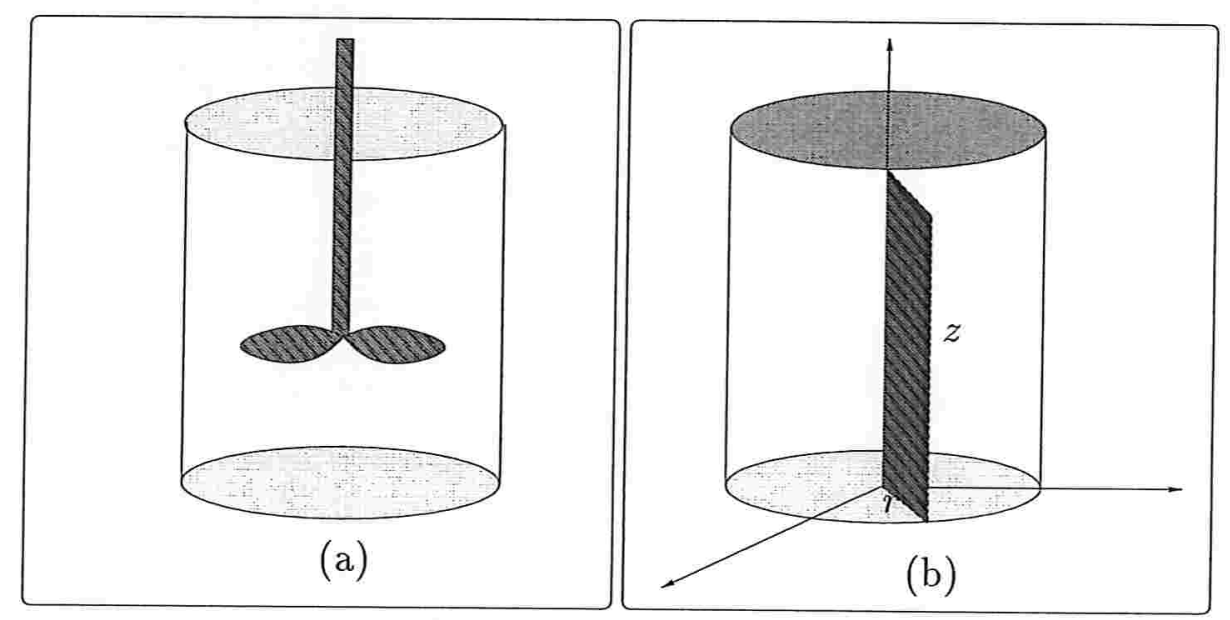

Figura 2.10: (a) Representação de um tanque simples com o eixo e o impelidor. (b) Representação da região $r \times z$ utilizada na modelagem empregando as equações de NavierStokes.

Por se tratar de um tanque cilíndrico, optou-se em solucionar as equações de NavierStokes no retângulo representado pela direção r e z em (2.27), com as condições de contorno da Figura 2.11. No eixo de simetria é considerada a condição de contorno de Neumann, ou seja:

$$
0 \leq z \leq 1 \text { e } r=0 \Rightarrow \frac{\partial v_{r}}{\partial r}=\frac{\partial v_{z}}{\partial r}=0
$$

e para os demais contornos:

$$
0 \leq z \leq 1 \text { e } r=1,0 \leq r \leq 1 \text { e } z=0,0 \leq r \leq 1 \text { e } z=1 \Rightarrow v_{r}=v_{z}=0
$$




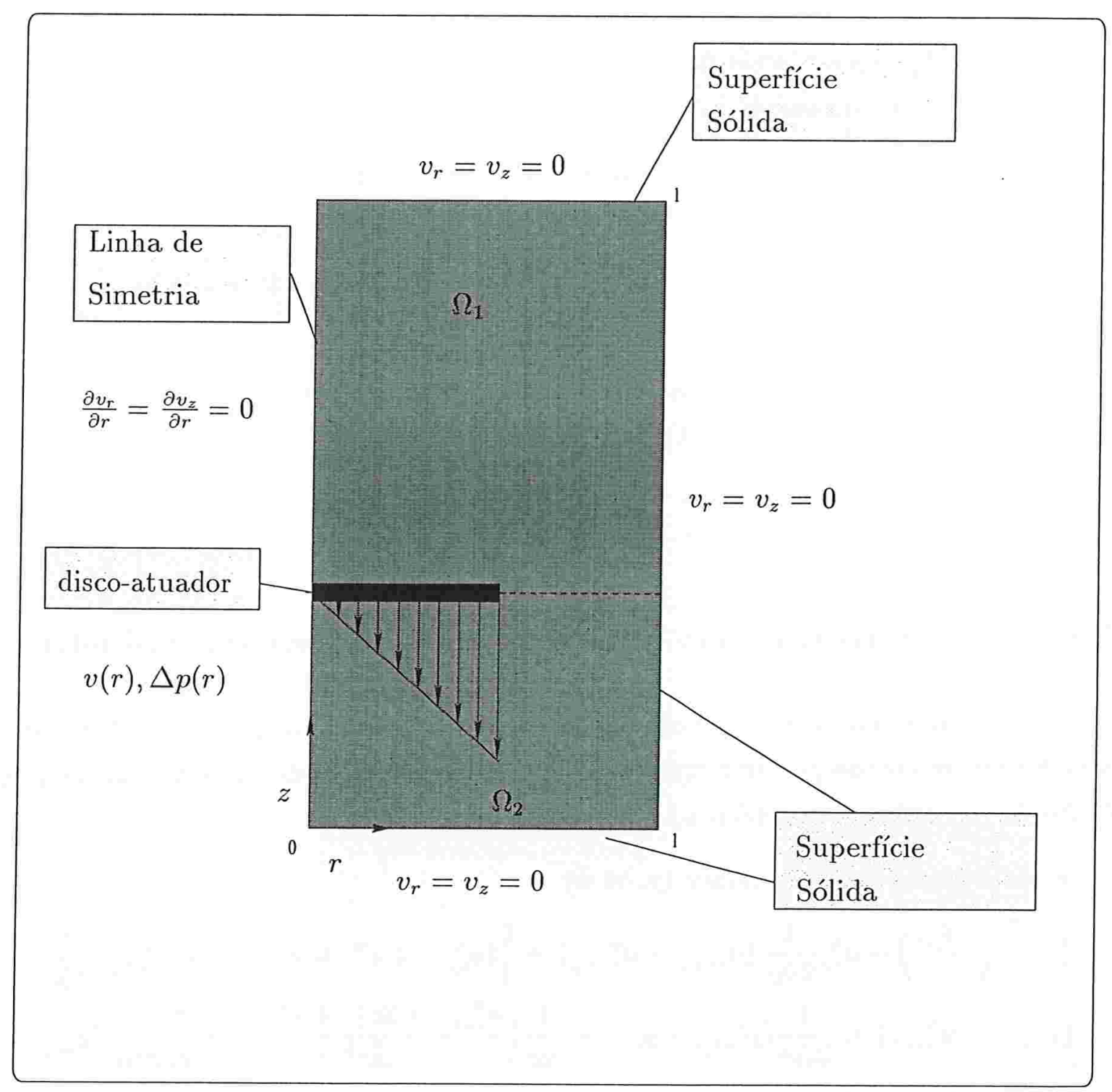

Figura 2.11: Condições empregadas na modelagem do tanque com geometria simples. 
As regiões $\Omega_{1}$ e $\Omega_{2}$ são regiões separadas pelo impelidor, que é representado pelo disco-atuador. A simples teoria do momento assume, a respeito do disco-atuador, o seguinte:

- o impelidor é representado por um número infinito de pás e pode ser considerado como um disco-atuador, acelerando uniformemente o fluido através do disco com nenhuma perda da força de impelir na extremidade da pá;

- a potência requerida para produzir o impulso é representada somente pela energia axial fornecida pelo fluxo composto pela corrente de arrasto;

- o disco é infinitamente fino de tal maneira que não há descontinuidade na velocidade nos dois lados do disco.

Utilizando o método da compressibilidade artificial, a equação da pressão em coordenadas cilíndricas (ver Apêndice A), é dada por:

$$
\frac{\partial p}{\partial t}+c_{0}^{2}\left(\frac{\partial v_{r}}{\partial r}+\frac{v_{r}}{r} \frac{\partial v_{z}}{\partial z}\right)=0
$$

\subsubsection{Discretização das Equações em Coordenadas Cilíndricas}

Considerando no eixo de simetria a condição de Neumann $\left(\frac{\partial u}{\partial r}=\frac{\partial v}{\partial z}=0\right)$ e o discoatuador (representado por uma função $f(r)$ ), o sistema (2.27) em conjunto com a equação (2.29) foi discretizado por diferenças finitas, obtendo:

- componente u da velocidade $\left(v_{r}=u\right)$

$$
\begin{aligned}
& \left(\frac{u_{i, j}^{n+1}-u_{i, j}^{n}}{\Delta t}\right)+u_{i, j}^{n} \frac{1}{2 \Delta r}\left(u_{i+1, j}^{n}-u_{i-1, j}^{n}\right)+\frac{1}{4}\left(v_{i, j-1}^{n}+v_{i, j}^{n}+v_{i+1, j-1}^{n}+v_{i+1, j}^{n}\right) \frac{1}{2 \Delta z} \\
& \left(u_{i, j+1}^{n}-u_{i, j-1}^{n}\right)=\frac{1}{2 \Delta r}\left(p_{i+1, j}^{n}-p_{i, j}^{n}\right)+\frac{1}{R e}\left(\frac{u_{i+1, j}^{n}-2 u_{i, j}^{n}+u_{i-1, j}^{n}}{\Delta r^{2}}+\frac{1}{r_{i}} \frac{1}{2 \Delta r}\left(u_{i+1, j}^{n}\right.\right. \\
& \left.\left.-u_{i, j}^{n}\right)-\frac{u_{i, j}^{n}}{r_{i}^{2}}+\frac{1}{\Delta z^{2}}\left(u_{i, j+1}^{n}-2 u_{i, j}^{n}+u_{i, j-1}^{n}\right)\right)
\end{aligned}
$$

- componente $\mathrm{v}$ da velocidade $\left(v_{z}=v\right)$

$$
\begin{aligned}
& \left(\frac{v_{i-1, j}^{n+1}-v_{i, j}^{n}}{\Delta t}\right)+\frac{1}{2 \Delta r}\left(v_{i+1, j}^{n}-v_{i-1, j}^{n}\right) \frac{1}{4}\left(u_{i, j-1}^{n}+u_{i, j}^{n}+u_{i+1, j-1}^{n}+u_{i+1, j}^{n}\right)+ \\
& v_{i, j}^{n} \frac{1}{2 \Delta z}\left(v_{i, j+1}^{n}-v_{i, j-1}^{n}\right)=\frac{1}{2 \Delta z}\left(p_{i+1, j}^{n}-p_{i, j}^{n}\right)+\frac{1}{R e}\left(\frac{v_{i+1, j}^{n}-2 v_{i, j}^{n}+v_{i-1, j}^{n}}{\Delta r^{2}}+\right.
\end{aligned}
$$


$\left.\frac{1}{r_{i}} \frac{1}{2 \Delta r}\left(v_{i+1, j}^{n}-v_{i-1, j}^{n}\right)\right)$

- pressão

$\frac{p_{i, j}^{n+1}-p_{i, j}^{n}}{\Delta t}+c_{0}^{2}\left(\frac{1}{\Delta r}\left(u_{i, j}^{n+1}-u_{i-1, j}^{n+1}\right)+\frac{u_{i, j}^{n+1}}{r_{i}}+\frac{1}{\Delta z}\left(v_{i, j}^{n+1}-v_{i, j-1}^{n+1}\right)\right)=0$

Com a condição de Neumann para o eixo de simetria, a componente $v$ desta fronteira é obtida por:

$$
v_{f r}(1, j)^{n}=v(1, j)^{n}
$$

onde $v_{f r}$ é o valor da velocidade na fronteira. A componente u da velocidade já está definida na fronteira vertical.

Considerando o disco-atuador localizado na metade da altura do tanque $(\mathrm{C} / \mathrm{T}=1 / 2)$ e a relação diâmetro do impelidor pelo diâmetro interno do tanque igual a $1 / 2(\mathrm{D} / \mathrm{T}=1 / 2)$, a discretização nesta região para a componente $v$ é dada por:

- para $i=0, k / 2$ : f é uma função que define o campo de velocidades através do disco-atuador.

$$
v_{(i, k / 2)}^{n}=f_{(i, k / 2)}^{n}
$$

- para $i=k / 2+1, n$, obtém-se a componente $v$ como citado anteriormente.

Em coordenadas cilíndricas com o disco-atuador, as simulações tiveram por objetivo verificar o comportamento do campo de velocidade de acordo com a função escolhida e obteve-se os gráficos mostrados na Figura 2.12 e Figura 2.13.

Com dois discos-atuadores, o primeiro a $25 \%$ do fundo do tanque e o segundo a $50 \%$ do fundo do tanque obteve-se a Figura 2.14.

Uma vez obtido o campo de velocidades, a etapa seguinte é analisar o comportamento das partículas no cilindro, para tanto é preciso compreender o fenômeno de transporte e a sua modelagem. 

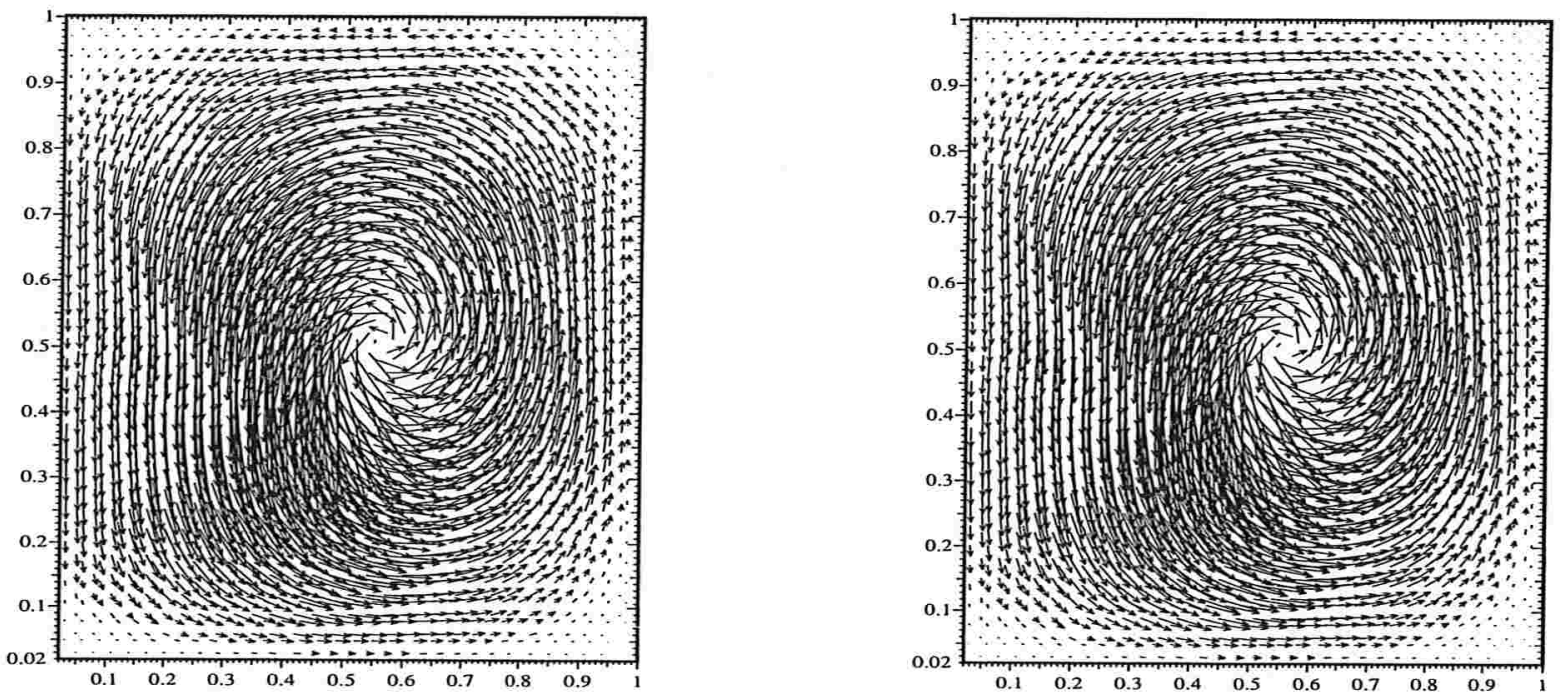

$$
\operatorname{Re}=1,2
$$

$$
\operatorname{Re}=10
$$

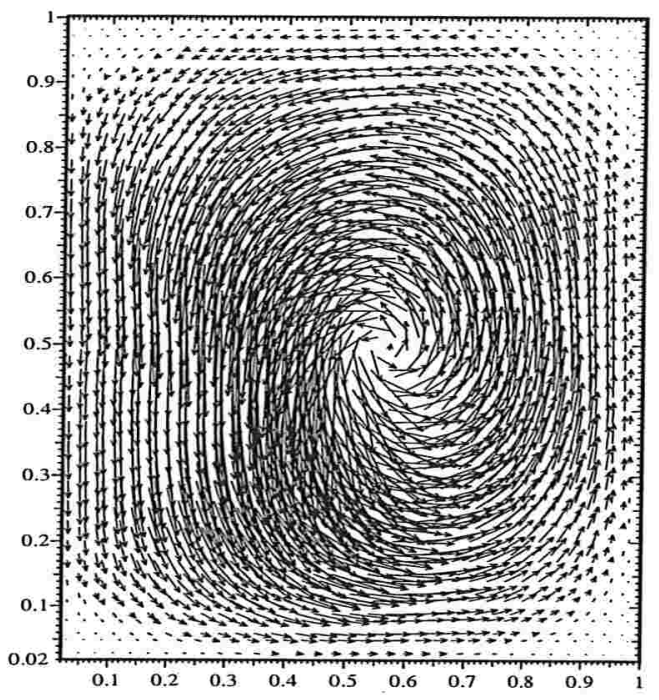

$$
\operatorname{Re}=50
$$

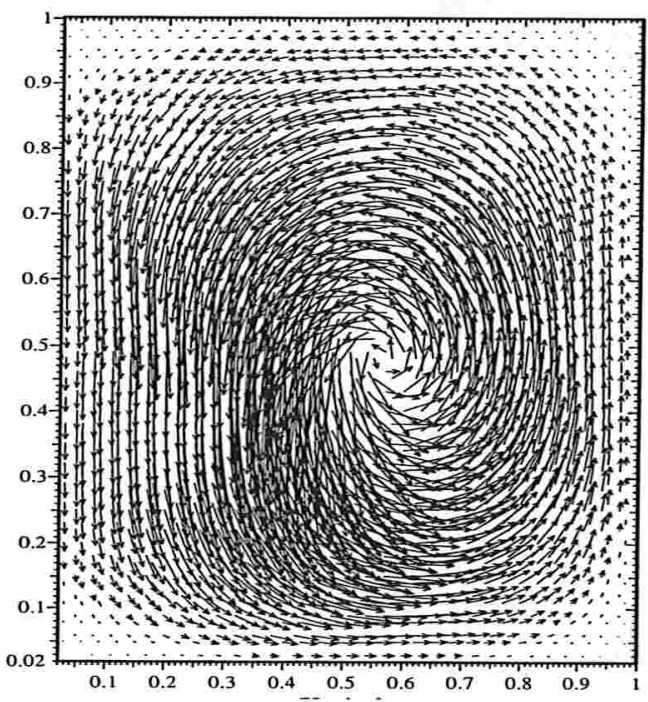

$\operatorname{Re}=100$

Figura 2.12: Representação do comportamento do fluido na região $[0,1] \times[0,1]$ do cilindro, através do campo de velocidade por vetores, com um disco-atuador definido pela função: $f(r)=-0,5 * r$, para uma malha $32 \times 32, R e_{\text {fluido }}=1,2,10,50$ e 100 . 


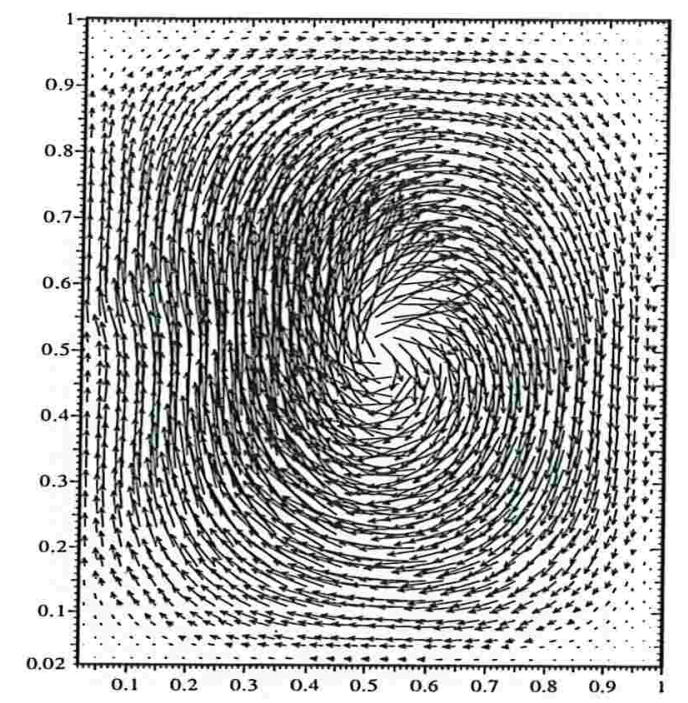

$$
\mathrm{Re}=1,2
$$

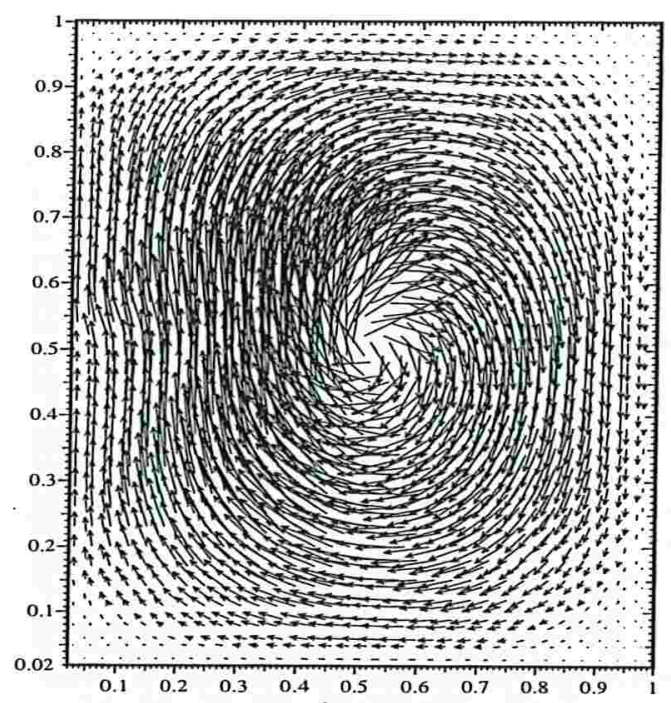

$$
\operatorname{Re}=50
$$

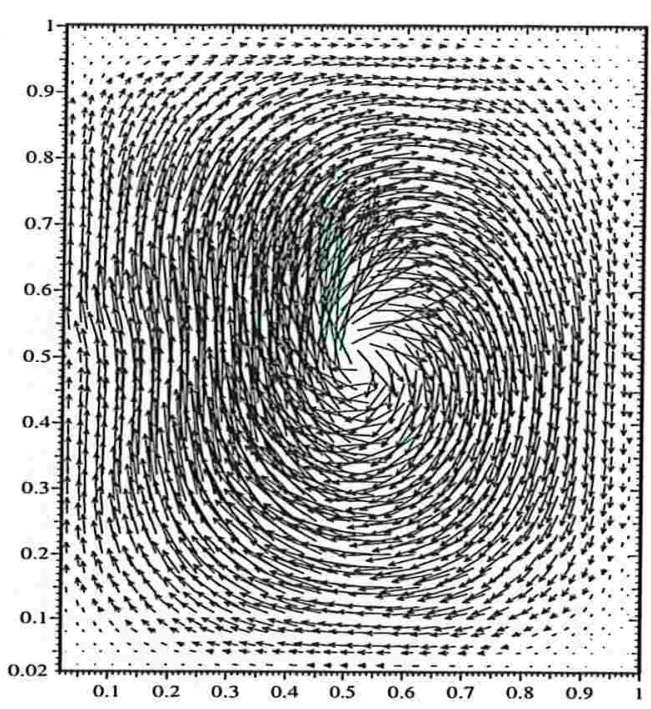

$$
\mathrm{Re}=10
$$

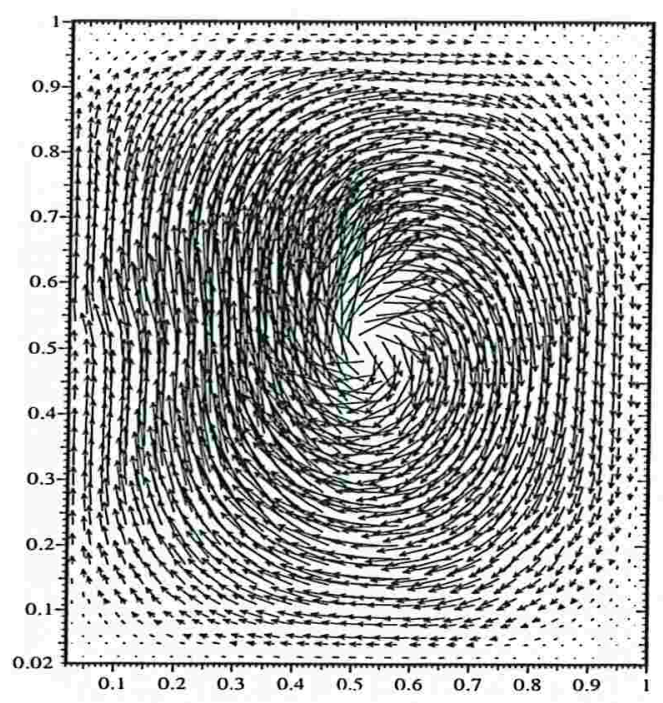

$$
\operatorname{Re}=100
$$

Figura 2.13: Representação do comportamento do fluido na região $[0,1] \times[0,1]$ do cilindro, através do campo de velocidades por vetores, com um disco-atuador definido pela função: $f(r)=0,5 * r$, para uma malha $32 \times 32, R e_{\text {fluido }}=1,2,10,50$ e 100. 
Solução das Equações de Navier- Stokes na Cavidade pelo Método das
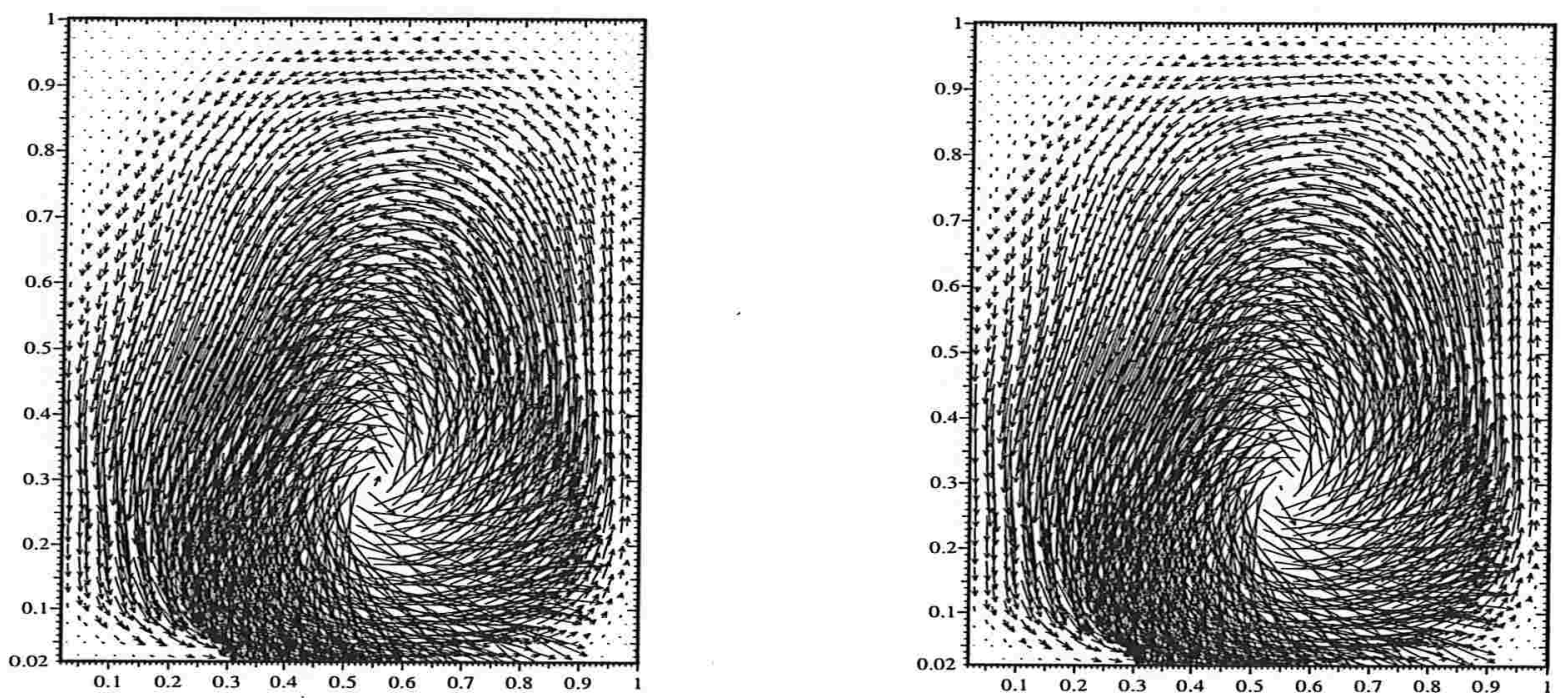

$$
\operatorname{Re}=1,2
$$

$$
\operatorname{Re}=10
$$
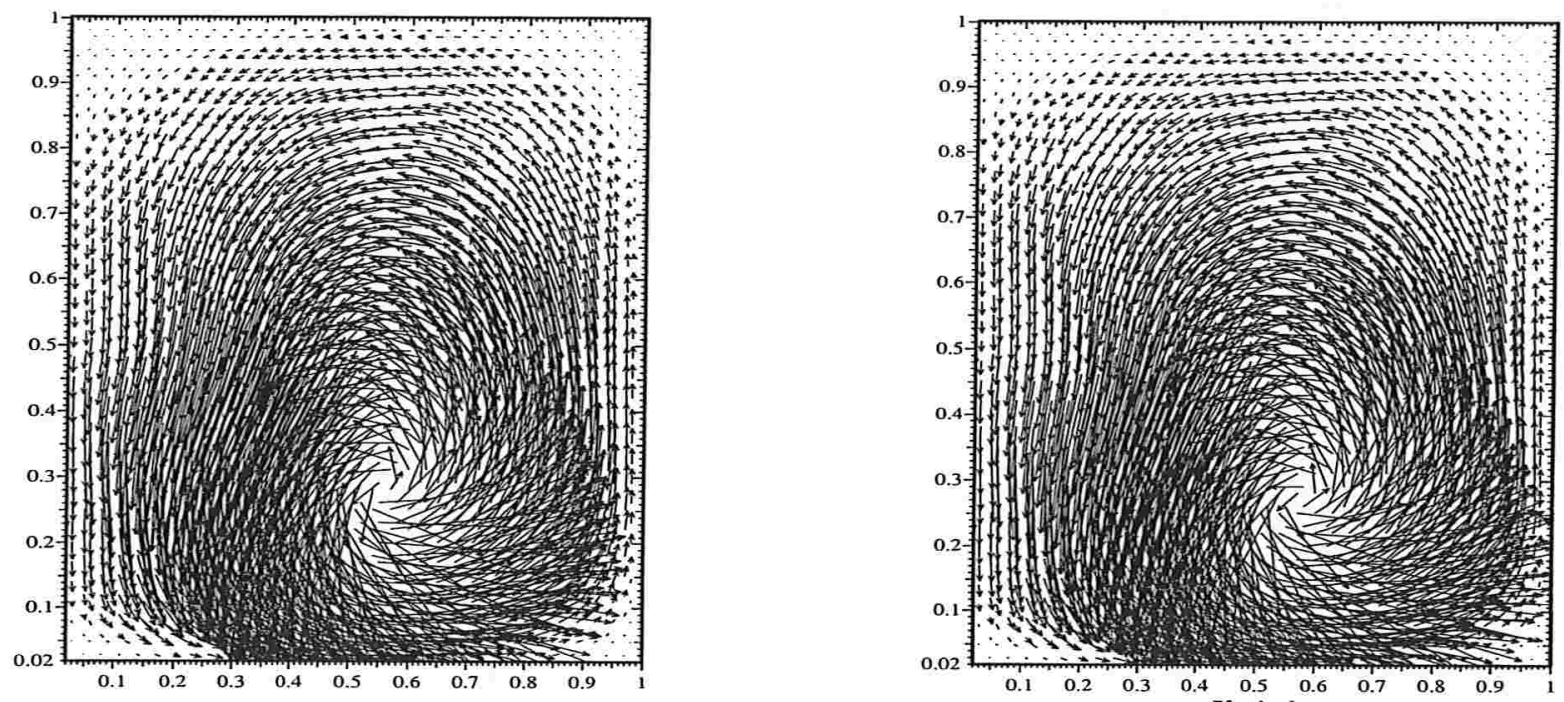

$$
\mathrm{Re}=50
$$

$$
\operatorname{Re}=100
$$

Figura 2.14: Representação do comportamento do fluido na região $[0,1] \times[0,1]$ do cilindro, através do campo de velocidades por vetores, com dois discos-atuadores definidos pelas funções: $f_{1}(r)=-0,5 * r$ e $f_{2}(r)=-2 / 9 * r$ para uma malha $32 \times 32, R e_{\text {fluido }}=1,2,10,50$ e 100 . 


\section{Modelagem Matemática do Transporte de Partículas}

Os fenômenos de transporte envolvem três áreas: momento, calor e massa e iniciam este capítulo. Em seguida tem-se o movimento da partícula em um fluido e a influência do coeficiente de arrasto sobre uma partícula.

O modelo adotado para determinar a trajetória da partícula em um tanque é um sistema de equações diferenciais ordinárias (EDO's) discretizado pelo método de Euler, preditor-corretor Euler Modificado e Runge-Kutta de $4^{\underline{a}}$ ordem. Testes foram realizados para análise do comportamento da partícula em um cilindro com ou sem influência do campo de velocidades e uma análise da constante de elasticidade.

\subsection{Fenômenos de Transporte}

O transporte de propriedades como massa, momento e energia através de um meio, sólido ou fluido, em virtude de condições existentes neste meio caracteriza um fenômeno de transporte. Variações em tal meio podem conduzir a certos resultados, por exemplo, a difusão é a variação em um meio condutor do movimento de espécies químicas presentes neste meio e variações na temperatura resultam no transporte de energia. Os gradientes de velocidade produzem tensões no fluido, tensões estas que dependem da viscosidade.

Em [4] é citado o trabalho pioneiro "Principles of Chemical Engineering", publicado em 1923 como primeiro a enfatizar a importância do conceito de operaçóes unitárias 
como uma fundamental aproximação para separações físicas como destilação, evaporação, secagem, etc. Estudar grupos de operações, tal como destilação, é afirmar que similaridade dos equipamentos não é o fundamental no processo, ou seja, aplicar os princípios da destilação na separação de oxigênio líquido do nitrogênio líquido é o mesmo aplicado em milhares de outras destilações corriqueiras que ocorrem nas indústrias do mundo todo. $\mathrm{O}$ fenômeno de transporte é um tópico importante, trata-se da base da maioria dos grupos de operações. Pode-se dizer que tal fenômeno compreende três áreas: transferência de calor, transferência de massa e transferência de momento (movimento do fluido).

Um simples exemplo de transporte de calor é a condução de calor em uma região de alta temperatura para uma região de baixa temperatura através de uma barra, como mostra a Figura 3.1 [4].

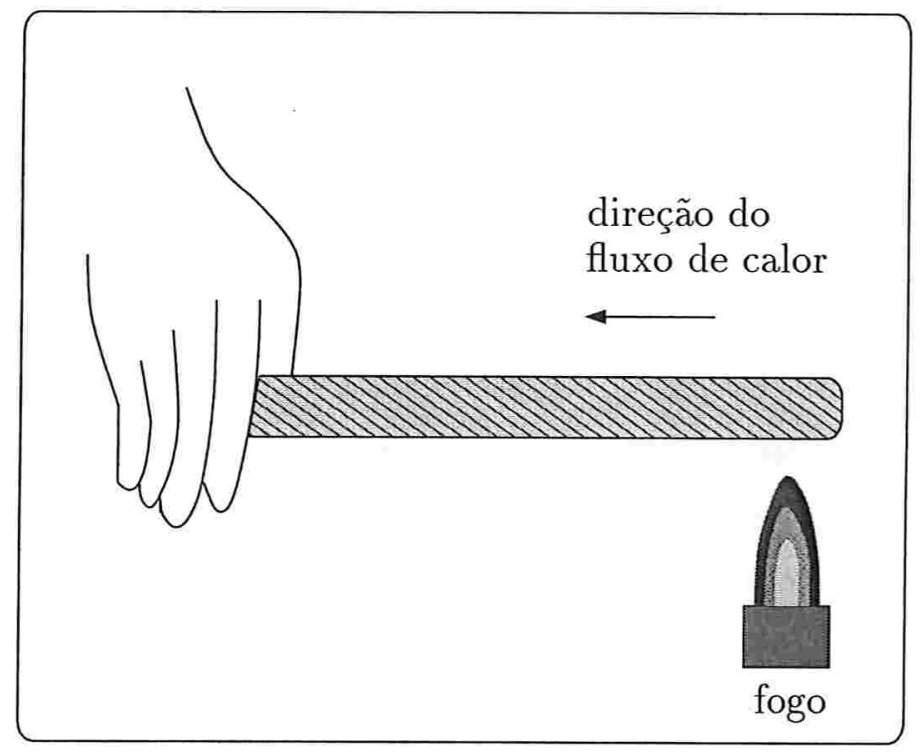

Figura 3.1: Transferência de calor molecular.

Se um dos extremos da barra tem a temperatura ambiente e está segura firmemente e a outra extremidade está sobre uma chama, o calor é transferido para a extremidade fixa da barra a partir do extremo sobre a chama por transporte molecular. As moléculas aquecidas na chama tem mais energia que as moléculas do outro extremo da barra. Como as moléculas colidem a energia é transferida das moléculas mais quentes para as mais frias. O processo é repetido milhares de vezes até que a barra toda é aquecida também e a diferença entre as temperaturas (temperatura do calor da chama menos a temperatura 
da mão) é a força motriz para a transferência de calor.

Para o transporte de massa a situação é mais complicada pois deve haver pelo menos duas espécies presentes. Na Figura 3.2 [4] foram considerados dois frascos idênticos unidos por uma válvula. O primeiro frasco contém nitrogênio puro e o outro oxigênio puro. Ambos tem a mesma pressão e temperatura. Abrindo a válvula, o oxigênio irá difundir para o lado do nitrogênio e o nitrogênio para o lado do oxigênio até que cada frasco contenha $50 \%$ de nitrogênio e $50 \%$ de oxigênio. A concentração é a força motriz.

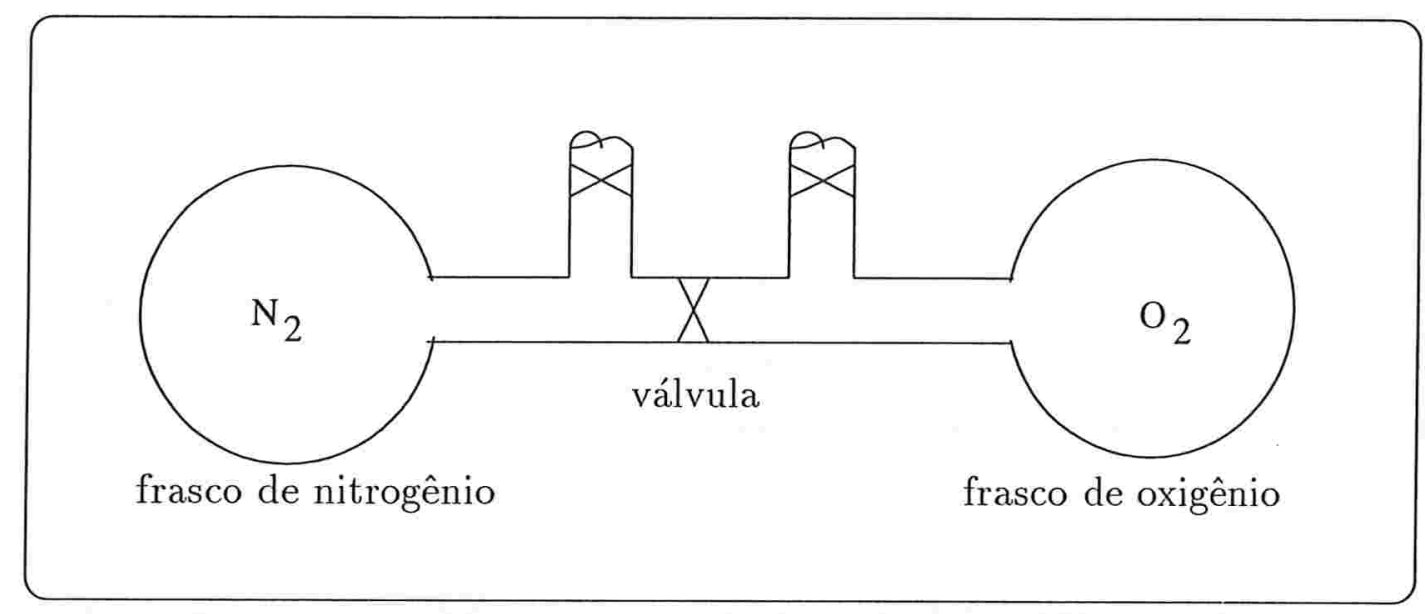

Figura 3.2: Transferência de massa molecular.

O escoamento do fluido é um simples exemplo de transferência de momento. A força motriz para o fluido é uma diferença de pressão. Por exemplo, quando a válvula de uma fonte de água é aberta, a água jorra em forma de jato porque a pressão dentro da fonte é maior que a pressão atmosférica que o jato descarrega. A Figura 3.3 [4] mostra um exemplo de escoamento de um fluido (gás ou líquido) em um tubo, neste caso uma fumaça soprada em um tubo. Uma bomba ou um ventilador força o fluido através do tubo. Se a bomba ou o ventilador é muito pequeno em relação ao tubo, então cria somente uma pequena pressão e o escoamento no tubo pode ser relativamente baixo e será laminar. Se há uma larga pressão, o escoamento no tubo será muito grande e, provavelmente, turbulento. No caso laminar (transporte molecular), o fluido emitido pelo tubo é de forma suave, ordenada. Já no caso turbulento, o movimento do fluido é caótico com blocos de moléculas (vórtices) movendo em todas as direções. 


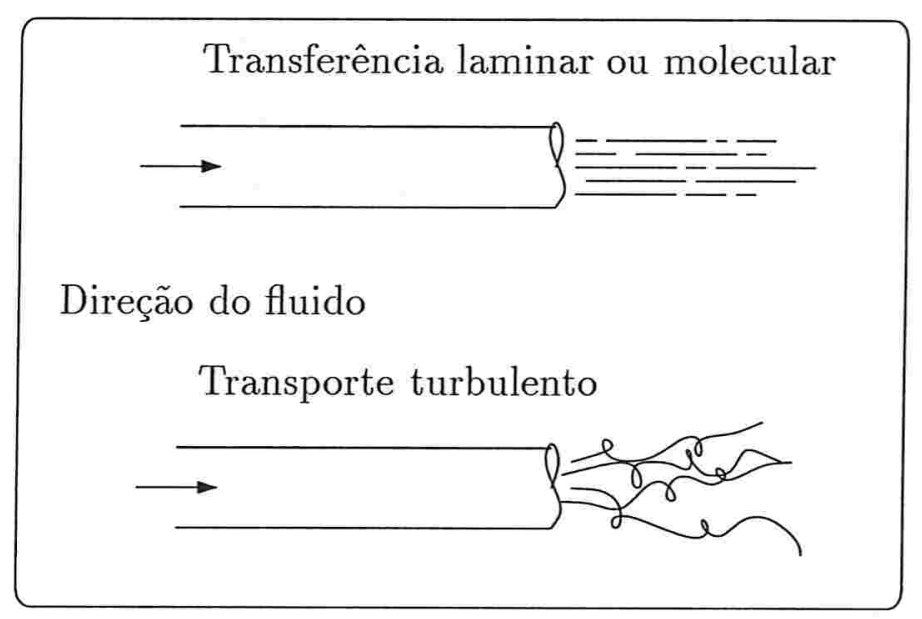

Figura 3.3: Transferência de momento.

Em resumo, o mecanismo molecular envolve o transporte de calor por condução, de massa por difusão molecular e de momento no caso do escoamento laminar.

\subsection{O Modelo Matemático do Movimento de uma Partícula no Fluido}

Muitos processos de separação de partículas de tamanhos e formas diferentes dependem de variações que estas sofrem quando são submetidas a ação do movimento do fluido.

Os métodos empregados para determinar o tamanho das partículas submetidas a uma classificação envolve a relação de movimento - coeficiente de transporte - entre as partículas e o fluido envolvido que exercerá um arrasto sobre a partícula.

A força de arrasto sobre a partícula é dada por

$$
F_{D}=\frac{C_{D} A_{p} \rho U^{2}}{2}
$$

onde

$F_{D}$ : força de arrasto

$C_{D}$ : coeficiente de arrasto (admensional)

$A_{p}$ : área da partícula projetada na direção do movimento 
$\rho$ : densidade do fluido envolvido

$\mathrm{U}$ : velocidade relativa entre a partícula e o fluido

A força de arrasto, definida em (3.1), é exercida na direção paralela à velocidade do fluido.

A trajetória de uma partícula de formato esférico foi modelada através de um sistema de equações diferenciais ordinárias (EDO's) obtido por meio do balanço de forças da partícula inerte com as forças atuando sobre ela que pode ser escrita (na direção x em coordenadas cartesianas) como:

$$
\begin{gathered}
F_{x}=\epsilon C_{D} \rho_{f} \frac{\left|u-u_{p}\right|\left(u-u_{p}\right)}{2} A_{p} \\
F_{x}=m_{p} \ddot{x}_{p}
\end{gathered}
$$

onde:

$F_{x}$ : força na direção $\mathrm{x}$

$\epsilon$ : constante de elasticidade

$C_{D}$ : coeficiente de arrasto

$\rho_{f}$ : densidade do fluido

$u$ : componente de velocidade do fluido na direção $\mathrm{x}$

$u_{p}$ : componente da velocidade da partícula na direção $\mathrm{x}$

$A_{p}$ : área da partícula projetada na direção $\mathrm{x}$

$m_{p}$ : massa da partícula

$\ddot{x}_{p}$ : aceleração da partícula na direção $\mathrm{x}$

Igualando (3.2) e (3.3), tem-se:

$$
m_{p} \ddot{x}_{p}=\epsilon C_{D} \rho_{f} \frac{\left|u-u_{p}\right|\left(u-u_{p}\right)}{2} A_{p}
$$

Como $\rho_{p}=\frac{m_{p}}{V_{p}}$, tem-se $m_{p}=\rho_{p} V_{p}$, onde $V_{p}$ é o volume da partícula e $m_{p}$ é a massa da partícula e:

$$
\begin{gathered}
\rho_{p} V_{p} \ddot{x}_{p}=\epsilon C_{D} \rho_{f} \frac{\left|u-u_{p}\right|\left(u-u_{p}\right)}{2} A_{p} \\
\rho_{p} \ddot{x}_{p}=\epsilon C_{D} \rho_{f} \frac{\left|u-u_{p}\right|\left(u-u_{p}\right)}{2} \frac{A_{p}}{V_{p}}
\end{gathered}
$$


tem-se:

Uma vez que $\frac{A_{p}}{V_{p}}=\frac{4 \pi r_{p}^{2}}{\frac{4}{3} \pi r_{p}^{3}}=\frac{3}{r_{p}}\left(r_{p}\right.$ é o raio da partícula esférica $)$ então, na direção x

$$
\ddot{x}_{p}=\epsilon C_{D} \frac{3}{2} \frac{\rho_{f}}{\rho_{p}} \frac{\left|u-u_{p}\right|\left(u-u_{p}\right)}{r_{p}}
$$

onde

$\ddot{x}_{p}$ : aceleração da partícula na direção $\mathrm{x}$

$\epsilon$ : constante de elasticidade

$C_{D}$ : coeficiente de arrasto

$\rho_{f}$ : densidade do fluido

$\rho_{p}$ : densidade da partícula

$u$ : velocidade do fluido na direção $\mathrm{x}$

$u_{p}$ : velocidade da partícula na direção $\mathrm{x}$

$r_{p}:$ raio da partícula

Para a direção y, em coordenadas cartesianas, tem-se o efeito da gravidade e do empuxo:

$$
\begin{gathered}
F_{y}=\epsilon\left(C_{D} \rho_{f} \frac{\left|v-v_{p}\right|\left(v-v_{p}\right)}{2} A_{p}+\left(\rho_{p}-\rho_{f}\right) V_{p} g\right) \\
F_{y}=m_{p} \ddot{y}_{p}
\end{gathered}
$$

onde:

$\epsilon$ : constante de elasticidade

$F_{y}$ : componente da força na direção y

$C_{D}$ : coeficiente de arrasto

$\rho_{f}$ : densidade do fluido

$v$ : componente da velocidade do fluido na direção y

$v_{p}$ : componente da velocidade da partícula na direção y

$A_{p}$ : área da partícula projetada na direção y

$\rho_{p}$ : densidade da partícula

$V_{p}$ : volume da partícula

$g$ : gravidade

$m_{p}$ : massa da partícula

$\ddot{y}_{p}$ : aceleração da partícula na direção y 
Igualando-se (3.5) e (3.6):

$$
m_{p} \ddot{y}_{p}=\epsilon\left(C_{D} \rho_{f} \frac{\left|v-v_{p}\right|\left(v-v_{p}\right)}{2} A_{p}+\left(\rho_{p}-\rho_{f}\right) V_{p} g\right)
$$

Substituindo $m_{p}$ por $\rho_{p} V_{p}$, tem-se:

$$
\rho_{p} V_{p} \ddot{y}_{p}=\epsilon\left(C_{D} \rho_{f} \frac{\left|v-v_{p}\right|\left(v-v_{p}\right)}{2} A_{p}+\left(\rho_{p}-\rho_{f}\right) V_{p} g\right)
$$

E substituindo $A_{p}$ por $4 \pi r_{p}^{2}$ e $V_{p}$ por $\frac{4}{3} \pi r_{p}^{3}$, tem-se:

$$
\ddot{y}_{p}=\epsilon\left(C_{D} \frac{\rho_{f}}{\rho_{p}} \frac{3}{2} \frac{\left|v-v_{p}\right|\left(v-v_{p}\right)}{r_{p}}+\frac{\rho_{p}-\rho_{f}}{\rho_{p}} g\right)
$$

onde

$\epsilon$ : constante de elasticidade

$\rho_{p}$ : densidade da partícula

$\rho_{f}$ : densidade do fluido

$C_{D}$ : coeficiente de arrasto

$v$ : componente da velocidade do fluido na direção y

$v_{p}$ : componente da velocidade da partícula na direção y

$r_{p}$ : raio da partícula

$\mathrm{g}=9,8 \mathrm{~m} / \mathrm{s}^{2}:$ aceleração da gravidade

O valor do $C_{D}$ é dado em função do número de Reynolds $\left(R e_{p}\right)$ da partícula para um regime turbulento, da seguinte forma:

- $0<\left(R e_{p}\right)<2 \rightarrow C_{D}=\frac{24}{R e_{p}}$

- $2<\left(R e_{p}\right)<500 \rightarrow C_{D}=18,5 /\left(R e_{p}\right)^{0,6}$

- $500<\left(R e_{p}\right)<100000 \rightarrow C_{D}=0,44$

$\operatorname{com} R e_{p}=\frac{d_{p} \cdot U \cdot \rho_{p}}{\mu}$

onde

$d_{p}$ : diâmetro da partícula $(\mathrm{m})$

$\mathrm{U}$ : diferença entre a velocidade do fluido e da partícula $(\mathrm{m} / \mathrm{s})$

$\rho_{p}$ : densidade da partícula $\left(\mathrm{kg} / \mathrm{m}^{3}\right)$

$\mu$ : viscosidade do fluido (Pa.s) 
Para as simulações a serem feitas para análise do comportamento das partículas ao longo da trajetória, com diâmetros $10 \mu m, 50 \mu m$ e $100 \mu m$, o $R e_{p}$ empregado é tal que $C_{D}=0,44$.

\subsection{Discretização Temporal do Modelo}

O modelo adotado foi discretizado por diferenças finitas com o intuito de analisar a variação do passo no tempo $\Delta t$. Assim foram implementados os métodos de Euler, Euler Modificado e Runge-Kutta $4^{\mathrm{a}}$ ordem para uma análise de eficiência computacional.

\subsubsection{Método de Euler}

Utilizando o método de Euler na discretização do sistema obtido, através da equação (3.4) para a abscissa $\left(x_{p}\right)$ da partícula e (3.7) para a ordenada $\left(y_{p}\right)$ da partícula

$$
\left\{\begin{array}{l}
\dot{x}(t)=u(t) \\
\dot{u}(t)=\epsilon C_{D} \frac{3}{2} \frac{\rho_{F}}{\rho_{p}} \frac{\left|u-u_{p}\right|\left(u-u_{p}\right)}{r_{p}}
\end{array}\right.
$$

e

$$
\left\{\begin{array}{l}
\dot{y}(t)=v(t) \\
\dot{v}(t)=\epsilon\left(C_{D} \frac{\rho_{f}}{\rho_{p}} \frac{3}{2} \frac{\left|v-v_{p}\right|\left(v-v_{p}\right)}{r_{p}}+\frac{\rho_{p}-\rho_{f}}{\rho_{p}} g\right)
\end{array}\right.
$$

obtém-se

$$
\left\{\begin{array}{l}
u_{p}^{(n+1)}=u_{p}^{(n)}+\Delta t f_{1}\left(u_{p}^{(n)}\right) \\
x^{(n+1)}=x^{(n)}+\Delta t u_{p}^{(n)}
\end{array}\right.
$$

onde

$$
f_{1}\left(u_{p}^{(n)}\right)=\epsilon\left(C_{D} \frac{3}{2} \frac{\rho_{F}}{\rho_{p}} \frac{\left|u^{(n)}-u_{p}^{(n)}\right|\left(u^{(n)}-u_{p}^{(n)}\right)}{r_{p}}\right)
$$

$\mathrm{e}$

$$
\left\{\begin{array}{l}
v_{p}^{(n+1)}=v_{p}(n)+\Delta t \cdot f_{2}\left(v_{p}^{(n)}\right) \\
y^{(n+1)}=y^{(n)}+\Delta t v_{p}^{(n)}
\end{array}\right.
$$


onde

$$
f_{2} v_{p}^{(n)}=\epsilon\left(C_{D} \frac{\rho_{f}}{\rho_{p}} \frac{3}{2} \frac{\left|v^{(n)}-v_{p}^{(n)}\right|\left(v^{(n)}-v_{p}^{(n)}\right)}{r_{p}}+\frac{\rho_{p}-\rho_{f}}{\rho_{p}} g\right)
$$

Para melhorar o passo no tempo, optou-se em implementar um método de $2^{\underline{a}}$ ordem (método de Euler Modificado) e outro de $4^{\mathrm{a}}$ ordem (Método de Runge-Kutta).

\subsubsection{Método de Euler Modificado}

O sistema (3.8) pode ser escrito como:

$$
\left\{\begin{array}{l}
\dot{x}(t)=u(t) \\
\dot{u}(t)=\epsilon C_{D} \frac{3}{2} \frac{\rho_{f}}{\rho_{p}} \frac{\left|u-u_{p}\right|\left(u-u_{p}\right)}{r_{p}}=f_{1}(t, u)
\end{array}\right.
$$

Usando o método de Euler Modificado, que é um método Preditor-Corretor, tem-se:

- Fórmula Preditora

$$
\left\{\begin{array}{l}
x^{\prime(n+1)}(p t)=x^{(n)}(p t)+\Delta t u^{(n)}(p t) \\
u^{\prime(n+1)}(p t)=u^{(n)}(p t)+\Delta t f_{1}^{(n)}(p t)
\end{array}\right.
$$

- Fórmula Corretora

$$
\left\{\begin{array}{l}
x^{(n+1)}(p t)=x^{(n)}(p t)+\frac{\Delta t}{2}\left(u^{(n)}+x^{\prime(n+1)}(p t)\right) \\
u^{(n+1)}(p t)=u^{(n)}(p t)+\frac{\Delta t}{2}\left(f_{1}^{(n)}(p t)+f_{1}^{\prime(n+1)}(p t)\right)
\end{array}\right.
$$

Uma forma análoga pode ser obtida para o sistema (3.9).

\subsubsection{Método de Runge-Kutta de Quarta Ordem}

Reescrevendo o sistema (3.8):

$$
\left\{\begin{array}{l}
\dot{x}(t)=u(t)=f_{1}(t, u) \\
\dot{u}(t)=\epsilon C_{D} \frac{3}{2} \frac{\rho_{f}}{\rho_{p}} \frac{\left|u-u_{p}\right|\left(u-u_{p}\right)}{r_{p}}=f_{2}(t, u)
\end{array}\right.
$$


As fórmulas de Runge-Kutta para este sistema são:

$$
\begin{gathered}
k_{1}=\Delta t u^{n}=\Delta t f_{1}\left(u^{n}\right) \\
l_{1}=\Delta t\left[\epsilon C_{D} \frac{3}{2} \frac{\rho_{f}}{\rho_{p}} \frac{\left|u^{n}-u_{p}^{n}\right|\left(u^{n}-u_{p}^{n}\right)}{r_{p}}\right]=\Delta t f_{2} u^{n} \\
k_{2}=\Delta t\left(u^{n}+\frac{1}{2} l_{1}\right)=\Delta t f_{1}\left(u^{n}+\frac{1}{2} l_{1}\right) \\
l_{2}=\Delta t\left[\epsilon C_{D} \frac{3}{2} \frac{\rho_{f}}{\rho_{p}} \frac{\left|u^{n}-\left(u_{p}^{n}+\frac{1}{2} l_{1}\right)\right|\left(u^{n}-\left(u_{p}^{n}+\frac{1}{2} l_{1}\right)\right)}{r_{p}}\right]=\Delta t f_{2}\left(u^{(n)}+\frac{1}{2} l_{1}\right) \\
l_{3}=\Delta t\left[\epsilon C_{D} \frac{3}{2} \frac{\rho_{f}}{\rho_{p}} \frac{\left|u^{(n)}-\left(u_{p}^{(n)}+\frac{1}{2} l_{2}\right)\right|\left(u^{(n)}-\left(u_{p}^{(n)}+\frac{1}{2} l_{2}\right)\right)}{r_{p}}\right]=\Delta t f_{2}\left(u^{(n)}+\frac{1}{2} l_{2}\right) \\
l_{4}=\Delta t\left[\epsilon C_{D} \frac{3}{2} \frac{\rho_{f}}{\rho_{p}} \frac{\left|u^{(n)}-\left(u_{p}^{(n)}+\frac{1}{2} l_{3}\right)\right|\left(u^{(n)}-\left(u_{p}^{(n)}+\frac{1}{2} l_{3}\right)\right)}{r_{p}}\right]=\Delta t f_{2}\left(u^{(n)}+\frac{1}{2} l_{3}\right)
\end{gathered}
$$

Ainda:

$$
\begin{gathered}
x^{(n+1)}=x_{n}+\frac{1}{6}\left(k_{1}+2 k_{2}+2 k_{3}+k_{4}\right) \\
u^{(n+1)}=u_{n}+\frac{1}{6}\left(l_{1}+2 l_{2}+2 l_{3}+l_{4}\right)
\end{gathered}
$$

Estas são as fórmulas de Runge-Kutta para um sistema de duas equações de primeira ordem usando o clássico conjunto de fórmulas de $4^{\mathrm{a}}$ ordem que correspondem às séries de Taylor das funções usando termos até $4 \stackrel{\text { a }}{\text { ordem. }}$

Analogamente, obtém-se $y^{(n+1)} \mathrm{e} \cdot v^{(n+1)}$.

\subsection{Modelagem Matemática para Colisões entre as Partículas e a Parede}

Quando a partícula encontra um contorno físico (uma parede ou um contorno interno) é aplicada uma condição para aquele contorno, conforme mostra as condições de contorno empregadas no modelo (Figura 3.4). 


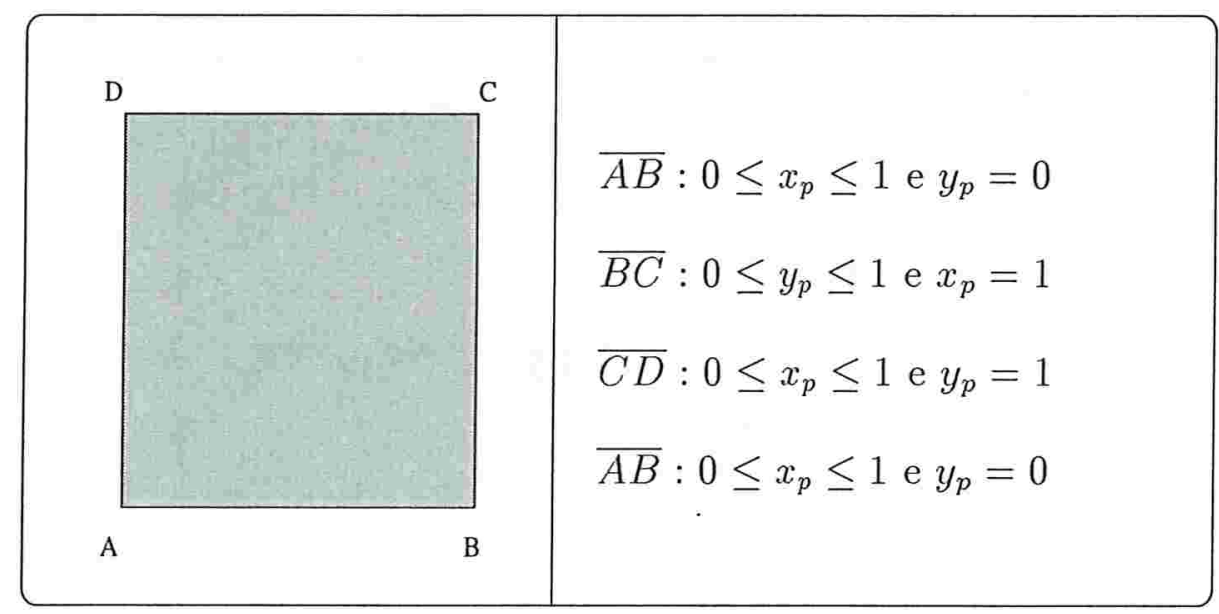

Figura 3.4: Contorno físico considerado no rebatimento.

A condição de contorno pode ser definida separadamente para cada parede como está descrito abaixo:

- se $x_{p}^{\prime}(n+1)>0, x_{p}^{\prime}(n+1)$ é a abscissa da partícula após uma evolução temporal, o valor de $x_{p}(n+1)$ é determinado pelo esquema da Figura 3.5.

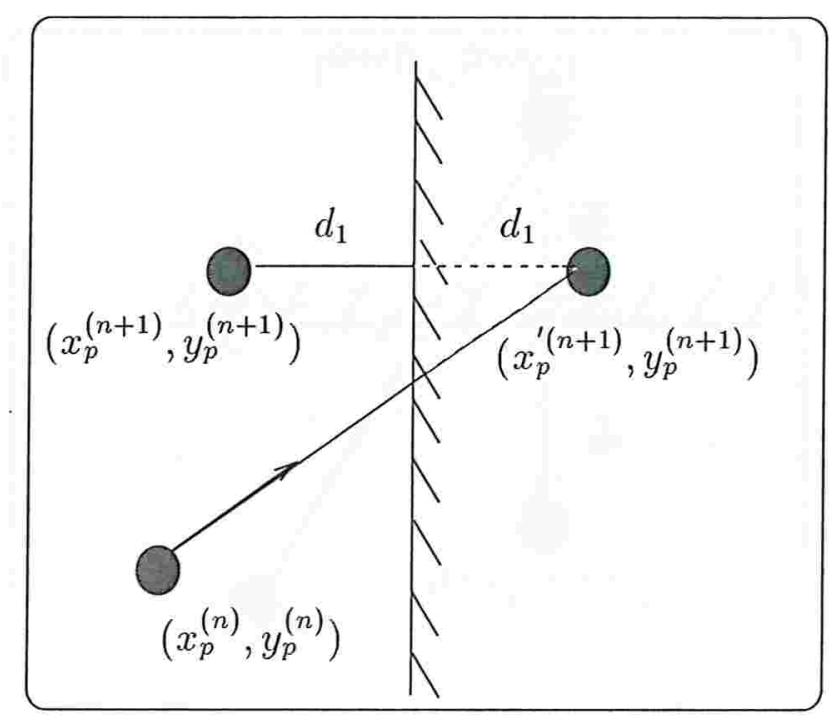

Figura 3.5: Rebatimento usado na parede $0 \leq y_{p} \leq 1$ e $x_{p}>1$. 
- se $y_{p}^{\prime}(n+1)<1, y_{p}^{\prime}(n+1)$ é a abscissa da partícula após uma evolução temporal, o valor de $y_{p}(n+1)$ é determinado pelo esquema da Figura 3.6.

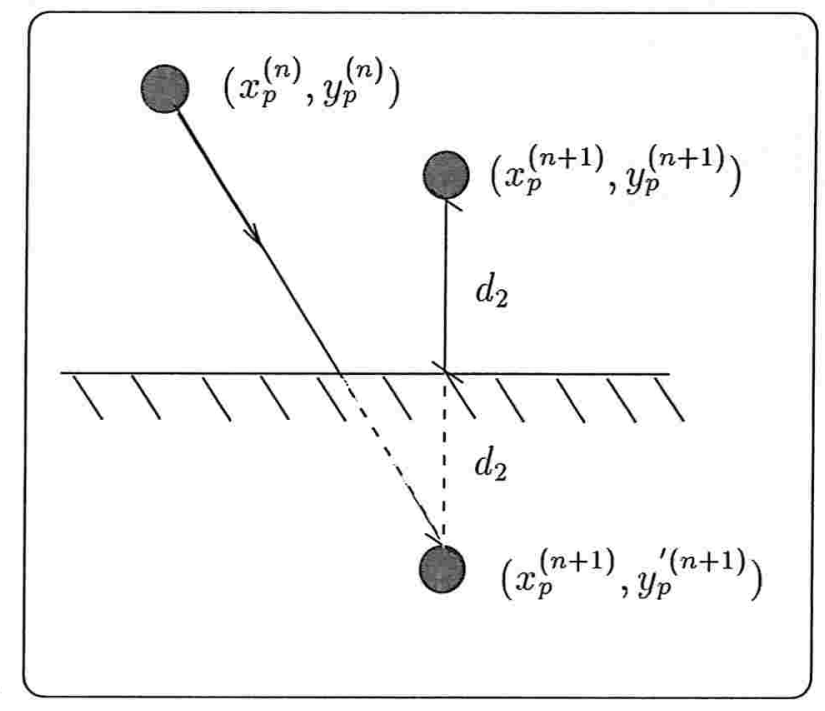

Figura 3.6: Rebatimento empregado na parede $0 \leq x_{p} \leq 1$ e $y_{p}<0$.

- se $y_{p}^{\prime}(n+1)>1, y_{p}^{\prime}(n+1)$ é a ordenada da partícula após uma evolução temporal, o valor de $y_{p}(n+1)$ é determinado pelo esquema da Figura 3.7.

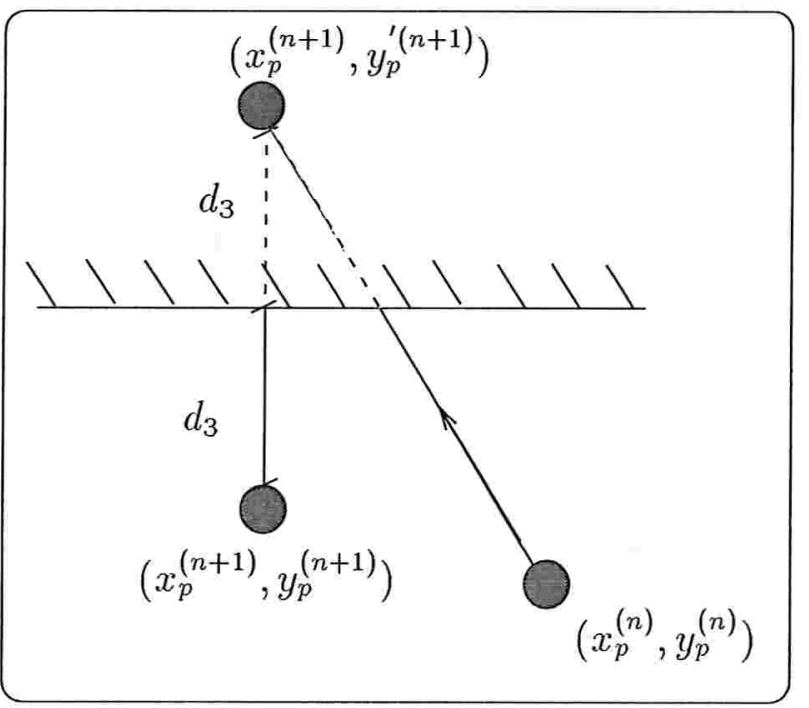

Figura 3.7: Rebatimento usado na parede $0 \leq x_{p} \leq 1$ e $y_{p}>1$ 
- se $x_{p}^{\prime}(n+1)<0, x_{p}^{\prime}(n+1)$ é a abscissa da partícula após uma evolução temporal, o valor de $x_{p}(n+1)$ é determinado pelo esquema da Figura 3.8 .

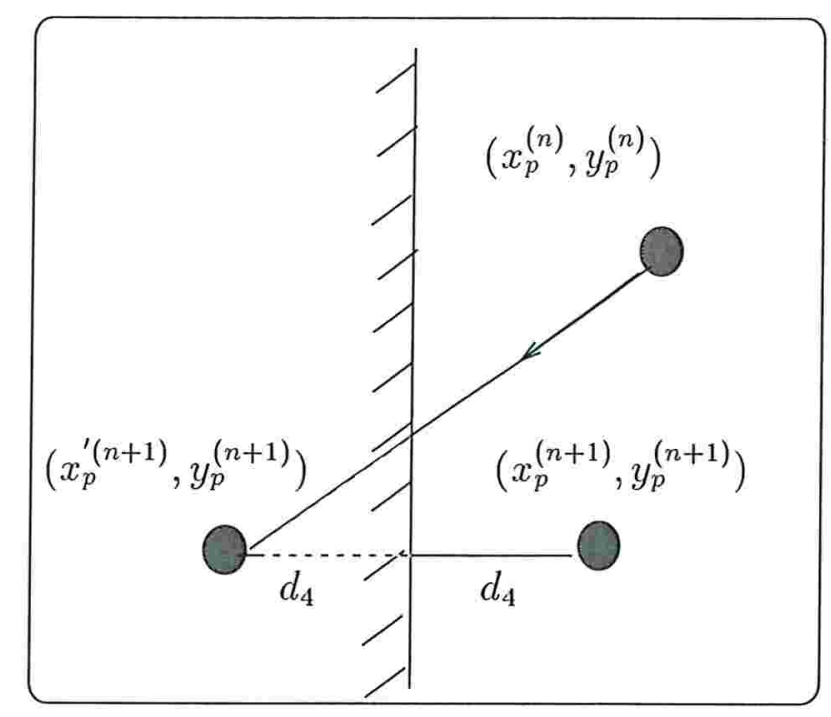

Figura 3.8: Rebatimento usado na parede $0 \leq y_{p} \leq 1$ e $x_{p}<0$.

E após os rebatimentos, tem-se:

$$
\begin{aligned}
& y_{p}^{(n+1)}=\left|y_{p}^{\prime(n+1)}\right|, \text { se } y_{p}^{\prime(n+1)}<0 . \\
& x_{p}^{(n+1)}=1,0-2,0 *\left(x_{p}^{\prime(n+1)}-1,0\right), \text { se } x_{p}^{\prime(n+1)}>1,0 . \\
& y_{p}^{(n+1)}=1,0-2,0 *\left(y_{p}^{\prime(n+1)}-1,0\right), \text { se } y_{p}^{\prime(n+1)}>1,0 . \\
& x_{p}^{(n+1)}=\left|x_{p}^{\prime(n+1)}\right|, \text { se } x_{p}^{\prime(n+1)}<0 .
\end{aligned}
$$

Em duas dimensões, para determinar o valor de u e v na posição $\left(x_{p}, y_{p}\right)$ considera-se a matriz dos valores funcionais $\mathrm{u}(\mathrm{i}, \mathrm{j})$, i e $\mathrm{j}$ variando de 1 até $\mathrm{n}$, sendo $\mathrm{n}$ o número de partições do domínio $[0,1] \times[0,1]$.

A idéia é estimar, por interpolação bilinear, a função u (componente horizontal da velocidade do fluido) para alguma partícula de coordenadas $\left(x_{p}, y_{p}\right)$.

Uma importante informação para o cálculo da trajetória é definir a célula em que a partícula $\left(x_{p}, y_{p}\right)$ se encontra e os quatro pontos que definem a célula. Por conveniência enumera-se estes pontos de 1 a 4 , no sentido anti-horário começando pelo lado esquerdo e inferior (Figura 3.9). 


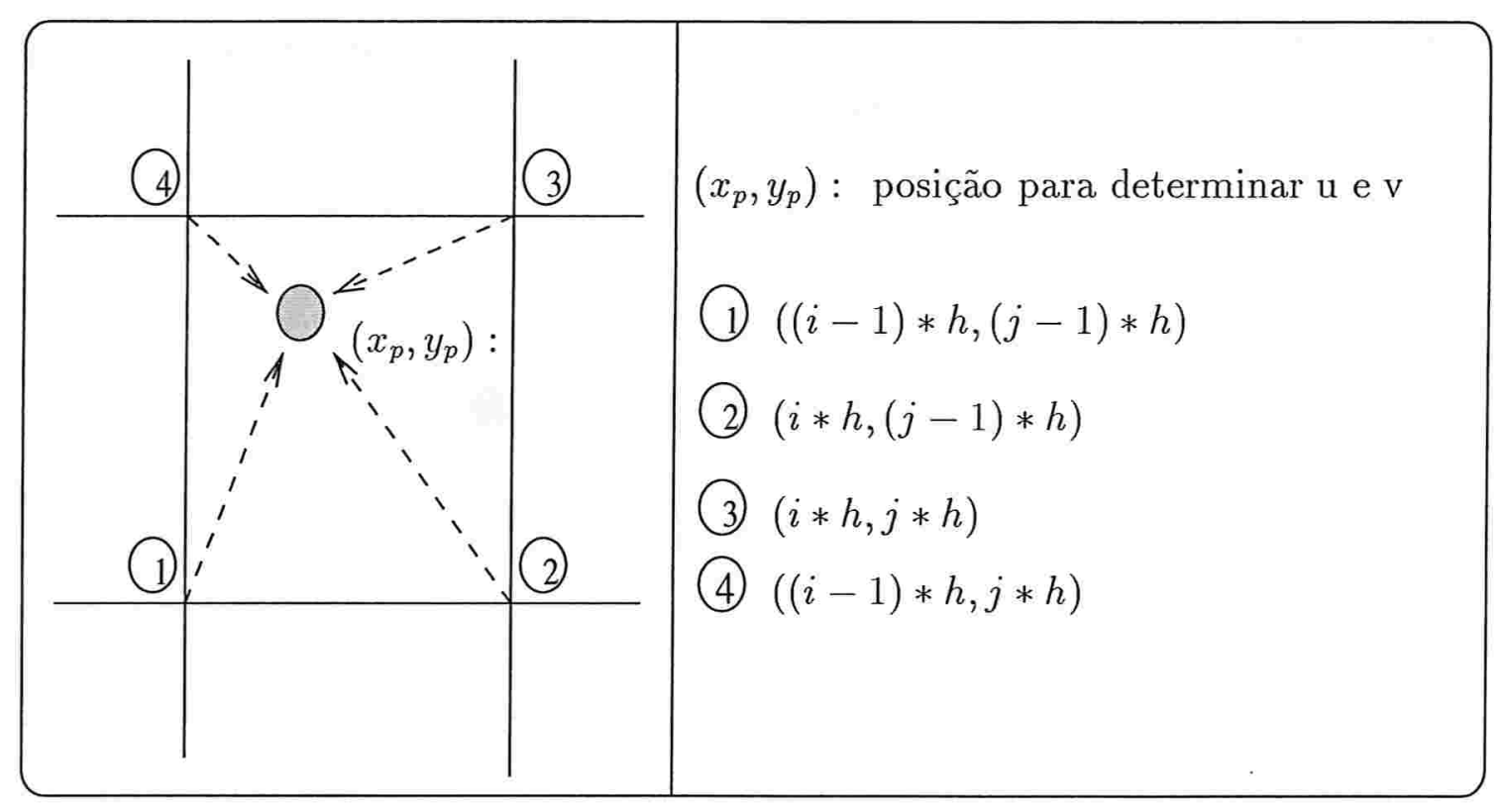

Figura 3.9: Pontos empregados em uma interpolação bilinear.

Ou seja, para $x(i-1, j) \leq x_{p} \leq x(i, j-1)$ e $y(i-1, j-1) \leq y_{p} \leq y(i, j)$, utiliza-se $u(i-1, j-1), u(i, j-1), u(i, j), u(i-1, j)$, nesta ordem; $u$ é a componente horizontal da velocidade do fluido.

A interpolação bilinear é uma das técnicas mais empregadas para determinar, em duas dimensões, o valor da velocidade na posição $\left(x_{p}, y_{p}\right)$ devido a sua simplicidade. Utiliza-se os termos auxiliares:

$$
\begin{aligned}
& \operatorname{taux} 1=\left(x_{p}-x(1)\right) /(x(2)-x(1)) \\
& \operatorname{taux} 2=\left(y_{p}-x(2)\right) /(y(3)-y(2))
\end{aligned}
$$

que variam de 0 a 1 e o valor de $\mathrm{u}$ interpolado na posição $\left(x_{p}, y_{p}\right)$ é dado por:

$$
\begin{gathered}
u=(1-\operatorname{tau} x) *(1-\operatorname{tau} 2) * u 1+\operatorname{tau} x 1 *(1-\operatorname{taux} 2) * u 2+ \\
(1-\operatorname{tau} x) * \operatorname{tau} x 2 * u 3+(1-\operatorname{taux} 1) * \operatorname{tau} x 2 * u 4
\end{gathered}
$$

com

$$
\begin{aligned}
u 1 & \equiv u(i-1, j-1) \\
u 2 & \equiv u(i, j-1) \\
u 3 & \equiv u(i, j) \\
u 4 & \equiv u(i-1, j) .
\end{aligned}
$$


3.5 Testes do Comportamento das Partículas sem Influência do Campo de Velocidades

De forma análoga obtém-se o valor de v (componente vertical da velocidade do fluido) no cálculo da trajetória da partícula.

Como os pontos obtidos na interpolação variam de célula para célula na malha a função interpoladora muda constantemente de valor, sendo calculada a cada iteração.

\subsection{Testes do Comportamento das Partículas sem In- fluência do Campo de Velocidades}

Considerando a velocidade do fluido no interior do tanque nula $(u=v=0)$, só existe a gravidade $g$, no instante inicial as partículas estão em pontos da diagonal com velocidade inicial: componente horizontal da velocidade da partícula, $u_{p}=-1,0 \mathrm{~m} / \mathrm{s}$ e componente vertical da velocidade da partícula, $v_{p}=0,0 \mathrm{~m} / \mathrm{s}$.

Assim, sem influência do campo de velocidades do fluido, apenas com a velocidade da partícula, a densidade do fluido $\left(\rho_{f}=2,0\right)$ e a densidade da partícula $\left(\rho_{p}=1,0\right)$ da Tabela 3.1, tem-se uma análise do comportamento das partículas, partindo da diagonal, cada quadro na Figura 3.11 representa uma partícula e sua trajetória, utilizando o Método de Euler.

\begin{tabular}{|c|c|c|c|c|c|c|c|}
\hline$p t$ & $x_{p}(p t)=y_{p}(p t)$ & $r(p t)$ & $\Delta_{p}(p t)$ & $u_{p}(p t)$ & $v_{p}(p t)$ & $\rho_{p} / \rho_{f}$ & Figura \\
\hline $1 \leq p t \leq 9$ & $0,1 * p t$ & 1,0 & 0,01 & $-1,0$ & 0,0 & $1 / 2$ & 4.10 \\
\hline $1 \leq p t \leq 9$ & $0,1 * p t$ & 1,0 & 0,01 & $-1,0$ & 0,0 & $2 / 1$ & 4.11 \\
\hline
\end{tabular}

Tabela 3.1: Comportamento das partículas na cavidade sem influência do fluido: pt é o índice da partícula, $x_{p}$ e $y_{p}$ são as coordenadas de cada partícula pt, r é o raio, $u_{p}$ e $v_{p}$ são as componentes horizontal e vertical da velocidade, $\rho_{p}$ e $\rho_{f}$ as densidades da partícula e do fluido.

Os testes foram realizados para uma constante de elasticidade $(\epsilon)$ igual a 1 e como era de se esperar, devido a densidade, as partículas percorrem a trajetória sedimentando ou indo para a parte superior do tanque. Pela condição imposta de $\epsilon=1,0$ (parede rígida) a energia das partículas não decai após sucessivas colisões com as paredes, Figura 3.10 e 3.11 respectivamente. 

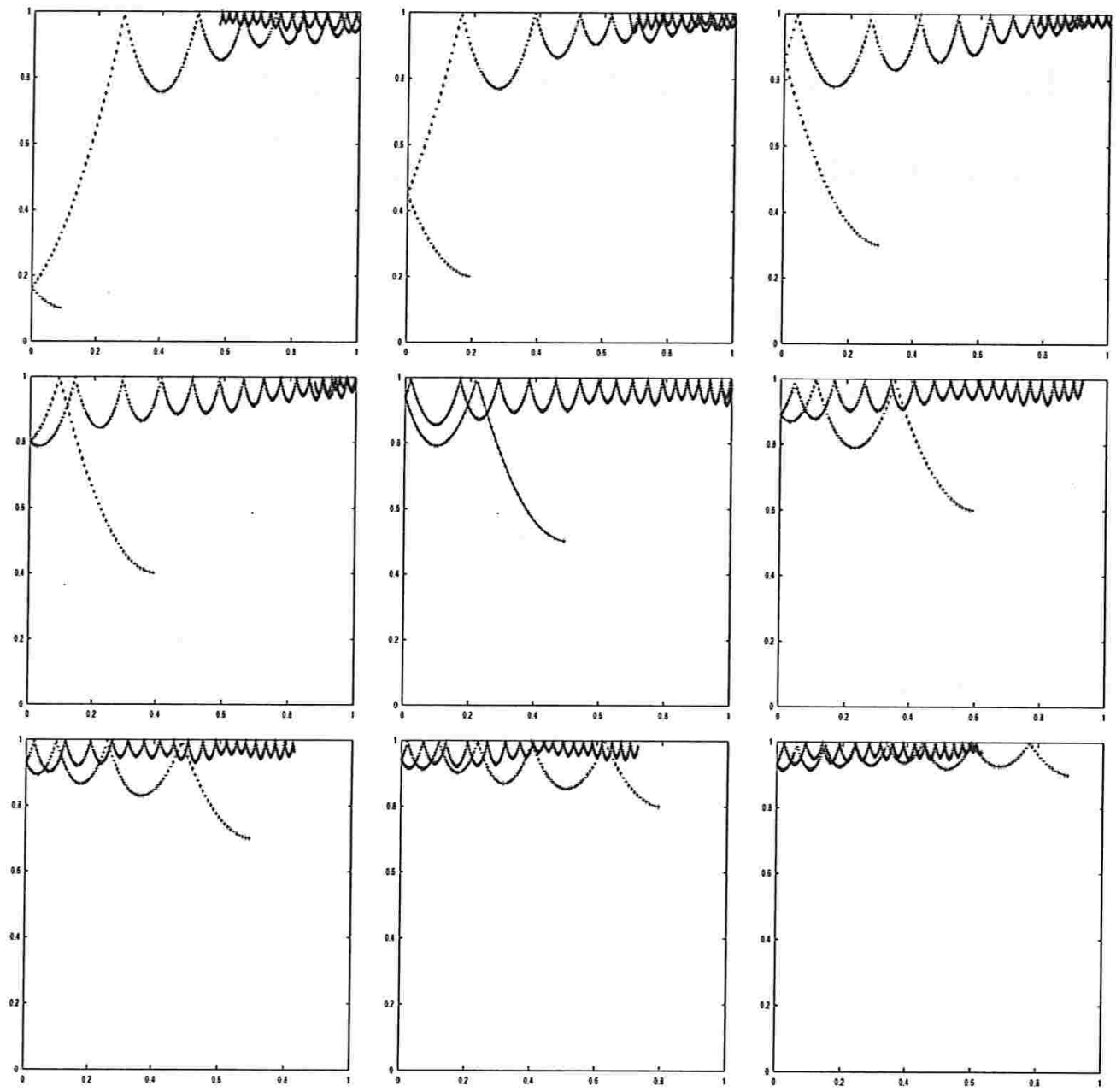

Figura 3.10: Comportamento das partículas que partem da diagonal, utilizando o método de Euler e os dados da Tabela $3.1\left(\rho_{p} / \rho_{f}=1 / 2\right)$. 

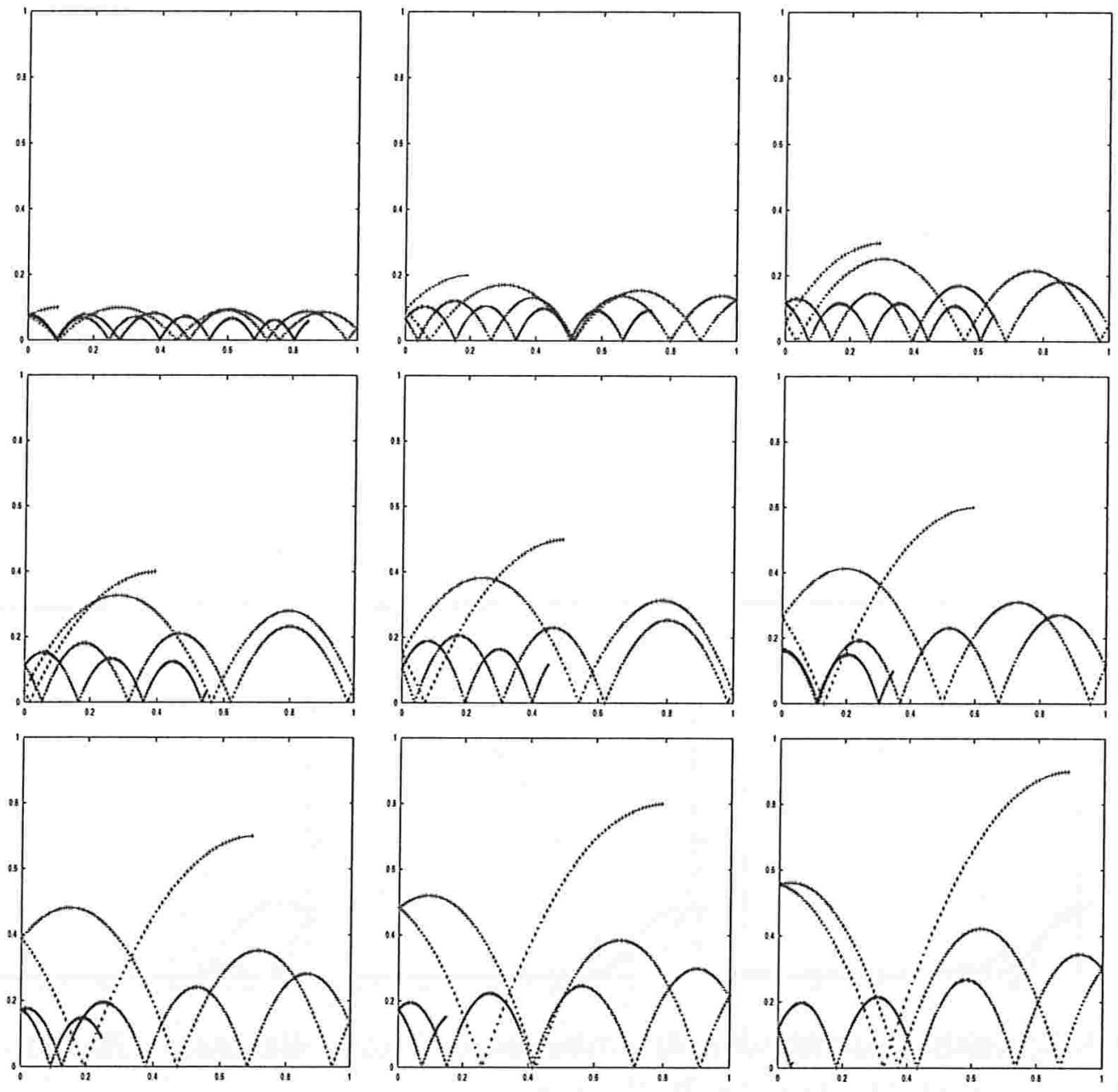

Figura 3.11: Comportamento das partículas que partem da diagonal, utilizando o método de Euler e os dados da Tabela $3.1\left(\rho_{p} / \rho_{f}=2 / 1\right)$. 
Os testes a seguir foram feitos para as partículas da Tabela $3.1, \rho_{p} / \rho_{f}=2 / 1$, utilizando para a constante de elasticidade, $\epsilon=0,3$ e $\epsilon=0,6$, com o objetivo de mostrar a variação no comportamento da trajetória em relação à Figura $3.11(\epsilon=1,0)$.
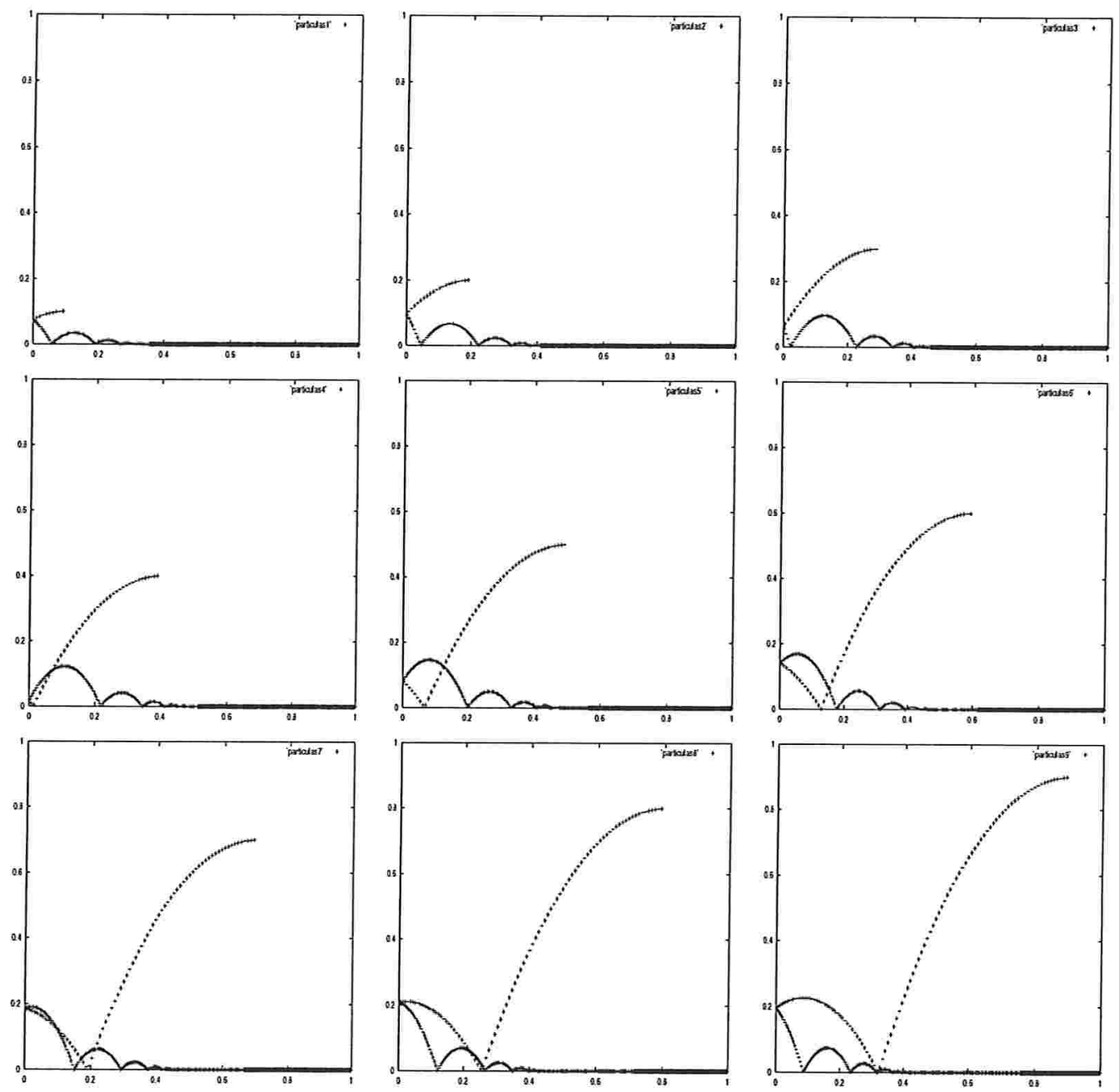

Figura 3.12: Comportamento das partículas que partem da diagonal, utilizando o método de Euler e constante de elasticidade $\epsilon=0,6$.

Neste teste observa-se que há a perda de energia das partículas devido a ação da gravidade e influência da posição de lançamento das mesmas no tanque. 

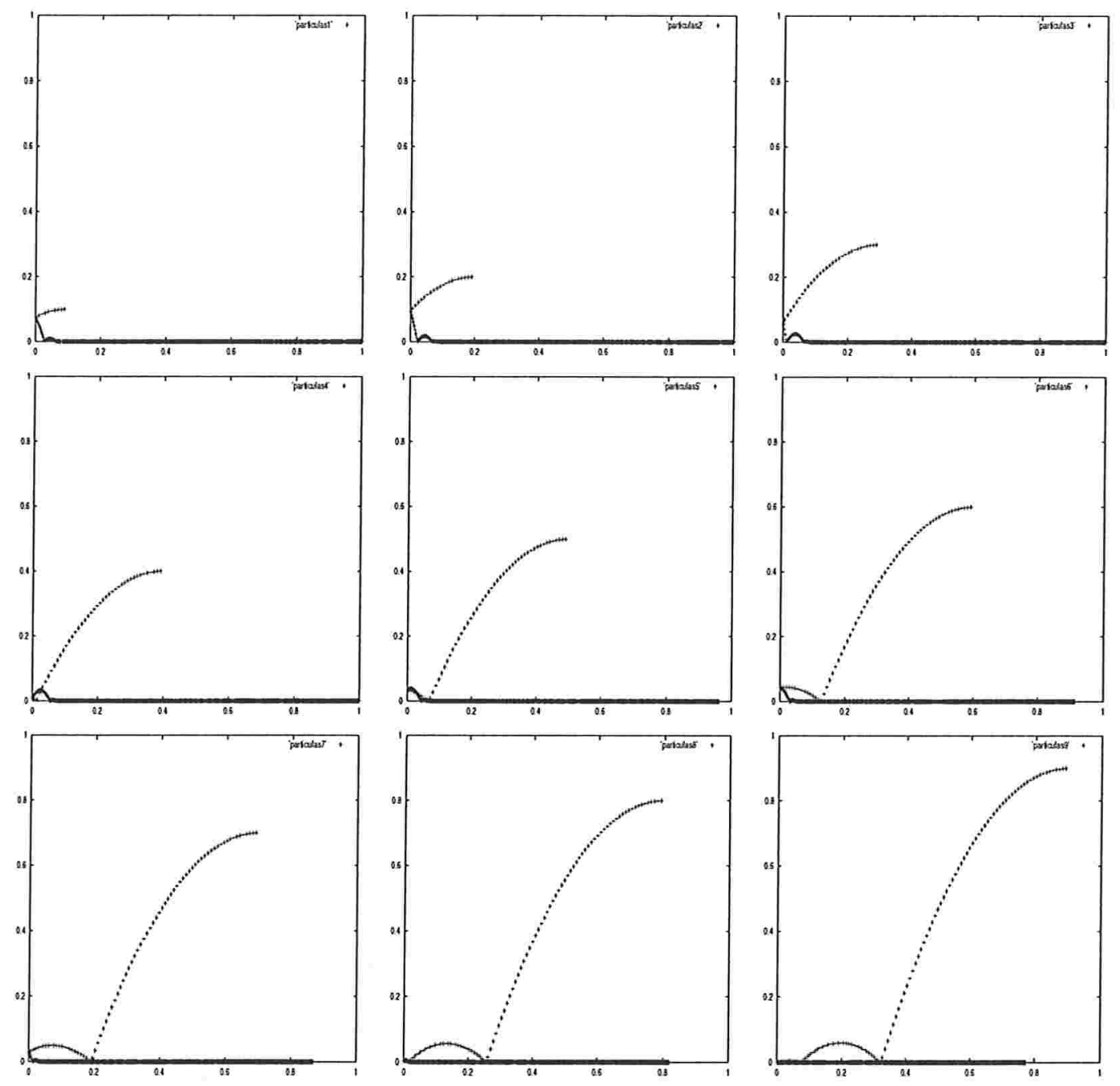

Figura 3.13: Comportamento das partículas que partem da diagonal, utilizando o método de Euler e constante de elasticidade $\epsilon=0,3$. 
Como no teste da Figura 3.12, na Figura 3.13 verifica-se uma perda de energia a cada colisão com a parede, desta vez mais significativas em relação a $\epsilon=0,6$ e $\epsilon=1,0$ (parede rígida) como era de se esperar.

Com os testes realizados com os métodos de Euler, Euler Modificado e Runge-Kutta, observou-se ser o último mais indicado para a realização de um conjunto de testes para analisar a influência do fluido, sentido do impelidor, densidade da partícula e do fluido, além da variação das componentes da velocidade da partícula, pois o mesmo permite o uso de um passo maior no tempo (no caso das simulações permitiu utilizar $\Delta t=10^{-3}$ para o mesmo caso testado com o Método de Euler $\Delta t=10^{-4}$ ). 


\section{Simulações para Suspensão de Partículas}

A suspensão de sólidos em um tanque com agitação é de grande aplicação nas indústrias em processos como em dissolução, polimerização, cristalização e precipitação. Neste capítulo será abordada a definição do estado de suspensão, sua importância e alguns dos testes feitos para a análise da suspensão no modelo adotado em regime laminar, variando a posição do impelidor, o número de impelidores, a relação D/T (D: comprimento do impelidor e T: diâmetro interno do tanque) e da função que define o disco-atuador que representa o impelidor.

\subsection{Definição do estado de suspensão}

Os dois estados de suspensão e distribuição de sólidos mais utilizados são:

- mínima suspensão completa;

- suspensão homogênea.

Na mínima suspensão completa nenhuma partícula permanece na base do tanque por um período superior a 1 ou 2 segundos, assim a superfície de todas as partículas está em contato com o fluido e conseqüentemente exposta à reação química e ao transporte de massa e energia.

O principal parâmetro envolvido é a velocidade mínima de agitação $\left(N_{J S}\right)$ que é uma 
das propriedades do fluido e do sólido, função da geometria do tanque e do impelidor e teve uma primeira correlação descrita por Zwietering (1958).

Obtida através de análise dimensional e levantamento de dados de laboratório [15], a correlação de Zwietering é dada por:

$$
N_{J S}=\frac{S \nu^{0,1} d_{p}^{0,2}\left(g \frac{\Delta \rho}{\rho_{L}}\right)^{0,45} X^{0,13}}{D^{0,85}}
$$

onde

$N_{J S}$ : velocidade mínima de agitação

$S$ : número adimensional que leva em conta o efeito da geometria

$\nu$ : viscosidade cinemática $\left(\mathrm{m}^{2} / \mathrm{s}\right)$

$\Delta \rho$ : diferença entre a densidade do sólido e do fluido líquido $\left(\mathrm{kg} / \mathrm{m}^{3}\right)$

$\rho L$ : densidade do líquido $\left(\mathrm{kg} / \mathrm{m}^{3}\right)$

$g$ : constante gravitacional $\left(9,81 \mathrm{~m} / \mathrm{s}^{2}\right)$

$X$ : massa de sólidos/massa de líquidos (adimensional)

$D$ : diâmetro do impelidor $(m)$

A velocidade mínima de rotação pouco depende da viscosidade, da concentração de sólidos e do diâmetro da partícula. A densidade do sólido e do líquido tem um peso maior sendo que o diâmetro do impelidor e o número adimensional tem uma maior importância na mínima suspensão completa, com isso, é necessário verificar tais parâmetros para possibilitar o cálculo de $N_{J S}$.

A suspensão é dita completa quando a velocidade de rotação é superior a $N_{J S}$. Segundo alguns pesquisadores, na distribuição axial a concentração de sólidos geralmente atinge o seu máximo em um ponto situado um pouco acima do impelidor.

A distribuição de partículas sólidas em um tanque agitado é uma função complexa e, do ponto de vista teórico, não foi resolvida satisfatoriamente, assim os critérios sugeridos foram feitos a partir de ensaios em laboratórios. Em [15] é citada uma das sugestões para obtenção da distribuição de sólidos nos tanques fornecida por Magelli (1990):

$$
\frac{\phi_{(z)}}{\phi_{(m)}}=\left[\frac{P e}{1-e^{-P e}}\right] e^{-P e^{(z / H)}}
$$




$$
P e=330\left(\frac{N D}{U_{t}}\right)^{-1,17}\left(\frac{\epsilon d_{p}^{4}}{\nu^{3}}\right)^{-0,095}
$$

onde

$\phi_{z}$ : concentração do sólido em um ponto

$\phi_{m}$ : concentração média do sólido no tanque

Pe: número de Peclet

D: diâmetro do impelidor

$\mathrm{N}$ : velocidade do impelidor

$U_{t}$ : velocidade terminal da partícula

$\epsilon$ : média da potência por unidade de massa

$d_{p}$ : tamanho da partícula sólida

$\nu$ : viscosidade cinemática do líquido

A suspensão homogênea é o tipo de suspensão em que as partículas estão suspensas uniformemente em todo o volume do tanque. O parâmetro utilizado para calcular a homogeneidade é:

$$
\sigma=\sqrt{\frac{1}{n} \sum_{1}^{n}\left(\frac{C}{C_{a v}}-1\right)^{2}}
$$

onde:

$\sigma$ : qualidade da suspensão

$C$ : concentração volumétrica local $\left(\mathrm{m}^{3} / \mathrm{m}^{3}\right)$

$C_{a v}$ : concentração volumétrica média $\left(\mathrm{m}^{3} / \mathrm{m}^{3}\right)$

Tais parâmetros podem ser determinados nas simulações a serem realizadas, porém não será feita esta abordagem nos testes a serem realizados.

\subsection{Simulações}

Uma das maneiras de calcular a qualidade da suspensão é o uso da CFD, uma vez que a concentração dos sólidos em cada ponto é conhecida. Assim, na seqüência são apresentadas as simulações para algumas funções que representam o impelidor, a fim de analisar o comportamento das partículas esféricas em sua trajetória. No instante inicial, cada partícula de diâmetro $d_{p}=10 \mu \mathrm{m}, 50 \mu \mathrm{m}$ e $100 \mu \mathrm{m}\left(1 \mu \mathrm{m}=10^{-6} \mathrm{~m}\right)$, está em uma célula da malha de discretização e partem do repouso (velocidade inicial zero), havendo uma 
influência do fluido na trajetória da partícla mas não há uma influência da partícula na velocidade do fluido, para isto há a necessidade de uma formulação transiente. Os gráficos são plotados a $0 \%, 20 \%, 30 \%, 50 \%, 75 \%$ e $100 \%$ do tempo total (10s), estas frações do tempo possibilitam uma boa visualização da distribuição das partículas ao longo da tajetória. Para a densidade da partícula $(\rho)$, optou-se pela resina $\left(\rho_{\text {resina }}=1370 \mathrm{~kg} / \mathrm{m}^{3}\right)$ e para o fluido a densidade da água $\left(\rho_{\text {fluido }}=1000 \mathrm{~kg} / \mathrm{m}^{3}\right)$, ainda $C_{D}=0,44$ para o coeficiente de arrasto que será constante para os testes a serem realizados, considerando que $R e_{p}$ varia entre 500 e 100000 .

O tanque é cilíndrico e possui $2 \mathrm{~m}$ de diâmetro por $1 \mathrm{~m}$ de altura, com o eixo no centro. Para as simulações numéricas utilizou-se a região destacada na Figura 2.10 (Cap.2, Seção 2.5 ), malha $n \times n, \mathrm{n}=64$ e $h=\frac{1}{\Delta r}=\frac{1}{\Delta z}=\frac{1}{n}$, com variação do diâmetro do impelidor (D) em função do diâmetro interno do tanque $(\mathrm{T}), \mathrm{D} / \mathrm{T}=1 / 2$ e $\mathrm{D} / \mathrm{T}=3 / 4$, além do número de impelidores e a posição dos mesmos.

Para cada teste realizado foi construída uma tabela compactando a malha $n \times n$. São 4096 células e cada uma contém uma partícula no início da simulação e ao final da mesma cada bloco contendo 64 células foi reduzido em uma célula na malha compactada $(8 \times 8)$ para facilitar a contagem das partículas. Para uma melhor visualização do número de partículas suspensas optou-se em utilizar como critério o espaço percorrido pelas mesmas ao longo da trajetória, considerando-se que sedimentam as partículas que percorreram um menor espaço e as que têm influência do vórtice formado pelo movimento do fluido no tanque em que estão suspensas.

Os primeiros testes foram realizados nas Estações de Trabalho do IME-USP (Instituto de Matemática e Estatística da Universidade de São Paulo), nas máquinas fradim - Sun Ultra 250, jaca - Sun Enterprise 3000 e rebutosa - Sun SparcServer 1000. Devido ao grande número de testes a serem realizados e por se ter um custo de tempo alto em tais máquinas, optou-se em realizar os demais testes no LCCA-CCE (Laboratório de Computação Científica Avançada do Centro de Computação Eletrônica) da USP, cujo sistema operacional é o AIX Operating System - AIX Version 4.1 e as características na máquina utilizada, DEC Alpha 4100 - lince.lcca.usp.br, com 4 processadores de $466 \mathrm{MHz}$, 2 GB de memória, 98 GB de área em disco, 2,3 Gflops, que possibilitou um ganho de tempo para simulações em uma malha mais refinada, reduzindo o tempo em até 4 vezes em relação às demais máquinas. 


\subsubsection{Simulações para $\mathrm{C} / \mathrm{T}=1 / 2, \mathrm{D} / \mathrm{T}=1 / 2$ e $\mathrm{D} / \mathrm{T}=3 / 4$}

O impelidor está localizado a $0,5 \mathrm{~m}$ do fundo do tanque $(C / T=1 / 2)$ e a função que o representa é $f(r)=-0,5 * r$. A Figura 4.1, X-Axis: eixo $\mathrm{r}$ e Y-Axis: eixo $z$, mostra o campo de velocidade do fluido obtido para a relação $D / T=1 / 2$, ou seja $D=1 \mathrm{~m}$ e $T=2 m$, na região $r \times z,[0,1] \times[0,1]$.

Mon Nov 5 14:34:54 2001

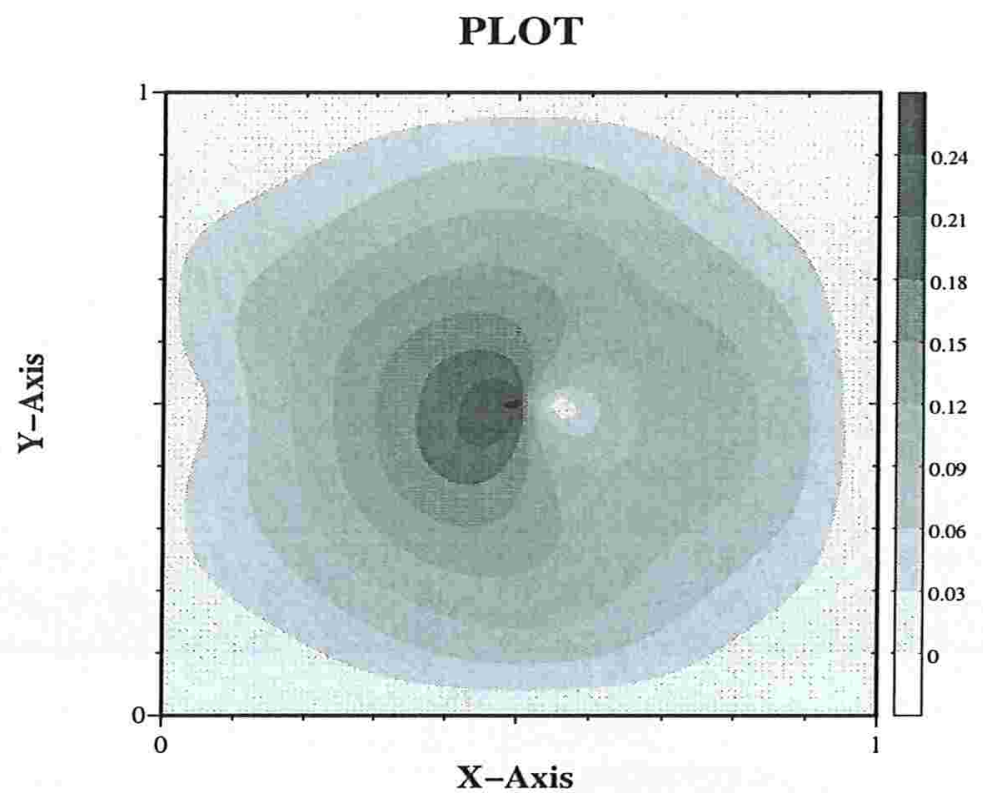

Figura 4.1: Representação do campo de velocidade no tanque, região $[0,1] \times[0,1]$, malha $64 \times 64$, utilizando um disco-atuador definido por $f(r)=-0,5 * r, C / T=1 / 2$ e $D / T=$ $1 / 2$.

A velocidade máxima obtida $\left|v_{\text {fluidomax }}\right|=0,24 \mathrm{~m} / \mathrm{s}$ e na Figura 4.2, que será considerada a "simulação-padrão", referencial para as demais simulações, são apresentadas as posição das partículas ao longo da simulação. 

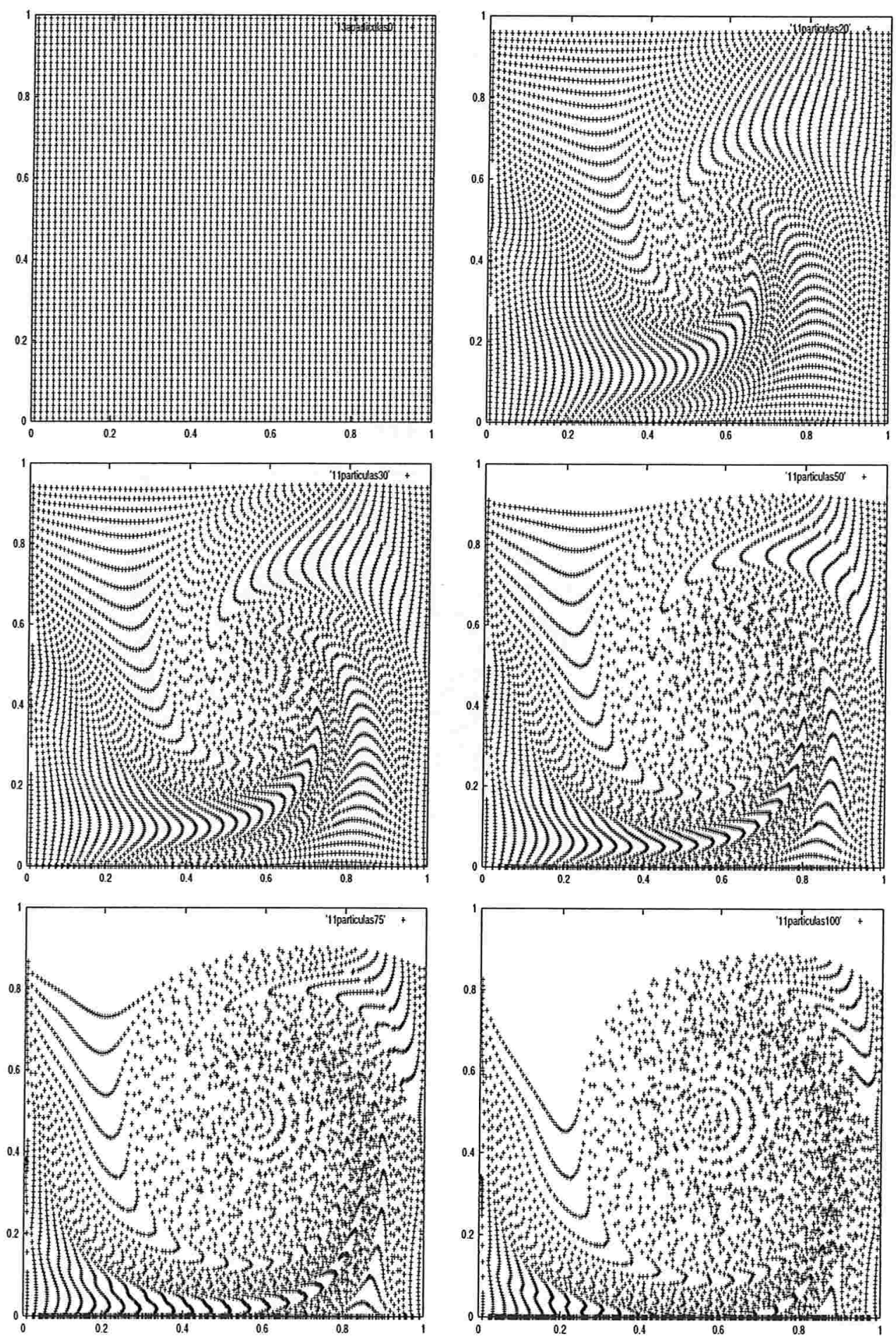

Figura 4.2: Posições das partículas $\left(d_{p}=100 \mu \mathrm{m}\right)$, ao longo da trajetória (10s), plotadas a 0 s, $2 \mathrm{~s}, 3 \mathrm{~s}, 5 \mathrm{~s}, 7,5 \mathrm{~s}$ e $10 \mathrm{~s}: C / T=1 / 2, D / T=1 / 2$ e $f(r)=-0,5 * r$. 
A Figura 4.3 é o gráfico do espaço percorrido por estas partículas $\left(d_{p}=100 \mu \mathrm{m}\right)$ durante os 10 s da simulação.

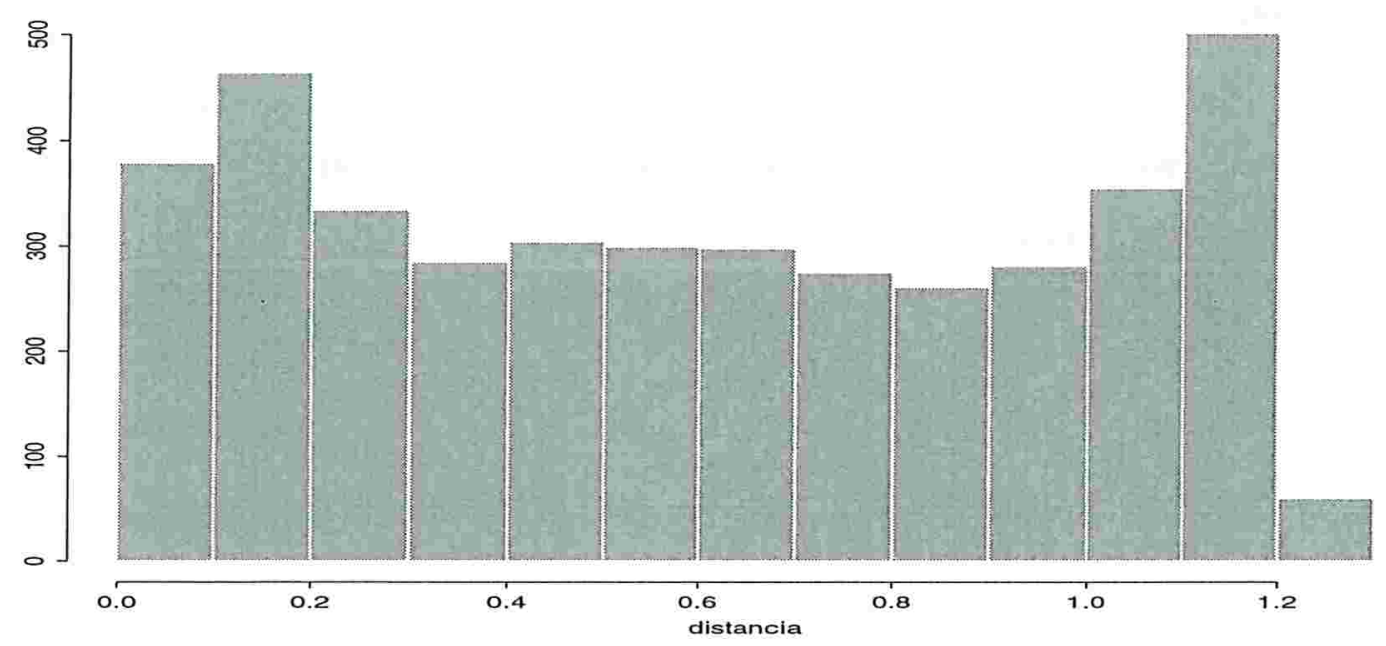

Figura 4.3: distância percorrida $\times$ número de partículas: representação do espaço percorrido pelas 4096 partículas $\left(d_{p}=100 \mu \mathrm{m}\right)$ ao longo da trajetória (tempo de simulação: 10s), $C / T=1 / 2, D / T=1 / 2$ e disco-atuador representado por $f(r)=-0,5 * r$.

E a Tabela 4.1 representa o número de partículas por célula, na malha compacta, no instante final da simulação.

\begin{tabular}{|c|c|c|c|c|c|c|c|c|}
\hline $\mathrm{j} \downarrow \mathbf{i} \rightarrow$ & $\mathbf{1}$ & $\mathbf{2}$ & $\mathbf{3}$ & $\mathbf{4}$ & $\mathbf{5}$ & $\mathbf{6}$ & $\mathbf{7}$ & $\mathbf{8}$ \\
\hline $\mathbf{1}$ & 0 & 0 & 0 & 0 & 0 & 0 & 0 & 0 \\
\hline $\mathbf{2}$ & 0 & 0 & 0 & 0 & 11 & 22 & 19 & 0 \\
\hline $\mathbf{3}$ & 2 & 0 & 0 & 18 & 44 & 72 & 64 & 39 \\
\hline $\mathbf{4}$ & 7 & 0 & 0 & 36 & 51 & 55 & 80 & 57 \\
\hline $\mathbf{5}$ & 17 & 0 & 3 & 38 & 38 & 62 & 70 & 91 \\
\hline $\mathbf{6}$ & 37 & 0 & 0 & 40 & 45 & 61 & 67 & 76 \\
\hline $\mathbf{7}$ & 66 & 25 & 0 & 18 & 50 & 53 & 72 & 88 \\
\hline $\mathbf{8}$ & 289 & 325 & 324 & 311 & 321 & 333 & 338 & 261 \\
\hline
\end{tabular}

Tabela 4.1: Número de partículas $\left(d_{p}=100 \mu \mathrm{m}\right)$ por célula no instante final $(10 \mathrm{~s}), C / T=$ $1 / 2, D / T=1 / 2$ e disco-atuador: $f(r)=-0,5 * r$. 
Nesta simulação observa-se que na região onde há uma menor velocidade do fluido as partículas tendem a se sedimentarem e pela Figura 4.3 tem-se que o número de partículas sedimentadas é de aproximadamente $25 \%$ do total, considerando que as partículas que precipitam são aquela que percorreram uma menor distância.

Para analisar a influência do tamanho da partícula na suspensão das mesmas, foram feitas simulações no mesmo campo de velocidades com partículas de $d_{p}=10 \mu m$ (Figura 4.4) e de $d_{p}=50 \mu m$ (Figura 4.5). 

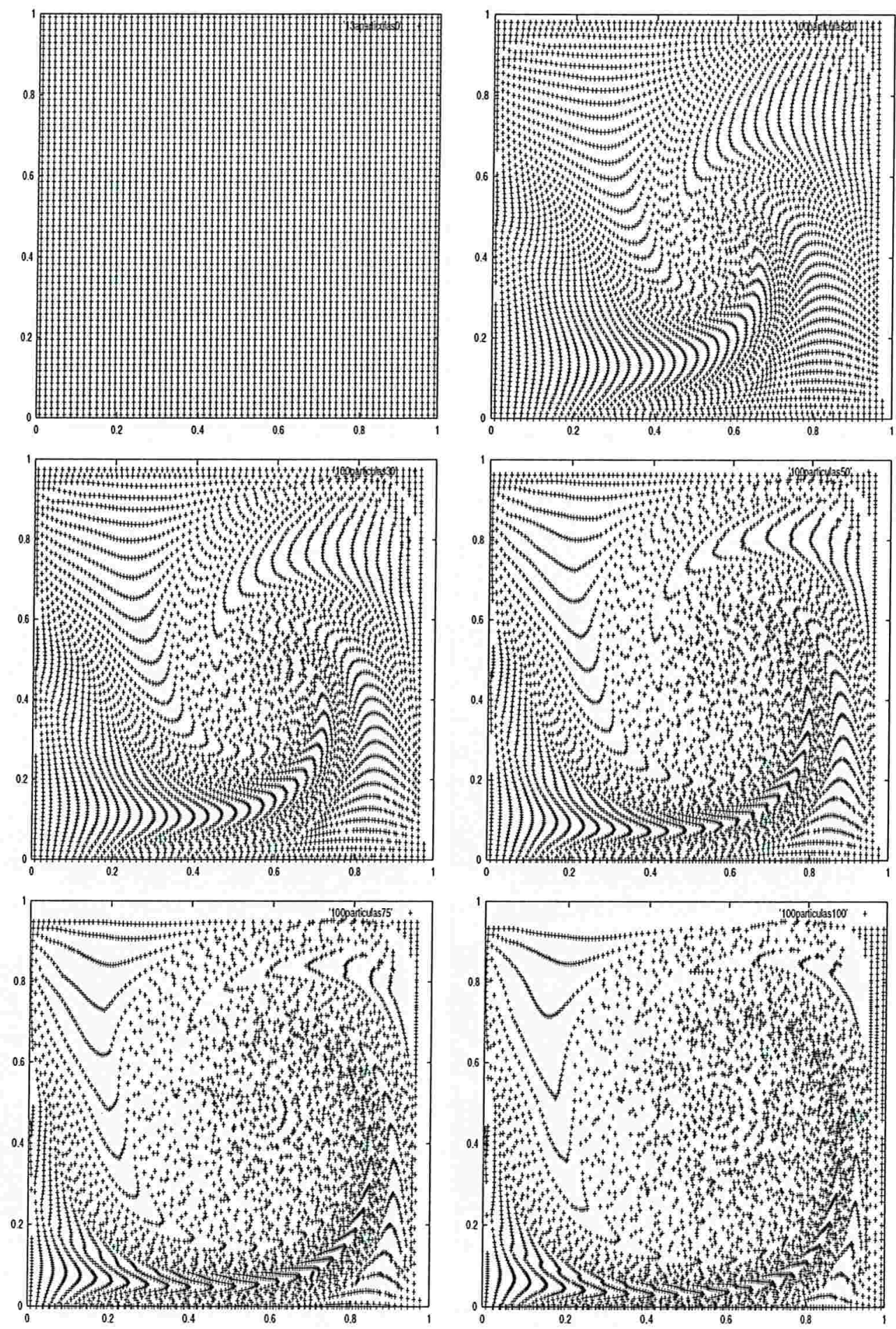

Figura 4.4: Posições das partículas $\left(d_{p}=10 \mu \mathrm{m}\right)$ ao longo da trajetória (10s), plotadas a 0s, 2s, 3s, 5s, 7,5s e 10s: $C / T=1 / 2, D / T=1 / 2$ e $f(r)=-0,5 * r$. 

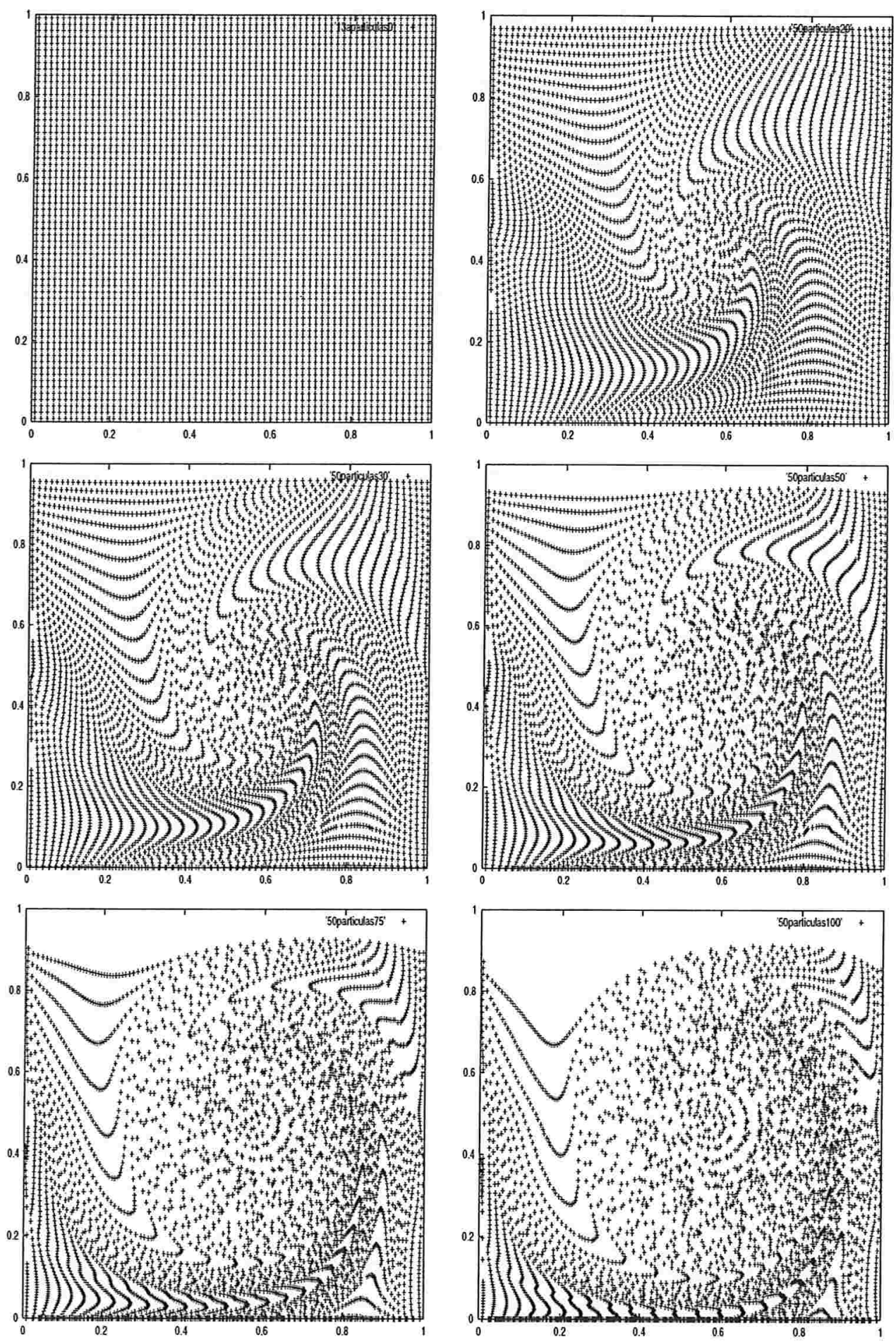

Figura 4.5: Posições das partículas $\left(d_{p}=50 \mu \mathrm{m}\right)$ ao longo da trajetória (10s), plotadas a 0s, $2 \mathrm{~s}, 3 \mathrm{~s}, 5 \mathrm{~s}, 7,5 \mathrm{~s}$ e $10 \mathrm{~s}: C / T=1 / 2, D / T=1 / 2$ e $f(r)=-0,5 * r$. 
Na Figura 4.6 tem-se o gráfico do número de partículas $\left(d_{p}=10 \mu \mathrm{m}\right)$ pelo espaço percorrido durante a simulação.

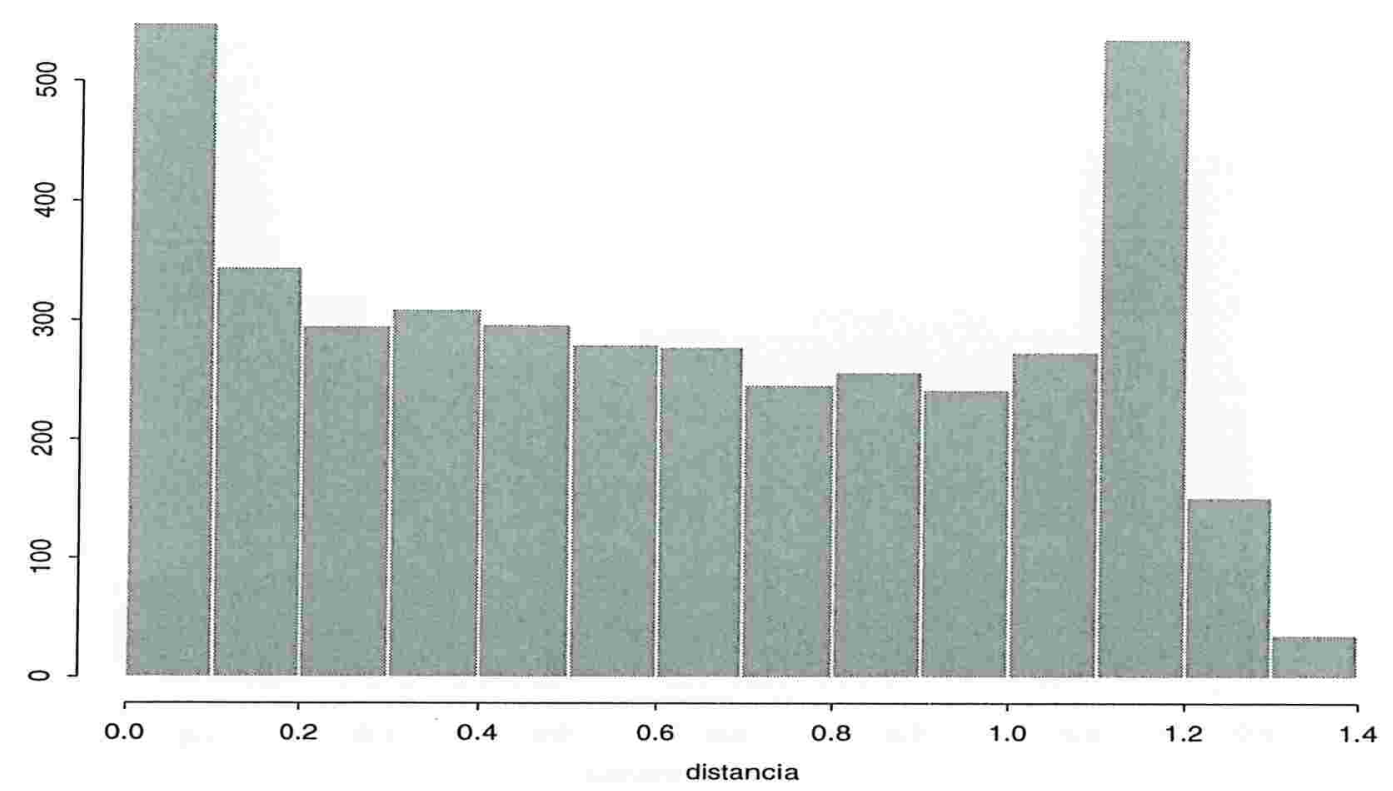

Figura 4.6: distância percorrida $\times$ número de partículas: representação do espaço percorrido pelas 4096 partículas $\left(d_{p}=10 \mu \mathrm{m}\right)$ ao longo da trajetória (tempo de simulação: 10s), $C / T=1 / 2, D / T=1 / 2$ e disco-atuador representado por $f(r)=-0,5 * r$. 
E a Figura 4.7 é o gráfico do espaço percorrido pelas 4096 partículas $\left(d_{p}=50 \mu \mathrm{m}\right)$ durante os 10 s da simulação.

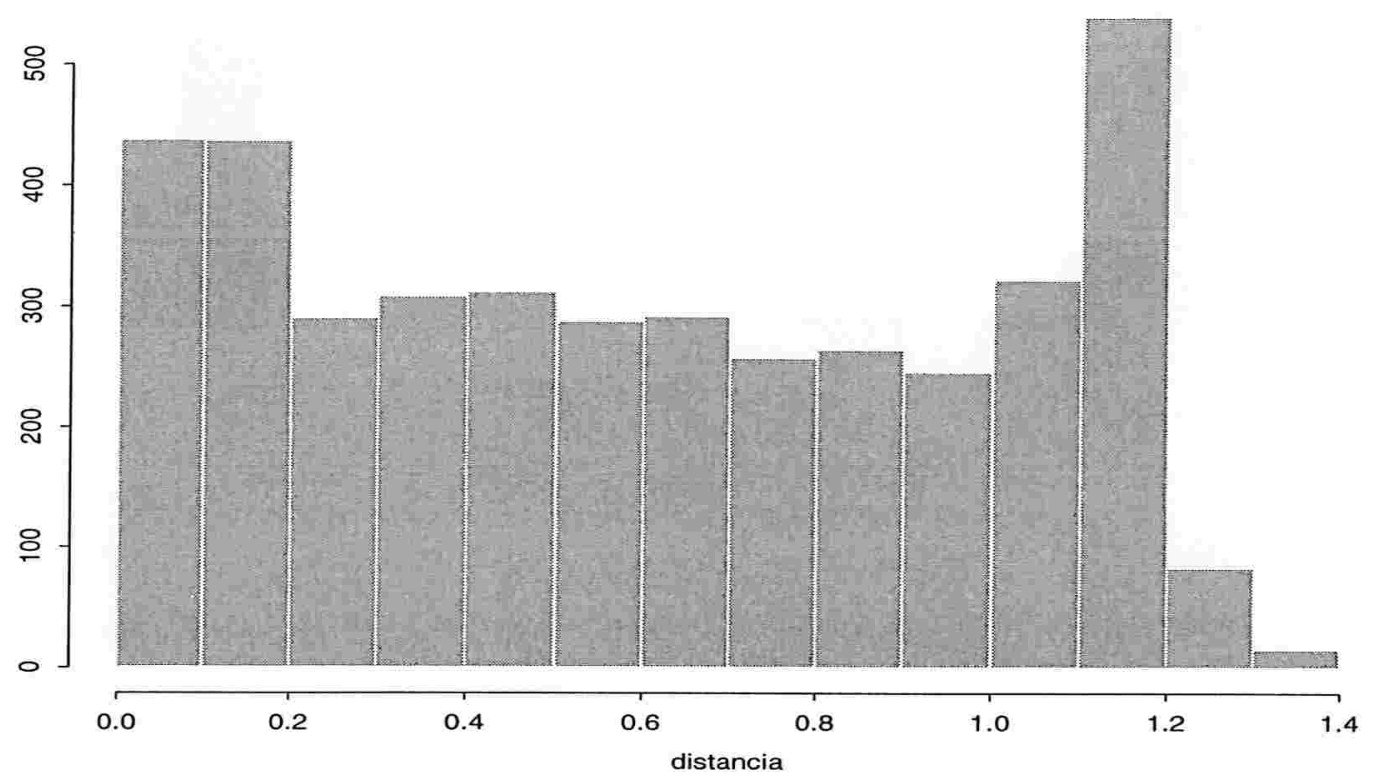

Figura 4.7: distância percorrida $\times$ número de partículas: representação do espaço percorrido pelas 4096 partículas $\left(d_{p}=50 \mu \mathrm{m}\right)$ ao longo da trajetória (tempo de simulação: 10s), $C / T=1 / 2, D / T=1 / 2$ e disco-atuador representado por $f(r)=-0,5 * r$. 
A Tabela 4.2 é a distribuição compacta das partículas $\left(d_{p}=10 \mu m\right)$ ao final da simulação.

\begin{tabular}{|c|c|c|c|c|c|c|c|c|}
\hline $\mathrm{j} \downarrow \mathbf{i} \rightarrow$ & $\mathbf{1}$ & $\mathbf{2}$ & $\mathbf{3}$ & $\mathbf{4}$ & $\mathbf{5}$ & $\mathbf{6}$ & $\mathbf{7}$ & $\mathbf{8}$ \\
\hline $\mathbf{1}$ & 30 & 15 & 16 & 20 & 25 & 36 & 35 & 46 \\
\hline $\mathbf{2}$ & 33 & 25 & 30 & 38 & 39 & 60 & 57 & 62 \\
\hline $\mathbf{3}$ & 35 & 25 & 27 & 44 & 68 & 82 & 89 & 58 \\
\hline $\mathbf{4}$ & 32 & 26 & 24 & 42 & 61 & 68 & 111 & 69 \\
\hline $\mathbf{5}$ & 56 & 21 & 29 & 53 & 65 & 68 & 101 & 96 \\
\hline $\mathbf{6}$ & 55 & 30 & 22 & 45 & 61 & 65 & 101 & 73 \\
\hline $\mathbf{7}$ & 70 & 60 & 38 & 38 & 48 & 73 & 138 & 65 \\
\hline $\mathbf{8}$ & 132 & 158 & 157 & 162 & 171 & 179 & 149 & 89 \\
\hline
\end{tabular}

Tabela 4.2: Número de partículas $\left(d_{p}=10 \mu \mathrm{m}\right)$ por célula no instante final $(10 \mathrm{~s}), C / T=$ $1 / 2, D / T=1 / 2$ e $f(r)=-0,5 * r$.

Na Tabela 4.3 tem-se a distribuição compacta das partículas $\left(d_{p}=50 \mu \mathrm{m}\right)$, após $10 \mathrm{~s}$.

\begin{tabular}{|c|c|c|c|c|c|c|c|c|}
\hline $\mathbf{j} \downarrow \mathbf{i} \rightarrow$ & $\mathbf{1}$ & $\mathbf{2}$ & $\mathbf{3}$ & $\mathbf{4}$ & $\mathbf{5}$ & $\mathbf{6}$ & $\mathbf{7}$ & $\mathbf{8}$ \\
\hline $\mathbf{1}$ & 0 & 0 & 0 & 1 & 11 & 17 & 18 & 7 \\
\hline $\mathbf{2}$ & 24 & 0 & 16 & 31 & 43 & 56 & 62 & 64 \\
\hline $\mathbf{3}$ & 37 & 25 & 23 & 45 & 58 & 85 & 79 & 64 \\
\hline $\mathbf{4}$ & 39 & 24 & 24 & 46 & 58 & 63 & 101 & 70 \\
\hline $\mathbf{5}$ & 49 & 29 & 27 & 41 & 58 & 64 & 81 & 89 \\
\hline $\mathbf{6}$ & 58 & 31 & 24 & 43 & 63 & 68 & 90 & 85 \\
\hline $\mathbf{7}$ & 66 & 50 & 41 & 37 & 45 & 63 & 124 & 76 \\
\hline $\mathbf{8}$ & 163 & 197 & 197 & 211 & 203 & 210 & 195 & 127 \\
\hline
\end{tabular}

Tabela 4.3: Número de partículas $\left(d_{p}=50 \mu \mathrm{m}\right)$ por célula no instante final $(10 \mathrm{~s}), C / T=$ $1 / 2, D / T=1 / 2$ e $f(r)=-0,5 * r$.

Pelos gráficos e pelas tabelas observa-se que um número maior de partículas percorreram uma distância menor e pelo critério adotado, pode-se dizer que mais partículas tendem a se sedimentarem. 
Comparando com o teste realizado na simulação da Figura 4.1, pode ser afirmado que o tamanho da partícula influencia na qualidade da suspensão e mais ainda, devido a ação da gravidade, as partículas de menor diâmetro $\left(d_{p}=10 \mu \mathrm{m}\right)$ apresentam um maior número de partículas suspensas em relação às partículas de maior diâmetro $\left(d_{p}=100 \mu m\right)$. 
A Figura 4.8 representa o campo de velocidade do fluido para a relação $D / T=3 / 4$ e $C / T=1 / 2$, na região $r \times z,[0,1] \times[0,1]$.

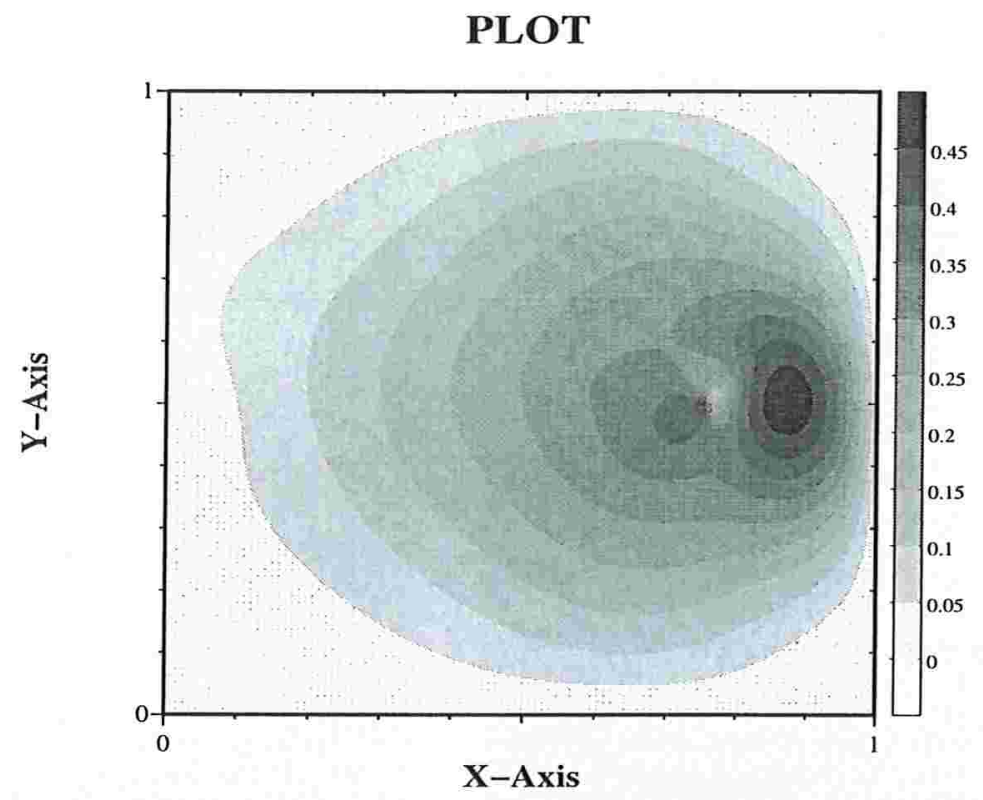

Figura 4.8: Representação do campo de velocidades no tanque, região $[0,1] \times[0,1]$, malha $64 \times 64$, utilizando um disco-atuador definido por $f(r)=-0,5 * r, C / T=1 / 2$ e $D / T=$ $3 / 4$.

A velocidade máxima obtida $\left|v_{\text {fluidomax }_{\text {max }}}\right|=0,45 \mathrm{~m} / \mathrm{s}$ e na Figura 4.9 são apresentadas as posição das partículas ao longo da simulação. 

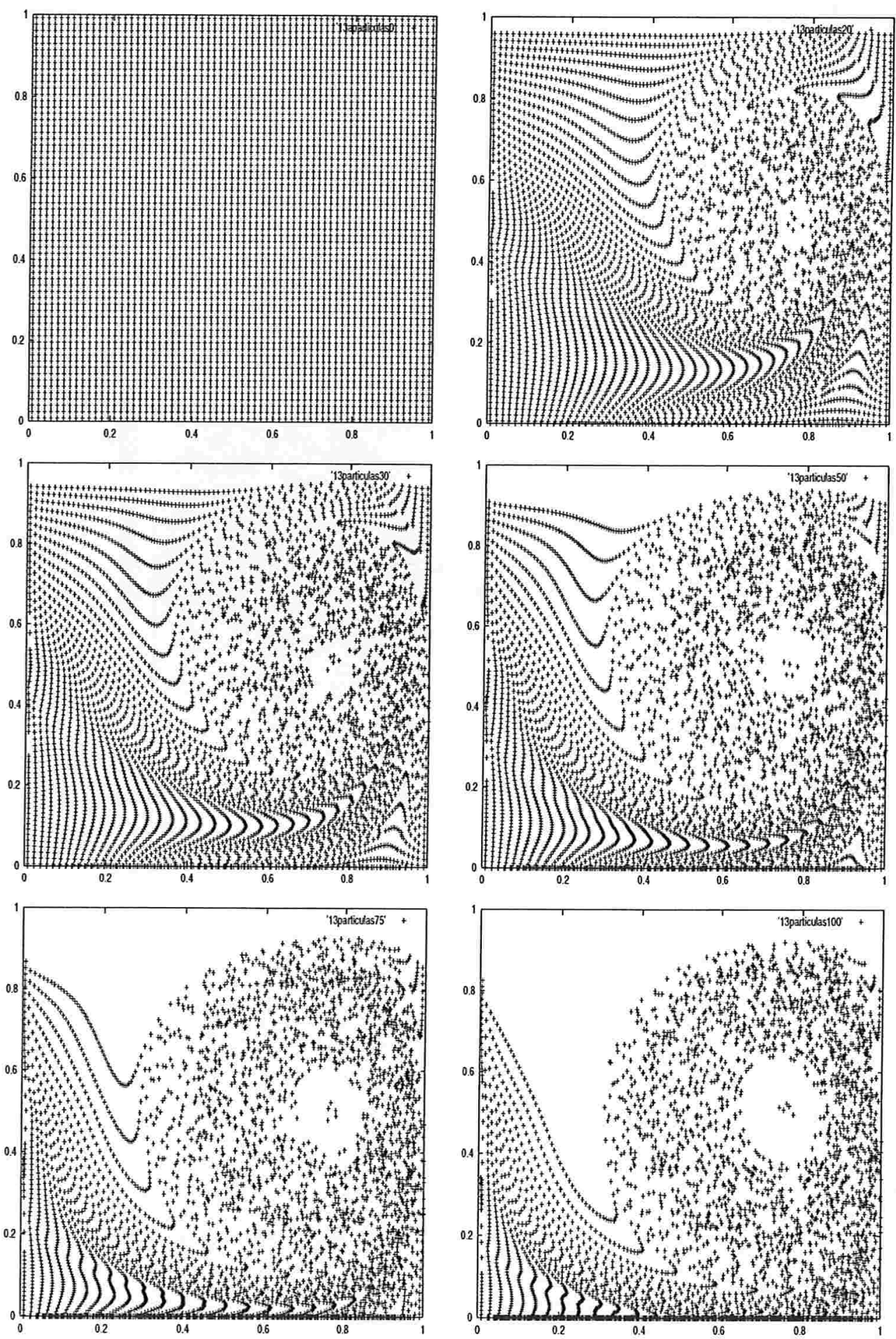

Figura 4.9: Posições das partículas $\left(d_{p}=100 \mu \mathrm{m}\right)$ ao longo da trajetória (10s), plotadas a 0s, 2s, 3s, 5s, 7,5s e 10s: $C / T=1 / 2, D / T=3 / 4$ e $f(r)=-0,5 * r$. 
Na Figura 4.10 tem-se a distância percorrida por estas partículas $\left(d_{p}=100 \mu m\right)$ durante os 10 s da simulação para a relação $D / T=3 / 4$ e a função $f(r)=-0,5 * r$ representando o disco-atuador.

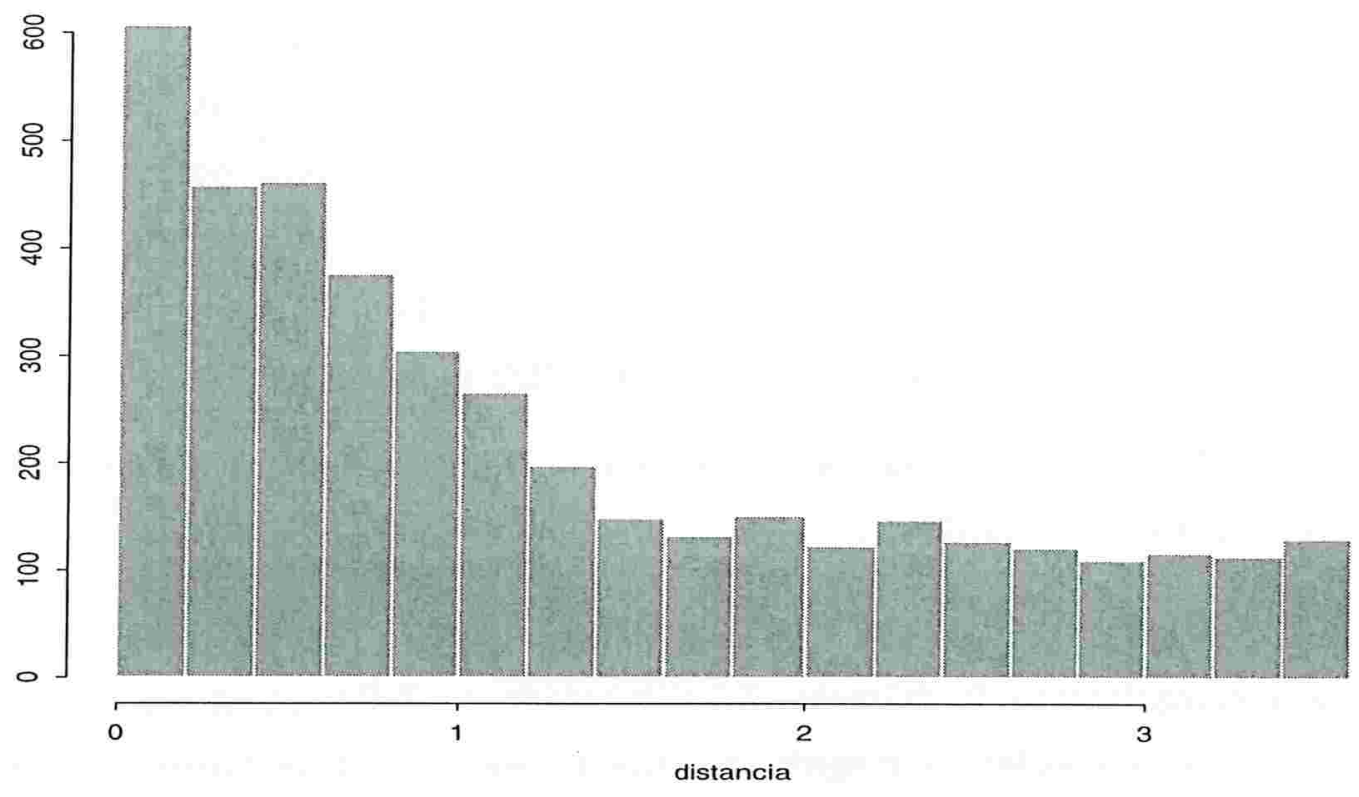

Figura 4.10: distância percorrida $\times$ número de partículas: representação do espaço percorrido pelas 4096 partículas $\left(d_{p}=100 \mu \mathrm{m}\right)$ ao longo da trajetória (tempo de simulação: $10 \mathrm{~s}), C / T=1 / 2, D / T=1 / 2$ e disco-atuador representado por $f(r)=-0,5 * r$. 
E na Tabela 4.4 sua distribuição na malha compacta.

\begin{tabular}{|c|c|c|c|c|c|c|c|c|}
\hline $\mathbf{j} \downarrow \mathbf{i} \rightarrow$ & $\mathbf{1}$ & $\mathbf{2}$ & $\mathbf{3}$ & $\mathbf{4}$ & $\mathbf{5}$ & $\mathbf{6}$ & $\mathbf{7}$ & $\mathbf{8}$ \\
\hline $\mathbf{1}$ & 0 & 0 & 0 & 0 & 4 & 17 & 21 & 7 \\
\hline $\mathbf{2}$ & 6 & 0 & 0 & 19 & 64 & 78 & 93 & 76 \\
\hline $\mathbf{3}$ & 27 & 0 & 7 & 48 & 54 & 70 & 69 & 95 \\
\hline $\mathbf{4}$ & 42 & 4 & 16 & 44 & 49 & 15 & 28 & 95 \\
\hline $\mathbf{5}$ & 43 & 17 & 15 & 50 & 56 & 19 & 24 & 99 \\
\hline $\mathbf{6}$ & 63 & 34 & 17 & 49 & 59 & 73 & 70 & 103 \\
\hline $\mathbf{7}$ & 72 & 63 & 40 & 35 & 52 & 68 & 80 & 96 \\
\hline $\mathbf{8}$ & 184 & 215 & 227 & 233 & 222 & 230 & 234 & 206 \\
\hline
\end{tabular}

Tabela 4.4: Número de partículas $\left(d_{p}=100 \mu m\right)$ por célula no instante final $(10 \mathrm{~s}), C / T=$ $1 / 2, D / T=3 / 4$ e $f(r)=-0,5 * r$.

Como o comprimento do diâmetro foi aumentado em $0,5 \mathrm{~m}$, mantendo a função que representa o disco-atuador, a magnitude máxima da velocidade também aumentou e conseqüentemente o espaço percorrido por algumas partículas também, na Figura 4.3 a distância máxima percorrida é de $1,3 \mathrm{~m}$, enquanto que neste caso algumas partículas chegaram a percorrer $3,6 \mathrm{~m}$.

Como na Tabela 4.1 nota-se que a região onde há uma velocidade menor do fluido, as partículas tendem a se sedimentarem. Sendo o diâmetro do disco-atuador maior que no caso anterior, a velocidade de agitação envolve uma região maior e com isso pode se dizer que há um maior número de partículas suspensas e conseqüentemente participando de uma reação química.

Resolveu-se refazer o teste da relação $D / T=3 / 4$, trocando-se a função do discoatuador de $f(r)=-0,5 * r$ por $f(r)=-2 / 9 * r$, tal mudança foi feita com o objetivo de manter a mesma vazão da relação $\mathrm{D} / \mathrm{T}=1 / 2$. 
A Figura 4.11 mostra o campo de velocidades para este caso.

Tue Nov 13 14:31:00 2001

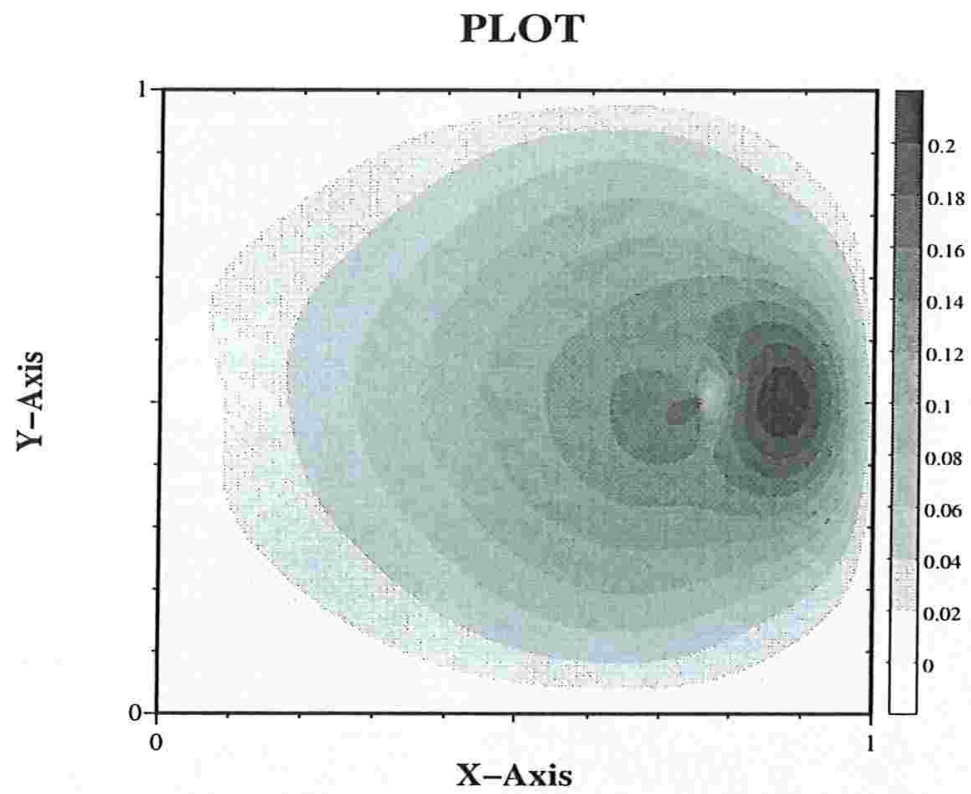

Figura 4.11: Representação do campo de velocidades no tanque, região $[0,1] \times[0,1]$, malha $64 \times 64$, utilizando um disco-atuador definido por $f(r)=-2 / 9 * r, C / T=1 / 2$ e $D / T=3 / 4$.

Percebe-se que a magnitude máxima da velocidade que antes era de $0,45 \mathrm{~m} / \mathrm{s}$ passa a ser de $0,2 \mathrm{~m} / \mathrm{s}$. E a Figura 4.12 mostra a trajetória das partículas após a simulação. 

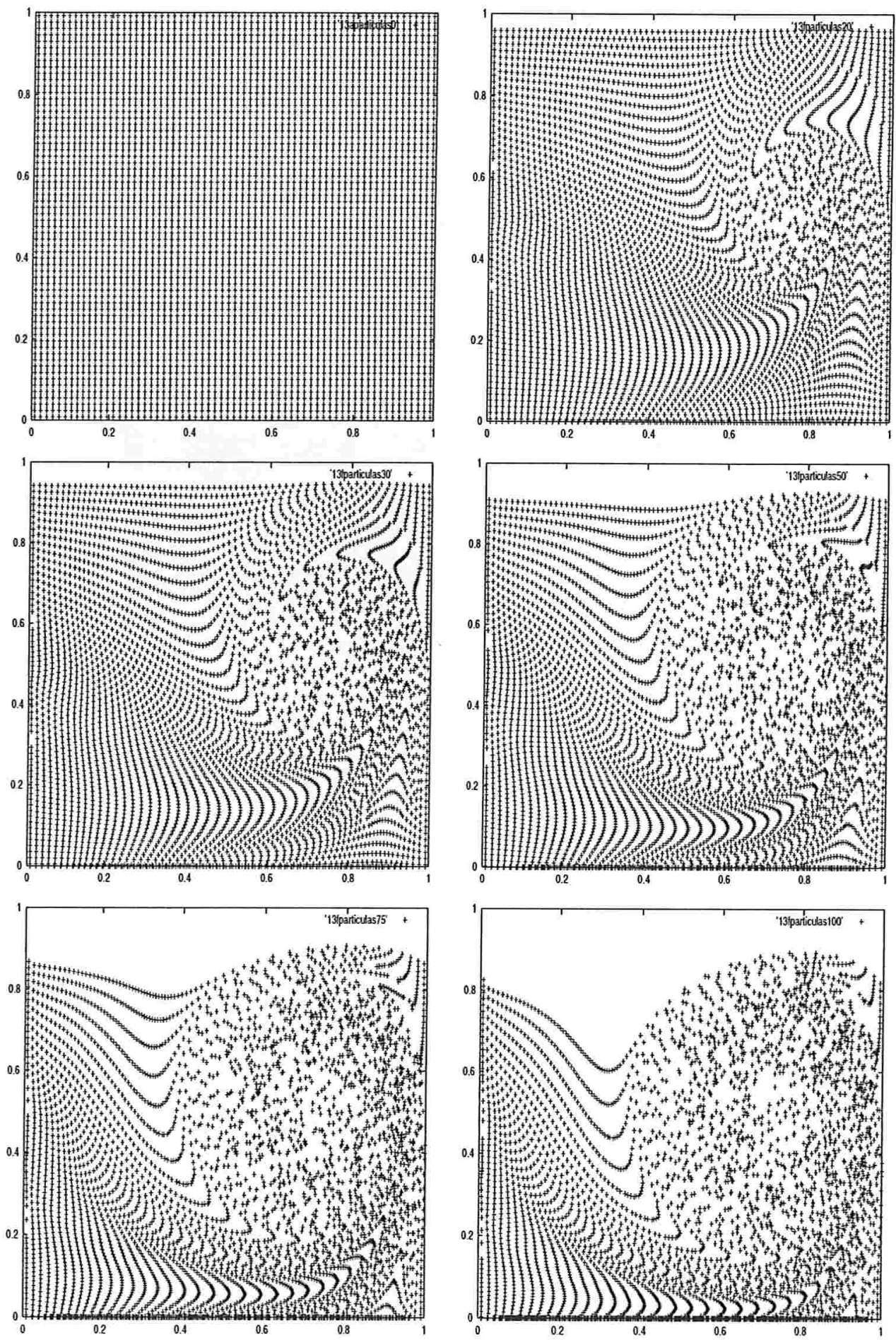

Figura 4.12: Posições das partículas ao longo da trajetória (10s), plotadas a $0 \mathrm{~s}, 2 \mathrm{~s}, 3 \mathrm{~s}, 5 \mathrm{~s}$, 7,5s e 10s: $C / T=1 / 2, D / T=3 / 4$ e $f(r)=-2 / 9 * r$. 
A distância percorrida pelas partículas após o tempo de simulação pode ser observado na Figura 4.13.

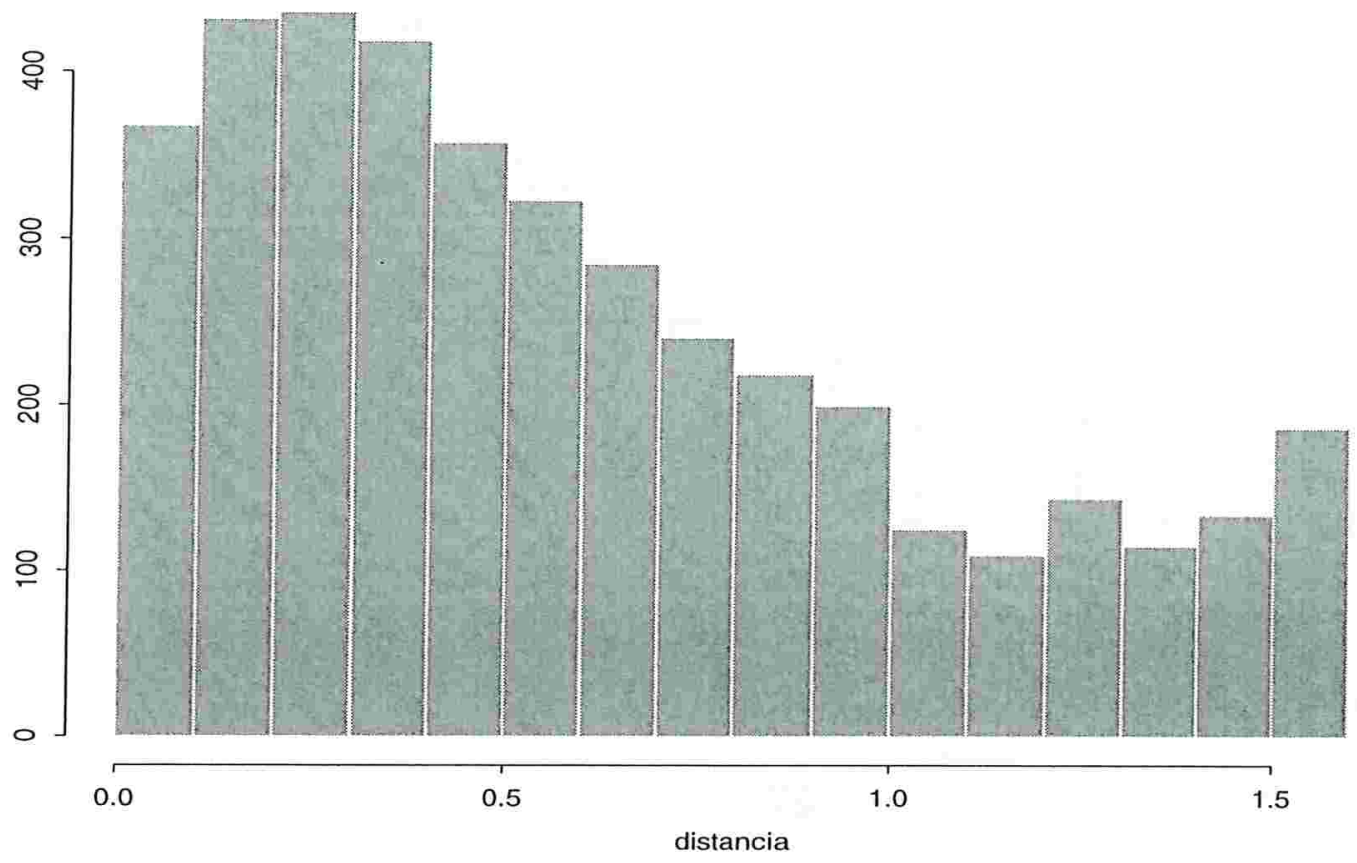

Figura 4.13: distância percorrida $\times$ número de partículas: representação do espaço percorrido pelas 4096 partículas $\left(d_{p}=100 \mu \mathrm{m}\right)$ ao longo da trajetória (tempo de simulação: 10s), $C / T=1 / 2, D / T=3 / 4$ e disco-atuador representado por $f(r)=-2 / 9 * r$. 
A Tabela 4.5 mostra a distribuição nas células, obtidas para esta função no instante final (10s), para o disco-atuador representado pela função $f(r)=-2 / 9 * r$, distância do disco em relação ao fundo do tanque $C / T=1 / 2$ e $D / T=3 / 4$.

\begin{tabular}{|c|c|c|c|c|c|c|c|c|}
\hline $\mathbf{j} \downarrow \mathbf{i} \rightarrow$ & $\mathbf{1}$ & $\mathbf{2}$ & $\mathbf{3}$ & $\mathbf{4}$ & $\mathbf{5}$ & $\mathbf{6}$ & $\mathbf{7}$ & $\mathbf{8}$ \\
\hline $\mathbf{1}$ & 0 & 0 & 0 & 0 & 0 & 3 & 9 & 1 \\
\hline $\mathbf{2}$ & 22 & 2 & 0 & 3 & 30 & 60 & 80 & 57 \\
\hline $\mathbf{3}$ & 50 & 34 & 8 & 31 & 56 & 63 & 64 & 89 \\
\hline $\mathbf{4}$ & 54 & 42 & 36 & 28 & 47 & 41 & 59 & 86 \\
\hline $\mathbf{5}$ & 59 & 45 & 31 & 36 & 52 & 48 & 58 & 75 \\
\hline $\mathbf{6}$ & 70 & 58 & 45 & 35 & 52 & 62 & 67 & 98 \\
\hline $\mathbf{7}$ & 68 & 76 & 70 & 63 & 50 & 62 & 69 & 99 \\
\hline $\mathbf{8}$ & 170 & 187 & 200 & 210 & 216 & 219 & 223 & 168 \\
\hline
\end{tabular}

Tabela 4.5: Número de partículas $\left(d_{p}=100 \mu \mathrm{m}\right)$ por célula no instante final $(10 \mathrm{~s}), C / T=$ $1 / 2, D / T=3 / 4$ e $f(r)=-2 / 9 * r$.

Comparando com o caso anterior, Tabela 4.4, nota-se um maior número de partículas suspensas, ou seja além do diâmetro do impelidor, a função que o representa influencia na trajetória das partículas. Portanto, pode se dizer que quanto mais próximo o diâmetro do disco-atuador do diâmetro do tanque e mantendo-se a mesma função na extremidade do disco da "simulação-padrão", tem-se um maior número de partículas suspensas em relação a ela.

Como a magnitude máxima da velocidade é menor em relação à simulação realizada com a função $f(r)=-0,5 * r$, as partículas percorreram uma distância semelhante ao da Figura 4.3, ou seja a distância máxima percorrida foi de $1,6 \mathrm{~m}$, enquanto que na "simulação-padrão" foi de $1.3 \mathrm{~m}$. 
Para se ter uma visão geral das simulações realizadas até o momento, é apresentado na seqüência um quadro-resumo, Tabela 4.6:

\begin{tabular}{|c|c|c|c|c|c|c|}
\hline $\begin{array}{c}\text { Simulação } \\
\text { (Figura) }\end{array}$ & $\begin{array}{c}\text { Diâmetro da } \\
\text { partícula }(\mu \mathrm{m})\end{array}$ & $\mathrm{C} / \mathrm{T}$ & $\mathrm{D} / \mathrm{T}$ & $f(r)$ & $\mathrm{Np}$ & $\begin{array}{c}\text { Tempo (h) de } \\
\text { CPU (LCCA) }\end{array}$ \\
\hline 4.4 & 10 & $1 / 2$ & $1 / 2$ & $-0,5 * r$ & 343 & 16.41 \\
\hline 4.5 & 50 & $1 / 2$ & $1 / 2$ & $-0,5 * r$ & 750 & 1.66 \\
\hline 4.2 & 100 & $1 / 2$ & $1 / 2$ & $-0,5 * r$ & 1059 & 1.66 \\
\hline 4.9 & 100 & $1 / 2$ & $3 / 4$ & $-0,5 * r$ & 1083 & 1.65 \\
\hline 4.12 & 100 & $1 / 2$ & $3 / 4$ & $-2 / 9 * r$ & 896 & 1.68 \\
\hline
\end{tabular}

$\mathrm{Np}$ : número de partículas na última fila da malha de discretização.

Tabela 4.6: Quadro-resumo das simulações realizadas nesta seção, 4.2.1.

Pelo quadro-resumo, observa-se que para simulações com o impelidor situado a $0,5 \mathrm{~m}$ do fundo do tanque $(\mathrm{C} / \mathrm{T}=1 / 2)$, relação $\mathrm{D} / \mathrm{T}=1 / 2$ e função $-0,5 * r$ para o disco-atuador, o número de partículas que tendem a se sedimentar é proporcional ao diâmetro da partícula, isso se deve à ação da gravidade sobre a mesma. E dentre as simulações com as partículas de mesmo diâmetro $\left(d_{p}=100 \mu \mathrm{m}\right)$ observa-se que o número de partículas que tendem a se sedimentar tem influência direta da relação D/T e da função que representa o discoatuador.

Pelo critério adotado, tem-se que as partículas que percorreram um maior espaço durante os 10 s são aquelas que ficaram suspensas por um tempo maior. O diâmetro do impelidor em função do diâmetro do tanque influencia na variação da qualidade da suspensão além da função que o define como pôde ser observado no quadro-resumo (Tabela 4.6) e pelos gráficos que mostram "distância percorrida $\times$ número de partículas". Ao trocar a função $f(r)$ de $-0,5 * r$ para $-2 / 9 * r$ possibilitou mostrar um maior número de partículas suspensas para um diâmetro de impelidor maior desde que mantida a mesma vazão.

O tempo de simulação para partículas com $10 \mu \mathrm{m}$ de diâmetro, devido ao tamanho do mesmo, foi necessário reduzir o passo no tempo em relação aos demais testes. Mudando o passo de $10^{-3}$ para $10^{-4}$, o tempo de CPU passou de aproximadamente $1,66 \mathrm{~h}$ para $16 \mathrm{~h}$. 


\subsubsection{Simulações para $\mathrm{C} / \mathrm{T}=1 / 4, \mathrm{D} / \mathrm{T}=1 / 2$ e $\mathrm{D} / \mathrm{T}=3 / 4$}

Segundo a prática, a posição do disco-atuador em relação ao fundo do tanque pode variar de $1 / 6$ a $1 / 2$, ou seja $\frac{1}{6}<C<\frac{1}{2}$ para um regime turbulento. Então, alterando a posição do impelidor em relação ao fundo do tanque $(\mathrm{C} / \mathrm{T}=1 / 4)$, para a relação $\mathrm{D} / \mathrm{T}=1 / 2$, ou seja $\mathrm{D}=1 \mathrm{~m}$ e $\mathrm{T}=2 \mathrm{~m}$, tem-se o campo de velocidades apresentado na Figura 4.14.

Tue Nov 6 13:09:23 2001

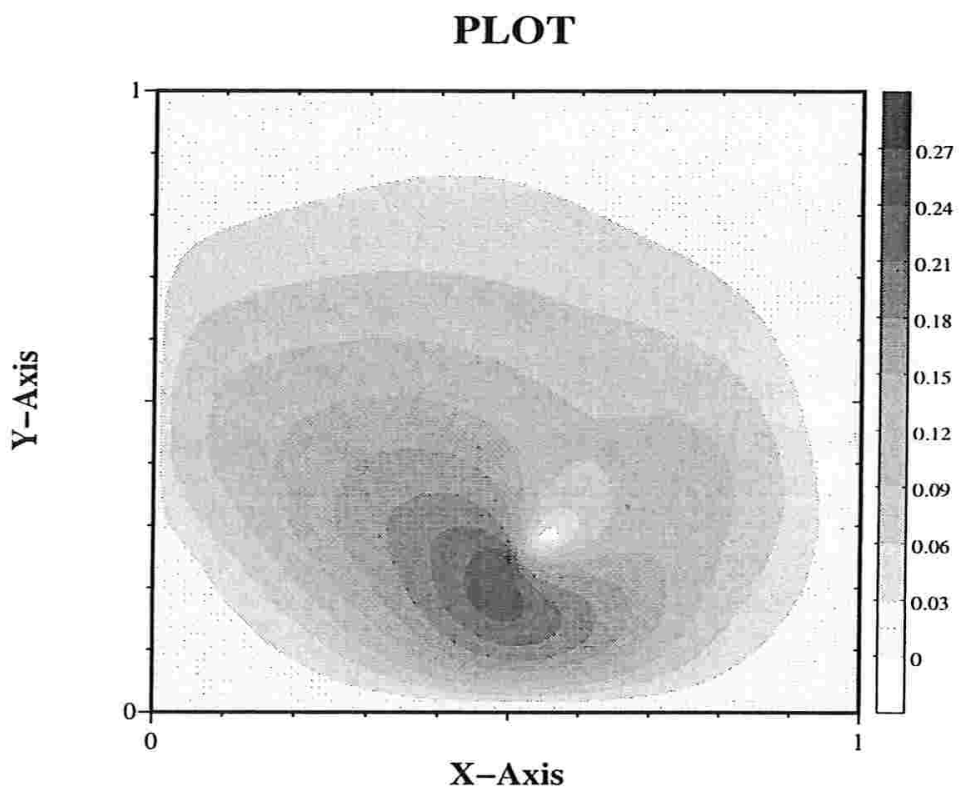

Figura 4.14: Representação do campo de velocidade no tanque, região $[0,1] \times[0,1]$, malha $64 \times 64$, utilizando um disco-atuador definido por $f(r)=-0,5 * r, \mathrm{C} / \mathrm{T}=1 / 4$ e $\mathrm{D} / \mathrm{T}=1 / 2$.

Pelo campo de velocidades, observa-se que a velocidade máxima obtida $\left|v_{\text {fluidomax }_{\text {max }}}\right|=$ $0,27 \mathrm{~m} / \mathrm{s}$. A Figura 4.15 mostra o comportamento das partículas durante a simulação. 

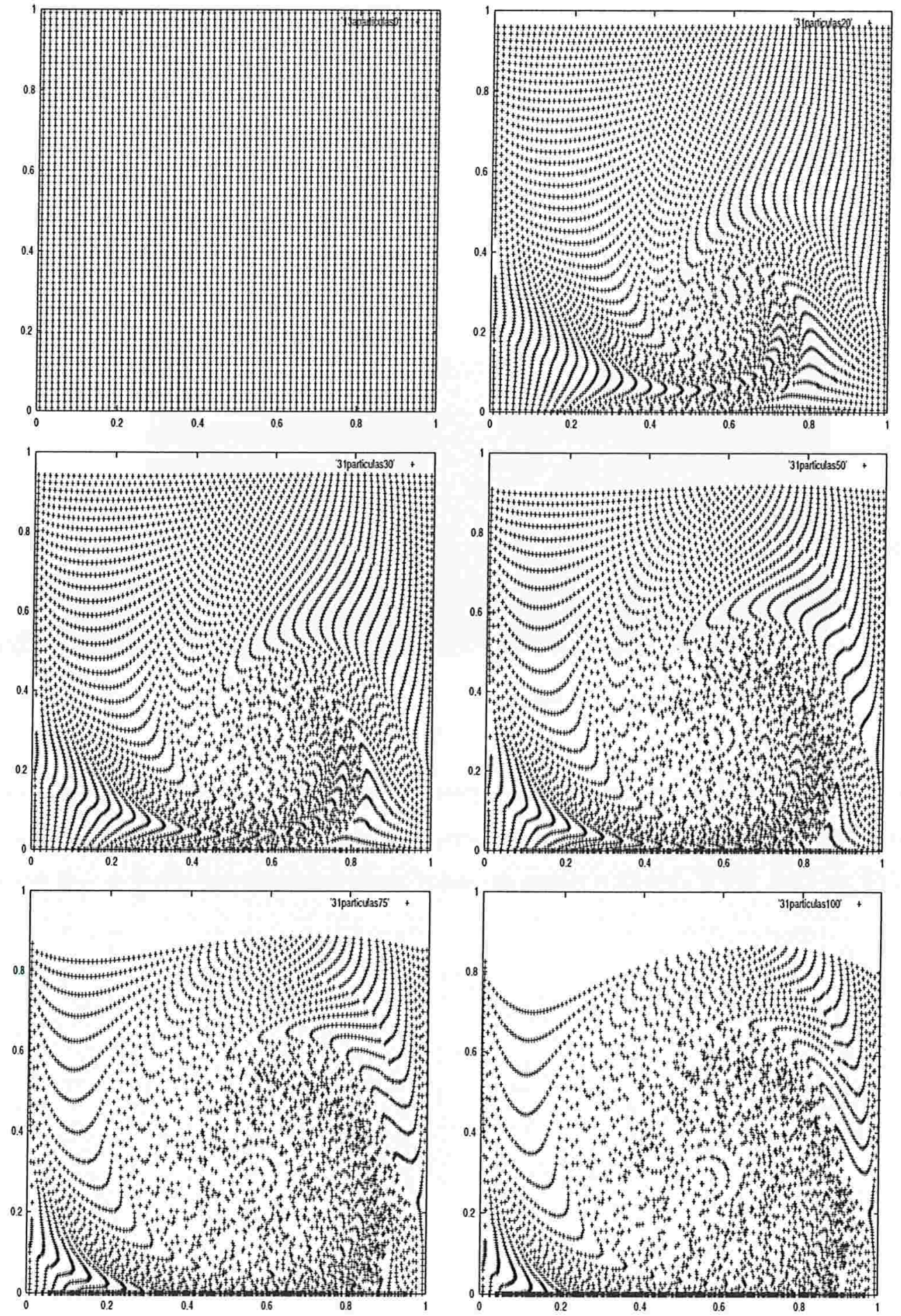

Figura 4.15: Posições das partículas ao longo da trajetória (10s), plotadas a 0s, 2s, 3s, 5s, 7,5s e 10s: $C / T=1 / 4, D / T=1 / 2$ e $f(r)=-0,5 * r$. 
A Figura 4.16 representa a distância percorrida pelas 4096 partículas $\left(d_{p}=100 \mu \mathrm{m}\right)$ durante os 10 s da simulação.

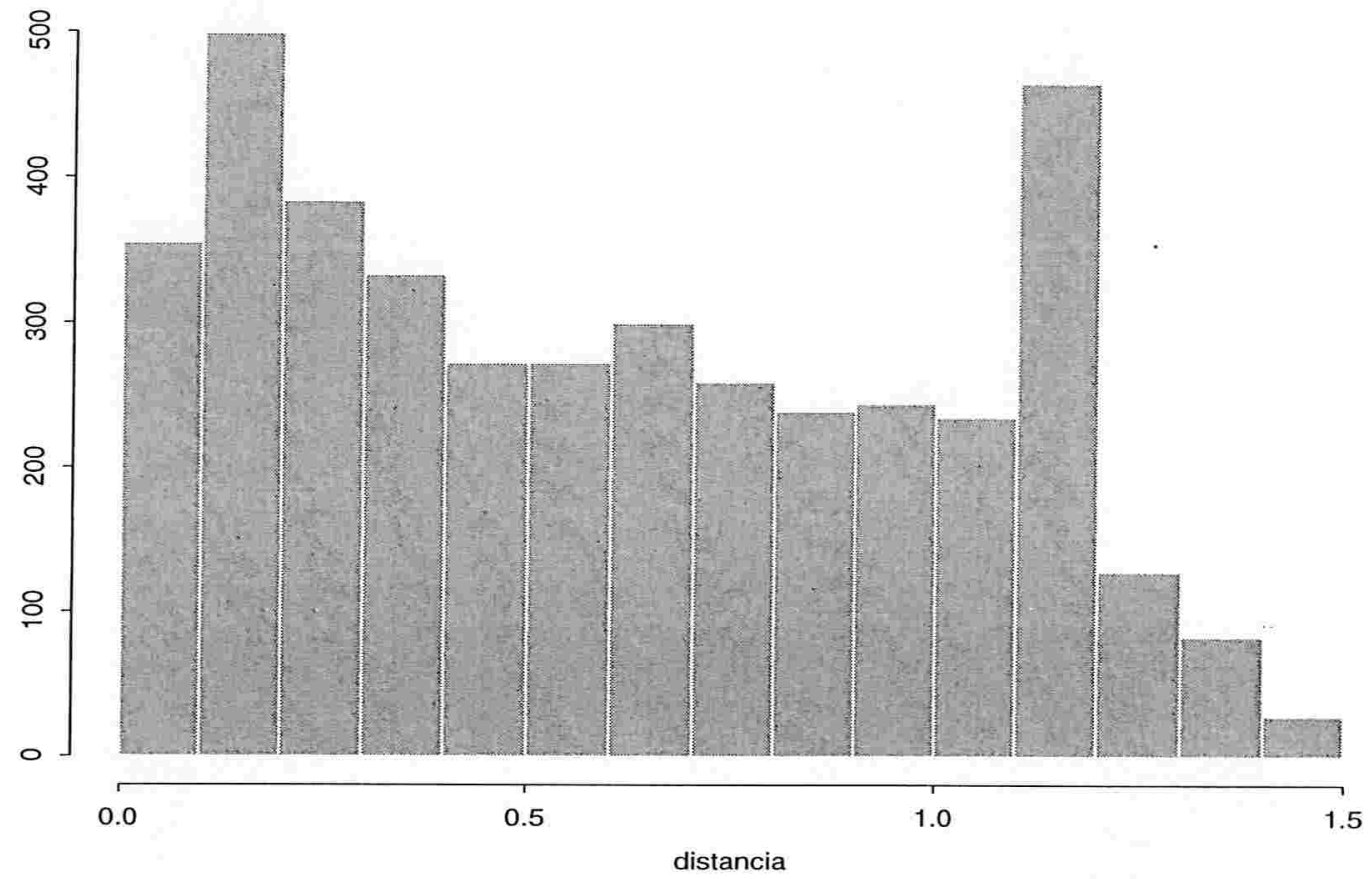

Figura 4.16: distância percorrida $\times$ número de partículas: representação do espaço percorrido pelas 4096 partículas $\left(d_{p}=100 \mu \mathrm{m}\right)$ ao longo da trajetória (tempo de simulação: 10 s), $C / T=1 / 4, D / T=1 / 2$ e disco-atuador representado por $f(r)=-0,5 * r$. 
E na Tabela 4.7 está representada a distribuição das 4096 partículas na malha compactada $8 \times 8$, posições das partículas ao final da simulação.

\begin{tabular}{|c|c|c|c|c|c|c|c|c|}
\hline $\mathrm{j} \downarrow \mathrm{i} \rightarrow$ & $\mathbf{1}$ & $\mathbf{2}$ & $\mathbf{3}$ & $\mathbf{4}$ & $\mathbf{5}$ & $\mathbf{6}$ & $\mathbf{7}$ & $\mathbf{8}$ \\
\hline $\mathbf{1}$ & 0 & 0 & 0 & 0 & 0 & 0 & 0 & 0 \\
\hline $\mathbf{2}$ & 7 & 0 & 13 & 27 & 43 & 52 & 58 & 42 \\
\hline $\mathbf{3}$ & 41 & 31 & 31 & 42 & 45 & 54 & 59 & 63 \\
\hline $\mathbf{4}$ & 32 & 25 & 29 & 34 & 70 & 79 & 75 & 68 \\
\hline $\mathbf{5}$ & 36 & 25 & 28 & 42 & 57 & 57 & 90 & 65 \\
\hline $\mathbf{6}$ & 39 & 32 & 29 & 47 & 53 & 60 & 83 & 65 \\
\hline $\mathbf{7}$ & 61 & 40 & 36 & 34 & 51 & 72 & 74 & 100 \\
\hline $\mathbf{8}$ & 206 & 234 & 235 & 232 & 236 & 224 & 237 & 196 \\
\hline
\end{tabular}

Tabela 4.7: Número de partículas $\left(d_{p}=100 \mu \mathrm{m}\right)$ por célula no instante final (10s), $C / T=$ $1 / 4, D / T=1 / 2$ e disco-atuador $f(r)=-0,5 * r$.

Como o disco-atuador está mais próximo do fundo do tanque $(\mathrm{C} / \mathrm{T}=1 / 4)$ do que as simulações anteriores, um grande número de partículas tendem a se sedimentar com a função escolhida. 
A Figura 4.17 é a representação do campo de velocidades para o impelidor a $0.25 \mathrm{~m}$ $(C / T=1 / 4)$ do fundo do tanque e $D / T=3 / 4$.

Wed Nov 14 16:42:57 2001

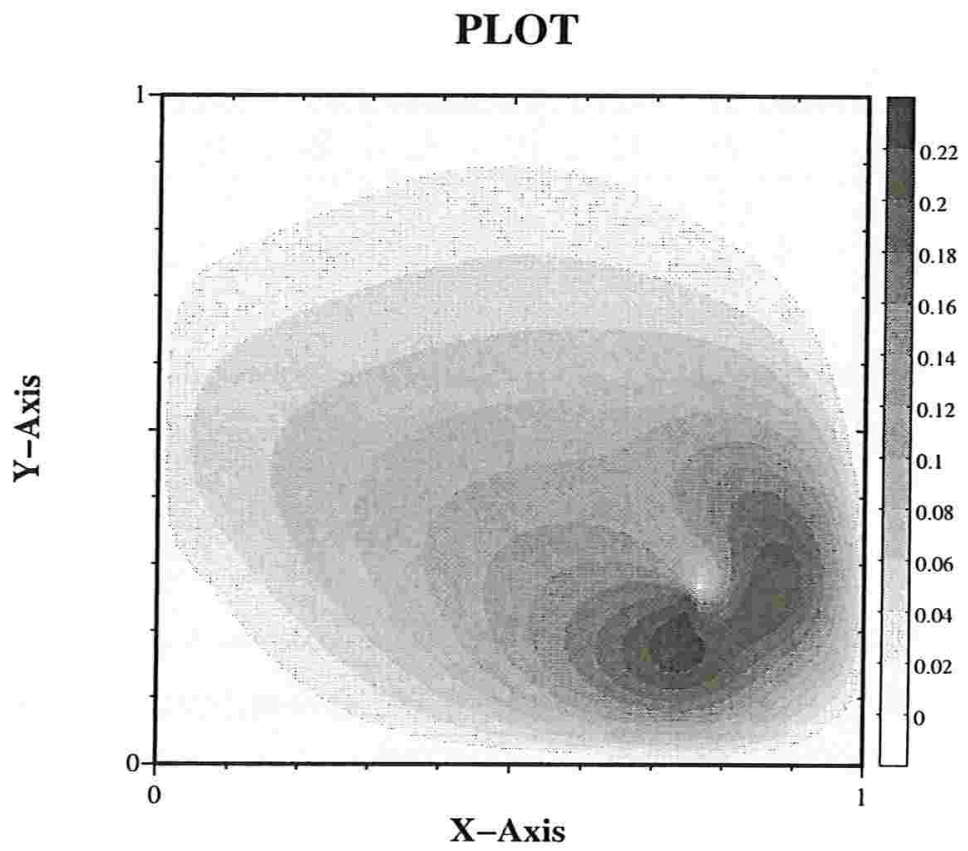

Figura 4.17: Representação do campo de velocidade no tanque, região $[0,1] \times[0,1]$, malha $64 \times 64$, utilizando um disco-atuador definido por $f(r)=-2 / 9 * r, C / T=1 / 4$ e $D / T=$ $3 / 4$.

Pode ser observado que a velocidade na extremidade do disco-atuador para a simulação realizada na região $[0,1] \times[0,1]$, é de $\left|v_{\text {fluidomax }}\right|=0,22 \mathrm{~m} / \mathrm{s}$. E a Figura 4.18 mostra o comportamento das partículas ao longo da trajetória. 

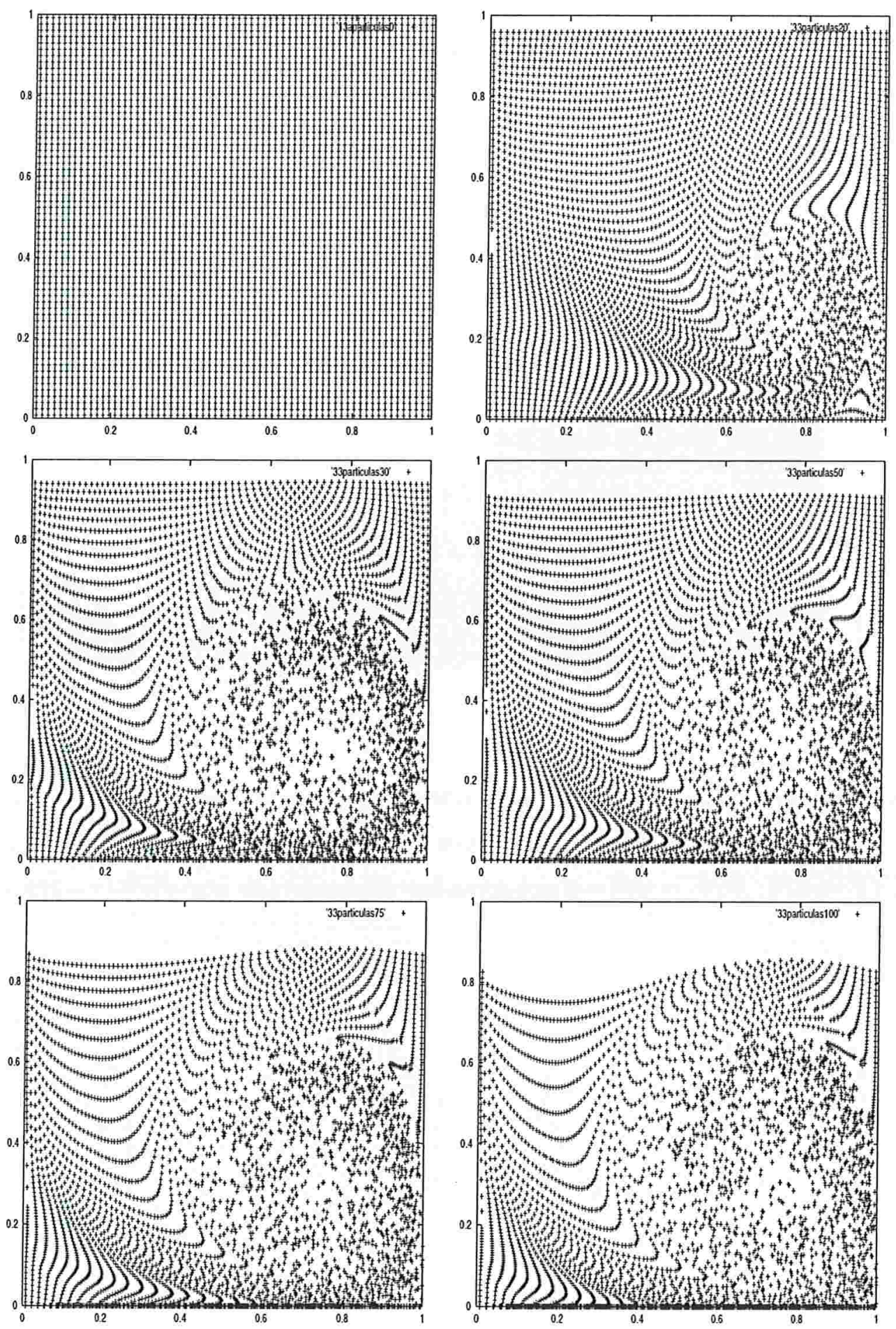

Figura 4.18: Posições das partículas ao longo da trajetória (10s), plotadas a $0 \mathrm{~s}, 2 \mathrm{~s}, 3 \mathrm{~s}, 5 \mathrm{~s}$, 7,5s e 10s: $C / T=1 / 4, D / T=3 / 4$ e $f(r)=-2 / 9 * r$. 
A Figura 4.19, representa a distância percorrida pelas 4096 partículas $\left(d_{p}=100 \mu \mathrm{m}\right)$ nesta simulação.

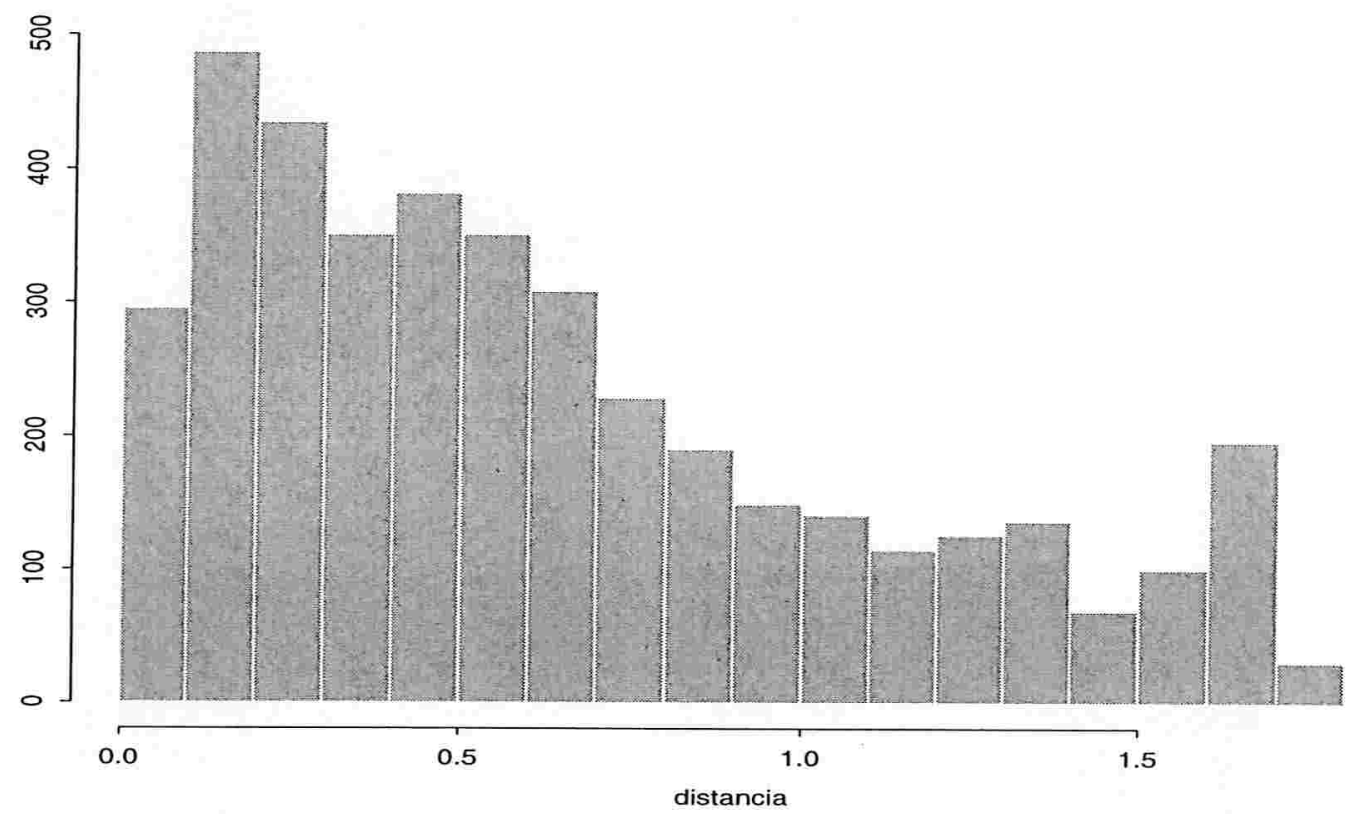

Figura 4.19: distância percorrida $\times$ número de partículas: representação do espaço percorrido pelas 4096 partículas $\left(d_{p}=100 \mu \mathrm{m}\right)$ ao longo da trajetória (tempo de simulação: 10 s), $C / T=1 / 4, D / T=3 / 4$ e disco-atuador representado por $f(r)=-2 / 9 * r$. 
A Tabela 4.8 representa a distribuição das 4096 partículas na malha compactada $8 \times 8$, com as posições das partículas ao final da simulação, em um tanque com $C / T=1 / 4$, $D / T=3 / 4$ e função que representa o disco-atuador $f(r)=-2 / 9 * r$.

\begin{tabular}{|c|c|c|c|c|c|c|c|c|}
\hline $\mathrm{j} \downarrow \mathrm{i} \rightarrow$ & $\mathbf{1}$ & $\mathbf{2}$ & $\mathbf{3}$ & $\mathbf{4}$ & $\mathbf{5}$ & $\mathbf{6}$ & $\mathbf{7}$ & $\mathbf{8}$ \\
\hline $\mathbf{1}$ & 0 & 0 & 0 & 0 & 0 & 0 & 0 & 0 \\
\hline $\mathbf{2}$ & 19 & 12 & 13 & 24 & 38 & 47 & 56 & 44 \\
\hline $\mathbf{3}$ & 48 & 33 & 38 & 39 & 44 & 45 & 60 & 68 \\
\hline $\mathbf{4}$ & 42 & 43 & 33 & 34 & 55 & 71 & 96 & 67 \\
\hline $\mathbf{5}$ & 44 & 33 & 32 & 32 & 60 & 54 & 75 & 89 \\
\hline $\mathbf{6}$ & 52 & 40 & 36 & 39 & 51 & 35 & 39 & 82 \\
\hline $\mathbf{7}$ & 86 & 68 & 52 & 37 & 50 & 54 & 64 & 87 \\
\hline $\mathbf{8}$ & 182 & 201 & 223 & 226 & 228 & 231 & 224 & 221 \\
\hline
\end{tabular}

Tabela 4.8: Número de partículas $\left(d_{p}=100 \mu \mathrm{m}\right)$ por célula no instante final $(10 \mathrm{~s}), C / T=$ $1 / 4, D / T=3 / 4$ e disco-atuador: $f(r)=-2 / 9 * r$.

Pela Tabela 4.8, observa-se que mesmo com um diâmetro do impelidor maior há um número menor de partículas suspensas. Isso se deve a função escolhida para definir o disco-atuador além da posição do mesmo. Assim, a relação $D / T=1 / 2$ ou $D / T=3 / 4$ pouco influencia no espaço percorrido pelas partículas, pois a distância média percorrida foi de $0,64 \mathrm{~m}$ e a distância máxima percorrida foi de $1,8 \mathrm{~m}$. 
Para se ter uma visão geral das simulações realizadas nesta seção, é apresentado na seqüência um quadro-resumo, Tabela 4.9:

\begin{tabular}{|c|c|c|c|c|c|c|}
\hline $\begin{array}{c}\text { Simulação } \\
\text { (Figura) }\end{array}$ & $\begin{array}{c}\text { Diâmetro da } \\
\text { partícula }(\mu \mathrm{m})\end{array}$ & $\mathrm{C} / \mathrm{T}$ & $\mathrm{D} / \mathrm{T}$ & $f(r)$ & $\mathrm{Np}$ & $\begin{array}{c}\text { Tempo (h) de } \\
\text { CPU (LCCA) }\end{array}$ \\
\hline 4.15 & 100 & $1 / 4$ & $1 / 2$ & $-0,5 * r$ & 1214 & 1.70 \\
\hline 4.18 & 100 & $1 / 4$ & $3 / 4$ & $-2 / 9 * r$ & 1326 & 1.66 \\
\hline
\end{tabular}

Np: número de partículas na última fila da malha de discretização.

Tabela 4.9: Quadro-resumo das simulações realizadas nesta seção, 4.2.2

Pelo quadro-resumo, observa-se que para simulações com o impelidor situado a $0,25 \mathrm{~m}$ do fundo do tanque $(C / T=1 / 4)$, relação $D / T=1 / 2$ e função $-0,5 * r$ para o discoatuador, o número de partículas que tendem a se sedimentar, novamente, é proporcional ao diâmetro da partícula, isso se deve à ação da gravidade sobre a mesma.

E dentre as simulações com as partículas de mesmo diâmetro $\left(d_{p}=100 \mu m\right)$ observa-se que o número de partículas que tendem a se sedimentar tem influência direta da relação $\mathrm{D} / \mathrm{T}$ e da função que representa o disco-atuador. Ainda, o número de partículas sedimentadas em ambos os casos são bem próximos, mas há um número maior de partículas sedimentadas comparando com a "simulação-padrão" isso se deve, além da ação da gravidade, a posição do mesmo no tanque. 


\subsubsection{Simulações para $\mathrm{C} / \mathrm{T}=1 / 4, \mathrm{~S} / \mathrm{T}=1 / 4, \mathrm{D} / \mathrm{T}=1 / 2$ e $\mathrm{D} / \mathrm{T}=3 / 4$}

Em alguns casos há a necessidade de se adaptar o tanque colocando dois ou mais impelidores para promover uma melhor mistura (como já foi citado no Cap.1 - Seção 1.2). Para se fazer uma análise da contribuição do número de discos-atuadores no tanque nesta melhoria realizou-se os mesmos testes anteriores com dois discos-atuadores, um disco a $1 / 4$ do fundo do tanque $(C / T=1 / 4)$ e um segundo disco a $0,5 \mathrm{~m}$ do fundo do tanque $(S / T=1 / 4, S$ é a distância entre os dois impelidores). A Figura 4.20 representa o campo de velocidades obtido pelos discos-atuadores, ambos representados pela função $f(r)=-0,5 * r$, para a relação $D / T=1 / 2$.

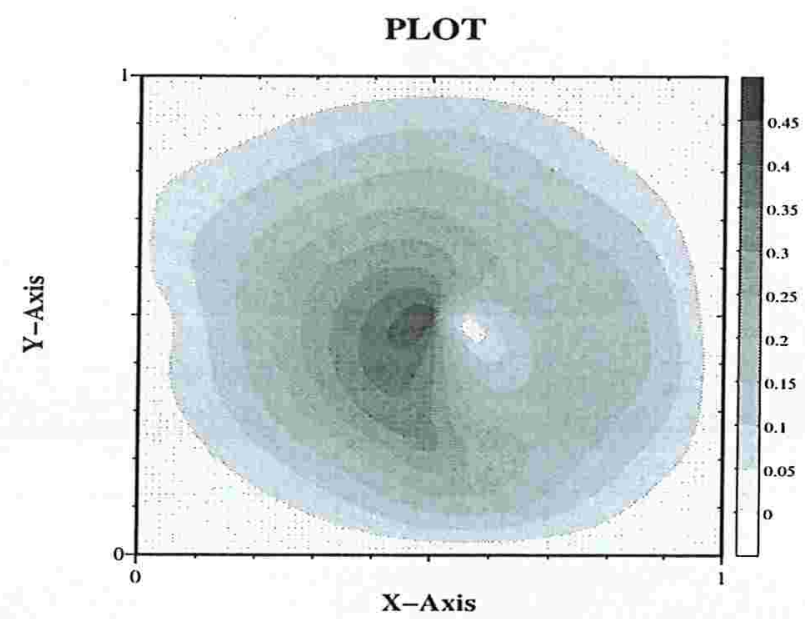

Figura 4.20: Representação do campo de velocidade no tanque, região $[0,1] \times[0,1]$, malha $64 \times 64$, utilizando dois discos-atuadores definidos por $f(r)=-0,5 * r, C / T=1 / 4$, $S / T=1 / 4$ e $D / T=1 / 2$.

Na Figura 4.21 é apresentado o comportamento das partículas ao longo da trajetória sob influência deste fluido gerado pelos dois discos-atuadores. A magnitude máxima da velocidade é $\left|v_{\text {fluido }_{\text {max }}}\right|=0,45 \mathrm{~m} / \mathrm{s}$. 

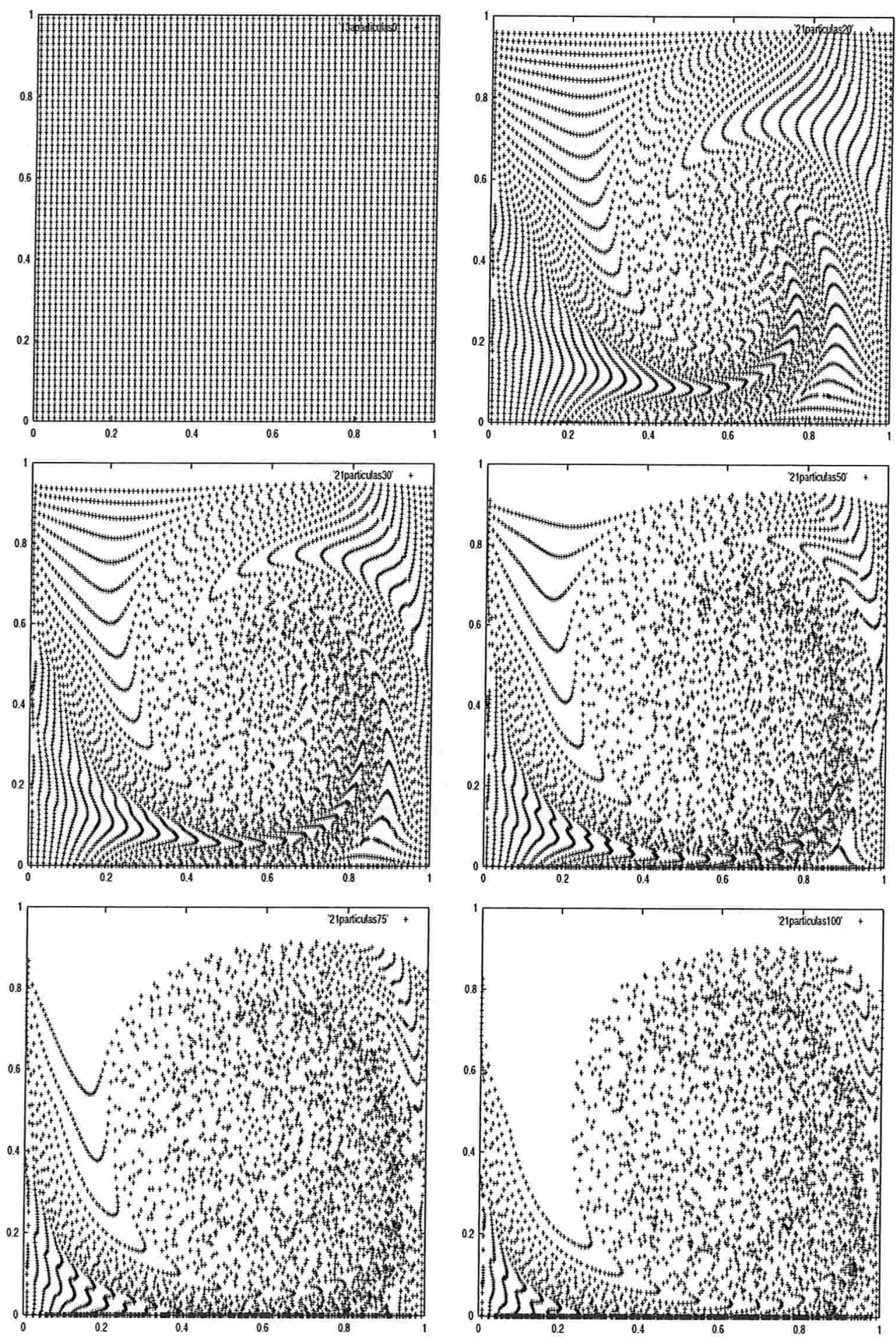

Figura 4.21: Posições das partículas ao longo da trajetória (10s), plotadas a $0 \mathrm{~s}, 2 \mathrm{~s}, 3 \mathrm{~s}, 5 \mathrm{~s}$, 7,5s e 10s: $C / T=1 / 2, S / T=1 / 4, D / T=1 / 2$ e $f(r)=-0,5 * r$. 
E a Figura 4.22 representa a distância percorrida pelas 4096 partículas $\left(d_{p}=100 \mu \mathrm{m}\right)$ durante os 10s da simulação no tanque.

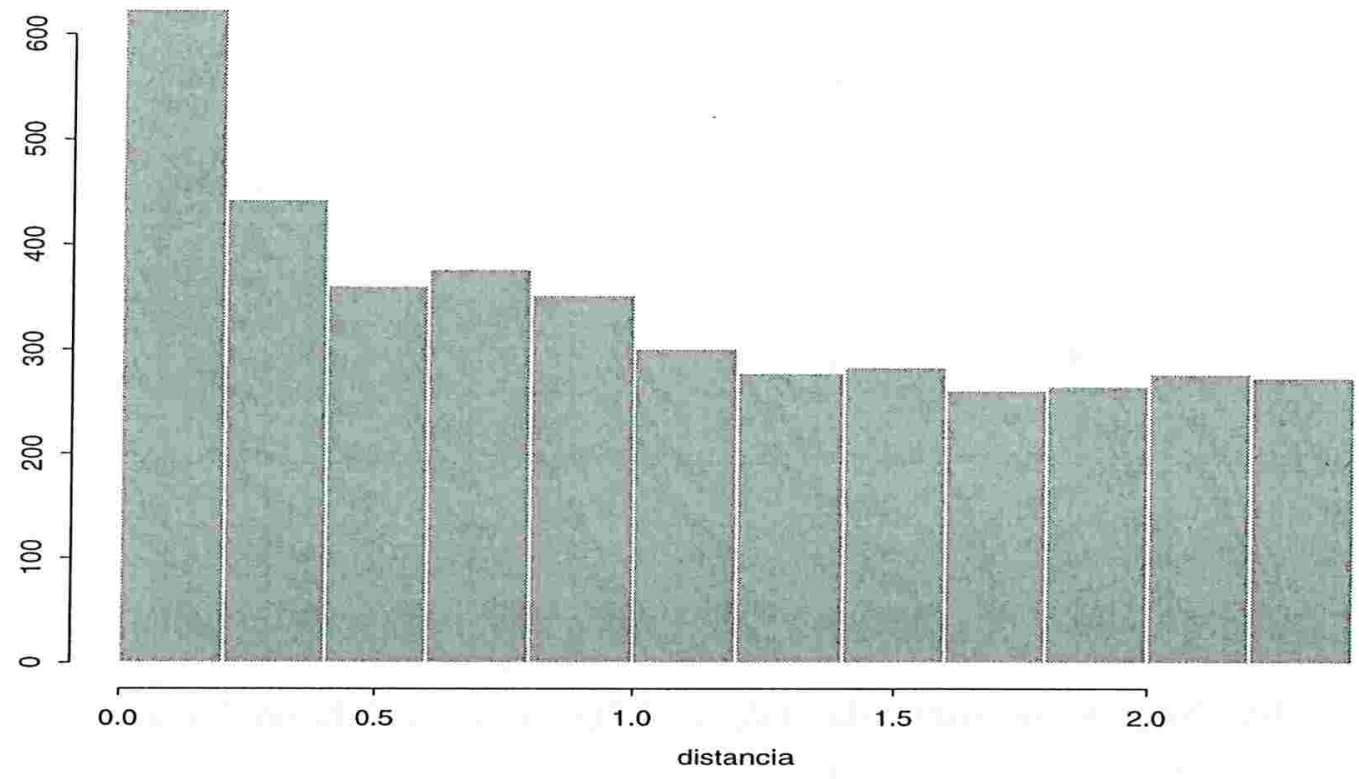

Figura 4.22: distância percorrida $\times$ número de partículas: representação do espaço percorrido pelas 4096 partículas $\left(d_{p}=100 \mu \mathrm{m}\right)$ ao longo da trajetória (tempo de simulação: 10s), $C / T=1 / 2, S / T=1 / 4, D / T=1 / 2$ e disco-atuador representado por $f(r)=-0,5 * r$. 
Na Tabela 4.10 está representada a distribuição das 4096 partículas na malha compactada $8 \times 8$, com as posições das partículas ao final da simulação, para o tanque com as relações $C / T=1 / 4, S / T=1 / 4, D / T=1 / 2$ e função que representa o disco-atuador $f(r)=-0,5 * r$.

\begin{tabular}{|c|c|c|c|c|c|c|c|c|}
\hline $\mathbf{j} \downarrow \mathbf{i} \rightarrow$ & $\mathbf{1}$ & $\mathbf{2}$ & $\mathbf{3}$ & $\mathbf{4}$ & $\mathbf{5}$ & $\mathbf{6}$ & $\mathbf{7}$ & $\mathbf{8}$ \\
\hline $\mathbf{1}$ & 0 & 0 & 0 & 0 & 4 & 13 & 12 & 1 \\
\hline $\mathbf{2}$ & 5 & 0 & 5 & 30 & 67 & 74 & 61 & 44 \\
\hline $\mathbf{3}$ & 9 & 0 & 26 & 54 & 57 & 67 & 99 & 59 \\
\hline $\mathbf{4}$ & 15 & 4 & 39 & 28 & 45 & 65 & 70 & 103 \\
\hline $\mathbf{5}$ & 25 & 3 & 24 & 36 & 29 & 48 & 91 & 83 \\
\hline $\mathbf{6}$ & 44 & 5 & 28 & 49 & 48 & 58 & 82 & 95 \\
\hline $\mathbf{7}$ & 75 & 40 & 28 & 48 & 61 & 65 & 78 & 104 \\
\hline $\mathbf{8}$ & 196 & 226 & 240 & 228 & 231 & 235 & 230 & 207 \\
\hline
\end{tabular}

Tabela 4.10: Número de partículas $\left(d_{p}=100 \mu \mathrm{m}\right)$ por célula no instante final $(10 \mathrm{~s})$, $C / T=1 / 4, S / T=1 / 4, D / T=3 / 4$ e disco-atuador: $f(r)=-2 / 9 * r$.

Comparando a Tabela 4.10 com a Tabela 4.1, "simulação-padrão" , observa-se que com dois discos-atuadores há um maior movimento do fluido e conseqüentemente um maior número de partículas suspensas para a função escolhida para definir o disco-atuador. A distância média percorrida pelas partículas foi de $1.03 \mathrm{~m}$ e a distância máxima percorrida pelas partículas foi de $2.4 \mathrm{~m}$. Comparando o gráfico da Figura $4.22 \mathrm{com}$ o gráfico da Figura 4.3 , obtido com apenas um disco-atuador, observa-se que com dois discos-atuadores o espaço percorrido pelas partículas é maior, porém há um número maior de partículas que tendem a se sedimentarem. O espaço percorrido pelas partículas suspensas é maior devido à magnitude máxima da velocidade ser maior na região onde está localizado o vórtice, combinação da velocidade produzida pelos dois discos-atuadores. 
Para $D / T=3 / 4$, o campo de velocidades está representado na Figura 4.23.

Wed Nav 14 16:44:35 2001

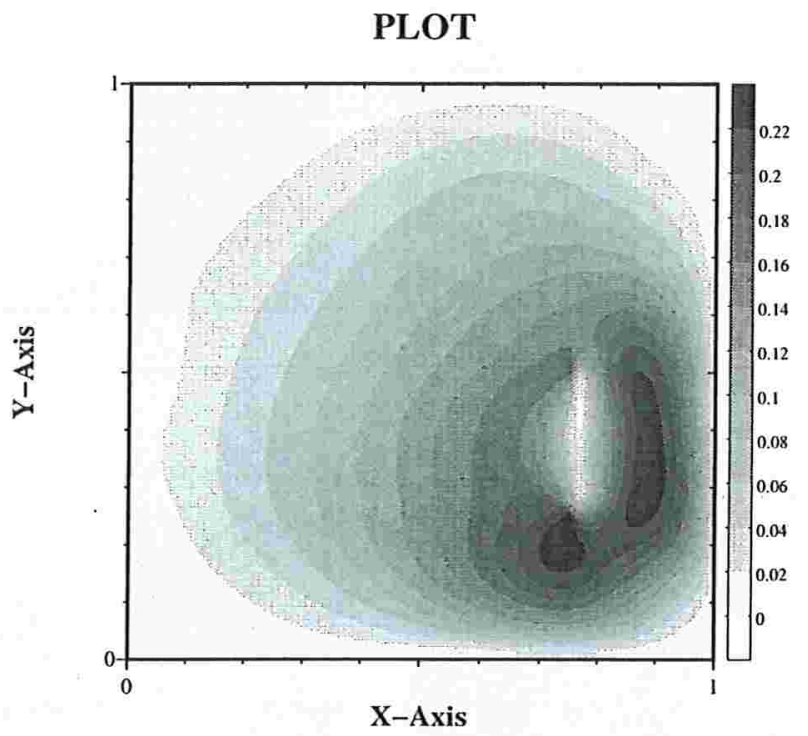

Figura 4.23: Representação do campo de velocidade no tanque, região $[0,1] \times[0,1]$, malha $64 \times 64$, utilizando dois discos-atuadores definidos por $f(r)=-0,5 * r, C / T=1 / 4$, $S / T=1 / 4$ e $D / T=3 / 4$.

A magnitude máxima da velocidade é $\left|v_{\text {fluidomax }_{\text {max }}}\right|=0,22 \mathrm{~m} / \mathrm{s}$. A Figura 4.24 mostra a trajetória das partículas ao longo do tempo sob influência deste campo de velocidades. 

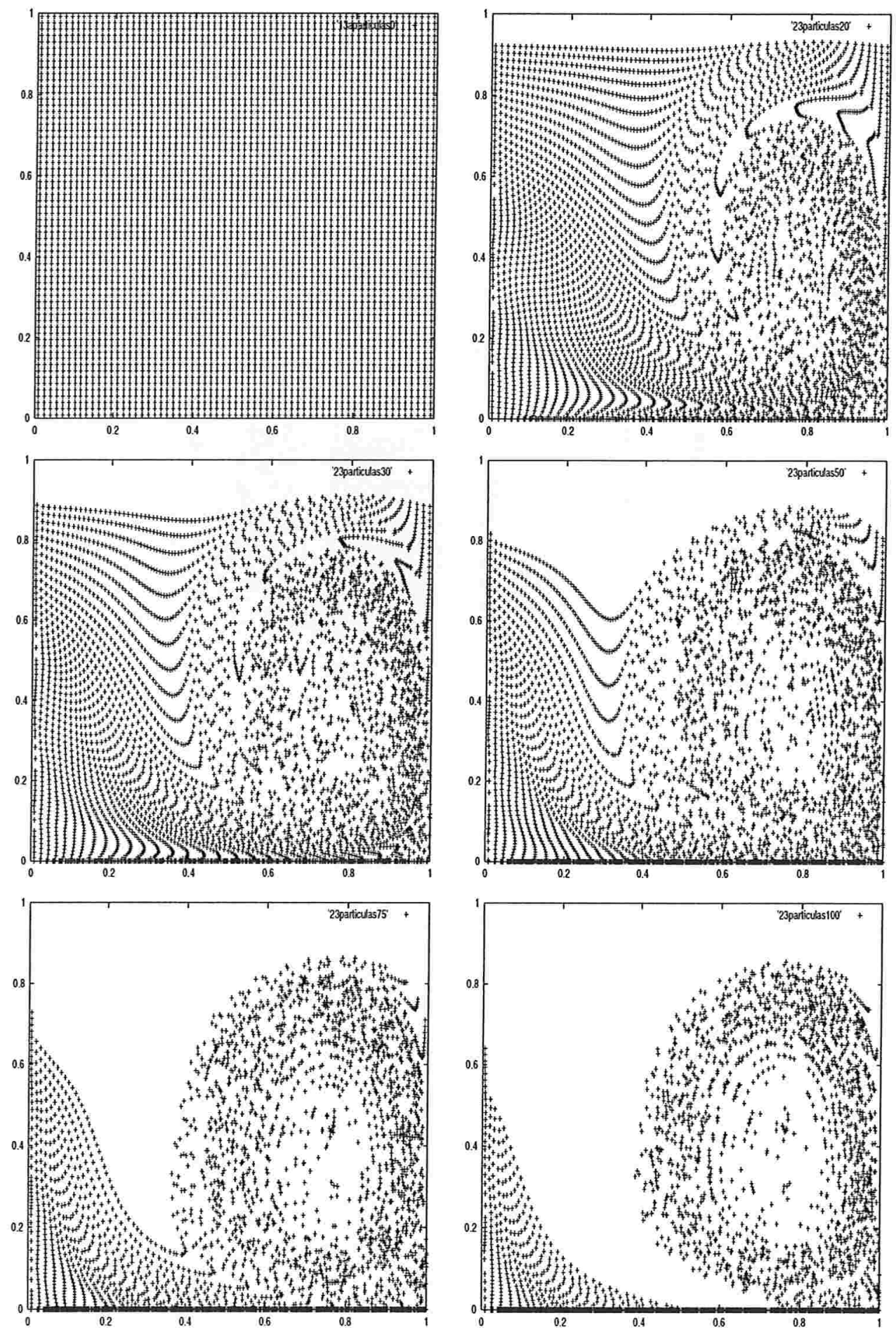

Figura 4.24: Posições das partículas ao longo da trajetória (10s), plotadas a $0 \mathrm{~s}, 2 \mathrm{~s}, 3 \mathrm{~s}, 5 \mathrm{~s}$, 7,5s e 10s: $C / T=1 / 4, S / T=1 / 4, D / T=3 / 4$ e $f(r)=-0,5 * r$. 
E a Figura 4.25 representa a distância percorrida pelas 4096 partículas $\left(d_{p}=100 \mu \mathrm{m}\right)$ durante os 10 s da simulação no tanque com a relação $D / T=3 / 4, C / T=1 / 4$ e $S / T=1 / 4$, além da função $f(r)=-2 / 9 * r$ representando os dois discos-atuadores.

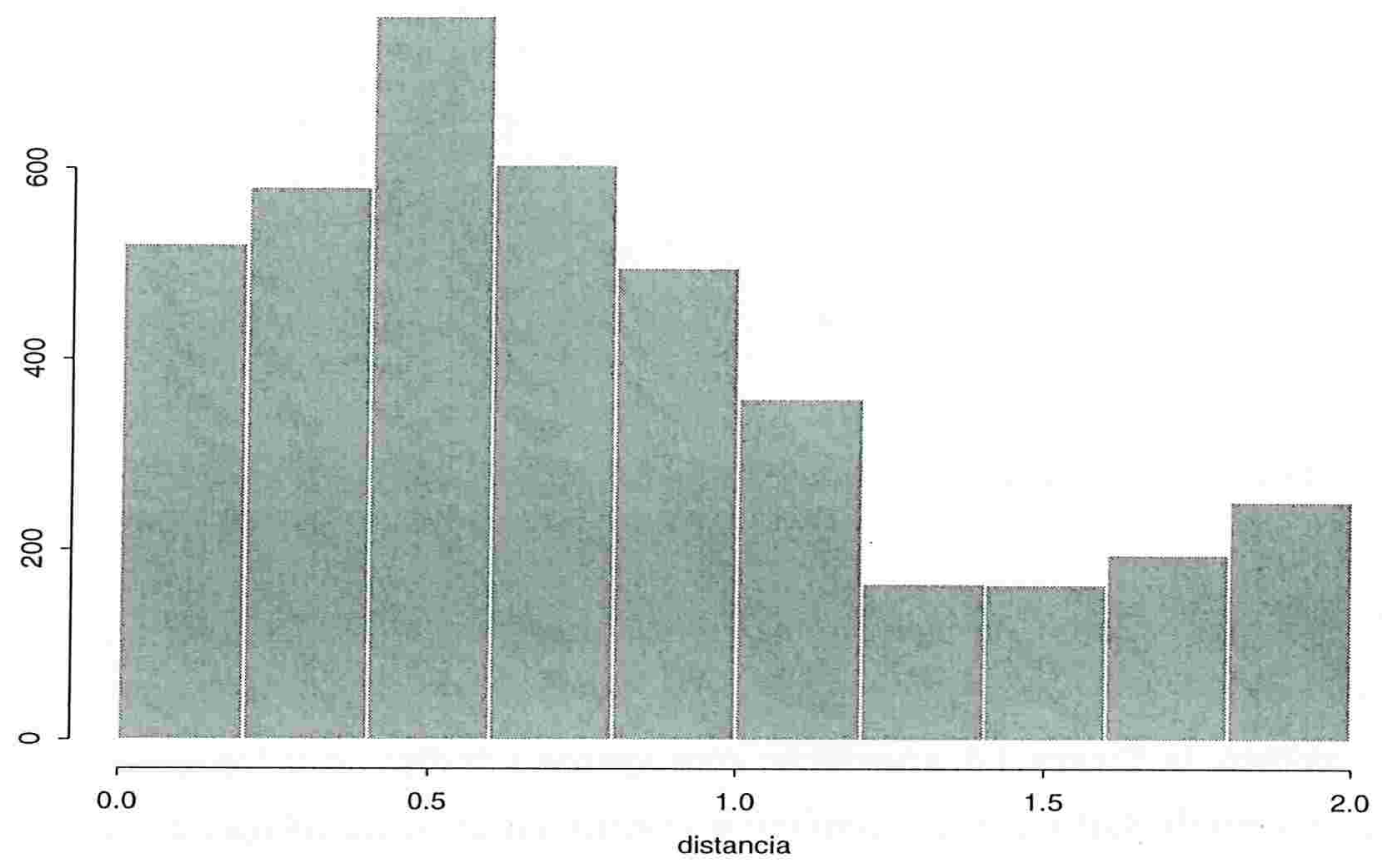

Figura 4.25: distância percorrida $\times$ número de partículas: representação do espaço percorrido pelas 4096 partículas $\left(d_{p}=100 \mu \mathrm{m}\right)$ ao longo da trajetória (tempo de simulação: $10 \mathrm{~s}$ ), $C / T=1 / 4, S / T=1 / 4, D / T=3 / 4$ e disco-atuador representado por $f(r)=-2 / 9 * r$. 
Na Tabela 4.11 estão distribuídas as 4096 partículas $\left(d_{p}=100 \mu m\right)$ após a simulação.

\begin{tabular}{|c|c|c|c|c|c|c|c|c|}
\hline $\mathbf{j} \downarrow \mathbf{i} \rightarrow$ & $\mathbf{1}$ & $\mathbf{2}$ & $\mathbf{3}$ & $\mathbf{4}$ & $\mathbf{5}$ & $\mathbf{6}$ & $\mathbf{7}$ & $\mathbf{8}$ \\
\hline $\mathbf{1}$ & 0 & 0 & 0 & 0 & 0 & 0 & 0 & 0 \\
\hline $\mathbf{2}$ & 0 & 0 & 0 & 0 & 0 & 14 & 22 & 9 \\
\hline $\mathbf{3}$ & 2 & 0 & 0 & 0 & 14 & 58 & 85 & 58 \\
\hline $\mathbf{4}$ & 37 & 1 & 0 & 0 & 47 & 44 & 60 & 92 \\
\hline $\mathbf{5}$ & 54 & 28 & 0 & 10 & 56 & 43 & 28 & 71 \\
\hline $\mathbf{6}$ & 58 & 48 & 11 & 16 & 54 & 37 & 42 & 87 \\
\hline $\mathbf{7}$ & 67 & 58 & 47 & 38 & 36 & 65 & 54 & 78 \\
\hline $\mathbf{8}$ & 266 & 293 & 303 & 310 & 321 & 328 & 324 & 322 \\
\hline
\end{tabular}

Tabela 4.11: Número de partículas $\left(d_{p}=100 \mu \mathrm{m}\right)$ por célula no instante final $(10 \mathrm{~s})$, $C / T=1 / 4, S / T=1 / 4, D / T=3 / 4$ e disco-atuador: $f(r)=-2 / 9 * r$.

A distância máxima percorrida pelas partículas $(2 \mathrm{~m})$, é das partículas que se concentraram próximo à extremidade do disco-atuador. Ao comparar o gráfico da Figura 4.25 com o gráfico da Figura 4.3, simulação com apenas um disc- atuador, novamente há um maior número de partículas que tendem a se sedimentarem em relação ao caso da Figura 4.3. Isso se deve ao fato do segundo disco-atuador estar próximo do fundo do tanque e da função que os representam.

Para se ter uma visão geral das simulações realizadas nesta seção, é apresentado na seqüência um quadro-resumo, Tabela 4.12:

\begin{tabular}{|c|c|c|c|c|c|c|}
\hline $\begin{array}{c}\text { Simulação } \\
\text { (Figura) }\end{array}$ & $\begin{array}{c}\text { Diâmetro da } \\
\text { partícula }(\mu \mathrm{m})\end{array}$ & $\mathrm{C} / \mathrm{T}$ & $\mathrm{D} / \mathrm{T}$ & $f(r)$ & $\mathrm{Np}$ & $\begin{array}{c}\text { Tempo (h) de } \\
\text { CPU (LCCA) }\end{array}$ \\
\hline 4.20 & 100 & $1 / 2$ & $1 / 2$ & $-0,5 * r$ & 1230 & 1.66 \\
\hline 4.21 & 100 & $1 / 2$ & $3 / 4$ & $-2 / 9 * r$ & 1988 & 1.66 \\
\hline
\end{tabular}

Np: número de partículas na última fila da malha de discretização.

Tabela 4.12: Quadro-resumo das simulações realizadas nesta seção, 4.2.3, para dois discosatuadores, $\mathrm{S} / \mathrm{T}=1 / 4$.

Pelo quadro-resumo, observa-se que quase $50 \%$ das partículas da simulação tendem a 
se sedimentarem quando o impelidor fica próximo da largura do tanque, para uma melhor visualização, usando o critério citado, as partículas que percorreram uma distância menor são aquelas que tendem a se sedimentar, que pode ser observado pela distância percorrida em cada caso.

Assim, segue que as partículas que percorreram um maior espaço durante os 10 s são aquelas que ficaram suspensas por mais tempo e pelos histogramas se tem uma idéia do número de partículas suspensas/sedimentadas, ou seja, a variação da qualidade da suspensão sofre influência da relação do diâmetro do impelidor em função do diâmetro do tanque e sua posição em relação ao fundo do tanque, além da função que o representa. 


\subsubsection{Simulações para partículas não-esféricas}

Para finalizar os testes foram feitas simulações supondo que as partículas são nãoesféricas, ou seja, as partículas possuem uma forma geométrica qualquer que implica em variação em sua trajetória, alterando a direção e também o sentido. Para simular tal alteração, aplicou-se uma flutuação aleatória nas componentes $u$ e $v$ da velocidade das partículas.

Os testes foram feitos com o objetivo de se fazer uma estudo comparativo entre a trajetória de uma partícula esférica $\left(d_{p}=100 \mu\right)$ em um tanque com a relação $D / T=1 / 2$, $C / T=1 / 2$ e disco-atuador representado pela função $f(r)=-0,5 * r$, cujo campo de magnitude das velocidades do fluido está representado na Figura 4.1. Novamente, as condições inciais das partículas são cada uma em uma célula da malha $64 \times 64$, e o campo de velocidades utilizado é da Figura 4.1.

A Figura 4.26 representa a distribuição destas 4096 partículas $\left(d_{p}^{\prime}=100 \mu m\right.$, maior diâmetro da partícula não-esférica), com variação aleatória em $1 \%$ das componentes $u$ e $v$, com o disco-atuador representado por $f(r)=-0,5 * r, C / T=1 / 2, D / T=1 / 2$. 

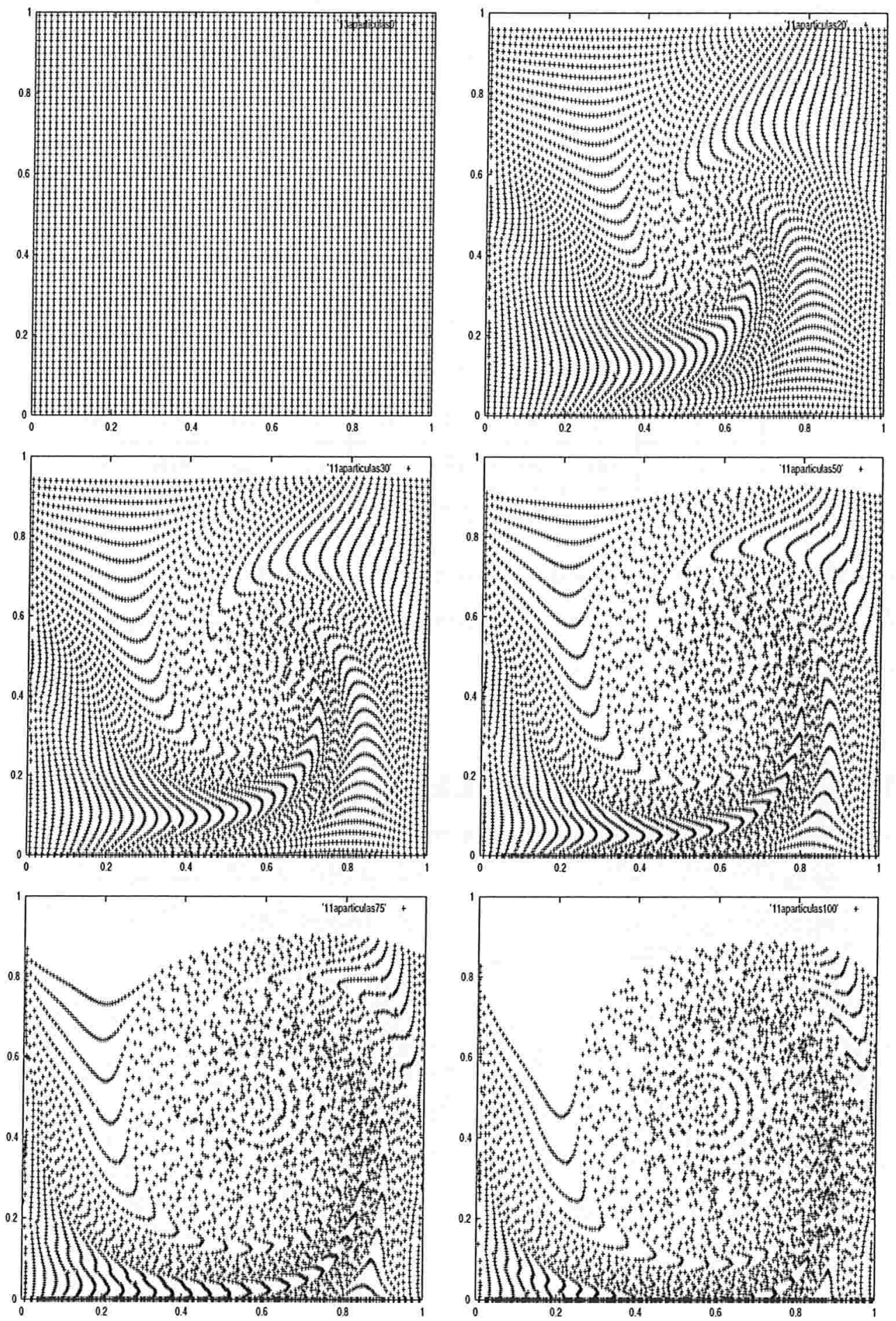

Figura 4.26: Posição das partículas não-esféricas ao longo da trajetória, com variação aleatória em $1 \%$ das componentes $u$ e $v$ da velocidade da partícula: $C / T=1 / 2, D / T=2$ e $f(r)=-0,5 * r$. 
A Tabela 4.13 mostra a distribuição destas 4096 partículas no tanque após 10s de simulação para uma variação em $1 \%$ das componentes das velocidades $u$ e $v$ das partículas.

\begin{tabular}{|c|c|c|c|c|c|c|c|c|}
\hline $\mathbf{j} \downarrow \mathbf{i} \rightarrow$ & $\mathbf{1}$ & $\mathbf{2}$ & $\mathbf{3}$ & $\mathbf{4}$ & $\mathbf{5}$ & $\mathbf{6}$ & $\mathbf{7}$ & $\mathbf{8}$ \\
\hline $\mathbf{1}$ & 0 & 0 & 0 & 0 & 1 & 6 & 3 & 0 \\
\hline $\mathbf{2}$ & 5 & 0 & 4 & 19 & 42 & 53 & 65 & 49 \\
\hline $\mathbf{3}$ & 23 & 0 & 17 & 38 & 64 & 80 & 74 & 64 \\
\hline $\mathbf{4}$ & 42 & 8 & 26 & 45 & 53 & 65 & 97 & 69 \\
\hline $\mathbf{5}$ & 39 & 30 & 31 & 37 & 54 & 61 & 81 & 91 \\
\hline $\mathbf{6}$ & 62 & 33 & 29 & 37 & 53 & 63 & 84 & 90 \\
\hline $\mathbf{7}$ & 66 & 51 & 40 & 44 & 47 & 58 & 104 & 75 \\
\hline $\mathbf{8}$ & 195 & 215 & 228 & 234 & 229 & 245 & 225 & 153 \\
\hline
\end{tabular}

Tabela 4.13: Número de partículas não-esférica por célula no instante final (10s) com variação aleatória em $1 \%$ das componentes $u$ e $v$ da velocidade da partícula: $C / T=1 / 2$, $D / T=1 / 2$ e $f(r)=-0,5 * r$.

A Figura 4.27 é a distribuição das 4096 partículas $\left(d_{p}=100 \mu m\right)$, com variação aleatória em $2 \%$ das componentes $u$ e $v$ da velocidade das partículas. 

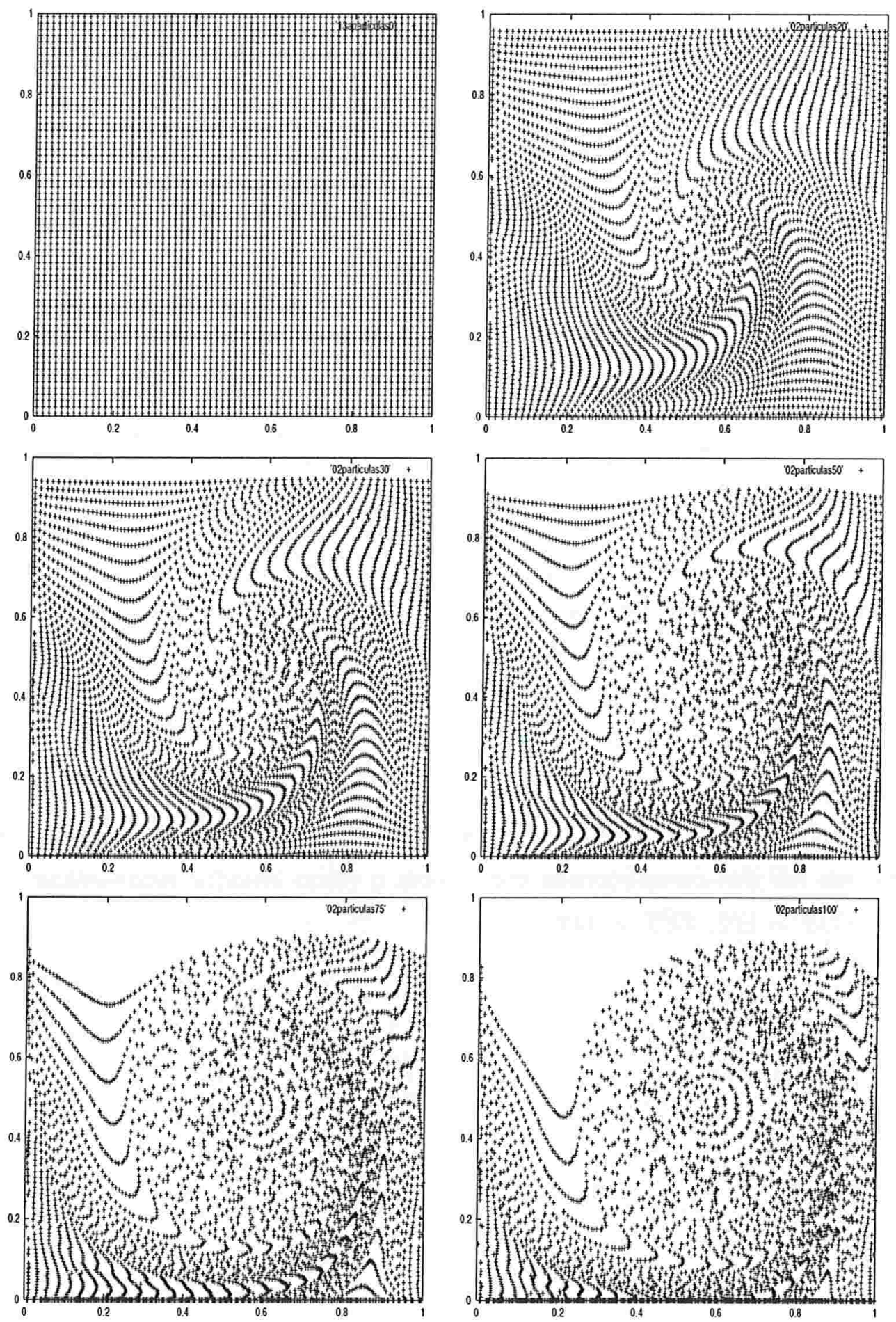

Figura 4.27: Posição das partículas não-esférica ao longo da trajetória, com variação aleatória em $2 \%$ das componentes $u$ e $v$ da velocidade da partícula: $C / T=1 / 2, D / T=1 / 2$ e $f(r)=-0,5 * r$. 
A Tabela 4.14, mostra a variação da trajetória para a partícula não-esférica variando em $2 \%$ o valor das componentes da velocidade com as mesmas condições da Figura 4.1.

\begin{tabular}{|c|c|c|c|c|c|c|c|c|}
\hline $\mathbf{j} \downarrow \mathbf{i} \rightarrow$ & $\mathbf{1}$ & $\mathbf{2}$ & $\mathbf{3}$ & $\mathbf{4}$ & $\mathbf{5}$ & $\mathbf{6}$ & $\mathbf{7}$ & $\mathbf{8}$ \\
\hline $\mathbf{1}$ & 0 & 0 & 0 & 0 & 1 & 6 & 4 & 0 \\
\hline $\mathbf{2}$ & 5 & 0 & 4 & 20 & 42 & 53 & 62 & 50 \\
\hline $\mathbf{3}$ & 24 & 0 & 18 & 38 & 63 & 79 & 75 & 64 \\
\hline $\mathbf{4}$ & 40 & 8 & 26 & 46 & 53 & 66 & 96 & 69 \\
\hline $\mathbf{5}$ & 40 & 30 & 30 & 38 & 54 & 60 & 82 & 91 \\
\hline $\mathbf{6}$ & 60 & 33 & 29 & 35 & 53 & 63 & 84 & 89 \\
\hline $\mathbf{7}$ & 68 & 51 & 40 & 46 & 46 & 58 & 105 & 76 \\
\hline $\mathbf{8}$ & 196 & 213 & 230 & 232 & 227 & 248 & 225 & 152 \\
\hline
\end{tabular}

Tabela 4.14: Número de partículas não-esférica por célula no instante final (10s) com variação em $2 \%$ das componentes $u$ e $v$ da velocidade da partícula: $C / T=1 / 2, D / T=1 / 2$ e $f(r)=-0,5 * r$.

A Figura 4.28 é a distribuição destas 4096 partículas $\left(d_{p}=100 \mu m\right)$, com variação aleatória em $5 \%$ das componentes $u$ e $v$, com o disco-atuador representado por $f(r)=$ $-0,5 * r, C / T=1 / 2, D / T=1 / 2$. 

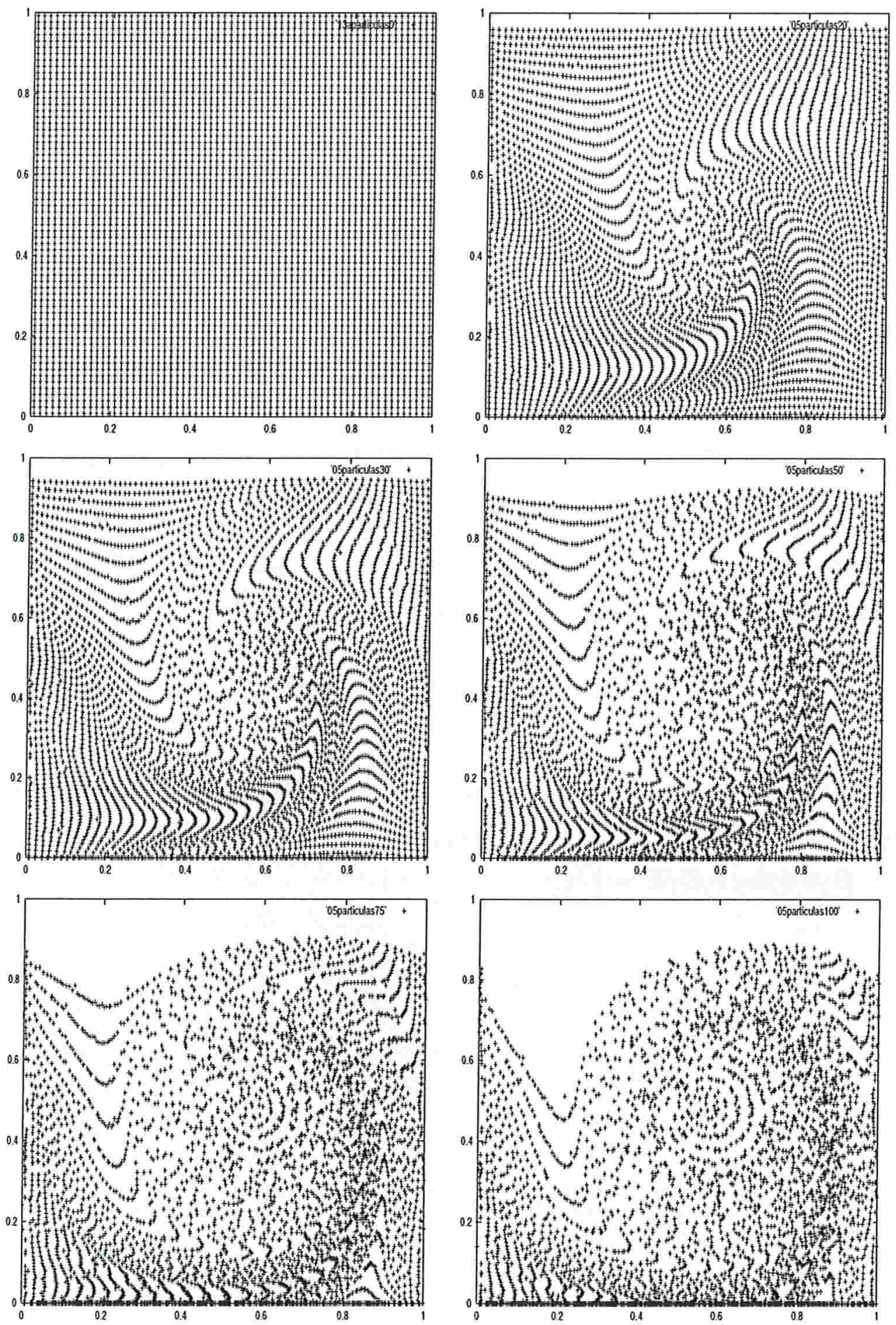

Figura 4.28: Posição das partículas não-esférica ao longo da trajetória, com variação aleatória em $5 \%$ das componentes $u$ e $v$ da velocidade da partícula: $C / T=1 / 2, D / T=2$ e $f(r)=-0,5 * r$. 
A Tabela 15, mostra a variação da trajetória para a partícula não-esférica variando em $5 \%$ o valor das componentes da velocidade das partículas, $u$ e $v$.

\begin{tabular}{|c|c|c|c|c|c|c|c|c|}
\hline $\mathbf{j} \downarrow \mathbf{i} \rightarrow$ & $\mathbf{1}$ & $\mathbf{2}$ & $\mathbf{3}$ & $\mathbf{4}$ & $\mathbf{5}$ & $\mathbf{6}$ & $\mathbf{7}$ & $\mathbf{8}$ \\
\hline $\mathbf{1}$ & 0 & 0 & 0 & 0 & 2 & 5 & 4 & 0 \\
\hline $\mathbf{2}$ & 5 & 0 & 4 & 22 & 45 & 51 & 62 & 51 \\
\hline $\mathbf{3}$ & 25 & 0 & 18 & 38 & 63 & 76 & 76 & 62 \\
\hline $\mathbf{4}$ & 39 & 10 & 24 & 48 & 50 & 65 & 98 & 68 \\
\hline $\mathbf{5}$ & 39 & 28 & 29 & 42 & 56 & 64 & 84 & 90 \\
\hline $\mathbf{6}$ & 59 & 36 & 29 & 35 & 54 & 60 & 85 & 94 \\
\hline $\mathbf{7}$ & 68 & 51 & 37 & 49 & 44 & 59 & 101 & 72 \\
\hline $\mathbf{8}$ & 197 & 214 & 226 & 231 & 227 & 250 & 226 & 149 \\
\hline
\end{tabular}

Tabela 4.15: Número de partículas não-esférica por célula no instante final (10s) com variação em $5 \%$ das componentes $u$ e $v$ da velocidade da partícula, $C / T=1 / 2, D / T=1 / 2$ e $f(r)=-0,5 * r$.

A Figura 4.29 é a distribuição destas 4096 partículas $\left(d_{p}=100 \mu m\right)$, com variação aleatória em $10 \%$ das componentes $u_{p}$ e $v_{p}$, com o disco-atuador representado por $f(r)=$ $-0,5 * r, C=0,5 * r, D / T=1 / 2$. 

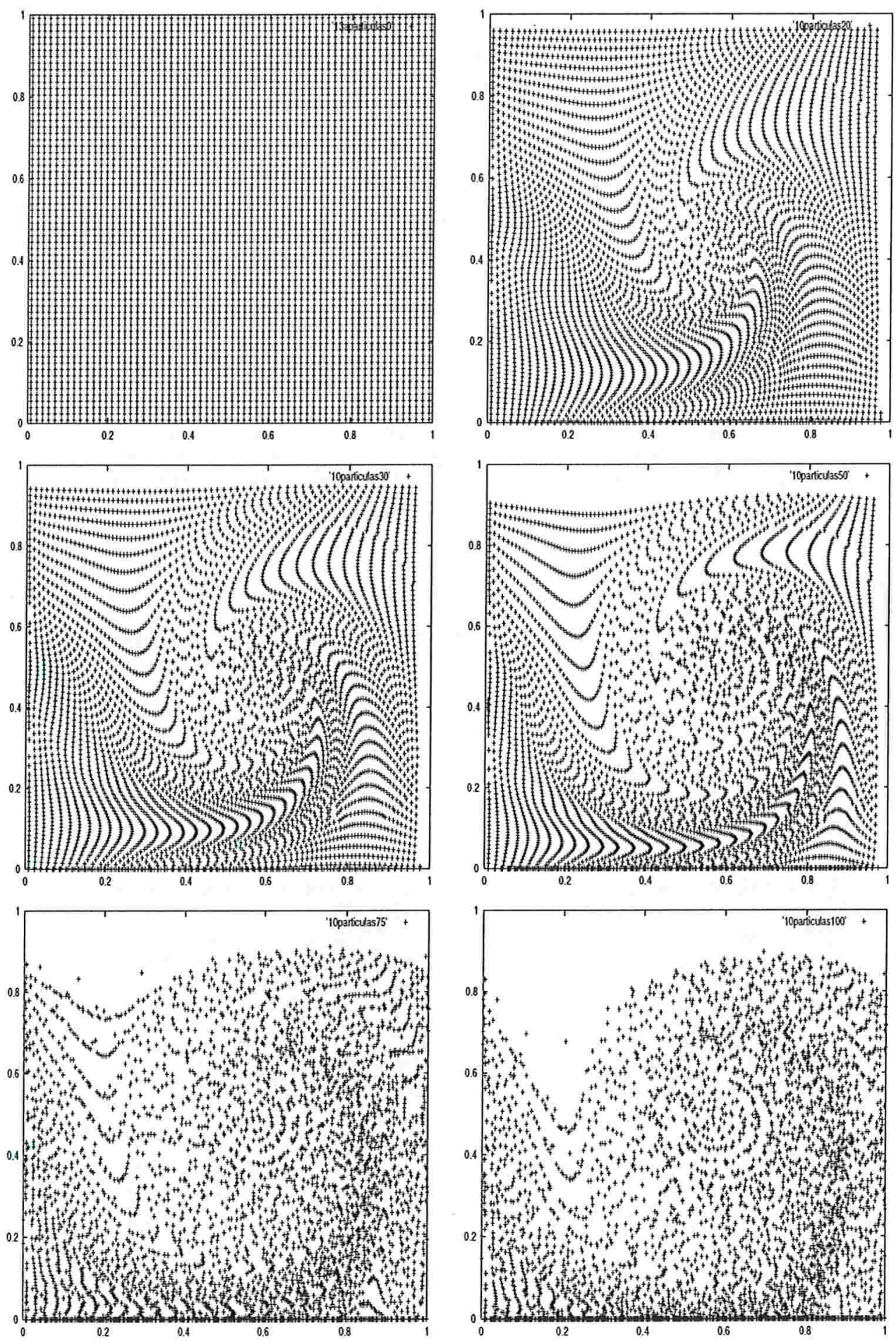

Figura 4.29: Posição das partículas não-esférica ao longo da trajetória, com variação aleatória em $10 \%$ das componentes $u$ e $v$ da velocidade da partícula: $C / T=1 / 2, D / T=2$ e $f(r)=-0,5 * r$. 
A Tabela 4.16, mostra a variação da trajetória para a partícula não-esférica variando em $10 \%$ o valor das componentes da velocidade das partículas, $u$ e $v$.

\begin{tabular}{|c|c|c|c|c|c|c|c|c|}
\hline $\mathbf{j} \downarrow \mathbf{i} \rightarrow$ & $\mathbf{1}$ & $\mathbf{2}$ & $\mathbf{3}$ & $\mathbf{4}$ & $\mathbf{5}$ & $\mathbf{6}$ & $\mathbf{7}$ & $\mathbf{8}$ \\
\hline $\mathbf{1}$ & 0 & 0 & 0 & 0 & 2 & 6 & 4 & 0 \\
\hline $\mathbf{2}$ & 7 & 0 & 7 & 19 & 48 & 52 & 59 & 53 \\
\hline $\mathbf{3}$ & 27 & 1 & 14 & 39 & 61 & 81 & 75 & 63 \\
\hline $\mathbf{4}$ & 35 & 11 & 25 & 45 & 52 & 62 & 100 & 64 \\
\hline $\mathbf{5}$ & 44 & 30 & 27 & 47 & 57 & 66 & 80 & 98 \\
\hline $\mathbf{6}$ & 58 & 36 & 29 & 38 & 53 & 61 & 83 & 89 \\
\hline $\mathbf{7}$ & 66 & 47 & 40 & 46 & 46 & 63 & 105 & 73 \\
\hline $\mathbf{8}$ & 194 & 216 & 225 & 232 & 225 & 239 & 223 & 148 \\
\hline
\end{tabular}

Tabela 4.16: Número de partículas não-esférica por célula no instante final (10s) com variação aleatória de $10 \%$ das componentes $u$ e $v$ da velocidade da partícula, $C / T=1 / 2$, $D / T=1 / 2$ e $f(r)=-0,5 * r$. 
Os gráficos com a distância percorrida pelas partículas em cada simulação são apresentadas nas Figuras 4.30-4.33.

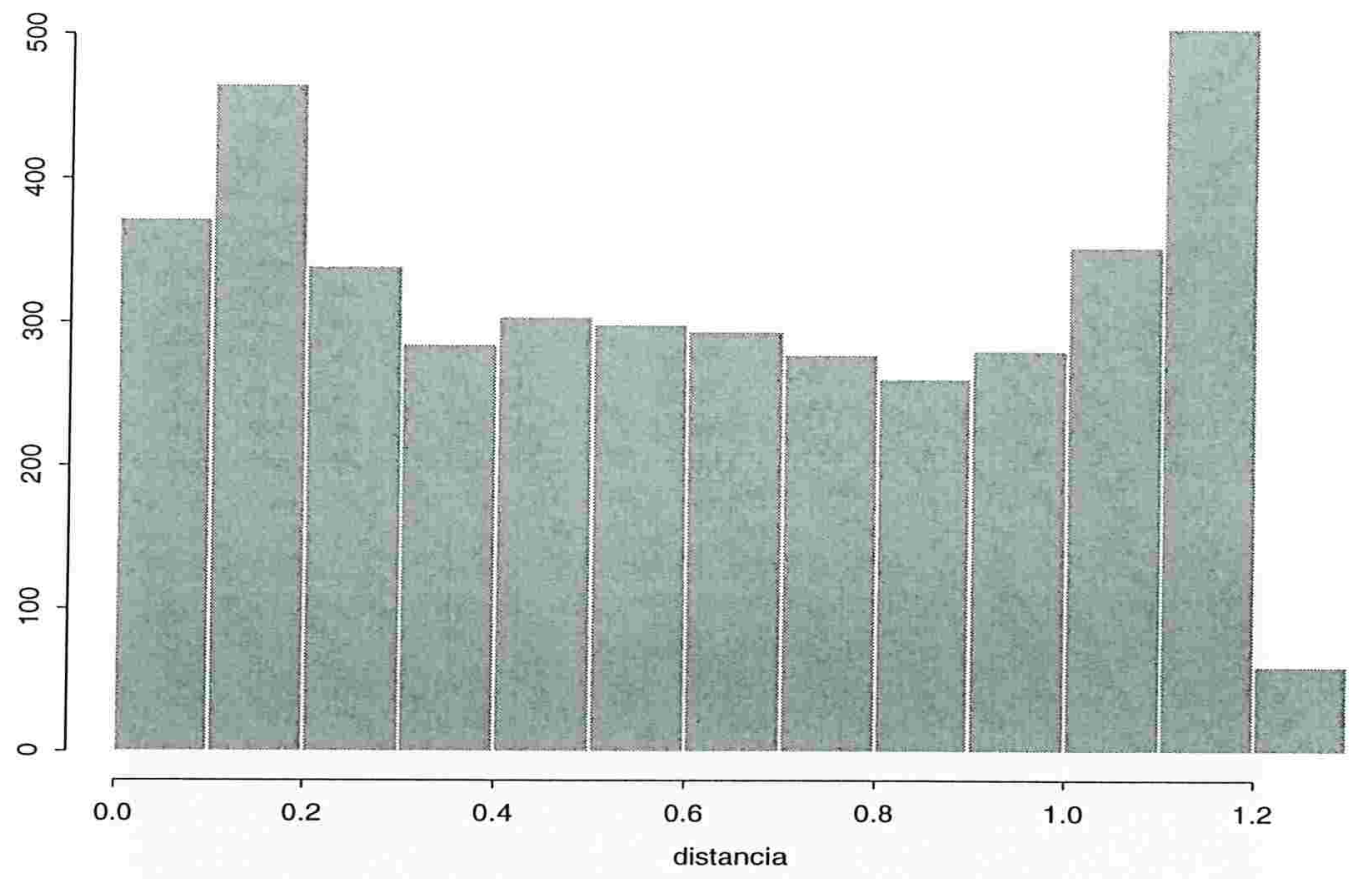

Figura 4.30: distância percorrida $\times$ número de partículas, representando o espaço percorrido pelas 4096 partículas não-esféricas ao longo da trajetória com uma variação aleatória de $1 \%$ das componentes da velocidade da partícula. 


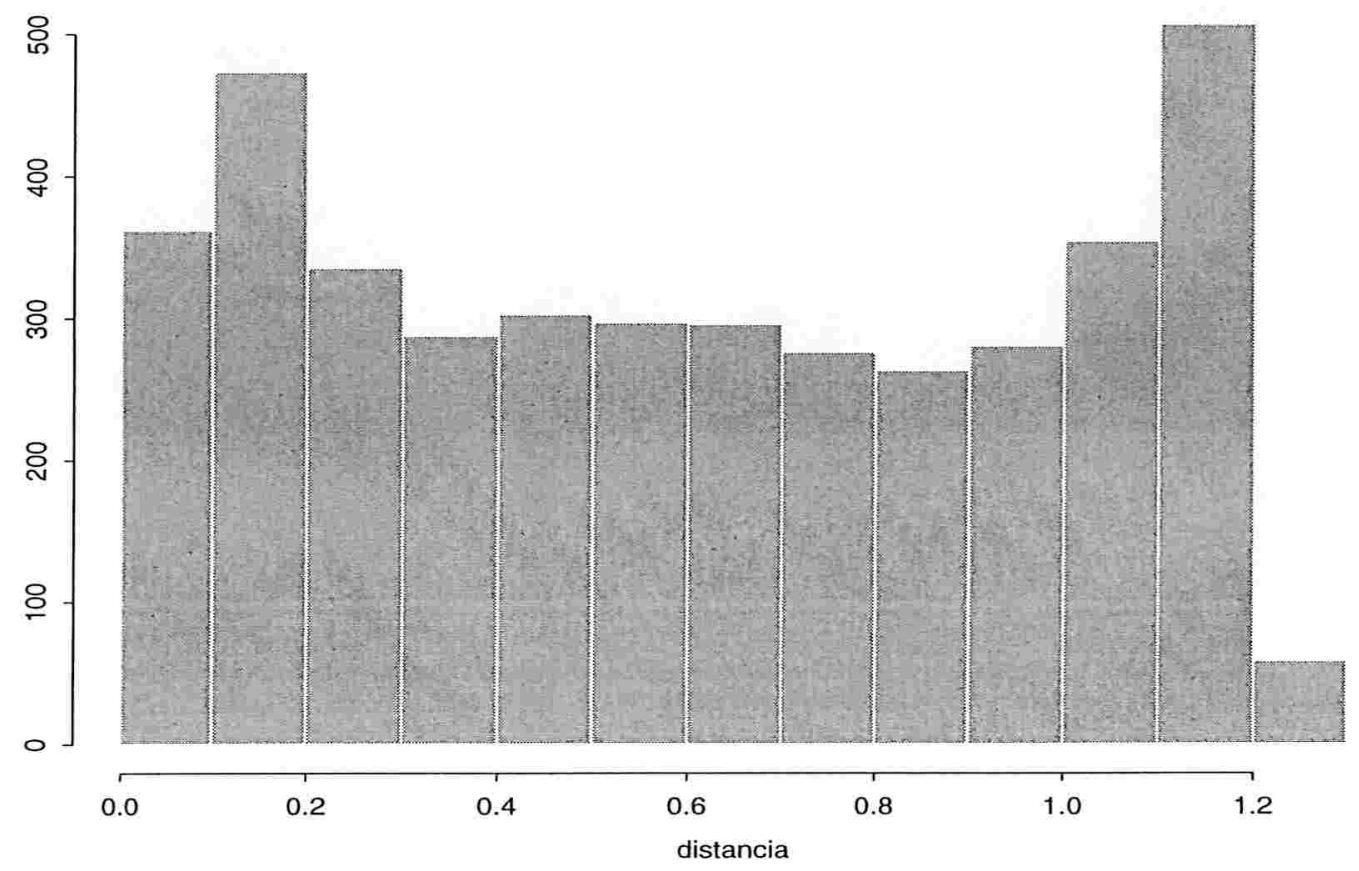

Figura 4.31: distância percorrida $\times$ número de partículas, representando o espaço percorrido pelas 4096 partículas não-esféricas ao longo da trajetória com uma variação aleatória de $2 \%$ das componentes da velocidade da partícula. 


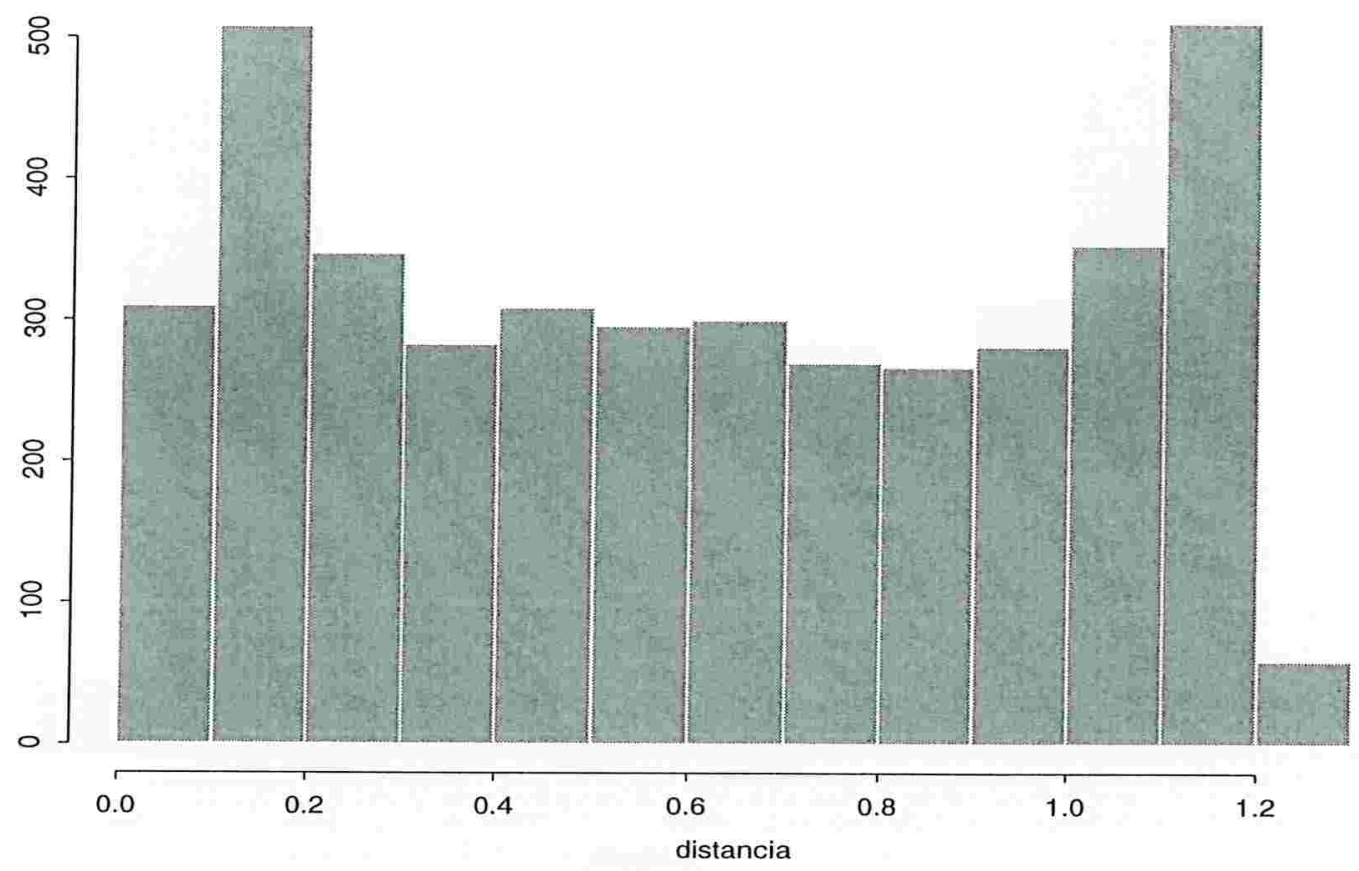

Figura 4.32: distância percorrida $\times$ número de partículas, representando o espaço percorrido pelas 4096 partículas não-esféricas ao longo da trajetória com uma variação aleatória de $5 \%$ das componentes da velocidade da partícula. 


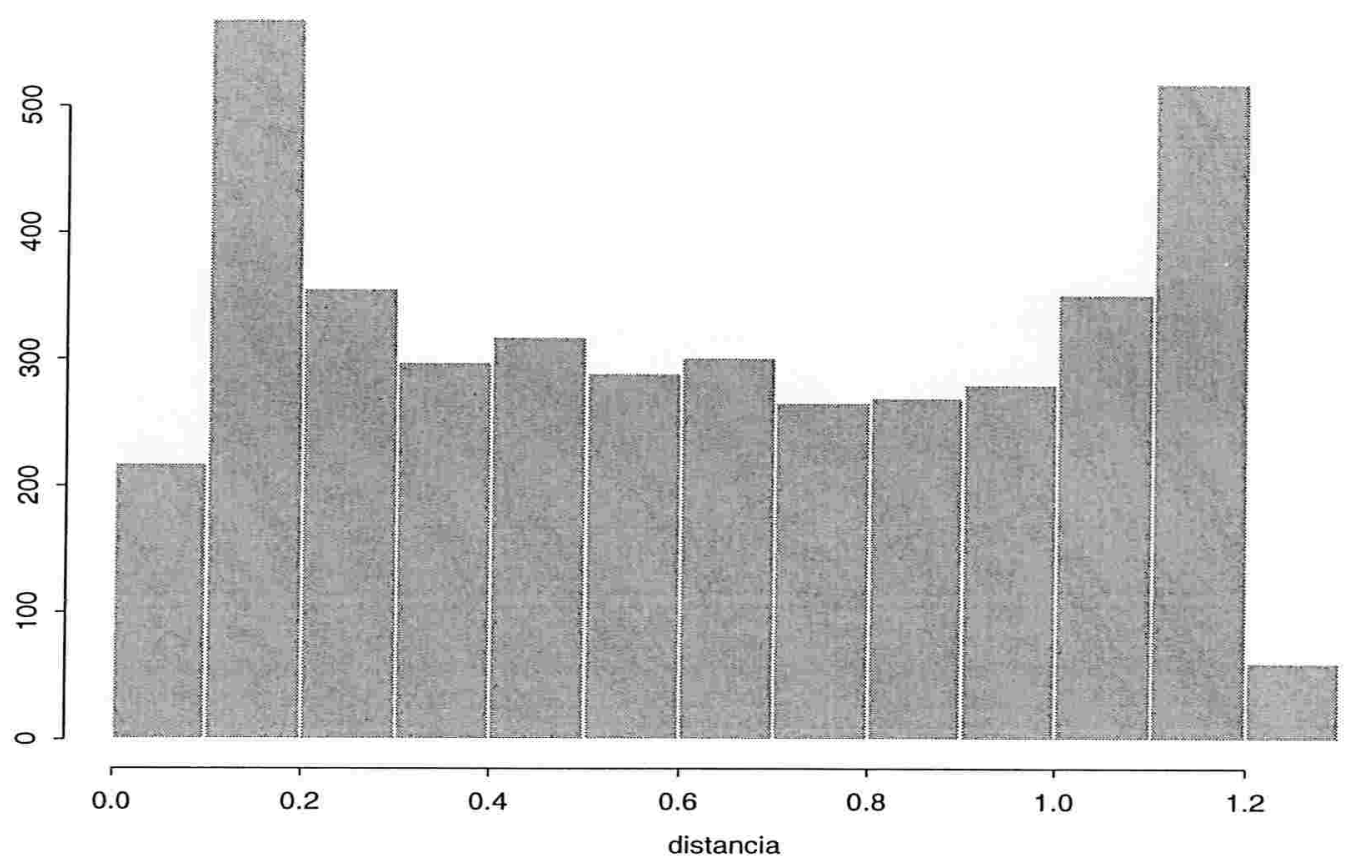

Figura 4.33: distância percorrida $\times$ número de partículas, representando o espaço percorrido pelas 4096 partículas não-esféricas ao longo da trajetória com uma variação aleatória de $10 \%$ das componentes da velocidade da partícula. 
E na Figura 4.34, a posição final das partículas em cada caso simulado.
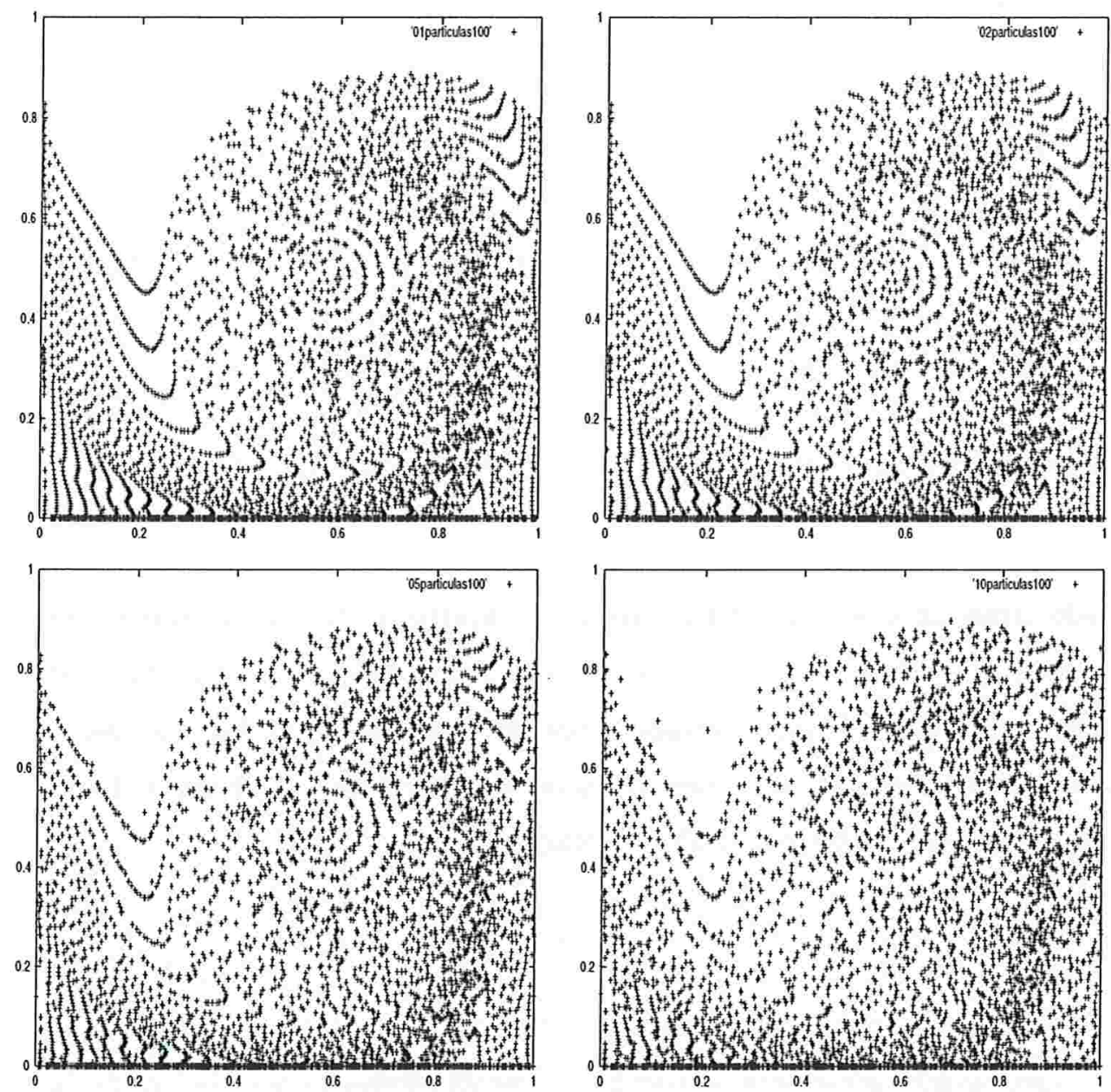

Figura 4.34: Posição das partículas não-esféricas, com variação aleatória em $1 \%, 2 \%$, $5 \%$ e $10 \%$ das componentes $u$ e $v$ da velocidade da partícula: $C / T=1 / 2, D / T=2$ e $f(r)=-0,5 * r$. 
O quadro-resumo apresentado na Tabela 4.15, apresenta uma visão geral do comportamento das partículas não-esféricas:

\begin{tabular}{|c|c|c|c|c|c|}
\hline $\begin{array}{c}\text { Simulação } \\
\text { (Figura) }\end{array}$ & $\begin{array}{c}\text { Variação de } \\
u_{p} \text { e } v_{p}\end{array}$ & $\mathrm{C} / \mathrm{T}$ & $\mathrm{D} / \mathrm{T}$ & $f(r)$ & $\begin{array}{c}\text { Número de partículas } \\
\text { (última fila) }\end{array}$ \\
\hline 4.26 & $1 \%$ & $1 / 2$ & $1 / 2$ & $-0,5 * r$ & 1065 \\
\hline 4.27 & $2 \%$ & $1 / 2$ & $1 / 2$ & $-0,5 * r$ & 1053 \\
\hline 4.28 & $5 \%$ & $1 / 2$ & $1 / 2$ & $-0,5 * r$ & 1055 \\
\hline 4.29 & $10 \%$ & $1 / 2$ & $1 / 2$ & $-0,5 * r$ & 1028 \\
\hline
\end{tabular}

Tabela 4.17: Quadro-resumo das simulações realizadas nesta seção, 4.2.4.

Fazendo uma análise da última linha da malha e dos histogramas da Figuras 3033, observa-se que o número de partículas que tendem a se sedimentar é menor quando há uma variação em $10 \%$ das componentes da velocidade, embora a mesma seja pouco significativa. Tal resultado pode ser observado nos gráficos da Figura 4.33 que mostra a posição final das partículas em cada simulação. 


\section{Conclusão}

Com este trabalho mostrou-se o potencial da aplicação da CFD (Computational Fluid Dynamics) na simulação de determinados processos em tanques agitados. Observou-se a possibilidade do uso de um código de simulação, partindo de um modelo simplificado, permitindo o trabalho conjunto entre Analistas Numéricos e Engenheiros Químicos na resolução de problemas da Engenharia Química que envolvem tanques agitados e o transporte de partículas.

A modelagem do tanque agitado foi feita através das equações de Navier-Stokes em coordenadas cilíndricas, partindo da solução da mesma em uma cavidade e o impelidor representado por um disco-atuador. Como o método de discretização adotado, Método MAC (marker and cell), exige condições de estabilidade, estudos foram feitos para esta análise obteve-se a região de estabilidade e definida pelos fatores de relaxação $\alpha$ e $\beta$, determinados através dos critérios de estabilidade de Fourier para $\Delta x=\Delta y$ :

$$
\Delta t \leq\left(\frac{\operatorname{Re} \Delta^{2} x}{4} \cdot \alpha\right), \alpha<1
$$

E do método matricial de análise de estabilidade

$$
\frac{4 \Delta t}{\Delta^{2} x}\left(\frac{1}{R e}+\frac{\Delta c_{0}^{2}}{2}\right) \leq 1
$$

e observou-se que a região encontrada satisfaz os critérios teóricos de estabilidade.

O movimento do fluido foi obtido definindo uma função para o mesmo e a posição do disco em relação ao fundo do tanque $(\mathrm{C} / \mathrm{T}$ ), a relação $\mathrm{D} / \mathrm{T}$ (diâmetro do impelidor pelo diâmetro interno do tanque) e a função que o define influenciam no campo de velocidades do fluido. 
O modelo adotado para o transporte de partículas é um sistema de EDO's e foi feita uma análise do comportamento das partículas em uma região do tanque cilíndrico, $r \times z$ : $[0,1] \times[0,1]$ sem a influência do campo de velocidades do fluido para a constante de elasticidade $\epsilon, 0<\epsilon \leq 1$ com partículas dispostas em pontos na diagonal da região com uma velocidade inicial $\left(u_{p}=-1.0 \mathrm{~m} / \mathrm{s}\right.$ e $\left.v_{p}=0 \mathrm{~m} / \mathrm{s}\right)$ e percebeu-se que a perda de energia destas partículas ao longo do tempo dependem de sua posição na região de simulação e da ação da gravidade $(g)$, ou seja, quanto mais afastada do fundo do tanque a partícula percorre uma distância maior para as constantes de elasticidade testadas.

$\mathrm{Na}$ análise da suspensão/sedimentação, importante nas indústrias químicas, foram empregados:

- na geometria do tanque:

- função que define o disco-atuador,

$$
f(r)=-0.5 r \text { e } f(r)-2 / 9 * r ;
$$

- distância do impelidor ao fundo do tanque $(\mathrm{C} / \mathrm{T})$,

$$
C / T=1 / 2 \text { e } C / T=1 / 4
$$

- relação $\mathrm{D} / \mathrm{T}$ ( $\mathrm{D}=$ diâmetro do imeplidor e $\mathrm{T}=$ diâmetro interno do tanque),

$$
D / T=1 / 2 \text { e } D / T=3 / 4 ;
$$

- distância entre impelidores (S/T)

$$
S / T=1 / 4
$$

- das partículas:

- 4096 partículas esféricas de diâmetro $d_{p}=10 \mu \mathrm{m}, 50 \mu \mathrm{m}$ e $100 \mu \mathrm{m}$, cada uma em cada célula da malha de discretização da região $[0,1] \times[0,1]$ discretizada para $\mathrm{n}=64$, no instante inicial;

$-C_{D}=0,44$ (coeficiente de arrasto);

- tempo de simulação: 10s.

Para as simulações efetuadas, obteve-se o quadro-resumo (Tabela 5.1) 


\begin{tabular}{|c|c|c|c|c|c|c|c|}
\hline $\begin{array}{c}\text { Simulação } \\
\text { (Figura) }\end{array}$ & $\begin{array}{c}d_{p} \\
(\mu \mathrm{m})\end{array}$ & $\mathrm{C} / \mathrm{T}$ & $\mathrm{S} / \mathrm{T}$ & $\mathrm{D} / \mathrm{T}$ & $f(r)$ & $\mathrm{Np}$ & $\begin{array}{c}\text { Tempo (h) de } \\
\text { CPU (LCCA) }\end{array}$ \\
\hline 4.4 & 10 & $1 / 2$ & & $1 / 2$ & $-0,5 * r$ & 343 & 16.41 \\
\hline 4.5 & 50 & $1 / 2$ & & $1 / 2$ & $-0,5 * r$ & 750 & 1.66 \\
\hline 4.2 & 100 & $1 / 2$ & & $1 / 2$ & $-0,5 * r$ & 1059 & 1.66 \\
\hline 4.9 & 100 & $1 / 2$ & & $3 / 4$ & $-0,5 * r$ & 1083 & 1.65 \\
\hline 4.12 & 100 & $1 / 2$ & & $3 / 4$ & $-2 / 9 * r$ & 896 & 1.68 \\
\hline 4.15 & 100 & $1 / 4$ & & $1 / 2$ & $-0,5 * r$ & 1214 & 1.70 \\
\hline 4.18 & 100 & $1 / 4$ & & $3 / 4$ & $-2 / 9 * r$ & 1326 & 1.66 \\
\hline 4.21 & 100 & $1 / 4$ & $1 / 4$ & $1 / 2$ & $-0,5 * r$ & 1230 & 1.66 \\
\hline 4.24 & 100 & $1 / 4$ & $1 / 4$ & $3 / 4$ & $-2 / 9 * r$ & 1988 & 1.66 \\
\hline
\end{tabular}

$\mathrm{Np}$ : número de partículas na última fila da malha de discretização

Tabela 5.1: Quadro-resumo das simulações realizadas na análise da trajetória e sedimentação das partículas.

Pelos critérios adotados para análise do número de partículas suspensas/sedimentadas (distância percorrida durante a simulação e o número de partículas na última fila da malha de discretização), notou-se que, como era de se esperar, as partículas com menor diâmetro tendem a ficar mais tempo suspensas durante a simulação devido a ação da gravidade.

Ainda, das simulações realizadas com partículas com $d_{p}=100 \mu m$ de diâmetro, a que apresentou um maior número de partículas suspensas foi a simulação realizada para $\mathrm{D} / \mathrm{T}=3 / 4, \mathrm{C} / \mathrm{T}=1 / 4$ e $f(r)=-2 / 9 * r$, para as dimensões do tanque escolhida.

Do estudo feito para partículas não-esféricas $\left(d_{p}^{\prime}=100 \mu m\right)$ obteve-se os resultados apresentados no quadro-resumo (Tabela 5.2). 


\begin{tabular}{|c|c|c|c|c|c|}
\hline $\begin{array}{c}\text { Simulação } \\
\text { (Figura) }\end{array}$ & var & $\mathrm{C} / \mathrm{T}$ & $\mathrm{D} / \mathrm{T}$ & $f(r)$ & $\begin{array}{c}\text { Número de partículas } \\
\text { (última fila) }\end{array}$ \\
\hline 4.2 & $0 \%$ & $1 / 2$ & $1 / 2$ & $-0.5 * r$ & 1059 \\
\hline 4.26 & $1 \%$ & $1 / 2$ & $1 / 2$ & $-0.5 * r$ & 1065 \\
\hline 4.27 & $2 \%$ & $1 / 2$ & $1 / 2$ & $-0.5 * r$ & 1053 \\
\hline 4.28 & $5 \%$ & $1 / 2$ & $1 / 2$ & $-0.5 * r$ & 1055 \\
\hline 4.29 & $10 \%$ & $1 / 2$ & $1 / 2$ & $-0.5 * r$ & 1028 \\
\hline
\end{tabular}

var: variação aleatória das componentes $u_{p}$ e $v_{p}$ da velocidade da partícula.

Tabela 5.2: Quadro-resumo das simulações realizadas na análise da trajetória e sedimentação das partículas não-esféricas.

Percebeu-se que houve uma variação muito pequena no comportamento das partículas ao longo da trajetória, alterando-a de forma pouco significativa.

Dada a complexidade e o número de parâmetros envolvidos esta elaboração em regime laminar é uma etapa inicial necessária; como trabalho futuro sugere-se:

- mudar de regime laminar para regime turbulento, mais empregado nas indústrias químicas;

- mudar o método de discretização para a pressão, passando do método explícito para um método implícito, por exemplo o uso da equação de Poisson para pressão, visando a evolução temporal conjugada do escoamento e do transporte de partículas;

- substituir a superfície superior, atualmente a parede é sólida, por uma superfície livre;

- desenvolver um estudo com geometrias mais complexas acrescentando os outros parâmetros envolvidos na agitação como torque, bombeamento, potência e outros, para se ter um modelo mais próximo da realidade.

O objetivo do trabalho no contexto de modelagem matemática foi cumprido. Além disso, os estudos realizados representam um ponto de partida para a construção de um modelo mais completo, seguindo a filosofia de substituição de ferramentas proprietárias. 


\section{Equações de Navier Stokes em Coordenadas Cilíndricas}

Para a dedução das equações de Navier-Stokes em um sistema de coordenadas cilíndricas, incluindo um termo de força de corpo, parte-se das equações em sua forma cartesiana (A.1).

$$
\rho\left(\frac{\partial v_{i}}{\partial t}+v_{j} \frac{\partial v_{i}}{\partial v_{j}}\right)=-\frac{\partial p}{\partial x_{i}}+\mu \frac{\partial}{\partial x_{j}}\left(\frac{\partial v_{i}}{\partial x_{j}}+\frac{\partial v_{j}}{\partial x_{i}}\right)+f_{i}
$$

Como as componentes da velocidade são $(\mathrm{u}, \mathrm{v}, \mathrm{w})$ em coordenadas cartesianas $(\mathrm{x}, \mathrm{y}, \mathrm{z})$ então as equações ficam:

$$
\left\{\begin{aligned}
\rho\left(\frac{\partial u}{\partial t}+u \frac{\partial u}{\partial x}+v \frac{\partial u}{\partial y}+w \frac{\partial u}{\partial z}\right) & =-\frac{\partial p}{\partial x}+\mu\left(\frac{\partial^{2} u}{\partial x^{2}}+\frac{\partial^{2} u}{\partial y^{2}}+\frac{\partial^{2} u}{\partial z^{2}}\right)+X \\
\rho\left(\frac{\partial u}{\partial t}+u \frac{\partial v}{\partial x}+v \frac{\partial v}{\partial y}+w \frac{\partial v}{\partial z}\right) & =-\frac{\partial p}{\partial y}+\mu\left(\frac{\partial^{2} v}{\partial x^{2}}+\frac{\partial^{2} v}{\partial y^{2}}+\frac{\partial^{2} v}{\partial z^{2}}\right)+Y \\
\rho\left(\frac{\partial u}{\partial t}+u \frac{\partial w}{\partial x}+v \frac{\partial w}{\partial y}+w \frac{\partial w}{\partial z}\right) & =-\frac{\partial p}{\partial x}+\mu\left(\frac{\partial^{2} w}{\partial x^{2}}+\frac{\partial^{2} w}{\partial y^{2}}+\frac{\partial^{2} w}{\partial z^{2}}\right)+Z
\end{aligned}\right.
$$

onde $\vec{F}=(X, Y, Z)$, ou ainda, podemos escrever:

$$
\rho\left(\frac{\partial \vec{V}}{\partial t}+(\vec{V} \cdot \nabla) \vec{V}\right)=-\nabla p+\mu \nabla^{2} \vec{V}+F
$$

Prova-se a identidade abaixo que será substituída em (A.3), uma vez que a forma $(\vec{V} . \nabla) \vec{V}$ não é conveniente para se fazer uma troca de sistema de coordenadas.

$$
(\vec{V} \cdot \nabla) \vec{V}=\nabla\left(\frac{1}{2} \vec{V}^{2}\right)-\vec{V} \times(\nabla \times \vec{V})
$$


No segundo membro de (A.4), tem-se:

$$
\begin{aligned}
& \nabla\left(\frac{1}{2} \vec{V}^{2}\right)=\left(\frac{\partial}{\partial x}, \frac{\partial}{\partial y}, \frac{\partial}{\partial z}\right)\left(\frac{1}{2}(u, v, w) \cdot(u, v, w)\right)= \\
& =\left(\frac{\partial}{\partial x}\left(\frac{1}{2} u^{2}+\frac{1}{2} v^{2}+\frac{1}{2} w^{2}\right), \frac{\partial}{\partial y}\left(\frac{1}{2} u^{2}+\frac{1}{2} v^{2}+\frac{1}{2} w^{2}\right), \frac{\partial}{\partial z}\left(\frac{1}{2} u^{2}+\frac{1}{2} v^{2}+\frac{1}{2} w^{2}\right)\right)= \\
& =\left(u \frac{\partial u}{\partial x}+v \frac{\partial v}{\partial x}+w \frac{\partial w}{\partial x}, u \frac{\partial u}{\partial y}+v \frac{\partial v}{\partial y}+w \frac{\partial w}{\partial y}, u \frac{\partial u}{\partial z}+v \frac{\partial v}{\partial z}+w \frac{\partial w}{\partial z}\right)
\end{aligned}
$$

ainda,

$$
\nabla \times \vec{V}=\left|\begin{array}{ccc}
\vec{i} & \vec{j} & \vec{k} \\
\frac{\partial}{\partial x} & \frac{\partial}{\partial y} & \frac{\partial}{\partial w} \\
u & v & w
\end{array}\right|=\left(\frac{\partial w}{\partial y}-\frac{\partial v}{\partial z}, \frac{\partial u}{\partial z}-\frac{\partial w}{\partial x}, \frac{\partial v}{\partial x}-\frac{\partial u}{\partial y}\right)
$$

e, calculando $\vec{V} \times(\nabla \times \vec{V})$ :

$$
\begin{aligned}
& \vec{V} \times(\nabla \times \vec{V})=\left|\begin{array}{ccc}
\vec{i} & \vec{j} & \vec{k} \\
u & v & w \\
\frac{\partial w}{\partial y}-\frac{\partial v}{\partial z} & \frac{\partial u}{\partial z}-\frac{\partial w}{\partial x} & \frac{\partial v}{\partial x}-\frac{\partial u}{\partial y}
\end{array}\right|= \\
& =\left(v \frac{\partial v}{\partial x}-v \frac{\partial u}{\partial y}-w \frac{\partial u}{\partial z}+w \frac{\partial w}{\partial x}, w \frac{\partial w}{\partial y}-w \frac{\partial v}{\partial z}-u \frac{\partial v}{\partial x}+v \frac{\partial u}{\partial y}, u \frac{\partial u}{\partial z}-u \frac{\partial w}{\partial x}-v \frac{\partial w}{\partial y}+v \frac{\partial v}{\partial z}\right)
\end{aligned}
$$

Assim, tem-se:

$$
\nabla\left(\frac{1}{2} \vec{V}^{2}\right)-\vec{V} \times(\nabla \times \vec{V})=\left(u \frac{\partial u}{\partial x}+v \frac{\partial u}{\partial y}+w \frac{\partial u}{\partial z}, u \frac{\partial v}{\partial x}+v \frac{\partial v}{\partial y}+w \frac{\partial v}{\partial z}, w \frac{\partial w}{\partial x}+v \frac{\partial w}{\partial y}+w \frac{\partial w}{\partial z}\right)
$$

Desenvolvendo o primeiro membro de (A.4), tem-se:

$$
\begin{aligned}
& (\vec{V} \cdot \nabla) \vec{V}=\left((u, v, w) \cdot\left(\frac{\partial}{\partial x}, \frac{\partial}{\partial y}, \frac{\partial}{\partial z},\right)\right) \cdot(u, v, w)=\left(u \frac{\partial}{\partial x}+v \frac{\partial}{\partial y}+w \frac{\partial}{\partial z}\right) \cdot(u, v, w)= \\
& =\left(u \frac{\partial u}{\partial x}+v \frac{\partial u}{\partial y}+w \frac{\partial u}{\partial z}, u \frac{\partial v}{\partial x}+v \frac{\partial v}{\partial y}+w \frac{\partial v}{\partial z}, u \frac{\partial w}{\partial x}+v \frac{\partial w}{\partial y}+w \frac{\partial w}{\partial z}\right)
\end{aligned}
$$

E ainda, faz-se necessário mostrar a igualdade $\nabla \times(\nabla \times \vec{V})=\nabla(\nabla \cdot \vec{V})-\nabla^{2} \vec{V}$.

Assim: 


$$
\begin{aligned}
\nabla \times(\nabla \times \vec{V})= & \left|\begin{array}{ccc}
\vec{i} & \vec{j} & \vec{k} \\
\frac{\partial}{\partial x} & \frac{\partial}{\partial y} & \frac{\partial}{\partial w} \\
\frac{\partial w}{\partial y}-\frac{\partial v}{\partial z} & \frac{\partial u}{\partial z}-\frac{\partial w}{\partial x} & \frac{\partial v}{\partial x}-\frac{\partial u}{\partial y}
\end{array}\right|=\left(\frac{\partial^{2} v}{\partial y \partial x}-\frac{\partial^{2} u}{\partial y^{2}}-\frac{\partial^{2} u}{\partial z^{2}}+\frac{\partial^{2} w}{\partial z \partial x}\right.
\end{aligned}
$$

$\nabla \cdot \vec{V}=\left(\frac{\partial}{\partial x}, \frac{\partial}{\partial y}, \frac{\partial}{\partial z}\right) \cdot(u, v, w)=\frac{\partial u}{\partial x}+\frac{\partial v}{\partial y}+\frac{\partial w}{\partial z}$

Portanto,

$\nabla(\nabla \cdot \vec{V})=\left(\frac{\partial}{\partial x}, \frac{\partial}{\partial y}, \frac{\partial}{\partial z}\right) \cdot\left(\frac{\partial u}{\partial x}+\frac{\partial v}{\partial y}+\frac{\partial w}{\partial z}\right)=$

$=\left(\frac{\partial^{2} u}{\partial^{2} x}+\frac{\partial^{2} v}{\partial x \partial y}+\frac{\partial^{2} w}{\partial x \partial z}, \frac{\partial^{2} u}{\partial y \partial x}+\frac{\partial^{2} v}{\partial y^{2}}+\frac{\partial^{2} w}{\partial y \partial z}, \frac{\partial^{2} u}{\partial z \partial x}+\frac{\partial^{2} v}{\partial z \partial y}+\frac{\partial^{2} w}{\partial z^{2}}\right)$

Mas:

$\nabla^{2} \vec{V}=\left(\nabla^{2} u, \nabla^{2} v, \nabla^{2} w\right)=$

$=\left(\frac{\partial^{2} u}{\partial x^{2}}+\frac{\partial^{2} u}{\partial y^{2}}+\frac{\partial^{2} u}{\partial z^{2}}, \frac{\partial^{2} v}{\partial x^{2}}+\frac{\partial^{2} v}{\partial y^{2}}+\frac{\partial^{2} v}{\partial z^{2}}, \frac{\partial^{2} w}{\partial x^{2}}+\frac{\partial^{2} w}{\partial y^{2}}+\frac{\partial^{2} w}{\partial z^{2}}\right)$

Assim, tem-se:

$$
\begin{aligned}
\nabla\left(\nabla \cdot \vec{V}-\nabla^{2} \vec{V}\right)= & \left(\frac{\partial^{2} v}{\partial x \partial y}+\frac{\partial^{2} w}{\partial x \partial z}-\frac{\partial^{2} u}{\partial y^{2}}-\frac{\partial^{2} u}{\partial z^{2}}, \frac{\partial^{2} u}{\partial y \partial x}+\right. \\
& \left.+\frac{\partial^{2} w}{\partial y \partial z}-\frac{\partial^{2} v}{\partial x^{2}}-\frac{\partial^{2} v}{\partial w^{2}}, \frac{\partial^{2} u}{\partial z \partial x}+\frac{\partial^{2} v}{\partial z \partial y}-\frac{\partial^{2} w}{\partial x^{2}}-\frac{\partial^{2} w}{\partial y^{2}}\right)
\end{aligned}
$$

Logo, de (A.5) e (A.6), tem-se:

$$
\nabla \times(\nabla \times \vec{V})=\nabla(\nabla \cdot \vec{V})-\nabla^{2} \vec{V}
$$

Então, considerando as identidades (A.4) e (A.7) a equação vetorial (A.3) pode ser escrita na forma invariante usada na transformação de coordenadas, ou seja:

$$
\rho\left(\frac{\partial \vec{V}}{\partial t}+\nabla\left(\frac{1}{2} \vec{V}^{2}\right)-\vec{V} \times(\nabla \times \vec{V})\right)=-\nabla p+\mu \nabla \times(\nabla \times \vec{V})+F
$$


ou ainda:

$$
\rho\left(\frac{\partial \vec{V}}{\partial t}-\vec{V} \times(\nabla \times \vec{V})\right)=-\nabla\left(\rho+\frac{1}{2} \vec{V}^{2}\right)-\mu \nabla \times(\nabla \times \vec{V})
$$

Agora, considerando $\left(x_{1}, x_{2}, x_{3}\right)$ as coordenadas de um sistema ortogonal qualquer e $\vec{V}=\left(v_{1}, v_{2}, v_{3}\right)$ as coordenadas correspondentes da velocidade, o incremento em alguma direção ê é dado por $d s$, Figura A.1, assim:

$$
d s=d \bar{s} \hat{e}
$$

$\log \mathrm{e}$

$$
d s=h_{1} \partial x_{1} \vec{i}+h_{2} \partial x_{2} \vec{j}+h_{3} \partial x_{3} \vec{k}
$$

e

$$
d s^{2}=d s . d s=h_{1}^{2} \partial x_{1}^{2}+h_{2}^{2} \partial x_{2}^{2}+h_{3}^{2} \partial x_{3}^{2}
$$

onde $h_{j} \partial x_{j}$ é o incremento na direção de $x_{j}$.

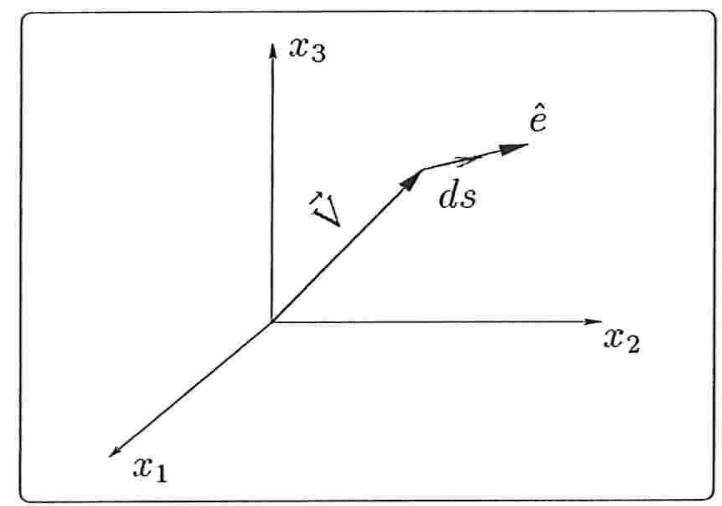

Figura A.1: Incremento em uma direção $\hat{e}$

É possível obter:

$$
\begin{gathered}
\nabla f=\left(\frac{1}{h_{1}} \frac{\partial f}{\partial x_{1}}, \frac{1}{h_{2}} \frac{\partial f}{\partial x_{2}}, \frac{1}{h_{3}} \frac{\partial f}{\partial x_{3}},\right), \\
\operatorname{div} \vec{V}=\nabla f=\frac{1}{h_{1} h_{2} h_{3}}\left(\frac{\partial}{\partial x_{1}}\left(h_{2} h_{3} v_{1}\right)+\frac{\partial}{\partial x_{2}}\left(h_{3} h_{1} v_{2}\right)+\frac{\partial}{\partial x_{3}}\left(h_{1} h_{2} v_{3}\right)\right)
\end{gathered}
$$


e $\nabla \times \vec{V}=\left(\gamma_{1}, \gamma_{2}, \gamma_{3}\right)$, com:

$$
\left\{\begin{array}{l}
\gamma_{1}=\frac{1}{h_{2} h_{3}}\left(\frac{\partial}{\partial x_{2}}\left(h_{3} v_{3}\right)-\frac{\partial}{\partial x_{3}}\left(h_{2} v_{2}\right)\right) \\
\gamma_{2}=\frac{1}{h_{3} h_{1}}\left(\frac{\partial}{\partial x_{3}}\left(h_{1} v_{1}\right)-\frac{\partial}{\partial x_{1}}\left(h_{3} v_{3}\right)\right) \\
\gamma_{3}=\frac{1}{h_{1} h_{2}}\left(\frac{\partial}{\partial x_{1}}\left(h_{2} v_{2}\right)-\frac{\partial}{\partial x_{2}}\left(h_{1} v_{1}\right)\right)
\end{array}\right.
$$

E mais ainda:

$$
\begin{aligned}
& \vec{V} \times(\nabla \times \vec{V})=\left|\begin{array}{ccc}
\vec{i} & \vec{j} & \vec{k} \\
v_{1} & v_{2} & v_{3} \\
\gamma_{1} & \gamma_{2} & \gamma_{3}
\end{array}\right|=\left(v_{2} \gamma_{3}-v_{3} \gamma_{2}, v_{3} \gamma_{1}-v_{1} \gamma_{3}, v_{1} \gamma_{2}-v_{2} \gamma_{1}\right) \\
& \nabla \times(\nabla \times \vec{V})=\left(\varphi_{1}, \varphi_{2}, \varphi_{3}\right),
\end{aligned}
$$

onde:

$$
\left\{\begin{array}{l}
\varphi_{1}=\frac{1}{h_{2} h_{3}}\left(\frac{\partial}{\partial x_{2}}\left(h_{3} \gamma_{3}\right)-\frac{\partial}{\partial x_{3}}\left(h_{2} \gamma_{2}\right)\right) \\
\varphi_{2}=\frac{1}{h_{3} h_{1}}\left(\frac{\partial}{\partial x_{3}}\left(h_{1} \gamma_{1}\right)-\frac{\partial}{\partial x_{1}}\left(h_{3} \gamma_{3}\right)\right) \\
\varphi_{3}=\frac{1}{h_{1} h_{2}}\left(\frac{\partial}{\partial x_{1}}\left(h_{2} \gamma_{2}\right)-\frac{\partial}{\partial x_{2}}\left(h_{1} \gamma_{1}\right)\right)
\end{array}\right.
$$

\section{A.1 Coordenadas Polares Cilíndricas}

Para $\left(x_{1}, x_{2}, x_{3}\right)=(r, \theta, z)$, a mudança de coordenadas, coordenadas cartesianas para cilíndricas, é dada por:

$$
\begin{aligned}
& x=r \cos \theta ; y=r \operatorname{sen} \theta ; z=z . \\
& h_{1}=1 ; h_{2}=r ; h_{3}=1 . \\
& \left(v_{1}, v_{2}, v_{3}\right)=\left(v_{r}, v_{\theta}, v_{z}\right), \text { conforme pode ser observado na Figura A.2. }
\end{aligned}
$$




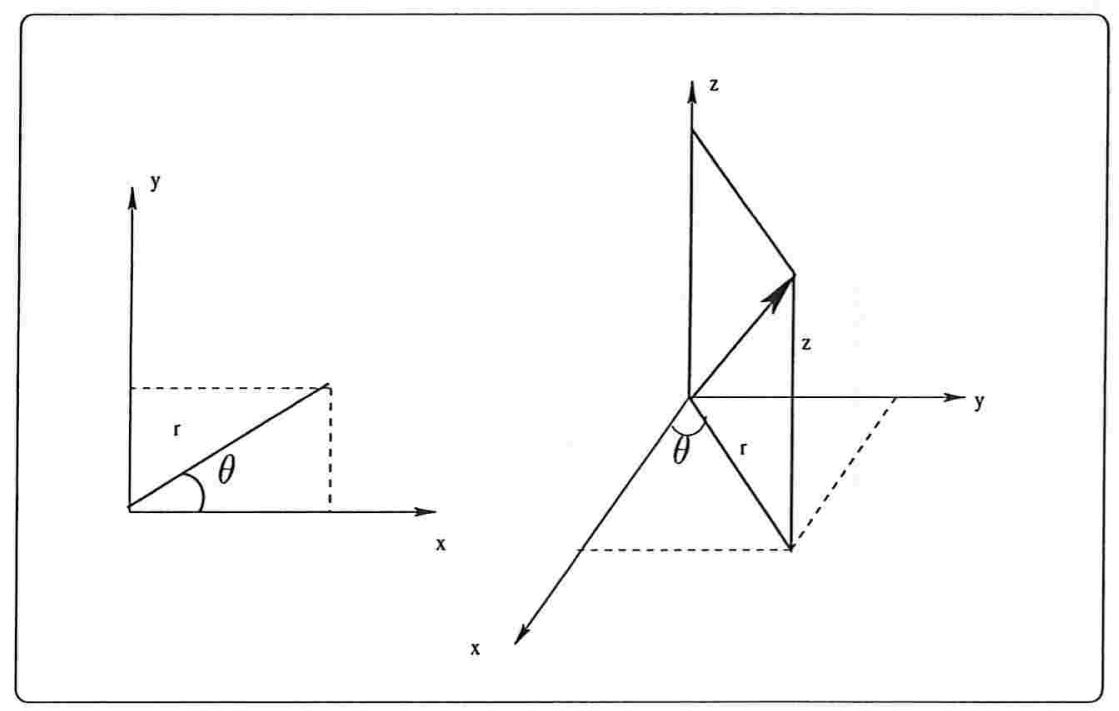

Figura A.2: Coordenadas cilíndricas

$$
\nabla \times \vec{V}=\left(\gamma_{1}, \gamma_{2}, \gamma_{3}\right)
$$

Reescreve-se (A.15) utilizando as relações acima:

$$
\left\{\begin{array}{c}
\gamma_{1}=\frac{1}{r} \frac{\partial v_{z}}{\partial \theta}-\frac{\partial v_{\theta}}{\partial z} \\
\gamma_{2}=\frac{\partial v_{r}}{\partial z}-\frac{\partial v_{z}}{\partial r} \\
\gamma_{3}=\frac{\partial v_{\theta}}{\partial r}+\frac{1}{r} v_{\theta}-\frac{1}{r} \frac{\partial v_{r}}{\partial \theta}
\end{array}\right.
$$

Lembrando que $(\nabla \times \vec{V})=\left(\gamma_{1}, \gamma_{2}, \gamma_{3}\right)$, substituindo em (A.17), tem-se:

$$
\begin{gathered}
\varphi_{1}=\frac{1}{h_{2} h_{3}}\left(\frac{\partial}{\partial \theta}\left[\frac{\partial v_{\theta}}{\partial r}+\frac{1}{r} v_{\theta}-\frac{1}{r} \frac{\partial v_{r}}{\partial \theta}\right]-\frac{\partial}{\partial z}\left[r \frac{\partial v_{r}}{\partial z}-r \frac{\partial v_{z}}{\partial r}\right]\right) \\
\varphi_{2}=\frac{\partial}{\partial z}\left(\frac{1}{r} \frac{\partial v_{z}}{\partial \theta}-\frac{\partial v_{\theta}}{\partial z}\right)-\frac{\partial}{\partial r}\left(\frac{\partial v_{\theta}}{\partial r}-\frac{1}{r} v_{\theta}-\frac{1}{r} \frac{\partial v_{r}}{\partial \theta}\right)
\end{gathered}
$$

Assim, escreve-se $\nabla(\nabla \cdot \vec{V})-\nabla^{2} \vec{V}=\nabla(\operatorname{div} \vec{V})-\nabla \times(\nabla \times \vec{V})$ em suas componentes 
$\phi_{1}, \phi_{2}, \phi_{3}$

$$
\begin{gathered}
\phi_{1}=\frac{\partial}{\partial r}\left(\frac{\partial v_{r}}{\partial r}+\frac{v_{r}}{r}+\frac{1}{r} \frac{\partial v_{\theta}}{\partial \theta}+\frac{\partial v_{z}}{\partial z}\right)-\frac{1}{r}\left[\frac{\partial}{\partial \theta}\left(\frac{\partial v_{r}}{\partial r}+\frac{v_{r}}{r}-\frac{1}{r} \frac{\partial v_{r}}{\partial \theta}\right)-\frac{\partial}{\partial z}\left(r \frac{\partial v_{r}}{\partial z}-r \frac{\partial v_{z}}{\partial r}\right)\right] \\
\phi_{2}=\frac{\partial}{\partial \theta}\left(\frac{\partial}{\partial r} v_{r}+\frac{1}{r} v_{r}+\frac{1}{r} \frac{\partial v_{r}}{\partial r}+\frac{\partial v_{z}}{\partial z}\right)-\frac{\partial}{\partial z}\left(\frac{1}{r} \frac{\partial v_{z}}{\partial \theta}-\frac{\partial v_{\theta}}{\partial z}\right)-\frac{\partial}{\partial r}\left(\frac{\partial v_{\theta}}{\partial r}-\frac{1}{r} v_{\theta}-\frac{1}{r} \frac{\partial v_{r}}{\partial \theta}\right) \\
\phi_{3}=\frac{\partial}{\partial z}\left(\frac{\partial v_{r}}{\partial r}+\frac{v_{r}}{r}+\frac{1}{r} \frac{\partial v_{\theta}}{\partial \theta}+\frac{\partial v_{z}}{\partial z}\right)-\frac{1}{r}\left[\frac{\partial}{\partial r}\left(r \frac{\partial v_{r}}{\partial z}-r \frac{\partial v_{z}}{\partial r}\right)-\frac{\partial}{\partial \theta}\left(\frac{1}{r} \frac{\partial v_{z}}{\partial \theta}-\frac{\partial v_{\theta}}{\partial z}\right)\right]
\end{gathered}
$$

Portanto,

$$
\begin{gathered}
\phi_{1}=\frac{\partial^{2} v_{r}}{\partial r^{2}}+\frac{1}{r} \frac{\partial v_{r}}{\partial r}+\frac{1}{r^{2}} \frac{\partial^{2} v_{r}}{\partial \theta^{2}}+\frac{\partial^{2} v_{r}}{\partial z^{2}}-\frac{v_{r}}{r^{2}}-\frac{2}{r^{2}} \frac{\partial v_{\theta}}{\partial \theta} \\
\phi_{2}=\frac{\partial^{2} v_{\theta}}{\partial r^{2}}+\frac{1}{r} \frac{\partial v_{\theta}}{\partial r}+\frac{1}{r^{2}} \frac{\partial^{2} v_{\theta}}{\partial \theta^{2}}+\frac{\partial^{2} v_{\theta}}{\partial z^{2}}-\frac{v_{\theta}}{r^{2}}+\frac{2}{r^{2}} \frac{\partial v_{r}}{\partial \theta} \\
\phi_{3}=\frac{\partial^{2} v_{z}}{\partial r^{2}}+\frac{1}{r} \frac{\partial v_{z}}{\partial r}+\frac{1}{r} \frac{\partial^{2} v_{z}}{\partial \theta^{2}}+\frac{\partial^{2} v_{z}}{\partial z^{2}}
\end{gathered}
$$

Analogamente, são calculadas as componentes de $\nabla\left(\frac{1}{2} \vec{V}^{2}\right)-\vec{V} \times(\nabla \times \vec{V})$

$$
\begin{aligned}
& \nabla\left(\frac{1}{2} \vec{V}^{2}\right)=\nabla(\left.\frac{1}{2} v_{r}^{2}+\frac{1}{2} v_{\theta}^{2}+\frac{1}{2} v_{z}^{2}\right)=\left(v_{r} \frac{\partial v_{r}}{\partial r}+v_{\theta} \frac{\partial v_{\theta}}{\partial r}+v_{z} \frac{\partial v_{z}}{\partial r}\right. \\
&\left.\frac{v_{r}}{r} \frac{\partial v_{r}}{\partial \theta}+\frac{v_{\theta}}{r} \frac{\partial v_{\theta}}{\partial \theta}+\frac{v_{z}}{r} \frac{\partial v z}{\partial \theta}, v_{r} \frac{\partial v_{r}}{\partial z}+v_{\theta} \frac{\partial v_{\theta}}{\partial z}+v_{z} \frac{\partial v_{z}}{\partial z}\right)
\end{aligned}
$$$$
\vec{V} \times(\nabla \times \vec{V})=\left(v_{\theta} \frac{1}{r}\left(\frac{\partial}{\partial r}\left(r v_{\theta}\right)-\frac{\partial v_{r}}{\partial \theta}\right)-v_{z}\left(\frac{\partial v_{r}}{\partial z}-\frac{\partial v_{z}}{\partial r}\right)\right.
$$$$
v_{z} \frac{1}{r}\left(\frac{\partial v_{z}}{\partial \theta}-\frac{\partial}{\partial z}(r v \theta)\right)-v_{r} \frac{1}{r}\left(\frac{\partial}{\partial r}\left(r v_{\theta}\right)-\frac{\partial v_{r}}{\partial \theta}\right),
$$$$
\left.v_{r}\left(\frac{\partial v_{r}}{\partial z}-\frac{\partial v_{z}}{\partial r}\right)-v_{\theta} \frac{1}{r}\left(\frac{\partial v_{z}}{\partial \theta}-\frac{\partial}{\partial z}(r v \theta)\right)\right)=
$$$$
\left(v_{\theta} \frac{\partial v_{\theta}}{\partial r}+\frac{v_{\theta}^{2}}{r}-\frac{v_{\theta}}{r} \frac{\partial v_{r}}{\partial \theta}-v_{z} \frac{\partial v_{r}}{\partial z}+v_{z} \frac{\partial v_{z}}{\partial r}, \frac{v_{z}}{r} \frac{\partial v_{z}}{\partial \theta}-v_{z} \frac{\partial v_{z}}{\partial z}-v_{r} \frac{\partial v_{r}}{\partial r}-v_{r} \frac{v_{\theta}}{r}+\frac{v_{r}}{r} \frac{\partial v_{r}}{\partial \theta},\right.
$$

$$
\left.v_{r} \frac{\partial v_{r}}{\partial z}-v_{r} \frac{\partial v_{z}}{\partial r}-\frac{v_{r}}{r} \frac{\partial v_{z}}{\partial \theta}+v_{\theta} \frac{\partial v_{\theta}}{\partial z}\right)
$$


Assim,

$$
\begin{gathered}
\nabla\left(\frac{1}{2} \vec{V}^{2}\right)-\vec{V} \times(\nabla \times \vec{V})=\left(v_{r} \frac{\partial v_{r}}{\partial r}+\frac{v_{\theta}}{r} \frac{\partial v_{r}}{\partial \theta}+v_{z} \frac{\partial v_{r}}{\partial z}-\frac{v_{\theta}^{2}}{r}, v_{r} \frac{\partial v_{\theta}}{\partial r}+\frac{v_{\theta}}{r} \frac{\partial v_{\theta}}{\partial \theta}+v_{z} \frac{\partial v_{z}}{\partial z}+v_{r} \frac{v_{\theta}}{r}\right. \\
\left.v_{r} \frac{\partial v_{z}}{\partial r}+\frac{v_{\theta}}{r} \frac{\partial v_{z}}{\partial \theta}+v_{z} \frac{\partial v_{z}}{\partial z}\right)
\end{gathered}
$$

Resumindo, a equação (A.3), considerando (A.14),(A.15), (A.16) e (A.17), é escrita, em coordenadas cilíndricas na seguinte forma:

- componente $\mathrm{r}$ da velocidade

$$
\begin{aligned}
& \rho\left(\frac{\partial v_{r}}{\partial t}+v_{r} \frac{\partial v_{r}}{\partial r}+\frac{v_{r}}{r} \frac{\partial v_{r}}{\partial \theta}+v_{z} \frac{\partial v_{r}}{\partial z}-\frac{v_{\theta}^{2}}{r}\right)=F_{r}-\frac{\partial P}{\partial r}+\mu\left(\frac{\partial^{2} v_{r}}{\partial r^{2}}+\frac{1}{r} \frac{\partial v_{r}}{\partial r}+\frac{1}{r^{2}} \frac{\partial^{2} v_{r}}{\partial \theta^{2}}+\frac{\partial^{2} v_{r}}{\partial z^{2}}-\frac{v_{r}}{r^{2}}-\right. \\
& \left.-\frac{2}{r} \frac{\partial v_{r}}{\partial \theta}\right)
\end{aligned}
$$

- componente $\theta$ da velocidade

$$
\begin{aligned}
& \rho\left(\frac{\partial v_{\theta}}{\partial t}+v_{r} \frac{\partial v_{\theta}}{\partial r}+\frac{v_{\theta}}{r} \frac{\partial v \theta}{\partial \theta}+v_{z} \frac{\partial v_{z}}{\partial z}+\frac{v_{r} v_{\theta}}{r}\right)=F_{\theta}-\frac{\partial P}{\partial \theta}+\mu\left(\frac{\partial^{2} v_{\theta}}{\partial r^{2}}+\frac{1}{r} \frac{\partial v_{\theta}}{\partial r}+\frac{1}{r} \frac{\partial^{2} v_{\theta}}{\partial \theta^{2}}+\right. \\
& \left.+\frac{\partial^{2} \theta}{\partial z^{2}}-\frac{v_{\theta}}{r^{2}}+\frac{2}{r^{2}} \frac{\partial v_{r}}{\partial \theta}\right)
\end{aligned}
$$

- componente $z$ da velocidade

$\rho\left(\frac{\partial v_{z}}{\partial t}+v_{r} \frac{\partial v_{z}}{\partial r}+\frac{v \theta}{r} \frac{\partial v_{z}}{\partial \theta}+v_{z} \frac{\partial v_{z}}{\partial z}\right)=F_{z}-\frac{\partial P}{\partial z}+\mu\left(\frac{\partial^{2} v_{r}}{\partial r^{2}}+\frac{1}{r} \frac{\partial v_{z}}{\partial r}+\frac{1}{r} \frac{\partial^{2} v_{z}}{\partial \theta^{2}}+\frac{\partial^{2} \theta}{\partial z^{2}}\right)$

Da mesma forma, para a equação da continuidade, tem-se:

$\nabla \cdot \vec{V}=0 \Longrightarrow \operatorname{div} \vec{V}=0 \mathrm{e}$

$$
\nabla \times \vec{v}=\left(\gamma_{1}, \gamma_{2}, \gamma_{3},\right)
$$

onde:

$$
\begin{aligned}
\gamma_{1} & =\frac{1}{h_{2} h_{3}}\left(\frac{\partial}{\partial x_{2}}\left(h_{3} v_{3}\right)-\frac{\partial}{\partial x_{3}}\left(h_{2} v_{2}\right)\right) \\
\gamma_{2} & =\frac{1}{h_{3} h_{1}}\left(\frac{\partial}{\partial x_{3}}\left(h_{1} v_{1}\right)-\frac{\partial}{\partial x_{1}}\left(h_{3} v_{3}\right)\right) \\
\gamma_{3} & =\frac{1}{h_{1} h_{2}}\left[\frac{\partial}{\partial x_{1}}\left(h_{2} \gamma_{2}\right)-\frac{\partial}{\partial x_{2}}\left(h_{1} \gamma_{1}\right)\right]
\end{aligned}
$$


Substituindo $\gamma_{1}$ e $\gamma_{2}$ em $\gamma_{3}$, tem-se:

$\gamma_{3}=\frac{1}{r}\left(\frac{\partial}{\partial r}\left[r \frac{\partial v_{r}}{\partial z}-r \frac{\partial v_{z}}{\partial r}\right]-\frac{\partial}{\partial r} \frac{1}{r} \frac{\partial v_{z}}{\partial \theta}-\frac{\partial v_{\theta}}{\partial z}\right)$

Para simplificar a análise considera-se igual a zero o termo $\nabla(\operatorname{div} \vec{V})$.

$\operatorname{div} \vec{V}=\frac{1}{h_{1} h_{2} h_{3}}\left(\frac{\partial}{\partial x_{1}}\left(h_{2} h_{3} v_{1}\right)+\frac{\partial}{\partial x_{2}}\left(h_{3} h_{1} v_{2}\right)+\frac{\partial}{\partial x_{3}}\left(h_{1} h_{2} v_{3}\right)\right.$

$\operatorname{div} \vec{V}=\frac{1}{r}\left(\frac{\partial}{\partial r}\left(r v_{r}\right)+\frac{\partial}{\partial r} v_{r}+\frac{\partial}{\partial z}\left(r v_{z}\right)\right)$

$\operatorname{div} \vec{V}=\frac{\partial v_{r}}{\partial r}+\frac{1}{r} v_{r}+\frac{1}{r} \frac{\partial v_{r}}{\partial r}+\frac{\partial v_{z}}{\partial z}$

Assim:

$\nabla(\operatorname{div} \vec{V})=\left[\frac{\partial}{\partial r}\left(\frac{\partial v_{r}}{\partial r}+\frac{1}{r} v_{r}+\frac{1}{r} \frac{\partial v_{r}}{\partial r}+\frac{\partial v_{z}}{\partial z}\right)\right.$

$$
\left.\frac{\partial}{\partial \theta}\left(\frac{\partial v_{r}}{\partial r}+\frac{1}{r} v_{r}+\frac{1}{r} \frac{\partial v_{r}}{\partial r}+\frac{\partial v_{z}}{\partial z}\right), \frac{\partial}{\partial z}\left(\frac{\partial v_{r}}{\partial r}+\frac{1}{r} v_{r}+\frac{1}{r} \frac{\partial v_{r}}{\partial r}+\frac{\partial v_{z}}{\partial z}\right)\right]
$$

Finalmente, tem-se as equações de Navier-Stokes em coordenadas cilíndricas [1]:

- $\frac{D v_{r}}{D t}-\frac{v_{\theta}^{2}}{r}=\frac{F_{r}}{\rho}-\frac{1}{\rho} \frac{\partial p}{\partial r}+\nu\left(\Delta v_{r}-\frac{v_{r}}{r^{2}}-\frac{2}{r^{2}} \frac{\partial v_{\theta}}{\partial \theta}\right)$

- $\frac{D v_{\theta}}{D t}+\frac{v_{r} v_{\theta}}{r}=\frac{F_{\theta}}{\rho}-\frac{1}{\rho} \frac{\partial p}{\partial \theta}+\nu\left(\Delta v_{\theta}-\frac{v_{\theta}}{r^{2}}-\frac{2}{r^{2}} \frac{\partial v_{r}}{\partial \theta}\right)$

- $\frac{D v_{z}}{D t}=\frac{1}{\rho} F_{z}-\frac{1}{\rho} \frac{\partial p}{\partial z}+\nu \Delta v_{z}$

onde:

$\Delta=\frac{\partial^{2}}{\partial r^{2}}+\frac{1}{r} \frac{\partial}{\partial r}+\frac{1}{r^{2}} \frac{\partial^{2}}{\partial \theta^{2}}+\frac{\partial^{2}}{\partial z^{2}}=\frac{1}{r} \frac{\partial}{\partial r}\left(r \frac{\partial}{\partial r}+\frac{1}{r^{2}} \frac{\partial^{2}}{\partial \theta^{2}}+\frac{\partial^{2}}{\partial z^{2}}\right)$

e

$\frac{D}{D t}=\frac{\partial}{\partial t}+v_{r} \frac{\partial}{\partial r}+\frac{v_{\theta}}{r} \frac{\partial}{\partial \theta}+v_{z} \frac{\partial}{\partial z}$ 


\section{Método das Diferenças Finitas}

A solução numérica calcula em alguns pontos de uma região $\mathrm{R}$ contínua, a solução do problema (discretização). Os pontos são denominados pontos discretos e formam a malha de discretização, o espaçamento da malha pode ser igualmente espaçado ou variável, representado na Figura B.1 [9].

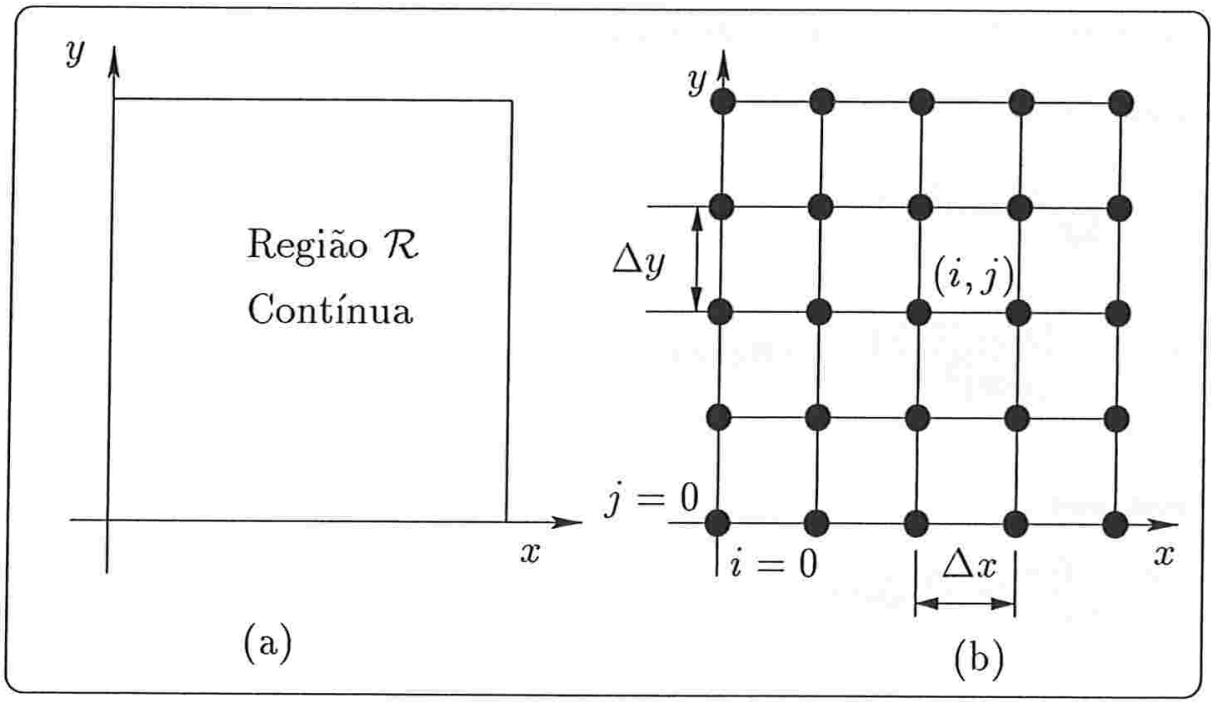

Figura B.1: (a) Região contínua; (b) região discretizada.

As aproximações por diferenças finitas têm como base a expansão em Série de Taylor de uma função $f$. 


\section{B.1 Teorema de Taylor}

Supondo que f seja uma função contínua no intervalo [a,b] de interesse que possua derivadas até ordem $n$ contínuas no intervalo, para todo ponto $x \in[a, b]$,

$$
f(x)=f\left(x_{0}\right)+\left.(\Delta x) \frac{d f}{d x}\right|_{x_{0}}+\left.\frac{(\Delta x)^{2}}{2 !} \frac{d^{2} f}{d x^{2}}\right|_{x_{0}}+\left.\frac{(\Delta x)^{3}}{3 !} \frac{d^{3} f}{d x^{3}}\right|_{x_{0}}+\cdots+R_{N}
$$

onde:

$\Delta x=x-x_{0}$

$R_{N}=\left.\frac{(\Delta x)^{N}}{N !} \frac{d^{N} f}{d x^{N}}\right|_{\varepsilon}, \varepsilon \in[a, b]$

\section{B.2 Fórmulas de Diferenças Finitas}

Partindo de combinações de expressões em Série de Taylor, tem-se as equações de diferenças finitas:

\section{Aproximações de Primeira Ordem}

- Progressivas

$\left.\frac{d f}{d x}\right|_{i}=\frac{f_{i+1}-f_{i}}{\Delta x}+O(\Delta x)$

$\left.\frac{d^{2} f}{d x^{2}}\right|_{i}=\frac{f_{i}-2 f_{i+1}+f_{i+2}}{(\Delta x)^{2}}+O(\Delta x)$

- Regressivas

$\left.\frac{d f}{d x}\right|_{i}=\frac{f_{i}-f_{i-1}}{\Delta x}+O(\Delta x)$

$\left.\frac{d^{2} f}{d x^{2}}\right|_{i}=\frac{f_{i}-2 f_{i-1}+f_{i-2}}{(\Delta x)^{2}}+O(\Delta x)$

Aproximações de Segunda Ordem

- Progressivas

$\left.\frac{d f}{d x}\right|_{i}=\frac{-3 f_{i}+4 f_{i+1}-f_{i+2}}{2 \Delta x}+O(\Delta x)^{2}$ 


$$
\left.\frac{d^{2} f}{d x^{2}}\right|_{i}=\frac{2 f_{i}-5 f_{i+1}+4 f_{i+2}-f_{i+3}}{(\Delta x)^{2}}+O(\Delta x)^{2}
$$

- Regressivas

$$
\begin{aligned}
& \left.\frac{d f}{d x}\right|_{i}=\frac{f_{i}-f_{i-1}}{\Delta x}+O(\Delta x) \\
& \left.\frac{d^{2} f}{d x^{2}}\right|_{i}=\frac{2 f_{i}-5 f_{i-1}+4 f_{i-2}-f_{i-3}}{(\Delta x)^{2}}+O(\Delta x)^{2}
\end{aligned}
$$

\section{- Centradas}

$$
\left.\frac{d f}{d x}\right|_{i}=\frac{f_{i+1}-f_{i-1}}{2 \Delta x}+O(\Delta x)^{2}
$$

As expressões de derivadas das equações diferenciais parciais são substituídas pelas aproximações discretas, transformando o sistema de EDP's num sistema algébrico nãolinear. 


\section{Referências Bibliográficas}

[1] CHORIN, Alexandre J.; MARSDEN, Jerrold E.. A Mathematical Introduction to Fluid Mechanics. 3rd. Edition. Springer-Verlag, New York, 1-45, 1993.

[2] BAKKER. http://www.bakker.org/cfm/cfmbook.htm

[3] BIOTHANE. http://www.biothane.com/phys_chem.html

[4] BRODKEY, Robert S., HERSHEY, Harry C.. Transport Phenomena - A Unified Appoach. 2nd ed. McGraw-Hill Book Co., Singapore, 1989.

[5] CHEMINEER. http://www.chemineer.com/impellers.asp

[6] COUlSON, J. M.; RICHARDSON, J. F.; BACKHURST J.R., HARKER, J. H.. Chemical Engineering Particle Technology ES Separation Processes. Volume 2. 4th ed. Great Britain, Oxford, 1991.

[7] FERZIGER, J. H.; PERIC, M.. Computational Methods for Fluid Dynamics. 2nd. Printed. Spring-Verlag, Berlin, 1997.

[8] FLUENT. http://www.fluent.com/solutions/whatcfd.htm

[9] FORTUNA, Armando de Oliveira. Técnicas Computacionais para Dinâmica dos Fluidos: Conceitos Básicos e Aplicações. Edusp-Editora da Universidade de São Paulo, 2000 .

[10] GESSOW, Alfred; JR, Garry C. Myers. Aerodynamics of the helicopter. Eighth Printing, p.46-65, 1993. 
[11] GNUPLOT. http://www.cs.darmouth.edu/gnuplot_ inf.html.

[12] HARNBY, N.; EDWARDS, M. F.; NIENOW, A. W. Mixing in the process industries. Second Edition. Butterworth-Heinemann Ltd., 1992.

[13] HALLIDAY, David; RESNICK, Robert; MURRILL, John. Fundamentos de Física Gravitação, Ondas e Termodinâmica. 3a. edição, Volume 2. LTC-Livros Técnicos e Científicos Editora S.A., 1994.

[14] IPT-INSTITUTO DE PESQUISAS TECNOLÓGICAS S.A.. Tecnologia da Cristalização. Curso da Divisão de Química. São Paulo, 2000.

[15] IPT-INSTITUTO DE PESQUISAS TECNOLÓGICAS S.A.. Agitação e Mistura na Indústria. Curso da Divisão de Química. São Paulo, 2001.

[16] LOPES. http://www.fe.up.pt/deqwww/docentes/JoseCL.html

[17] MALISKA, C. R. Transferência de Calor e Mecânica dos Fluidos Computacional. Rio de Janeiro, lTC Editora, 1995.

[18] MUEL. http://www.muel.com/engineering/agitatMechanics.cfm

[19] NAGATA, Shinji. Mixing - Principles and aplications. Tokyo : Kodansha Ltd., 1975.

[20] OLDSHUE, James Y. Fluid Mixing Technology. New York : Chemical Engineering Mc Graw Hill Pub Co, 1983.

[21] PERRY, Robert H., GREEN, Don W. Perry's Chemical Engineers' Handboook. Seventh Edition, Section Six.

[22] PEYRET, Roger; TAYLOR, Thomas D.. Computational Methods for Fluid Flow. 3rd. Printed. Springer-Verlag, New York, P.171-207, 1990.

[23] PHILAMIXERS. http://www.philamixers.com/radialimp.htm

[24] KOZAKEVICIUS, Alice de Jesus; SHIMABUKU, Liliane Fujii; SAITO, Olga Harumi; NÓS, Rudimar Luiz. Resolução Numérica das Equações de Navier-Stokes Formulação em Variáveis Primitivas. São Paulo, 1998. Relatório (Curso MAP5726Introdução à Mecânica dos Fluidos Computacional I - Fluidos Incompressíveis), Instituto de Matemática e Estatística, Universidade de São Paulo. 
[25] SANTOS, Luis Carlos de C.. Introdução à Mecânica dos Fluidos Computacional. Curso ministrado no XXI Congresso Nacional de Matemática Aplicada e Computacional. Caxambú, 1998.

[26] SCHEID, Francis. Análise Numérica. Mc Graw-Hill, Inc. Portugal, 2000

[27] SEMCOMAQ. http://www.semcomaq.com.br/semcomaqpor.htm

[28] SHIMABUKU, Liliane Fujii; SAITO, Olga Harumi; SANTOS, Luis Carlos de Castro.Um estudo Numérico dos Limites de Estabilidade para as Equações de NavierStokes na Cavidade. Trabalho apresentado ao XXII Congresso Nacional de Matemática Aplicada e Computacional. Santos, 1999.

[29] SAITO, Olga Harumi; SANTOS, Luis Carlos de Castro. Um Modelo Matemático para Tanques Agitados. Trabalho apresentado ao XXIII Congresso Nacional de Matemática Aplicada e Computacional. Santos, 2000.

[30] PLOTMTV.http://www.qpsf.edu.au/mirrors/csep/cornell_proceedings/tutorials/ Plotmtv/overview.html.

[31] TATTERSON, Gary B.. Fluid Mixing and Gas Dispersion in Agitated Tanks, USA : Mc Graw Hill, Inc, 1991.

[32] VARELLA, Fernando José Pereira. Uma Contribuição ao uso da Fluidodinâmica Computacional no Estudo da Agitação Mecânica de Líquidos. São Paulo, 1988. Dissertação (Mestrado em Engenharia) - Escola Politécnica, Universidade de São Paulo. 
